\title{
SCAFFOLDING THE CONTINUA OF BILITERATE DEVELOPMENT IN THE SPANISH LANGUAGE IMMERSION CLASSROOM
}

A Dissertation
presented to
the Faculty of the Graduate School
at the University of Missouri-Columbia
In Partial Fulfillment
of the Requirements for the Degree
Doctor of Philosophy
DAWN M. HESTON
Dr. Carol Gilles, Dissertation Supervisor
July 2018


(C) Copyright by Dawn Heston 2018

All Rights Reserved 
The undersigned, appointed by the dean of the Graduate School, have examined the dissertation entitled

\section{SCAFFOLDING THE CONTINUA OF BILITERATE DEVELOPMENT IN THE SPANISH LANGAUGE IMMERSION CLASSROOM}

presented by Dawn Heston, a candidate for the degree of doctor of philosophy and hereby certify that, in their opinion, it is worthy of acceptance.

Professor Carol Gilles

Professor Lisa Dorner

Professor Jill Ostrow

Professor Angie Zapata 


\section{ACKNOWLEDGEMENTS}

This dissertation project unites many elements of my personal and professional interests including: bilingualism, reading, and the art of teaching. As such, there are many individuals of influence whose contributions cannot be measured, and without whom, none of this would be possible. Thank you to my mother, who consistently urged me to continue to develop my Spanish-speaking abilities. Thank you to my father who explained that many people spend their lives making the simple complicated, when there is great value in making the complicated simple.

Mil gracias to my teachers: Sra. Rodríguez, Sra. Coughlin, and Sra. Warren, who provided support and encouragement in the earliest stages of my bilingualism.

With regards to my life at MU, Flore Zéphir was the finest mentor any person could ever hope for and I miss her every. single. day. Thank you to all members of this dissertation committee. Thank you to Carol Gilles who pushed me to continuously refine and rethink. You spent countless hours working with me and I want to assure you that I will "pay it forward" to my graduate students of the future. This dissertation is immeasurably better due to your open-ended questions about the data. Many of the ideas presented within this dissertation finally coalesced in my mind following one of our conversations. Thank you to Lisa Dorner who asked deep questions about the immersion classroom and its activities. Thank you to Jill Ostrow who told me to consider "Who is doing the work?" Thank you to Angie Zapata who taught me about "unpacking" and different ways of clearly presenting data.

Thank you to my family, friends, and colleagues for their unending support, sacrifices, encouragement, and prayers. This entire process has proven to be a test of 
both perseverance and patience for those closest to my heart, but we have been strengthened along the way as promised.

Finalmente, gracias a las estrellas del quinto grado y a la Profesora Nuria. Mil gracias por su interés, su apoyo, y su participación entusiasmada durante todo el proceso de la investigación. (Finally, thank you to the stars of fifth grade and Profesora Nuria. A thousand thank yous for your interest, your support, and your enthusiastic participation throughout the research process.) 


\section{TABLE OF CONTENTS}

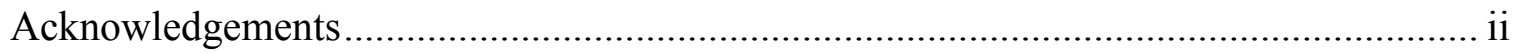

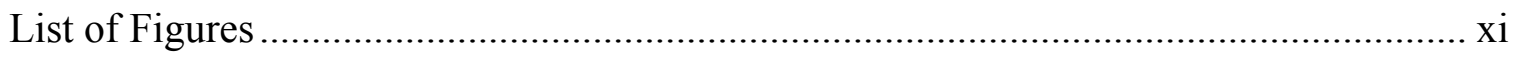

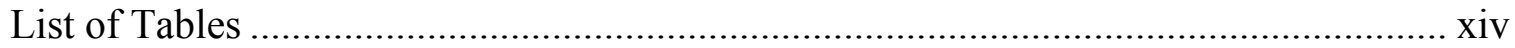

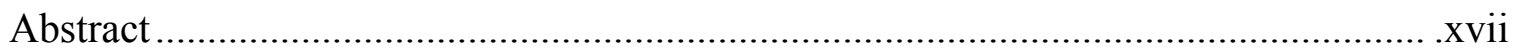

Chapter 1: Introduction - Teacher, Why Don't You Explain the Stories to Us? ................1

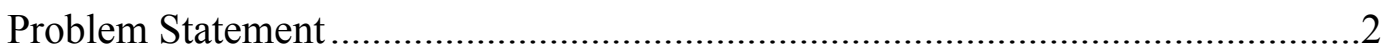

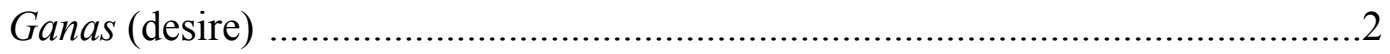

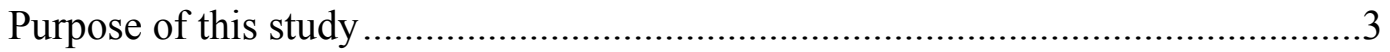

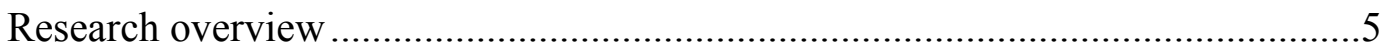

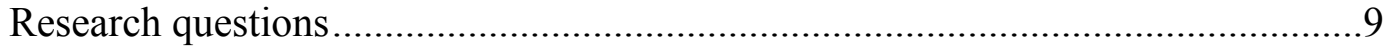

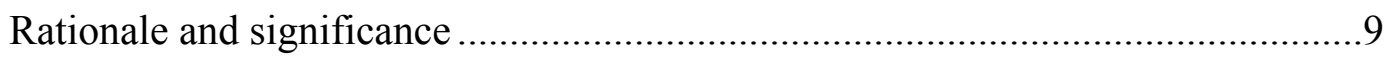

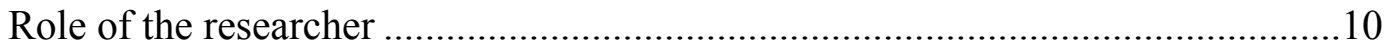

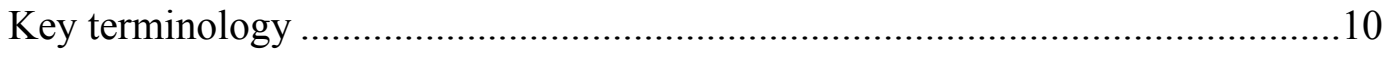

Research site: Spanish Language Immersion Program...................................11

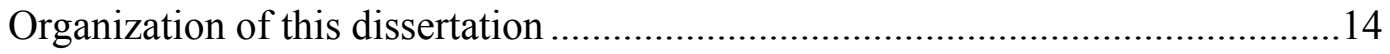

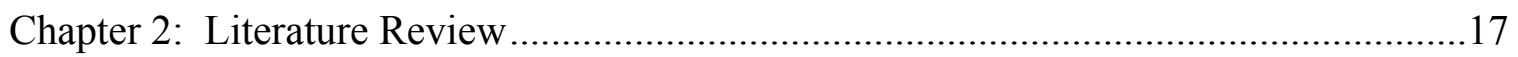

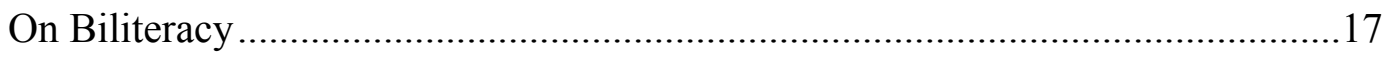

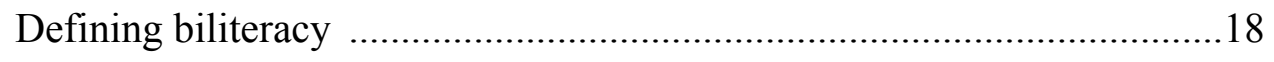

Bilinguals and their range of literacy practices....................................19

Biliteracy in the United States. .......................................................20

Biliteracy, educational policy, and assessment..................................23

Research on the relationship between languages and literacies................24 
Importance of literacy and biliteracy in achievement

More on the relationship between L1 and L2 .....................................28

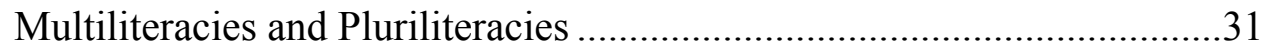

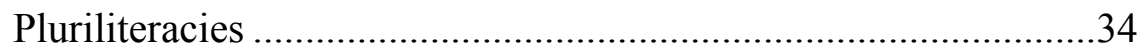

Biliteracy in this research project .....................................................34

On Sociocultural Theory and Research in Dual Language Environments ............36

Overview of Sociocultural Theoretical Frames ......................................38

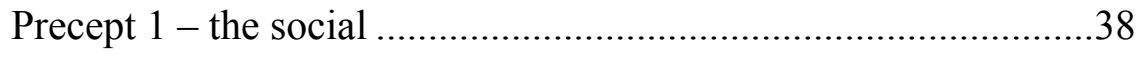

Precept 2 - mediational means. ..............................................39

Precept 3 - the importance of situated learning .........................42

Methodology and Application of Theory in the Classroom .....................45

Zone of Proximal Development..............................................45

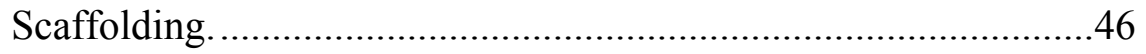

On Dual Language Education and Pedagogy ...................................................51

Program Design within Dual Language Programs .................................52

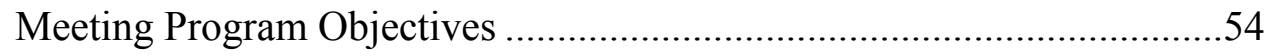

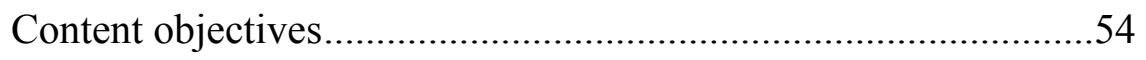

Language and culture objectives...........................................58

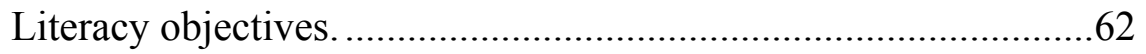

Other considerations .........................................................65

Concluding remarks on dual language programs.................................66 


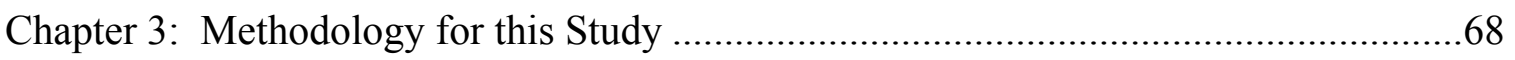

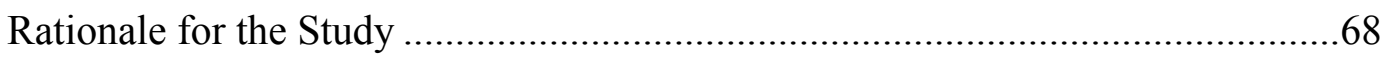

Primary Research Questions ...........................................................................

Theoretical and Methodological Frames ............................................................70

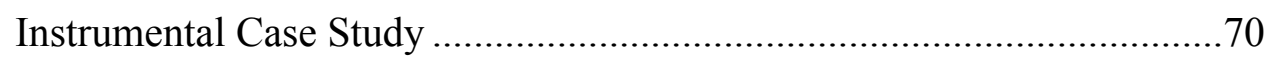

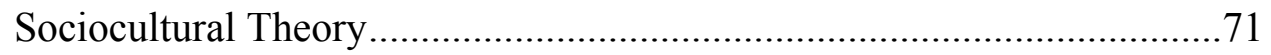

Analytical Methods Borrowed from Grounded Theory ...............................73

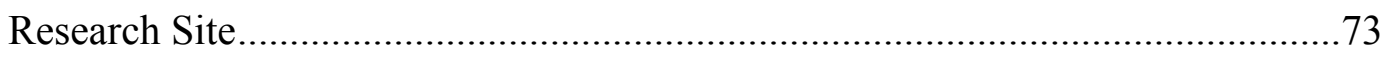

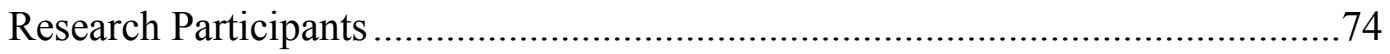

Student demographic data as provided by the teacher................................76

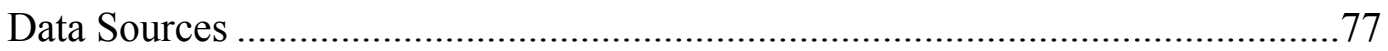

Data Collection \& Ongoing Analysis ...................................................................

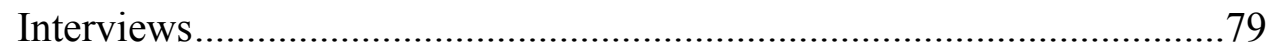

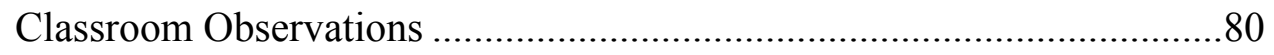

Additional interviews with the teacher .....................................................84

Artifacts, Lesson Plans, and Handouts .....................................................86

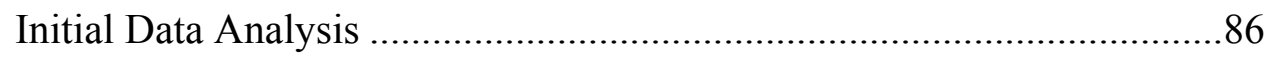

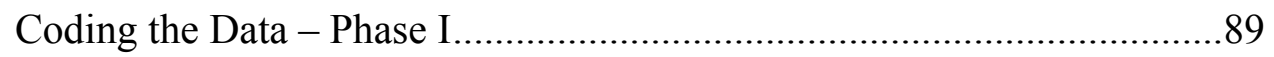

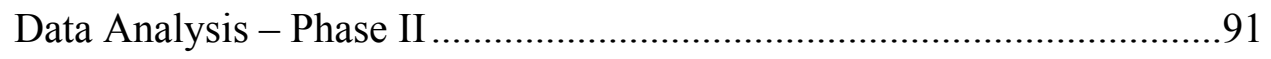

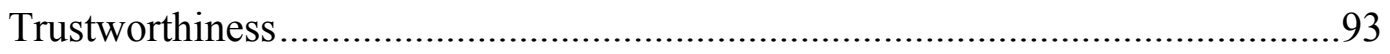

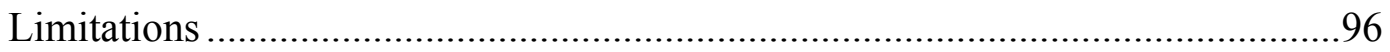

Concluding remarks regarding methodology ...................................................97 


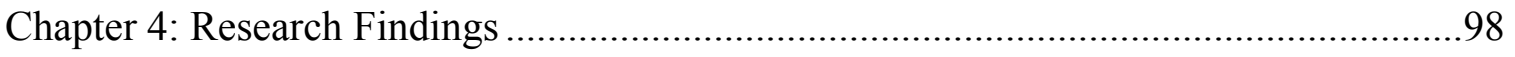

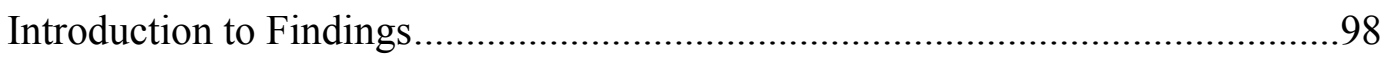

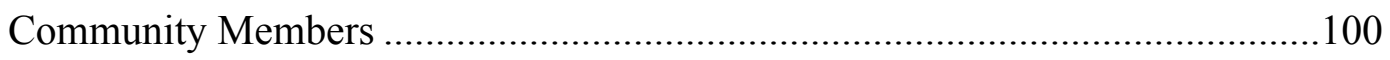

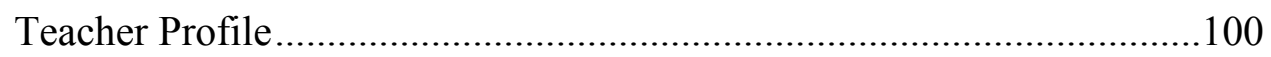

Additional sociocultural considerations...................................................102

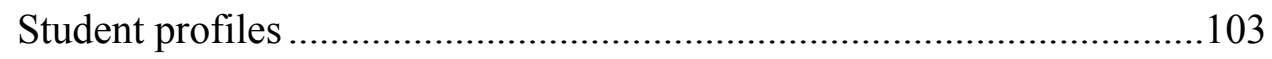

Terrell: The social leader ..........................................................103

Tessa: The business manager.......................................................104

Nikki: The gymnast.................................................................104

Santiago: The bridge builder.......................................................105

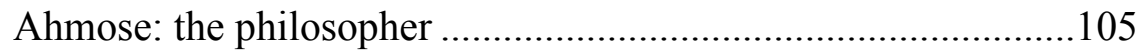

Rianna: the conscience..................................................................106

Jenna and Kishanda: the inseparable duo ……………………....106

Asha: Man on a mission................................................................107

The Context: Environmental concerns and learning ............................................107

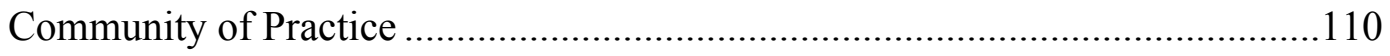

Organization and Structure are valued...................................................110

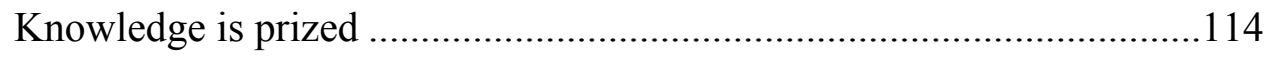

Encouragement is contagious ...........................................................116

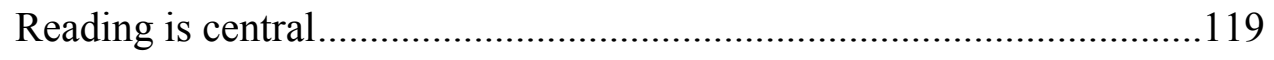

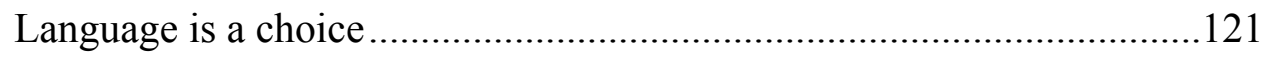

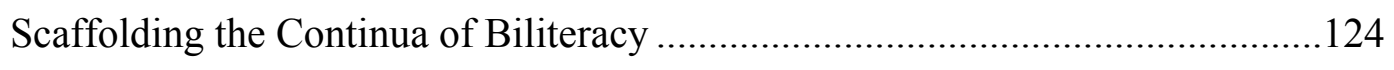

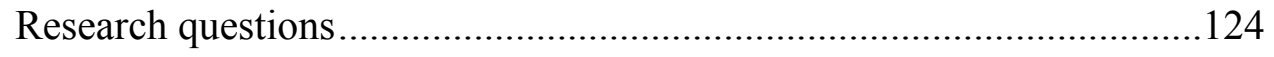


"Struggles" and "help."

Attending to affective needs

High-challenge, low-anxiety

Graphic representations of scaffolding in the continua of biliteracy .......135

Hornberger's model

Complications arise.

New visual model emerges: Scaffolding Episodes in the

Development of Biliteracy 138

Scaffolding with intentions and means

Visual support in the production phase. 143

Visual support in the reception phase

In the content area 156

In the language class 160

Student requests for assistance. 164

Vocabulary and clarification questions in production 165

Vocabulary and clarification questions in reception.

Scaffolding through building connections 176

Connecting real-life scenarios to reading objectives 178

Connecting real-life scenarios to abstract readings 187

Connecting real-life scenarios to student behavioral

struggles

Language Choice, Language Production, and Interpersonal Dynamics 
In whole class activities

Student language choice in word play .............................................. 198

Language choice one-on-one ......................................................204

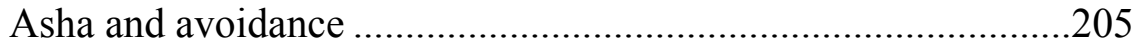

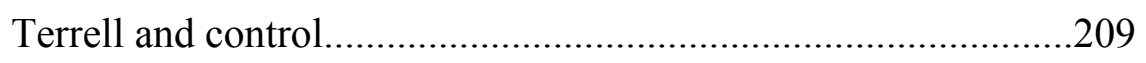

Language Ideologies, Language Practices, and Circles of Influence ..................216

Developing language ideologies based upon personal experiences .......219

Language Ideologies and Emerging Institutional Tensions in Full

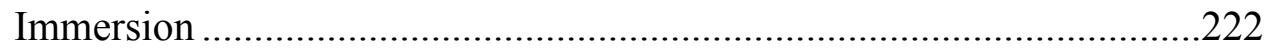

Effecting change through materials selection .................................22

Current language practices and seeking la “balanza.".........................230

Language Ideologies, Systemic Constraints and Influences..........................235

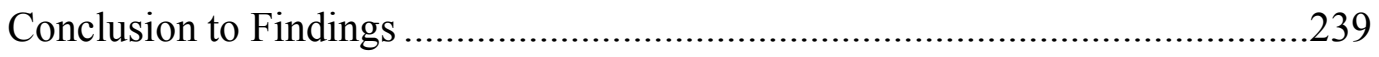

Chapter 5: Discussion of Findings and Future Research .......................................243

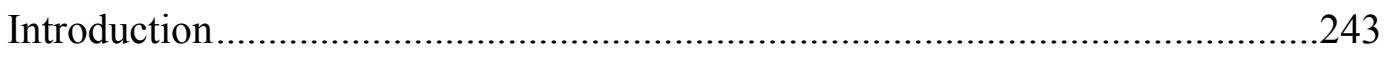

Discussion of Findings.........................................................................24

Profesora Nuria Created a Community of Practice to Facilitate

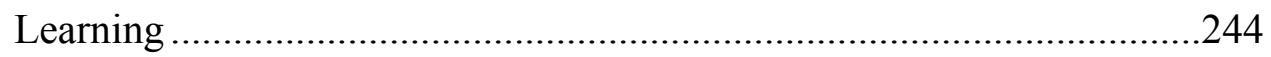

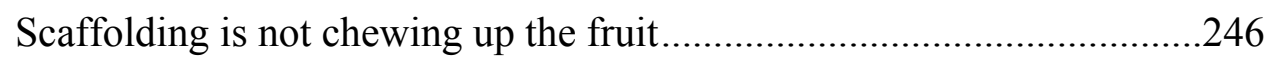

Pre-planned scaffolding with visual support...................................247

Pre-planned scaffolding leveraging background knowledge .................247

Scaffolds as vocabulary support in reception and production ...............247

Using the sociocultural lens to unpack elements of the school 
environment

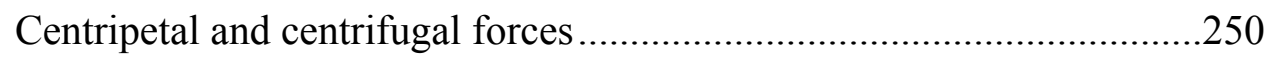

Exploring consequences of friction as a lack of harmonic balance.........258

Separation or combination of languages .....................................259

Emphasis on the goal of knowledge versus test scores................259

Segregation of writing from other literacy practices ...................260

Reading practices and encouragement (or not)............................262

Divergent presentation of independent reading materials ...........263

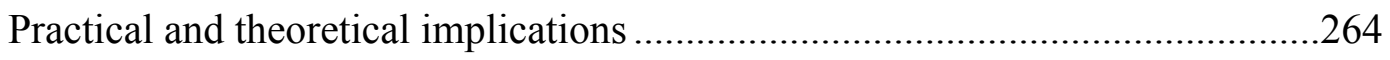

Implications for teachers .................................................................2.

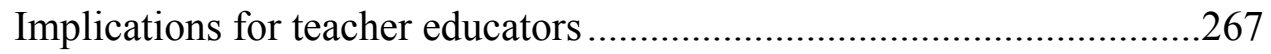

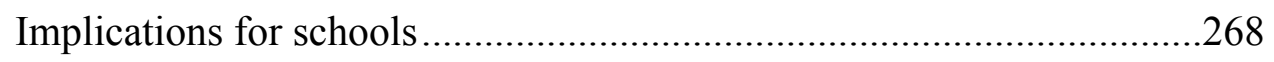

Implications for future research ........................................................2. 270

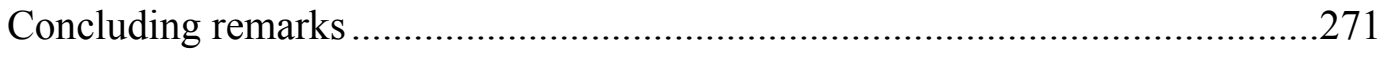

\section{APPENDIX}

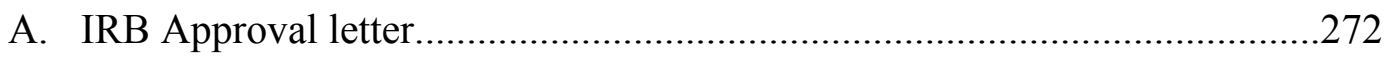

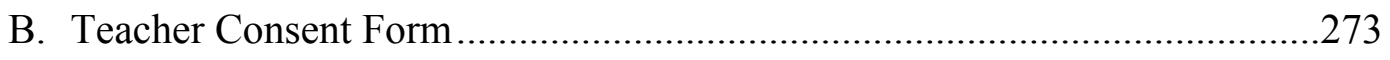

C. List of Questions for Semi-structured Pre-observation Interview .................275

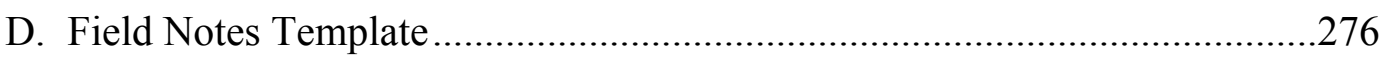

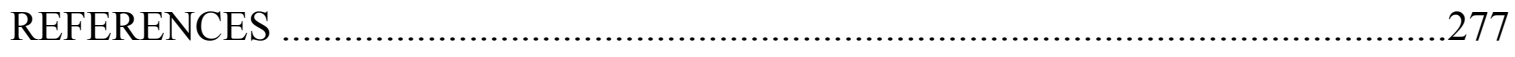

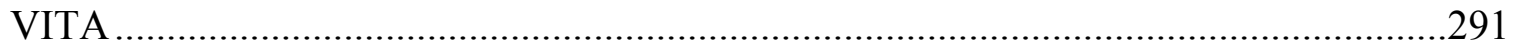




\section{LIST OF FIGURES}

$\begin{array}{lll}\text { Figure } & \text { Page }\end{array}$

1.1. Re-illustration of Hornberger's (2004) The continua of biliterate development

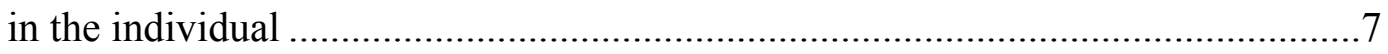

4.1. Classroom photograph: English reading materials …............................................119

4.2. Classroom photograph: English reading materials, close-up..................................119

4.3. Classroom photograph: Spanish reading materials.................................................120

4.4. Re-illustration of Hornberger's (2004) The continua of biliterate development

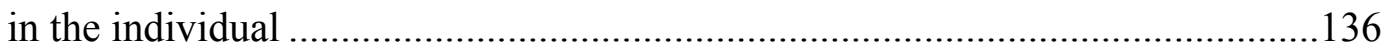

4.5. Model illustration: Adding a line to split Spanish from English .............................137

4.6. Model illustration: Adding zones for Production versus Reception.........................138

4.7. Model illustration: Scaffolding Episodes in the Development of Biliteracy ...........139

4.8. Model illustration: Scaffolding Episodes in the Development of Biliteracy,

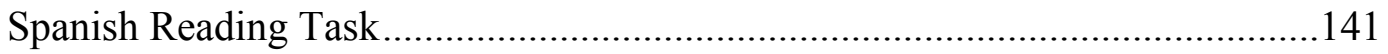

4.9. Classroom photograph: Wall poster, Resumir (Summarize) ...................................144

4.10. Model illustration: Scaffolding Episodes in the Development of Biliteracy, Spanish Reading and Spanish Writing Task ......................................................145

4.11 Model illustration: Scaffolding Episodes in the Development of Biliteracy, Spanish Speaking, Spanish Reading, and Spansih Listening Task.....................152

4.12 Classroom photograph: Food web visual on the interactive whiteboard...............157

4.13 Model illustration: Scaffolding Episodes in the Development of Biliteracy, Spanish Reading Task .158 
4.14. Model illustration: Scaffolding Episodes in the Development of Biliteracy, Spanish Reading Task

4.15. Model illustration: Scaffolding Episodes in the Development of Biliteracy, Spanish Writing Task

4.16 Model illustration: Scaffolding Episodes in the Development of Biliteracy, Spanish Reading Task

4.17 Model illustration: Scaffolding Episodes in the Development of Biliteracy, Spanish Reading and Spanish Writing Task

4.18 Model illustration: Scaffolding Episodes in the Development of Biliteracy, English Reading and Spanish Reading Task

4.19 Model illustration: Scaffolding Episodes in the Development of Biliteracy, Spanish Speaking Task

4.20 Model illustration: Scaffolding Episodes in the Development of Biliteracy, Spanish Writing Task .200

4.21 Model illustration: Scaffolding Episodes in the Development of Biliteracy, Spanish Reading Task .204

4.22. Model illustration: Scaffolding Episodes in the Development of Biliteracy, Spanish Speaking Task

5.1 Model illustration: Scaffolding Episodes in the Development of Biliteracy, Spanish Reading and Spanish Writing Task .248

5.2 Model illustration: Centripetal versus Centrifugal forces, Innovation versus Standardization .251

5.3 Model illustration: Centripetal versus Centrifugal forces, Phase 1 .254 
5.4 Model illustration: Centripetal versus Centrifugal forces, Phase 2 ........................255

5.5 Model illustration: Centripetal versus Centrifugal forces, Phase 3 ........................257 


\section{LIST OF TABLES}

Table

Page

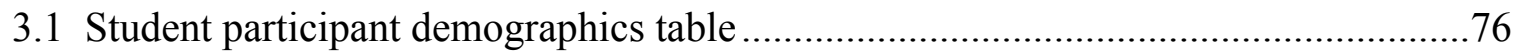

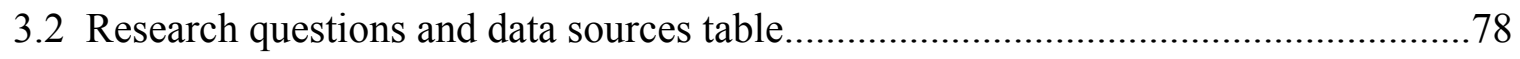

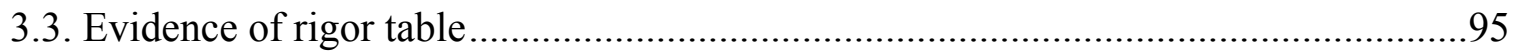

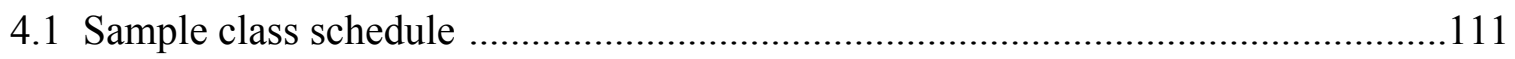

4.2. Transcript excerpt: Five, four, three, two, one routines......................................111

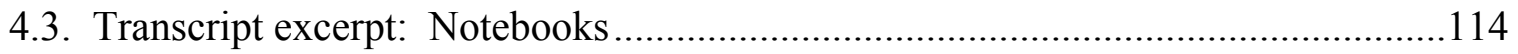

4.4. Transcript excerpt: "Keep it up, little buddy!” ................................................116

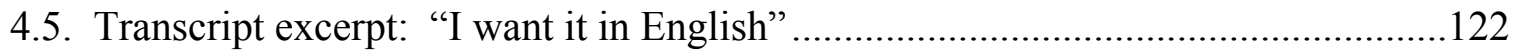

4.6. Transcript excerpt: Can you tell me in Spanish? ...............................................123

4.7. Transcript excerpt: Thank you to everyone who is ready ..................................128

4.8. Student participant reading levels information table .......................................130

4.9. Student participant reading levels with free and reduced lunches .........................133

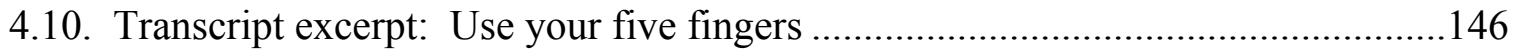

4.11. Transcript excerpt: You are going to write a summary together .......................148

4.12. Transcript excerpt: Ahmose provides a summary ...........................................149

4.13. Transcript excerpt: Snowy, since you were not here ....................................151

4.14. Transcript excerpt: Snowy, you will answer this ..........................................153

4.15. Transcript excerpt: I love it when you use the five (steps) .............................154

4.16. Assignment description: Create a food web for the tropical rainforest ................156

4.17. Transcript excerpt: El puercoespin (The Porcupine) .....................................161 
4.18. Transcript excerpt: “¿Cómo se dice 'to warm up’?” 165

4.19. Transcript excerpt: It is like a warm up

4.20. Comparing student reading levels: Barry, Nikki, and Tessa

4.21. Transcript excerpt: Exploratory talk "Un pájaro. Mocking.". 173

4.22. Transcript excerpt: Connecting with iReady objectives

4.23. Transcript excerpt: ¿Relevante o irrelevante? Part 1 182

4.24. Transcript excerpt: ¿Relevante o irrelevante? Part 2 186

4.25. Transcript excerpt: I take for granted. 187

4.26. Classroom reading: Gastamos más, pero disfrutamos menos .188

4.27. Transcript excerpt: What do you think?.

4.28. Building connections: Sequential scaffolding examples

4.29. Interview excerpt: "Para mí, ser profesora significa..." (For me, being a teacher means...)

4.30. Transcript excerpt: Talking about extra credit

4.31. Transcript excerpt: "I am faster than Rolando." .202

4.32. Transcript excerpt: “Alright. What do you do...?”. .203

4.33. Transcript excerpt: "Casi no leas en español" (You almost never read in Spanish). .205

4.34. Transcript excerpt: "I hate reading in Spanish" .208

4.35. Transcript excerpt: "Profesora, can you please go get the ball?" .211

4.36. Transcript excerpt: “QQué piensas del poema?” (What do you think about the poem?).

4.37. Interview excerpt: a private school in Honduras .219 
4.38. Interview excerpt: "Yo tenía una maestra de Aruba." (I had a teacher from Aruba.) .221

4.39. Transcript excerpt: Talking about pueblos and Mesa Verde

4.40. Transcript excerpt: "I'm tired of tests!" .239 


\title{
SCAFFOLDING THE CONTINUA OF BILITERATE DEVELOPMENT IN THE SPANISH LANGUAGE IMMERSION CLASSROOM
}

\author{
Dawn Heston
}

\author{
Dr. Carol Gilles, Dissertation Supervisor
}

\begin{abstract}
The purpose of this qualitative research project is to describe the scaffolding strategies used by a teacher to engage and support students as they work within the continua of biliterate development in the fifth-grade Spanish language immersion classroom. As language immersion programs and dual language schools continue to grow in popularity in Canada and the United States, this study seeks to illuminate and interpret a teacher's work with students in the Spanish Language Immersion Program (SLIP), a research site located in the urban Midwestern United States.

This instrumental case study employed the lens of Sociocultural Theory to explore the principal research question: How does the teacher scaffold student development of biliteracy within language and content instruction in the immersion school context? The research also explores pre-planned scaffolding versus interactional scaffolding, as well as the tensions and forces within the broader context that the teacher encounters while working with students in this bilingual educational environment.

Classroom observations, teacher interviews, administration interviews, and artifacts were analyzed using methods borrowed from Grounded Theory.

Findings from this study highlight the characteristics of the Community of Practice created by the teacher in this classroom that include a focus upon encouragement, knowledge, organization, and literate habitus. Additionally, two visual
\end{abstract}


models were created to present the data including: "Scaffolding Episodes in the Development of Biliteracy," to illustrate the task-oriented support provided by the teacher, and "Centripetal versus Centrifugal Forces," to present the forces and tensions that the teacher faced within the historical phases of the Spanish Language Immersion Program.

Key words: scaffolding, zone of proximal development, biliteracy, qualitative research, dual language, bilingual, reading comprehension, teacher education, charter schools 


\title{
Chapter 1: Introduction-Teacher, Why Don't You Explain the Stories to Us?
}

\author{
El Maestro Sufí contaba siempre una parábola al finalizar \\ cada clase, pero los alumnos no siempre entendian el \\ sentido de la misma... \\ -Maestro - lo encaró uno de ellos una tarde. - Tú nos \\ cuentas los cuentos pero no nos explicas su significado... \\ - Pido perdón por eso. - Se disculpó el maestro- \\ Permiteme que en señal de reparación te convide con un \\ rico melocotón.
}

Teacher Sufí always told a parable at the end of each class, but the students did not always understand what they meant...

On afternoon, a student confronted him, "Teacher, you tell us stories but you do not explain what they mean..." "I ask your forgiveness for that," the teacher apologized.

"Allow me to invite you to share a delicious peach as compensation." (from Mis Lecturas de $5^{\circ}$ y $6^{\circ}$ )

"El Maestro Suff" was a short story read by the fifth-grade students and teacher in the Spanish Language Immersion Program while participating in this study. The central message of this story later came to represent much more broadly the interactions that occurred between Profesora Nuria and her students during the 2017-2018 school year. (All places and persons associated with the research site mentioned in this document are pseudonyms.) As with this excerpt from "El Maestro Sufi,", this is only the beginning of the case and what it represents in the world of biliteracy and teaching.

This research looks through the lens of Sociocultural Theory to illuminate and interpret a teacher's work to assist students in the Spanish language immersion program. One of the primary goals of these programs is the promotion of bilingual literacy skills. It is at the nexus of literacy, bilingualism, and scaffolding within the zone of proximal development that this project is situated. The interactions between students and teacher 
are essential to understanding this urban bilingual educational environment, and I invite the reader to explore these interactions with me through this dissertation. Based upon these self-same classroom conversations, language ideologies and policies related to these educational environments are explored extensively to lend deeper understanding of the context and the tensions therein.

\section{Problem Statement}

The number of language immersion programs and dual language schools continue to grow in popularity in the United States and Canada. However, the inner-workings of these unique schooling environments have not been documented as extensively as monolingual English educational programs. Teachers, teacher education programs, researchers, and policy-makers express interest in further research and guidance to better understand and build successful educational environments that promote bilingualism and biliteracy. It is with this broad goal in mind that I started this journey with my first visit to the Spanish Language Immersion Program in a large city in the Midwestern United States in 2013.

\section{Ganas (Desire)}

This project was motivated by ganas (desire): the desire to better understand, the desire to witness personally, and the desire to inspire new directions in teacher education programs. In 2013, I first visited the Spanish Language Immersion Program as part of a class project requiring an expedition to an urban school to describe its academic programs. As a Spanish language teacher and literacy doctoral program student, I was immediately drawn to and intrigued by the educational possibilities presented by Spanish language immersion in general. During that initial visit, I recall walking through the halls 
on my school tour with the school principal, Doctora Martínez. In each classroom, there was a designated "ambassador student" who would come over to the door, and "host" us by briefly describing their current class activity and inquiring if we had any questions. One of the first classes we entered was a second grade room. I remember looking at the adorable six or seven-year old girl with her long braided hair and listening intently to her description of their math lesson. It was a surreal experience. How was it that (non-native Spanish speaking) second graders could speak about the lesson with such fluency in Spanish? My own college students struggled at times to form sentences. My mind was whirling with the possibilities and excited to see the ease with which these immersion school students could express themselves in the target language even in second grade. At the time, I noted what I already knew to be true; that there is a distinct difference between studying a phenomenon (or program design) in theory versus witnessing it unfold in person. I was ready to see more.

\section{Purpose of This Study}

"The principle aims of both one-way and two-way [immersion] programs are to promote additive bilingualism and biliteracy, academic achievement, and intercultural understanding" (Cammarata \& Tedick, 2012, p. 252).

The purpose of this study is to richly describe the scaffolding strategies used by a teacher in the Spanish language immersion classroom to engage and support students as they work within the continua of biliterate development (Hornberger, 2004). As the development of biliteracy is one of the primary stated goals of any dual language program, it is important to investigate how this is embodied and developed over time. 
According to Genesee (1987), "The most distinctive feature of immersion programs is their use of the second language to teach regular academic subjects, such as mathematics and science, in addition to language arts" (p. 16). And while the discipline acknowledges the primary goals of immersion education (Cammarata and Tedick 2012; Genesee 1987), and some of its unique features, there remains a gap in the area of scholarship, where one may seek to answer the call by Genesee who wrote over thirty years ago that, "little systematic examination of interaction patterns in immersion classes has been undertaken so that we do not know precisely how language is used by immersion teachers" (p.180). This overall sentiment has been expressed in a variety of ways by other, more recent researchers, that we do not possess the desired corpus of studies representing the lived experiences of language immersion teachers and students in the content areas (Cammarata \& Tedick 2012; Dorner \& Layton 2014; and Met 2008). This research specifically seeks to address that need and provide abundant examples from a fifth-grade Spanish immersion classroom that exemplify the work of a particular teacher with her students.

In addition to the call for research on teacher-student interaction patterns, Broner and Tedick (2011) specifically requested more qualitative data sets. They articulated the idea that qualitative analysis lends itself to deeper descriptions of the context of two languages in use that may be "missed" through quantitative (numerical data) studies (p.183). Clearly, based upon the nexus of these claims within the area of language immersion education there is a need for additional qualitative research that richly describes how the communities of practice function through authentic descriptions of the teachers' (and students') experiences in these learning environments. 
Therefore, this case study research project provides a detailed description of a fifth-grade immersion classroom environment and the ways that an individual teacher supports biliteracy development through scaffolding.

\section{Research Overview}

The research foundations of this project are situated at the intersection of literacy studies, bilingualism, Sociocultural Theory, and dual language education. This overview will serve as a road map to understanding the orientation of some previous studies and how they relate to the particular design of this project.

The high stakes value of literacy should compel us to investigate specifically what teachers do in the classroom to promote literacy development as it provides one of the primary essential keys to academic success. We know from a variety of sources the value of literacy. Met (2008) wrote, "literacy... is a tool for gaining, storing, interpreting, and retrieving information. As such, literacy is a critical element in academic success,"(p. 50). Therefore, one can assert that literacy skills provide the keys to not only access the information within the content areas, but also provides the essential abilities to recognize, recall, interpret and evaluate that information. Literacy itself has a complex history as a developing term over time through research mores. According to the Principles for Learning, (2010 ACTE, CoSN, NCTE, NCTM \& NSTA),

Being literate is necessary for learning. As students progress through school and engage with subject areas more deeply, concepts become more challenging. Students use a greater variety of learning resources with more and more complex language and structure and increasingly sophisticated graphical and numerical representations. Students learn writing and reading strategies, using evidence and 
reasoning pertinent to each subject area, to comprehend and represent knowledge using traditional and emerging media.

The concept of biliteracy on the surface represents the nexus of literacy and bilingualism. One of the most accepted and cited definitions of biliteracy in the educational research field that represents some of the nuanced multifaceted components of this term comes from Hornberger (2004). She describes her work on the 'continua of biliteracy' in this way,

The continua model of biliteracy uses the notion of intersecting and nested continua to demonstrate the multiple and complex interrelationships between bilingualism and literacy and the importance of the contexts, media, and content through which biliteracy develops. Biliteracy, in this model, refers to "any and all instances in which communication occurs in two (or more) languages in or around writing (Hornberger, 1990: 213)" (p. 156).

Additionally, Hornberger (2004) uses diagrams to reflect the intersections that occur within the various components of the continua. The portion of this continua to be utilized as a matter of central focus in this study will employ a representation of the intersections between the areas she describes as aspects of the individual's communicative repertoire in the development of biliteracy: L1 and L2, reception and production, and oral and written language. The intersection of these points is visually represented by Hornberger's (2004, p. 15) in "The continua of biliterate development in the individual," as re-illustrated in Figure 1.1. This project investigated how and at what points of intersection the teacher's scaffolds within the language and content area lessons occur within the biliteracy continua in the development of the individual student. 
Figure 1.1

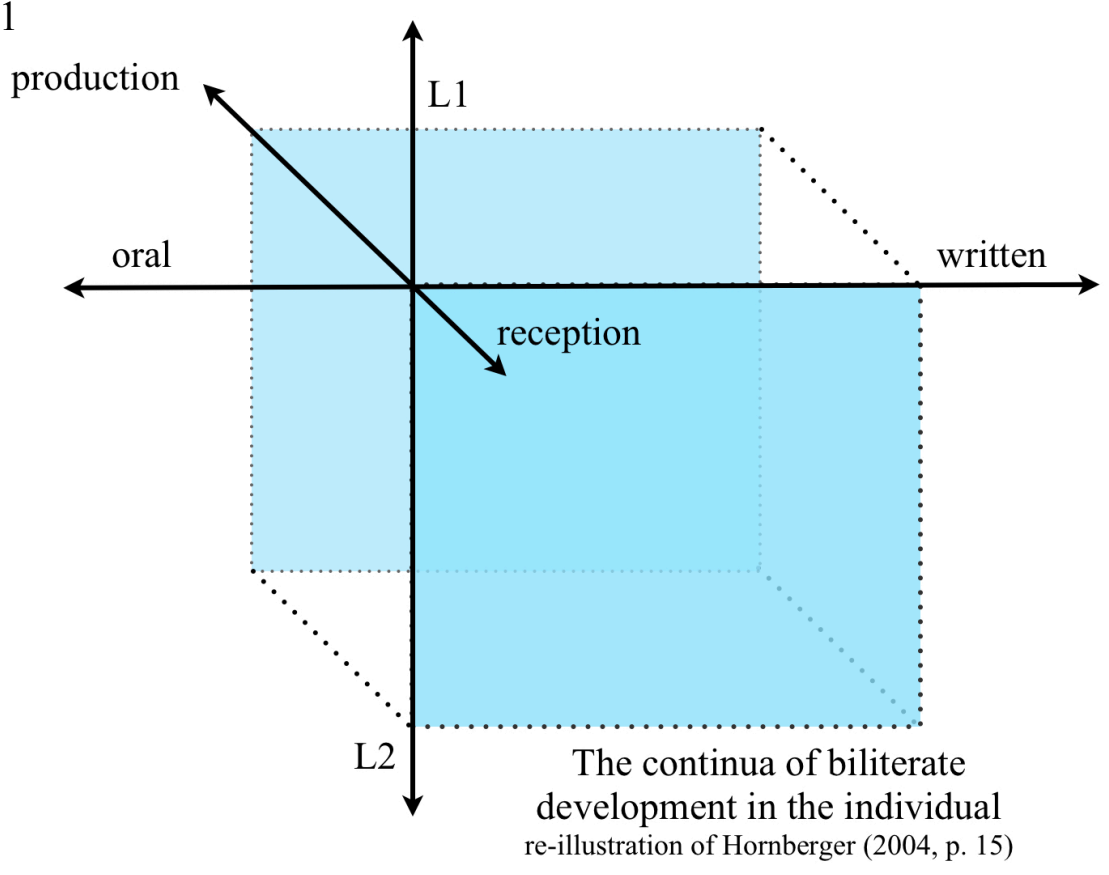

Lee and Smagorinsky (2000) wrote an appeal for research through the lens of sociocultural theory in order to better understand the development of language skills, knowledge, and the employment of various meditational means (tools) within their social contexts. They were particularly interested in the nature of the relationship between spoken language and knowledge development, the co-construction of understandings within groups working on assigned tasks, and "the ways in which literate practices occur and evolve outside traditional schooling" (pp. 4-5). Embedded within this study, there will be opportunities to view a portion of what they request. This will include what the teacher does to leverage, enhance and build upon the interaction and relationship between the student knowledge of the first language (English), and the second language (Spanish) and the meditational means employed to support the development of biliteracy.

Being that more numerous studies exist in the realm of test scores related to English language and literacy outcomes from immersion programs, Cammarata and 
Tedick (2012) write that,

Despite the wealth of research findings on language development in immersion and other scholarship to date, our understanding about content and language integration in immersion teaching remains incomplete. Missing are descriptions of immersion teachers' actual experiences with attempting to balance content and language in their instruction (p. 254).

This assertion by Cammarata and Tedick clearly expresses a gap in the current body of research in the area of what teachers are doing in their daily practices and interactions with students to balance language and content areas within the dual language school environment.

In addition to the calls for additional research made by these previously mentioned researchers in the field, I maintain an intense personal and professional interest in these contexts. As a person who was raised in the multilingual mileu of Northern California, I personally witnessed some of the lost opportunities to develop the rich linguistic resources of American students. In addition to this, in the current role of language and bilingual communication advocate, I am passionate about discovering and describing the work of individual teachers within the context of the dual language school environment.

Therefore, in order to respond to the gaps in research described by these researchers, and my own interests, this qualitative research project describes the fifthgrade teacher's interactions with students, particularly in the area of scaffolding biliteracy development. 


\section{Research Questions}

Within this context, this study sought answers to the following central question: How does the teacher scaffold student development of biliteracy within language and content instruction in the immersion school context? Additional, supportive questions included: What scaffolds are pre-planned as part of the lessons, and what are those that emerge organically through teacher interactions with students? What differences exist in the types of scaffolds provided for content area knowledge versus language, or their place relative to or within the continua of biliteracy? What forces or tensions does the teacher face as she scaffolds for biliteracy development?

\section{Rationale and Significance}

This project represents a body of research that advances our understandings of the complexity of teaching in the language immersion classroom. In addition to the interpersonal relationships in the language immersion classroom and their impact upon scaffolding, language ideologies are explored as a component of this bilingual dynamic. Additionally, the methods for scaffolding understanding of texts are explored in a variety of ways and represented clearly through Spanish - English classroom transcripts. The sample transcript excerpts are essential to one's understanding of the community and linguistic dynamics within this fifth-grade classroom. The accompanying translations and content analysis serve to deepen interpretation of these classroom conversations between the participating teachers and students. The research findings underscore the need for further exploration of these educational environments and teacher education programs to support their development. 


\section{Role of the Researcher}

As a doctoral student in Learning, Teaching and Curriculum, with an emphasis in Reading Education, I came to this project with numerous years as a Spanish language teacher who has worked in public middle school, high school, and university-level programs. My visits to the classroom at SLIP were in the role of researcher-observer. I did not participate in the classroom activities, although the students were clearly aware of my presence. It was my intention to observe as an outsider to the program, and to not interfere nor advise the teacher regarding her natural practices and habits. I was deeply intrigued by the Spanish-speaking abilities of the students in this program during my visits on two previous occasions, and was curious about how the students arrived at such abilities. Therefore, I designed this project around the idea of examining in-depth the work of teachers in this immersion school program.

\section{Key Terminology}

For the purposes of this study, I use the term "immersion" to describe the language program in which the students are taught their core classes through the target language of Spanish. Spanish is not the primary (home) language of the wider city community, nor for the majority of students at the school (although about $10-15 \%$ of the school population in any given year have come from Spanish-speaking homes). The school is self-described as an "immersion program" rather than "dual language," so I have elected to remain in keeping with their own nomenclature. Within the literature review, I will also integrate the term "dual language" as it is a broader term that also includes educational programs of this type, although not exclusively. 
Biliteracy refers to the language practices centering around texts of various types. This can include reading, writing, and viewing materials in Spanish and English in this educational program. Various aspects and considerations of the development of communicative skills in two languages will be explored throughout this project.

Scaffolding indicates the points at which the teacher intervenes to assist the student in the completion of a specific task that the student is unable to do independently at that point in the lesson. As illuminated through this project, this type of assistance can be performed in a myriad of ways with an eye always towards the future when the student can complete tasks on his or her own.

\section{Research Site: Spanish Language Immersion Program}

The Spanish Language Immersion Program (SLIP) was originally founded as a public charter school by a French teacher, Adelaide Boudreaux, who had studied the immersion school model in her master's program and taught in other states prior to her arrival in this urban area. She had high hopes for the participation of her own children in language immersion but was dismayed by the absence of options in this city. Within a few years, she was able to build a coalition of interested parties with political and financial clout, including the city's former mayor, regional philanthropists, and government funding. This political and financial support assisted in the advancement of a plan to establish a language immersion charter school with programs in French and Spanish. Madame Boudreaux's mission aspired to elevate the possibilities of local urban education and provide a unique educational opportunity for children in the community of all backgrounds. A local media source (not cited in the reference list to preserve anonymity of the research site) published through a major university underscored this 
point with the statement that Boudreaux had "the vision" of a learning environment where all children from diverse economic conditions and racial backgrounds would be well-educated and bilingual (2012).

The educational model selected and described in its original charter was for full language immersion (French or Spanish) until second grade. Students would begin with kindergarten using the target (immersion) language from the first day of school in 100\% of their classes, in all subject areas from math and science to art and music. As reported, although $90 \%$ of the students in the program came from English speaking homes, this full immersion program model was selected for its potential for results. Madame Boudreaux described the benefits of this plan saying to parents enrolling their children that a kindergartener in full immersion could speak as well as a person graduating from a high school Spanish program, and a third-grade student in full immersion could speak as well as a graduate from a university language program (2012). In the original plan, classes conducted in English would be gradually integrated into the program beginning in second grade and increase gradually to a ratio of $80 \%$ English / $20 \%$ target (immersion) language during the school day in the $12^{\text {th }}$ grade. The school first opened with kindergarten students only and then phased in subsequent grades throughout the following years.

Since its inception, the media profile of the school has highlighted both the successes and challenges of this program. One barrier shared through the local newspaper arose almost immediately with regards to space and cost. Several charter schools in the city attempted to purchase vacant school buildings from the local public school district and were prohibited from doing so (2009), which caused an increase in upfront costs for this charter school and others. SLIP was able to open in a renovated 
warehouse that required extensive work to bring it up to the required safety standards for schools at double the price. After its first few years, the school received positive reviews in national media for its innovative program and its support of diverse student populations. Notably, the Spanish Embassy recognized the program for academic excellence. Also, it was reported that during that particular year, approximately 60 percent of the students were on free or reduced lunch and the approximate racial demographics were 55 percent African American, 30 percent white and 10 percent Hispanic (2012).

Some complex issues raised in local media, included citing parental "trepidation" about choosing an unconventional program for their children and concerns about standardized test performance. Also in 2012, the local newspaper reported that in the first year of available state-required test scores, that students in the SLIP program (then in its fourth year) averaged above students in neighboring schools, but below the state average in both math and communication arts. Madame Boudreaux and Fred Genesee, a prominent researcher in immersion education, in the same article made the case for patience. They described the scores as the natural consequence of testing math in English while students in their first years of schooling are taught math in another language by design in this Spanish language program. Genesee's position advised that students in these types of programs need at minimum one year to achieve their grade level on standardized tests after they begin taking coursework in English.

After several years the school board lost its patience with the direction provided by Madame Boudreaux, and she left the leadership position. This move was deeply controversial and prompted vocal protests by the founder's supporters. One parent 
quoted in the local newspaper called the decision for removal "unconscionable," while others who spoke in favor of her removal explained that there were complex issues related to administrative responsibilities and budgeting impacting the decision-making process (2015).

According to teacher interviews from 2015, the school was following the model of full immersion as described in the charter. In addition, this model was also accompanied by a complex set of state standards for each subject area and the International Baccalaureate (IB) (see ibo.org). Briefly, the Primary Years Programme (PYP) is a constructivist, inquiry-based curricular framework designed for elementary / primary grades, usually around kindergarten to fifth grade in the U.S. According to the four teachers interviewed, this meant that teachers were to develop their own curriculum "from scratch" in cohort teams by grade level utilizing the five PYP themes, and layer those with the existing state standards for each subject area. The teachers viewed that the PYP also prohibited the regular use of textbooks. Because of this, and also because highquality texts in the schools' target languages were difficult to find, teachers regularly created, found, and / or translated relevant documents and materials for their classrooms. During the semester of this study, the new Director had been the lead administrator for more than one academic year. It is at that point, in Fall 2017, that this study began, and is situated within the school's complex background and history.

\section{Organization of This Dissertation}

This first chapter of the dissertation introduces the reader to the rationale supporting this project on both a personal and professional level. I included a brief 
selection from a class reading and other fundamental information to orient the reader toward the research site and the central research questions.

Chapter Two describes the relevant literature and representative breadth of research in three key areas: biliteracy, sociocultural theory and research, and dual language education and pedagogy. These areas of research are essential to understand the frames, theoretical background information, and pedagogical considerations necessary to conduct research related to scaffolding student development of biliteracy in a Spanish language immersion program such as SLIP.

The methods used to conduct this research are articulated within Chapter Three. Briefly, the methods employed in this research are those common to qualitative instrumental case studies with a sociocultural theoretical lens. The data collection phase included teacher interviews, classroom observations, field notes, and artifacts to deepen understanding of the operations of the classroom and the interactions between the teacher participant, Profesora Nuria, and her fifth-grade student participants. To increase the rigor, trustworthiness, and triangulation of the data, additional interviews were conducted, and member check protocols were included. Some of the analysis phase included methods from Grounded Theory (Charmaz, 2006). All research phases are described in detail within the Methods Chapter and supported by examples in the Findings chapter and the Appendices.

The research findings presented in Chapter Four are enumerated in four principal areas: descriptions of key participants, representations of classroom norms and practices, examples of scaffolding, and an accompanying analysis of language ideologies and practices. Essential to this presentation of findings are representative examples from 
classroom conversations, teacher and administrator interviews, and artifacts that invite the reader into the fifth-grade classroom. The core findings are centered around questions about scaffolding and how students are assisted by the teacher during their classwork, as illustrated utilizing a new visual model called "Scaffolding Episodes in the Development of Biliteracy." However, it must be noted that these interactions are inextricably linked to the classroom community and its surrounding environs. It is directly attributable to the sociocultural theoretical lens that the central section on scaffolding is literally and metaphorically "framed" by the descriptions of the participants and the language ideologies and practices.

Chapter Five includes a follow-up analysis of the findings, and its implications for immersion school teachers, programs, and researchers in these bilingual and biliterate environments. The deeper analysis and conclusion of this research ties back to the literature of the research of others, while simultaneously seeking to make a unique contribution to its continuation. 


\section{Chapter 2: Literature Review}

Within this chapter, I describe essential research that has been conducted in the past relevant to the themes that are covered within this project including: biliteracy, sociocultural theory, and dual language education and pedagogy. In each of these sections, the current body of research informs and guides the basis for this project and explains gaps described within the rationale section. These gaps include calls for further qualitative research into the actual teacher experiences in dual language school contexts, as well as descriptions of the teacher's work to support the student development of biliteracy.

\section{On Biliteracy}

Literacy is, as Gee (1996: 22) has aptly described, 'a socially contested term.'... They have demonstrated that literacy entails much more than the ability to read and write, that literacy practices are enmeshed within and influenced by social, cultural, political, and economic factors, and that literacy learning and use varies by situation and entails complex social interactions. If literacy is a socially contested term, the situation that has, in the literature to date, been dubbed 'biliteracy' is surely doubly contested.

-García, Barlett, \& Kleifgen, 2007, p. 207

Numerous researchers and educators have attempted to describe and define "literacy," both as a process and as a product. As described in the Encyclopedia of Bilingual Education (2008), "there is little consensus about what it means to be literate; however, the ability to interpret or produce meaning using written text is common to most definitions" (p. 529). This process or product becomes increasingly complex and 
multi-layered as skillsets in additional languages are injected into the narrative. Hopewell and Escamilla (2014) argue that

Biliteracy, or the development of reading, writing, speaking, listening, and thinking competencies in more than one language, is the outcome of a complex and dynamic process. It is made that much more complex because language acquisition takes place in a wide range of social contexts in which variation is the norm, and languages and literacies are in a state of constant evolution (p.181).

Therefore, in this project, multiple definitions of the terms; literacy, biliteracy, multiliteracies, and pluriliteracies will be described, compared, and analyzed for their application to educational contexts, and more specifically as they apply to studies in dual language education. While exploring these terms, I will also interweave descriptions of major studies that contribute to our understandings and applications of the same.

Defining biliteracy. Acknowledging that there are multiple definitions of the word literacy, I will be discussing those in the context of what the word biliteracy is generally understood to mean. Clarification will follow regarding the different dimensions and domains that are contained within the nuanced interpretations of what biliteracy means to the classroom teacher, educational researcher, and educational leadership.

One of the most accepted and cited definitions of biliteracy in the educational research field, comes from Hornberger (2004), who describes her work on the "continua of biliteracy" in in ways that emphasize, "the multiple and complex interrelationships between bilingualism and literacy" (Hornberger, 1990: 213)" (p. 156). As such, other authors, including those in the Encyclopedia of Bilingual Education (2008) explain the 
concept of biliteracy (in contrast to that of bilingualism) making the argument that, "literacy is often assumed to correspond with spoken languages as speech written down... [then] from a school perspective, language is typically conceived as four skills: speaking, listening, reading and writing. The notion of four skills, therefore, presumes literacy" ( $\mathrm{p}$. 531). According to Brisk and Harrington (2007), Bilinguals can have different degrees of biliteracy. When evaluating literacy of bilingual students it is important to distinguish between literacy (i.e., being able to function as a literate person in either language), and specific proficiency to read and write in a particular language (pp. 4-5).

This knowledge extends beyond decoding to achieve literacy, as cultural knowledge will inform the writer in standard expectations and norms for written communication. The second of these, "specific proficiency," appears to refer to the level of proficiency compared to grade level expectations for each language individually. Lessow-Hurley (2001) focused more upon the sociocultural implications and results of biliteracy, writing, "Biliteracy, then, includes the development of the full range of understanding and skills appropriate for an educated speaker of two languages" (p. 87).

Bilinguals and their range of literacy practices. As we look at bilinguals and their range of literacy practices, there are many that have referred to the connections between oral and written language. Valdés, as quoted in Baker (2011), wrote that it was virtually impossible to find a "balanced bilingual" due to the fact that in practice, many bilingual people select the language of use based upon context. Therefore, the languages the individual uses are not necessarily equivalent or equal. A person's skills actually directly mimic the useful application of one language or another in communication, and 
most individuals feel more confident in one language or another based upon context, domain, and register. These multiple dimensions of biliteracy are best described by Hornberger's 'continua of biliteracy' which embraces a multifaceted, 'nested' illustration of biliteracy in four dimensions; context, development, content, and media (2004). Embedded within the dimension of development, she notes a continuum of language use from oral to written, reception to production, and L1 to L2. These continua are represented within her article in graphic ways in an attempt to clarify their meaning and underscore the representation of the concept of literacy as a spectrum of skills, rather than static points. The remaining dimensions as described in her article also present useful ways for educators and researchers to look at the full range of language uses, contexts, and growth that occurs with students in the classroom over time as these dimensions intersect.

Biliteracy in the United States. According to Palmer and Martínez (2016), many "bilingual students in the United States find themselves in classrooms that do not cultivate their biliteracy" and must rely upon other resources outside of school for "nurturing" biliteracy skills (p. 379). Indeed, some authors view the current educational contexts, not as passive participants in a system that simply has an absence of programming for building literacy skills in minority languages, but as deliberate antagonists to the notion of biliteracy. Historically speaking, as explained by Rodriguez, Carrasquillo, and Lee (2014), there were researchers in the early $20^{\text {th }}$ century that "suggested that bilingualism had detrimental effects on thinking, and that learning two languages in childhood was destructive" (p. 18). Indeed, Cummins (1993), republished in Cummins, Baker, and Hornberger (2001), wrote, 
Only a tiny fraction of American schools even aspire to promote biliteracy. Most, in fact, are deliberately structured to minimize the possibility of biliteracy even among students who come to school already bilingual. Schools continue the tradition of eradicating students' bilingualism under the guise of helping them learn English. (p. 258)

Cummins is making reference to what is known as the practice of "subtractive bilingualism," versus "additive bilingualism." This is a point of concern, as numerous authors have noted the demographic shifts occurring in the United States and their implications for educational programming in general. Rodriguez et al. (2014) cite research that indicates fully greater than 10 percent of students in K-12 speak a language other than English in the home, and over 70 percent of those students are from Spanishspeaking homes. In more recent publications, illustrating and underscoring this trend of absence of programming Baker (2011) states, “Only a relatively small (and unknown) percentage of US students exit with well developed literacy in more than one language" (p. 313). This educational context and political issue in the United States, of a rejection by some of bilingualism in favor of English only, presents a unique conundrum as noted by Kenner, Gregory, Larson, and Marsh (2012) noted the significant proportions of children around the world that are educated in two languages (p. 364). They provide extensive examples of international studies that indicate the various ways that children in other countries are educated as evidence that, "it is clearly possible for very young children to become multiliterate" (p. 364).

Through vignettes embedded within ethnographic work, Zentella (1997) revealed that her participants, representing generations of Puerto Ricans living in New York, 
would strongly prefer to have a stronger repertoire of literacy skills in Spanish but lacked the community educational resources necessary to make this a reality. As Brisk and Harrington (2007), indicate, “The amount of environmental literacy in each language, both at home and outside the home, as well as the status and economic viability of the languages support or hinder motivation to learn to read and write in specific languages" (p. 11). This discussion is framed in yet another way by Segan and Carrasquillo (1998), as they write "context and opportunity play a critical role in how much and how often Spanish-language learners use the Spanish language” (p. 49). Those authors continue with the realization that providing learners the opportunity to talk also raises the scope of cognitive abilities as they reflect upon what they have read in a variety of ways.

Hopewell and Escamilla in their practitioner guide (2014) write,

We hypothesize that trajectories of biliteracy exist and that these trajectories likely differ based upon linguistic and sociocultural variables such as home language(s), time in the country, opportunities to learn, motivation, communities of residence, socioeconomic status, race, ethnicity, language status and political issues, among other factors. (p. 187)

Kenner et. al. (2012) note that children who live in bilingual or multilingual homes gain understanding of features of texts and literacy practices, including: "knowledge about different writing systems" and "knowledge about different cultural worlds" (pp. 368369). All of these points serve to underscore the necessity for increased implementation of specific educational programs that promote biliteracy to support language development. Dual language education programs fit into this category neatly, as characterized by Cammarata and Tedick (2012), "The principle aims of both one-way 
and two-way [immersion] programs are to promote additive bilingualism and biliteracy, academic achievement, and intercultural understanding” (p. 252). It is this centrality of the stated goal of "additive bilingualism and biliteracy" that distinguishes dual language education programs from other programs at this time.

Biliteracy, educational policy, and assessment. As Brisk and Harrington (2007) explain, "Bilingual programs, by definition, provide literacy instruction in both languages" (p. 21). Baker (2011) referred to the No Child Left Behind Act of 2001 when articulating the U.S. political emphasis on a skills approach to literacy, it assumes that literacy is the ability to decode symbols on a page into sounds, followed by making meaning from those sounds. Reading is about saying the words on the page. Writing is about being able to spell correctly and write in correct grammatical sentences. (p. 313)

Hornberger (2004) reports that through educational policies there exists "an implicit privileging of one end of the continua over the other" and that "written development over oral development" (pp. 158-159) is prioritized. It should be noted that this practice lies in direct contradiction to the indications that oral production skills are strongly tied to literacy skill development, as all four skills are interrelated. Fortune and Tedick (2015) noted relationships between oral proficiency and reading comprehension, and called for “tracking individual students' oral proficiency... to identify those who may need additional support with oral language to promote development of strong reading comprehension skills" (p 638).

Unfortunately, this does not reflect the reality of the sociopolitical influences of policy and standardized testing over curriculum in educational contexts. Students and 
teachers are not oblivious to this distinction, wherein the students' written work is more heavily weighted and more frequently evaluated or assessed than oral production of language. Orellana (2016) laments the existence of "strong forces [that] are at work to homogenize learning in school: to define what children should know and be able to do at the end of each grade, in each subject area, and in sub-divisions of those disciplines. Even after-school programs are being subjected to the forces of standardization" (p. xii). In J.M. González (2008), the author emphasizes three primary ways of measuring biliteracy and literacy rates in the United States, "involve direct assessments, literacy surrogates of equivalencies or self-reports" (p. 531). The author articulates the view that while direct assessments or tests provide some information, these historically have primarily emphasized measures of English literacy, and not literacy in other languages. Surrogate measures may include the number of years in school, and self-reported measures may include data from the U.S. Census, for example. This range of examples serves to remind educators that our information on literacy rates in languages other than English is incomplete. This can be seen as a significant issue, as many have recognized that the United States houses the fifth largest Spanish-speaking population in the world.

Research on the relationship between languages and literacies. Qualitative studies by Edelsky $(1986,1989)$, described extensively in Freeman and Freeman (2006), analyzed more than 500 classroom artifacts (writing samples) over time. Through this research, the inter-relationship between the growth of skills in both the L1 and the L2 was examined in a variety of ways. Indeed, this thought is supported by a variety of research performed since that time, including the work by Genesee (1987) and Reading (2008), showing that learning the process of decoding in Spanish is actually easier for students, 
as it exhibits both more consistent and clearer grapho-phonic relationships than English. Additionally, studies by Reading (2008) comparing Spanish immersion and French immersion students at the same school in the Midwestern United States found that the Spanish immersion students consistently had superior outcomes over the other groups in the L1 (English) testing at the end of first grade. Noting that the study participants constituted a somewhat homogeneous Caucasian English-speaking population, the author wrote that the median scores on L1 literacy tests in English were higher for students studying Spanish, in her words, suggesting "that learning English literacy skills was enhanced by concurrently learning a second language with a consistent orthography" ( $\mathrm{p}$. 142). That study, and similar studies by Genesee in Canada seek evidence of the transfer of skills from one language to another. Indeed, Genesee (1987) has written extensively about his research in the transfer of literacy skills from one language to another, but cautions that "it seems unlikely that poorly mastered [skills] in one language will transfer to another" (p. 142), concluding that this is one of the best arguments for bilingual educational programs. Reading (2008) posits that the consistent orthography of Spanish as compared to French or English (with regards to letter-sound correspondence) made the literacy skills, such as decoding, more easily accessible to the learners.

One of the central benefits of immersion education, as described by Cammarata and Tedick (2012), is "English-speaking immersion students of various academic abilities, regardless of ethnic or socioeconomic backgrounds, are capable of achieving high levels of functional proficiency in the immersion language while at the same time achieving academically as well as or better than non-immersion peers on standardized tests administered in English" (p. 252-3). Within this construct it is anticipated that there 
will be a transfer of skills built in the L2 to L1 and vice-versa. Met (2008) also expresses the ideal of anticipating that students in the immersion setting will match or exceed the attainment of L1 literacy skills of their monolingual peers, and considers this an additional impetus for calling for the prioritization of L2 language and literacy development across the curriculum.

Importance of literacy and biliteracy in achievement. A variety of sources acknowledge the value of literacy. Met (2008) describes, "literacy... is a tool for gaining, storing, interpreting, and retrieving information. As such, literacy is a critical element in academic success" (p. 50). Literacy skills provide the keys to not only accessing the information within these content areas, but also provides the essential abilities to recognize, recall, interpret and evaluate that information. Literacy skills allow students to gain access to knowledge in other curricular areas such as math, social studies, and the sciences. As further described by Met (2008), Language, reading and academics are powerfully connected once students have mastered the fundamentals of reading. Language is a key to accessing learning: texts in the social sciences are heavily laden with abstract concepts to which the primary access is language. (pp. 52-53)

She then proceeds to list specific ways in which textbooks, in a variety of curricular areas, impede and confound the second language reader particularly through nonstandard formatting, lack of context clues, incongruous visuals, and abstractions to name a few. Similarly, Reyes and Kleyn (2010) describe ways to work with reading and writing in each content area with specificity. This way, students are better equipped to interpret and learn from these diverse text types. 
Bialystok (1997, 2001), as reported in Baker (2011), studied extensively the reading and interpretive responses of bilingual children with regards to linking language, pictures, and symbols. The resulting reports seemed to indicate early advantages to bilingual students in terms of recognition and observance abilities as related to early literacy skills. There are studies that indicate that biliteracy in general, and specifically those in bilingual and dual language school environments possess advantages in gaining access to standard measures of academic success. Lindholm-Leary and Howard (2008), cite a large-scale study by Thomas and Collier (2002) that "found that only developmental bilingual programs and two-way immersion programs enabled ELLs [English Language Learners] to reach or surpass the $50^{\text {th }}$ percentile on standardized tests on all subjects in both languages. They also found the fewest dropouts from these programs" (p. 180). Thomas and Collier (2002) explain that their longitudinal study, with its mixed-methods approach, representing several school districts from diverse regions of the United States, noted that in one represented district "the pressure to teach more in English is strong" (p. 47) but that the "bilingual immersion students outperformed the monolingually schooled students at the end of the first year of the program" (p. 58). In the Encyclopedia of Bilingual Education (Gonzalez, 2008), the author noted research projects that found positive correlations between Hispanic student retention rates and bilingual programs (p. 231). For some, this type of research confirms the power of additive bilingualism policy over subtractive bilingualism models.

Beyond the context of academic success, Dworin (2003) writes that "Biliteracy is important because it may amplify the intellectual possibilities for children by providing them with access to a broader range of social and cultural resources" (p. 171). Baker 
(2011) takes this point even further and explains that the benefits of biliteracy are an essential component for overall success in a more global sense. He believes that biliteracy is especially important for students from a minority language background, as they must function within minority and majority language communities. He stated, "given that literacy empowers, emancipates, enculturates, educates, and can be inherently enjoyable activity, there seems to be a strong argument for biliteracy" (p. 321).

More on the relationship between L1 and L2. As Hornberger (2004), indicated in her continua of biliteracy, one of the components of this development of biliteracy is the relationship between the individuals' first language and second language. Zentella (1997), describes the relationship between the L1 and the L2 in this way;

The Spanish-English bilingual is like a conductor of two trains on parallel tracks whose cars are linked at similar places; she switches one car of the train on the Spanish track for a car on the English track or vice versa at the appropriate coupling points. (p. 123)

Her in-depth research and analysis explored the interactions between L1 and L2 in a Puerto Rican community in New York (nuyorican) and found consistency in the patterns inherent in their code-switching. As Gort (2012) describes it, the process of switching languages is seen as, "a natural and common discourse strategy" (p. 46). The six emergent-bilingual first graders represented within Gort's (2012) sample qualitative study on writing-related talk represented their bilingual and biliterate practices in ways similar to those described by Zentella (1997).

Recent researchers have begun investigating language mixing practices that they call translanguaging. This is not to be confused with translation. Creese and Blackledge 
(2010) explain, that while "bilingual education has traditionally argued that languages should be kept separate in the learning and teaching of languages" (p. 104), they found teachers in bilingual programs that utilized two languages simultaneously with "each language... used to convey a different informational message" (p. 108). They concluded that, "it is in the bilingualism of the text that the full message is conveyed" (p. 108). Orellana (2016) described her after school club language practices using this term, explaining that "collective translanguaging" (p. 105) best represented the general flow of communication patterns between participants.

In Kenner, Gregory, Larson, and Marsh (2012), they present a list of some cognitive and cultural challenges that may be provoked in developing biliteracy. These issues may include topics such as lexical awareness, in which students may understand that "words have different forms and properties" (p. 372) but that they may not know which words work most effectively in combination with others (collocation). Additionally, students may understand sound-symbol relationships in one language more clearly than the other. These skills can be effectively scaffolded within the classroom using techniques such as those mentioned in Gibbons (2002, 2015), Segan and Carrasquillo (1998), and Freeman and Freeman (2006), among others. One area in which this process becomes more problematic, as noted by Bialystock, Luk, and Kwan (2005), is when the languages being studied have distinctly different forms of writing, such as the difference between alphabetic systems versus character languages (for example, Chinese). In their study, they investigate extensively the transfer (or lack thereof) of skills in these scenarios noting, 
Phonological awareness, a crucial basis for reading, also transfers readily and even relates to reading in the other language. As with reading, however, the extent of such transfer likely depends on the relation between the languages and the relation between the writing systems. (p. 45)

In the research of Reyes (2006), she notes that previous research has been conducted with both sequential bilinguals (those who first learn L1, then add an L2), and simultaneous bilinguals (those who learn L1 and L2 concurrently). In her study, she focuses exclusively in on the emergent literacy of bilingual children in the Southwestern U.S, and uses this term to describe "the ongoing, dynamic development of concepts and expertise for thinking, listening, speaking, reading, and writing in two languages" (p. 269). Based upon her findings, she urges teachers and educational planners to consider the contexts and conditions before designing biliteracy instruction for bilingual students, writing that the, "conditions for biliteracy development are different for young children who are immersed in two languages from an early age (four to five years of age) than for older bilingual children who have already developed conventional literacy abilities in their L1 before becoming literate in their L2" (p. 287). She is also looking specifically at the language and literacy practices that students already possess as they arrive in the classroom and how those impact the language and literacy development in the classroom. Baker (2011) refers to Krashen's research (2002) as a way to "neatly sum up the argument" in favor of developing literacy skills beginning with the first (native) language of the student. He does this by presenting three primary arguments: that understanding what is on the page is essential to the process of learning to read, that the known language of communication is the one that is "easier to understand," and that once a person is 
capable of reading (decoding) text, those skills can transfer to another language (pp. 324$325)$.

Multiliteracies and pluriliteracies. Some emergent terms that have arisen around the beginning of the $21^{\text {st }}$ century, include multiliteracies and pluriliteracies. There have been different shifts relating to terminology intended to represent the shifts in thinking and valuing multiple voices. One way to look at these different layers, is related to the diverse ways that people use language. Heath (1983), as an ethnographer, studied intently the communities in which, "for more than two centuries, social and economic factors kept the majority of blacks and whites of this region apart in many ways. People in each group developed a separate set of techniques for adjusting to their physical and social environments" (p.10). This ethnographic years-long longitudinal study helped to initiate a trajectory in which researchers sought to understand the ways with words employed by communities in various contexts, including the relationship between home literacies and school literacy practices.

When we look at the most basic definition of literacy, we see a reference to the word text. However, we know from the area of New Literacy Studies (Gee, 2012) that the definition has been extended to a multi-modal approach that can include the combinations of text and video, text and audio, and even visual interpretations alone. New technologies have introduced additional modes to the common use of text. So, as we are discussing the definitions of these terms, we also can be considering what this means in terms of our focus in educational contexts, including specifically, in the classroom. One way that multimodal literacy practices have been explored, is reflected by Mills (2010), who writes about using graphic novels and digital moviemaking in the 
classroom to further develop literacy skills and provides the following advice for teachers that, "when designing multimodal texts, teachers also need to focus the students' attention on the visual, spatial, gestural, or audio modes embedded in a text” (p. 42). Mills clearly articulates some of the enhanced features of text commonly noted under the frames described in NLS. Kafle and Canagarajah (2015), refer to this as, "how people actually use literacy in their life worlds on a daily basis" (p. 243). Originally considered more of a "local" and "socially situated" descriptor of literacy practices, they acknowledge that various researchers have now expanded and applied the interpretation of this theory to in-school literacy practices as well.

It is important to understand these central features of NLS before delving into the working definition of the term multiliteracies and to what it refers. The impetus for the creation of the term multiliteracies has been articulated by Cope and Kalantzis (2009) as, "We were interested in the growing significance of two 'multi' dimensions of 'literacies' in the plural—-the multilingual and the multimodal" (p. 2). This lead to the creation of a "manifesto" created by the New London Group, 1996. They also were concerned by the notion that multiple discourses (as articulated by Gee) were not receiving enough attention in the domain of academic literacies. Additionally, they expressed concern about traditional models of literacy instruction in schools that did not include "critical framing" (p. 3) of topics therein. Another component included in this article is the notion of transformation. In this, they insist that language should not be replicated, but rather transformed and "reworked" into a new, dynamic form. They see this ideological shift as one of great power. 
Since that time, the term multiliteracies has been embraced by some researchers and practitioners in a variety of ways. Mills (2010) describes her work as, "situated practice... building on the life-world experiences of students, situating meaning-making in real-world contexts" (p. 15). She includes vignettes and examples from student dialogue that she feels exemplify the points that she makes about the student literacy practices, and argues that one of the primary features of teaching in this way, "acknowledges the multiple ways of communicating for different cultural and institutional purposes" (p. 96). She also makes the argument that justifications by those who feel compelled to defend the understanding of the term multiliteracies will become increasingly redundant over time as emergent technologies continue to underscore the multimodal, multicultural nature of modern communications.

Schwarzer, Haywood, and Lorenzen (2003) “describe collaborative work within this multiliterate classroom" with the stated goal of providing guidance "mainstream teachers who are interested in supporting linguistic diversity" (p. 453). They argue strongly against the practice of denying students access to their native languages in any classroom. In this article, they also repeatedly emphasize that the article is intended for monolingual teachers who wish to provide a multiliteracies learning context for their students, while acknowledging that when available, "dual language/bilingual programs are the ideal choice of instruction" (p. 455). Some of the practices promoted in the article include, increasing opportunities for student use of native languages, prominently placing multilingual print in the classroom, and inviting multilingual community members into the classroom, among others. Within the multiliteracies classroom, one can also see evidence of the practice of translanguaging, which can add another layer to the 
conversation of what and how languages are used. As Kafle and Canagarajah (2015) explain, the notion of multiliteracies not only transforms the language, it transforms the interactions between languages. While some may see the practice of translanguaging or code-meshing within text problematic, they write in response, "if we keep hanging on to the traditional notions of literacy, we will not only end up labeling the discourses of the multilingual students as deficient, but also find the new forms of literacies unproductive" (p. 248). There are many topics to consider within this framing, including, "How do we interpret a code-meshed text when it uses languages we may not be familiar with?" and a list of others catalogued in that same book chapter.

Pluriliteracies. García, Bartlett, and Kleifgen (2007), take this notion one step further, and introduce the label pluriliteracies, to integrate the continua of biliteracy and others to better "capture not only literacy continua with different interrelated axes, but also an emphasis on literacy practices in sociocultural contexts, the hybridity of literacy practices afforded by new technologies, and the increasing interrelationship of semiotic systems" (p. 215). Through this description, they are attempting to add additional dimensions to emphasize different points about the multicultural and multlilingual nature of modern communications. Based upon the available literature, it appears that the term multiliteracies currently has been embraced by more researchers and practitioners at this point than pluriliteracies.

Biliteracy in this research project. It appears that the term biliteracy is in more frequent use, specifically referring to the work that is taking place in dual language school contexts. There are various places on the spectrum for acceptance and use of the other terms. However, one must also recognize that the current working definition of a 
Dual Language Program specifically states that the language in use on the part of the teacher are pre-determined based upon curricular design, and with a specific aim of achieving bilingualism and biliteracy. It also must be recognized that biliteracy is a term that is in common use. One of the benefits of using the term biliteracy, is that the general populace has a basic understanding of what biliteracy means and to what it refers. When the term multiliteracies is used, it may not necessarily convey a clear message regarding the use of more than one language in communication with the layperson.

There is a currently growing movement to officially endorse through legislation in individual states a program called, the Seal of Biliteracy. This was a movement that was initiated in the state of California, can be added to a student's high school diploma in a recognized and standardized way. More information on this is available at http://sealofbiliteracy.org/. Earlier in this paper, the assessment component was mentioned in reference to the development of terminology related to literacy or biliteracy. So, here, with the Seal of Biliteracy, we have an embodiment of that practice, where clearly there are standardized measures of biliteracy, recognized by some states and used in this case to indicate a level of proficiency in two languages. One of the accepted measures in this case, of Spanish language proficiency, is the Advanced Placement Spanish Language Test. I personally see this as an extremely positive step, as the AP Spanish test, is actually an extremely rigorous test that focuses in on a variety of domains of use, including speaking, reading, listening, and writing with the clear integration of authentic materials (The College Board). So, in real terms, this could be considered a multiliteracies assessment. 
In the research domains, we will continue to see growth in the terminologies multiliteracies and pluriliteracies. However, I have elected to use the nomenclature biliteracy in this dissertation as the term that is most easily recognized in the vernacular and more readily understood.

\section{On Sociocultural Theory and Research in Dual Language Environments}

The term 'sociocultural' represents "the notion that human mental functioning results from participation in and appropriation of, the forms of cultural mediation integrated into social activities. (Lantolf \& Beckett, 2009, p. 259)

Sociocultural Theory is uniquely suited to studies of second language development and immersion school contexts for its interdisciplinary emphasis on the relationships between language, cognition, and culture. Lev Vygotsky is the acknowledged father of a complex and nuanced set of theories commonly known as Sociocultural Theory (SCT), and he is widely recognized for the influences of a multiplicity of disciplines to which he refers in his writings, including, but not limited to; literature, theatre, mathematics, psychology, linguistics, and neurology. Readers may note that there is some variation in spelling of his surname based upon English publication variants of Russian surnames, as in Vygotsky vs. Vygotskiî. Therefore, I will integrate citation of works based upon the variant used in the publication itself. It is also important to acknowledge the contributions of others who have worked to build upon the original theoretical frames and how they affect the trajectory of modern educational research. Vygotsky himself might be surprised to see the evolution of educational designs, theories, and practices that have developed based upon his transcribed lectures and writings about social psychology and human development. As his work contains 
numerous references to "future projects," and his life ended in his thirties after a lengthy illness, researchers and language theorists alike must recognize that his intended body of works was not developed (by himself) as he had envisioned (Swain, Steinman, \& Kinnear, 2011). Although his works are available to American researchers in translation, it seems the aperture of ambiguity provided by an early death and somewhat disparate translations may have created a potential stimulus for others to go further in developing those initial theories in a variety of ways.

In this section, I describe the major principles of Sociocultural Theory as they relate specifically to the field of second language development and dual language (immersion) education. In addition to this, I integrate the contributions of key researchers who have presented significant interpretations and related concepts of SCT with particular attention to dual language and language immersion classroom settings.

Overview of sociocultural theoretical frames. As described by Lantolf and Beckett (2009), the term 'sociocultural' represents "the notion that human mental functioning results from participation in and appropriation of, the forms of cultural mediation integrated into social activities" (p. 459). This orientation recognizes the nature of the individual as a member of a broader society. I will explore this concept further in a variety of ways. In the same article, Lantolf and Beckett acknowledge Wertsch (1985), for the precise nomenclature 'sociocultural,' as he is a major contributor to the American educator's understanding of the lectures and writings of Vygotsky. There are numerous ways that others have attempted to outline and describe the major theoretical principles of SCT. Lee and Smagorinsky (2000) describe SCT as a theory in which learning is mediated, social in nature, "constructed through joint activity" (p. 2), 
and represents a trajectory of potential. Wells (2000) depicts a historical perspective on learning and learned behaviors, accompanied by the mediating role of artifacts in activity, with an emphasis on the relationship between individual members of society and the society at large. Embedded within these particular descriptions, these researchers clearly present similar substructures consistent with the original writings of Vygotsky.

Precept 1 - the social. The first and most obvious precept of Sociocultural Theory (SCT) based upon its current nomenclature is the social component of learning and language development. By social component, researchers specifically refer to Vygotsky (1981) and his theory that human characteristics, including language use and thought patterns are "a copy from social interaction; all higher mental functions are internalized social relationships" (p. 164). This assertion carries relevance specific to the classroom environment where all of our students come from a range of social experiences that form their language practices, background knowledge, and thought processes.

As a component of this social milieu that informs and builds the learner's cognitive practices, Gutiérrez and Stone (2000) indicate that researchers such as Cole, Leont'ev and Wertsch have greatly contributed to our understanding of how this theoretical frame can "yield a repertoire of methodological tools to examine the mutual and interdependent relationship between the individual and the social world" (p. 151). As such, within the classroom activities, it is not just the individual who is and was shaped by the social environments (both past and present), but that selfsame social environment is concurrently shaped by the individual as an actor within that social space. Smagorinsky (2011) praises Vygotsky's argument against the "widespread notion that cognition takes place strictly within the skull," and for making the point that, "we learn 
not only words but ways of thinking through our engagement with the people who surround us” (p.197). As such, in Vygotskiı̌, Carton, and Rieber (1987), Vygotsky outlines his belief that, “An understanding of another's words requires more than an understanding of words alone; it requires that one understand the other's thoughts" (p. 4). One of the clear advantages to SCT in the American research context, according to Cole (1985) is that American (U.S.) researchers are more likely to seek to understand "real activities of real people," which necessarily combines what was promoted by Leont'ev as the "study of both the systems of social relations and of internal (cognitive) activity" (p. 159). Moreover, they emphasized the importance of thoughts embodied through social interactions. These concepts, the layers of the social and the individually internalized thought processes, Cole indicates, are typically studied in isolation from one another in other nations due to a lack of interdisciplinary research conventions.

Precept 2 -mediational means. The second precept of SCT most commonly recognized is based upon the transmission of information, meditational means, and understandings of tools (including language) through the cultural norms of the society. This transmission is both provided by and embodied through the social structures and practices previously mentioned in the first precept. Bomer (2003) describes this characterization of tools in the following manner:

A teacher externalizes mental processes into tools to which she then persuades children to assign meanings similar to hers. These meanings do not just come out of her head; she acquired them through participating in the larger culture, from her own process of education and from her ongoing conversation in social worlds. (p. 229) 
What this indicates is that every tool that is used within the classroom (Bomer's example being scissors) conveys a meaning assigned to it by the relevant society and culture that uses it. This notion of tools as a meditational means, something that people use while conveying meaning and socially assigned value, also applies directly to language itself. Swain and Lapkin (2013) write that "[Vygotsky] argued that our most important mediating tool is language" (p. 104). Bruner in Vygotskii et. al. (1987), explains that "for Vygotsky, language is a powerful system of tools for use - for use initially in talk, but increasingly, and once inwardness is achieved, in perception in memory, in thought, in imagination, even in the exercise of will” (p. 15). Vygotsky's own writings in Vygotskii et. al. (1987), emphasize the importance of word meaning, as he explained that "word meaning is a phenomenon of both speech and intellect," and that word meaning shifts and develops over time based upon experiences (p. 244). This is how children learn to differentiate between the concepts of what is a cow versus a calf versus a dog, as a "child's social interaction through speech is immediately linked with his differentiation and conscious awareness of word meanings" (p. 254).

Mediational means can also include artifacts, such as books, computers, and social interactions as they are culturally constructed materials and representative of symbolic means that inspire or provoke mental activity, including the learning of another language (Swain, Steinman, \& Kinnear, 2011). Our understandings of the conceptualization of artifact within SCT was further developed by Cole (1985) who posited that, "1. Artifacts are the fundamental constituents of culture," and " 2 . Artifacts are simultaneously ideal and material. They coordinate human beings with the world and one another in a way that combines the properties of tools and symbols" (p. 221). Cole 
also links past to present production of artifacts (material objects, including writings) to the expression of cultural values and language that may be transmitted through these meditational means, including those items produced by prior generations.

Communication of ideas through word choice, values, artifacts, and cultural influences expressed through language is already a natural central focus for second language and dual language educators who are actively involved in the work of building language and literacy skills outside of the home environment. This unique context may, at times, transmit or convey cultural knowledge and values that are different from those transmitted or possessed by the home culture of the student. Vygotsky also offers insights into various components of processing in a variety of modes of communication including the value of oral language production (talk). In this project, I have selected to use the terminology "second language development" as described by Gibbons (2002), who employed this term to focus in upon the learner's social process of growth in understanding and use of a second language (p. 19).

Vygotsky's writings make it clear that he believed that talk (oral language production) was a necessary component of the thinking process and vice versa. The relationship between thought and language is that language informs and shapes thought, just as thought informs and shapes language. These ideas also inspired the work by Mercer and Dawes (2008) in the classroom. They indicate that spoken language is used in a multiplicity of ways in the classroom including in exploratory talk. Exploratory talk allows "tentative thoughts" to be heard and exchanged which is "not only useful for an individual to sort out their thoughts, it can also help two or more people to solve problems because they are sharing ideas (some of which may be only partly developed) 
in a genuinely collaborative interaction" (p. 66). Cole (1985) states that "mediated activity has multidirectional consequences; it simultaneously modifies the subject in relation to others and...in relation to the situation as a whole, as well as the medium in which self and other interact” (p. 221). In the language classroom, we also extensively explore the interactions between the processes related to interpretive skills (listening and reading) versus productive skills (writing and speaking). Vygotsky and Kozulin (1986) also addressed these linguistic demands as a representation of language, thought, and culture in describing the differences between oral speech and writing, with oral speech characterized as more "spontaneous" while writing is more "deliberate and conscious" (p.183). Gibbons $(2002,2015)$ includes concrete examples of these processes in the classroom and explains how the different features of oral and written communication can be developed in the classroom. If language teachers understand these distinctions, they can be leveraged to assist students in their development of speaking and writing skills in the target language.

Precept 3 - the importance of situated learning. The third precept exists within the setting for potential for language learning and development as a result of these social and cultural interactions. This focus upon potential, development or growth in language is one of the most attractive aspects of SCT for language teachers. Vygotsky, while discussing word meaning specifically, articulated the shifts in language use and development over time in relationship to social and cultural (sociocultural) experiences. According to Smagorinsky (2013), "Vygotsky was adamant that this process [of learning] at least in school, should involve a dialogue between what one knows through personal experience outside school... and what one learns about... the scientific or academic 
concepts learned in school" (p. 198). This point invokes what I discuss regularly in methodology courses in language teacher education about the importance of the activation of background knowledge to assist students in bridging the gap between what is already known versus what is unknown (or less known). This, too, addresses the concept of potential and growth in knowledge and language development.

Lave and Wenger (1991), as explained by Wells (2000), "insist learning is not a separate and individual activity, but an integral aspect of participation in any 'community of practice"” (p. 56). These researchers are generally known for introducing the term “community of practice." Lave (1991) refers to learning through collaborative work, a traditional practice, more commonly performed through the apprenticeship process in other cultures. She goes on to urge (American) society, and those in "schooling" or education in particular, to consider the apprenticeship model embraced in other nations. She believes the traditional framework can serve as a model for what can be achieved through socially, culturally, and historically situated learning. Lave believed that this can provide a way through which those initially on the periphery can become integrated, whole members of a community of practice (COP). These models clearly rely upon more knowledgeable members shaping the knowledge and practices that are eventually appropriated by the learner through participation in activities. According to Swain et al. (2011), Lave and Wenger's writing on COP “intentionally moves way from schoolcentered discussion because learning happens beyond schools," and traditional schooling "is somewhat in opposition to Lave and Wenger's less structured conceptualization of learning" (p. 27). Cole (1985) specifically writes that the activities of children, and interactions, generally directed by adults, result in the "acquisition of culturally 
appropriate behavior... through interaction... in which adults guide children's behavior as an essential element in concept acquisition / acculturation / education" (p. 158). As previously mentioned, Vygotsky, too, refers to the context of in-school learning as one that is separate and distinct from the learning processes that take place out of school. However, the argument has been made that a school or classroom itself may be considered its own COP based upon the notion that Swain and Lapkin (2013) articulate, "One may grow into greater and more legitimate participation in a linguistic community, a professional community, or other type of community where there are preferred structures, routines, lexicons, and values" (p. 27). Lantolf and Thorne (2014) in (VanPatten \& Williams, 2014) explain that socially situated learning and developmental processes may take place in a variety of settings, "such as family life and peer group interaction and in institutional contexts like school organized sports activities and work places, to name only a few" (p. 197). These notions clearly underscore Vygotsky's original premise that learning takes place within a socially and culturally constructed context and that language, in particular, is constantly in development through experiences and assistance in that context.

Looking deeply at our own classrooms, teachers note that as a mark of the cyclical nature of the exchange of ideas and methodologies through these sociocultural experiences, the relationships between teaching philosophies and the expression of these through methodologies used within the classroom can be examined. Cuddapah and Clayton (2011) used the lens of COP to explore a new teacher cohort to maximize peer support of novice teachers and encourage higher retention rates. Swain and Lapkin (2013), in their qualitative study of teacher attitudes about the relationship between L1 
and L2, they

note that the teacher's methods in the classroom are also the embodiment of social worlds experienced by the teacher, thus simultaneously building a social world for their students that is similar to the cultures and socially constructed meditational means that they themselves appropriated previously. (p. 118)

It is this message that brings draws attention to the connection between teacher language ideologies and their expression through classroom practices.

Methodology and Application of Theory in the Classroom. In this section of the paper, I will be expounding upon the two primary strategies referred to in the literature for their use and application in the dual language classroom. These SCT-based applications, the zone of proximal development, and scaffolding are strongly interrelated, and readily embraced by numerous classroom practitioners in a variety of contexts.

Zone of Proximal Development. One of the most widely recognized expressions of Sociocultural Theory in the classroom is manifested in "the zone of proximal development" (ZPD). Interestingly, the ZPD was only mentioned by Vygotsky a few times in his writings, even though Smagorinsky (2011) refers to it as one of his most famous "propositions." The ZPD was described by Vygotsky (1978) as the "distance" between what an individual child can do alone based upon his or her "actual developmental level" and the level of "potential development as determined through problem solving under adult guidance or in collaboration with more capable peers" ( $\mathrm{p}$. 86). Lantolf and Thorne (2014) praise the ZPD as "forward-looking through its assertion that what one can do today with assistance is indicative of what one will be able to do independently in the future" (p. 206). Cole (1985) describes the ZPD as, "the structure 
of joint activity in any context where there are participants who exercise differential responsibility by virtue of differential expertise," (p. 155), accompanied by the broad goal of continuing with practice, until independence is achieved.

Wells (2000) emphasizes the now expanded notion of the ZPD, that it does not just emphasize face-to-face interactions, but that the collaboration can exist in and through the transmission of knowledge through "the legacy... of artifacts" (p. 57). This brings us back to the previously mentioned writings of Cole and his historical references to the role of artifacts in the transmission of cultural and linguistic knowledge as well. The ZPD is now seen by many as a "tool for class instruction" (Hedegaard, 2005). She further explains that it is up to teachers to employ its use as the knowledgeable other who is able to gauge the developmental stage of the learner and plan ways to support the learner in moving forward with assistance until the learner is capable of performing the task alone (p. 247). Other authors, including Swain et al. (2011), emphasize that "individualization is critical to creating a ZPD" (p. 29), and that the teacher's understanding of the individual student and his or her learning process will assist the teacher in selecting the most appropriate supports and supportive behaviors within the ZPD.

Scaffolding. The temporary supports and supportive behaviors created by and utilized within the ZPD by the knowledgeable other are most commonly referred to as scaffolding. This term originates from the building trades whereby while laying brick, one must use a support structure to stand upon to continue laying bricks above the natural reach of the bricklayer on the side of a building. This is of particular relevance to dual language classrooms and other multilingual settings, as the teachers are typically working 
with diverse groups of students, in two languages, and with a variety of curricular topics. Gibbons (2015), an Australian researcher, who has written extensively on the topic of scaffolding particular to multilingual educational contexts, explains, "Scaffolding, however, is not simply another word for help. It is a special kind of help that assists learners in moving toward new skills, concepts, or levels of understanding" (p. 16). In her text she includes numerous examples of ways that teachers can scaffold for students within the ZPD as a matter of practice, including modeling, message redundancy, and feedback.

Clark and Graves (2005) write that "instructional scaffolding [is] one of the most recommended, versatile, and powerful instructional techniques of constructivist teaching" (p. 570) in their practitioner article. They emphasize the distinction between types of scaffolding including those oral scaffolds that occur "in the moment" and those that constitute pre-planned "instructional frameworks." Other researchers, including Daniel, Martin-Beltrán, Peercy and Silverman (2016) exhort teachers to consider ways of scaffolding that go beyond reinforcement of traditional IRE patterns, and "yes" and "no" responses, and avoid "over-scaffolding" (p. 393). In their research of interaction patterns in the classrooms of eight teachers, they found that teacher's "closed-ended" questions and IRE interaction patterns inhibited the growth of students and missed opportunities for independent student engagement in higher-order literacy practices (p. 405). They recommended that teachers employ certain forms of scaffolds "only if students show they need further assistance" (p. 412). Earlier researchers, such as Tharp and Gallimore (1988) were noted for their work in defining "means" and "intentions" of scaffolding as two distinct points of interest. 
Van de Pol, Volman, and Beishuizen's (2010) article presents a ten-year overview of research and studies in scaffolding. They describe scaffolding as "a dynamic intervention finely tuned to the learner's ongoing progress, the support given by the teacher during scaffolding strongly depends upon the characteristics of the situation like the type of task... and the responses of the student" (p. 272). These characteristics of being attuned to the learner's progress and teacher support based upon the task will be highlighted in my research project. While van de Pol, et. al. (2010) criticized the variability of some research studies on scaffolding for their lack of pre-defined coding schemes, they praised others for their "descriptive studies" that include "rich narratives of scaffolding in the classroom" (p. 279).

Reynolds' (2017) research focuses upon synthesizing 57 studies in reading comprehension and interactional scaffolding, "defined as the in-person support an expert reader offers to a novice" (p. 135). He concluded that "a key theoretical specification of scaffolding in the ZPD requires the reader to be challenged to stretch beyond his or her current situation" (p. 146). It is this sense of challenge that requires emphasis, as the entire design of scaffolding is intended to provide only temporary assistance to the learner. Additionally, he notes that teachers should pay attention to the "materials" in use to "ensure that they do not inadvertently overscaffold students" (p. 148).

Again, due to the influence of Vygotsky and SCT, this terminology can be used to emphasize the types of interactions that occur within and without the school environments, as well as attempts to link the diverse social worlds in which our students interact. In one such research context, we find the writings of Dorner, Orellana, and Ligrining (2007), who wrote about how the children of immigrants and their parents were 
able to "work together and help each other" in a variety of ways. They name the relatively common practice of translating and mediating communication for their parents as "language brokering." They discussed in their research the practice of children providing translation to parents in the dominant language (English) in broader societal tasks, while the "parents scaffold[ed] children's understanding of the genre, topic and /or purposes of various artifacts, while children scaffold parents' understanding of linguistic and / or social practices" (p. 457). For example, we can imagine that if an immigrant parent needed to go to the bank, the child may have greater proficiency in global or academic language tasks in English, whereas the parent's knowledge of banking practices (as an adult) would be necessary to negotiate and complete the task of banking. These social practices and language experiences certainly affect the child, and as the ZPD and scaffolding within the ZPD should be individualized, these experiences outside of school may have serious implications for teaching practices in education and the activation of background knowledge to aid in the learning process. The work conducted around "language brokering" also explored ways that skills developed in the process, could be leveraged in the school setting. As previously mentioned, this notion is entirely compatible with the writings of Vygotsky and others in SCT. Unfortunately, as noted by Heath (1983), oftentimes the dominant school language practices do not necessarily mimic, value, nor leverage the language resources brought by the students to the classroom. Heath's most significant contributions, through her multi-year ethnographic study, as described by LeBlanc (2012), include, "the immense explanatory power it provided to literacy scholars and educators in order to demonstrate the culturally situated nature of literacy practices in and out of school,” (p. 429). Therefore, in Purcell-Gates, 
Melzi, Najafi, and Orellana (2011), the authors call for an exploration into, "specific ways to bridge home and formal literacy instruction for nonmainstream groups" (p. 24). Another area in which the concept of scaffolding may be useful in its application, lies in the intersection of skills among speaking, reading, listening, and writing. Hornberger (2004), also refers to this within the continua of biliteracy, as she notes the interactions and range of biliterate communications performed between productive and receptive skills and oral and written skills. The reader could refer back to Hornberger's Figure 1.2 that will be utilized extensively in this research to understand the interactions between the teacher and students in the ZPD. Understanding of literacy practices are essential to noticing "how and why people in different cultural and linguistic communities engage with written texts, including social interactions around such practices" (Purcell-Gates et al., 2011) (p. 22). If we seek to understand how our students are interacting with texts outside of school, we may have a better understanding of how to scaffold their interactions with texts within the classroom. In addition to this, Vygotsky (1986) characterized writing as more planned and deliberate when compared to the spontaneity of spoken language (p.183). Thus, we can leverage spoken language, thinking aloud, and other practices to scaffold the student's writing experiences as well. The same scaffolding strategies outlined by Gibbons $(2002,2015)$, modeling, recasting, and others can be utilized in a variety of modes to promote learning, appropriation, and future independence. These and other concepts provide teachers with additional strategies to scaffold the writing process within the multilingual classroom. 


\section{On Dual Language Education and Pedagogy}

In the United States, we have adopted the term dual language education to describe programs that adhere to the principles of additive bilingualism and biliteracy and cultural pluralism. (Tedick, Christian, \& Fortune, 2011b) As a natural consequence of an increasingly globalized marketplace of ideas and intercultural exchange, the dual language education model is increasing in popularity. According to J. M. González (2008), Dual-language programs began to emerge in the United States in 1963 (p. 229). Several authors, most notably Fortune and Tedick (2008), have reported that in the area of dual language education, there are three dominant models; one-way (foreign language), two-way (bilingual), and indigenous language immersion. The primary difference between the one-way and two-way immersion programs lies with the student populations served, as they move toward language and literacy development in the immersion language (IL). As Shrum and Glisan (2015) explain, one-way immersion programs are "for majority language students (that is, native English speakers) with limited to no proficiency in the L2 [IL]," whereas, the two-way programs require at minimum "a one-third of the students are native speakers of the L2 [IL]" (p. 117). Within these program design options, the current trends indicate an explosion of growth and interest in two-way immersion (TWI) schools since 2001. One study indicated a 309 percent growth in TWI charter school programs, in particular, in the United States in the period of time from 2001 to 2009 (Zehrbach, 2011). The heightened interest and upward trends of program participation require investigation of the structure and goals housed within these types of programs. 
Therefore, within this project, I will be discussing the impact of program design upon the program goals within dual language programs. Additionally, I will articulate various underlying pedagogical concerns and practices within these contexts, including; language skill development and ways of working in two languages, literacy skill development, and content-based instruction. In the interest of being concise, I have elected to primarily focus upon the Spanish-English language related examples and models, as did Palmer and Martínez (2016). They similarly indicated that this election was a function of personal experience underscored by the fact that the vast majority of these dual language programs have the primary objective of fomenting the development of these two languages in particular. However, many of the factors and aspects examined herein will be naturally applicable to other language contexts.

Program Design within Dual Language Programs. According to Cammarata and Tedick (2012), "The principle aims of both one-way and two-way [immersion] programs are to promote additive bilingualism and biliteracy, academic achievement, and intercultural understanding" (p. 252). While these programs share primary objectives, they simultaneously reflect different aspirations regarding the percentage of the day that students will use one language versus another. One-way immersion models may typically move from $100 \%$ target language (TL) or immersion language (IL) in the lower elementary grades and gradually increase English class periods from second grade onward. Other programs, such as those in a two-way immersion model, may begin on the outset, with either $90-10 \%, 80-20 \%$ or $70-30 \%$ with the final objective of $50 \%$ English and $50 \%$ Spanish, following several years of study. It is generally accepted that at least 
$50 \%$ of the school day must take place in the IL for the program to be considered a language immersion program (Tedick, Christian, \& Fortune, 2011a).

The first of these programs, one-way immersion, are also called foreign language immersion schools. They are intended for those students whose families (typically from the dominant culture) view the idea of speaking another language fluently as an attractive addition to their educational repertoire. This exists in comparison to the two-way immersion programs that generally require a high level of program participation by heritage speakers of the Spanish language, ideally 1:1 ratio (equal) enrollments of language majority and language minority students (Shrum \& Glisan, 2015). Potowski (2004) explains it this way, "Dual immersion [or TWI] is designed to benefit both language minority and language majority students. Language minority students (also called heritage language speakers) continue to develop their Spanish proficiency, particularly a formal academic variety that many students do not acquire at home" (p. 76). These programs, then, at their core, place a greater natural emphasis on intercultural understanding based upon the function of working directly with students from various language communities within the broader local community. Lessow-Hurley (2000) referred to Postman (1995), for his explanation of the interconnectedness of language and culture, by writing, "we use language to create the world... Language allows us to name things, but, more than that, it also suggests what feelings we are obliged to associate with the things we name" (pp. 83-84). Reyes and Kleyn (2010), highlight the programming distinction between immersion school or dual language school contexts, and traditional programs sheltered for ELLs as an example of, "Additive models [that] have as their goal the maintenance of the native language and the addition of a second language [English]" 
(p. 6). It was for that reason that Reyes and Kleyn (2010), described the connection between overall educational philosophy, which shapes methodology, which in turn informs strategies.

Meeting program objectives. In order to effectively discuss these programs, therefore, it is my intention to separate the elements of the stated objectives, and to use those as a way to look at the pedagogical practices taking place in these learning contexts. This is only for the purpose of clarity of objectives, while recognizing that in an ideal teaching and learning scenario, these areas would work together cohesively and coherently in a myriad of interconnected ways. As explained in J. M. González (2008), the measures of success of these high goals are represented by "high proficiency in the first and second languages for both groups of students, academic achievement as indicated by grade level or higher... and positive attitudes and behaviors about other cultures" (p. 230).

Content objectives. According to Genesee (1987), "The most distinctive feature of immersion programs is their use of the second language to teach regular academic subjects, such as mathematics and science, in addition to language arts" (p. 16). Generally, these academic content areas reflect benchmarks similar (if not identical) to those at other institutions in the same school district. Standardized testing is an underlying issue whose relevance to these discussions in the United States cannot be understated (Orellana, 2016). Teachers and students alike understand that they are expected to demonstrate performance through standardized tests that are not in the target language and contain specific content objectives therein. Clearly, the curricular objectives driven by state frameworks in the content areas heavily influence what 
concepts are taught in the classrooms. This is a component in the broader picture of the political landscape in which these dual language programs operate.

Some of the National Language Resource Centers (found at http://www.nflrc.org/) have produced a wealth of research scholarship and pragmatic pedagogical materials to support language learning in the United States. One of the main centers of study in the area of Content-Based Instruction (CBI) is the Center of Advanced Research on Language Acquisition (CARLA) at the University of Minnesota. This program includes a number of professors who are associated with campus programming and Summer Language Teaching Workshops, both of which are intended to serve language teachers nationwide. Many researchers have discussed the continuum from content-driven to language-driven objectives based upon the needs and designs of the program (Lyster \& Ballinger, 2011). Shrum and Glisan (2015), refer to the scholarship of Curtain and Dahlberg (2016), for their clarity in articulating the full spectrum of these programs, as "one end of the continuum shows those programs that are primarily language-driven but use content as the vehicle for communicative language use, while the other end illustrates the most content-based or content-driven language programs, such as immersion" (p. 112). Looking at the area of CBI, results of the research that has been conducted over time indicate what teachers are doing in the classroom in this context.

The work of Cammarata and Tedick (2012) with teachers in a year-long professional development series for foreign language teachers and immersion teachers uncovering teacher experiences, attitudes, and perceptions about language teaching, can enhance this discussion. Cammarata and Tedick discovered through their qualitative research project that the majority of teachers who teach in dual language schools are 
certified in the content area (math, science, history, etc.) of emphasis, or they are broadly certified in Elementary Education. They found that many of these teachers have not experienced much training in second language teaching methodologies if at all, as most states do not possess teacher certification programs or standards specific to bilingual or immersion settings. This certainly has implications for the teaching of content within these contexts. It is important to recognize that some of the strategies that are used in the content areas are very similar to those in any mathematics classroom or any science classroom. However, there are some studies within the body of research that demonstrate how these may work differently in a dual language environment.

It is noteworthy to look at the findings from Fortune, Tedick, and Walker (2008), who wrote that through their immersion school teacher interviews, they found that frequently the content objectives were central to classroom planning and a language objective, "if at all [included], was frequently reduced to the listing of content-specific vocabulary" (p. 80). One of the primary goals of professional development for teachers in these schools continues to be in the area of integrating language objectives within the content areas of study. Stoller (2004) cites some specific strategies used to better link language with content, including a framework called LCT (language, content, and tasks) in which, teachers are encouraged to structure their lessons so that language, content, and tasks are dealt with individually and in interaction with one another. The language domain helps students master semantic, syntactic, and pragmatic aspects of the language, in addition to the traditional four skills (reading, writing, speaking, and 
listening). The content domain focuses on school curriculum objectives and the content introduced in the textbook and other instructional materials. (p. 269) Working within a framework such as these may enhance the ability of the teacher to integrate the global objectives within the curricular design.

A presentation by Stoller (2002), in the form of a historic overview of studies in CBI, lists eight primary strategies labeled "Sound Teaching Practices that can be Integrated into CBI Classes" (p. 3). These strategies include standard methodologies such as enhanced visual supports, task-based activities, and information gathering. The most salient portion of his article lies in the focus upon the relationship between input and output. Within the area of input, he emphasizes "a variety of sources representing diverse perspectives," and output that provides multiple opportunities to "synthesize knowledge" (p. 3) from this variety of sources. Shrum and Glisan (2015) urge teachers to "select concepts that lend themselves to concrete, hands-on learning that is characteristic of the language classroom" and to simultaneously plan lessons that identify and integrate "content-obligatory" and "content-compatible" language (p. 123).

One difficulty raised by Reyes and Kleyn (2010), is that some school districts have limited understanding of the nature of the differences between languages. One of the main issues raised was the concept that encountering materials specific to teaching in two languages can be challenging. They wrote about experiences in which bilingual educators were told that they would be provided with materials in translation, or the teacher was told to translate the English-language materials for use in the Spanishlanguage classroom. Lack of appropriate curricular (content) materials in the immersion language is a common complaint. According to Reyes and Kleyn (2010), this is a 
common scenario, rather than providing internationally available materials from the target cultures. It should be noted that there is a concern that immersion language authentic materials may or may not reflect the school culture or teaching methodologies preferred in the United States educational contexts.

That being said, there are similarities in content objectives and approaches, as a teacher wrote, "Science is about exploring, children have to learn how to ask questions and explore and observe, the whole process of a scientific mind" (Reyes \& Kleyn, 2010, p. 53). This type of constructivist approach could take place in any elementary science classroom. However, what makes it distinctly different in a dual language program, is that, "teaching in a linguistically diverse classroom requires paying additional attention to students' backgrounds, because the integration of their cultures and language learning needs are central to the teaching and learning process" (pp. 53-4). Such a statement serves to highlight the importance of both cultural and linguistic responsiveness while meeting content objectives. Baker (2003) praises programs that are able to do this, characterizing them as, “'Strong' bilingual education typically has bilingualism, biliteracy, and cultural pluralism as intended outcomes. It achieves these outcomes mainly through students learning content (e.g., mathematics, social studies) through both languages" (p. 97).

Language and culture objectives. As Met (2008) explains, "language is at the heart of schooling and, because in immersion, language plays an even greater role than in other classrooms, immersion educators must be ever mindful of language, its role in the development of literacy and its influence on academic achievement" (p. 49). Unfortunately, this statement lies in direct contradiction to the findings of some 
researchers about what is happening in practice. For example, many of the six teachers interviewed by Fortune, Tedick, and Walker (2008) indicated that they are "always" teaching language, but when they looked at the course or daily lesson objectives, there were few language-based objectives. There is a distinction that we can make between what teachers are actually doing in the classroom versus what they are indicating through the stated lesson or global course objectives. Of course, as stated previously, there is a repeated theme surrounding dual language program design of the interconnectedness of content instruction and language instruction. Pica (2002) states that, "Empirical studies have shown that many L2 needs can be addressed during the course of informal conversation, open-ended communication, and the exchange of message meaning" (p. 4). As a result, at times, through the scaffolding of discursive practices in the classroom, "Familiar scripts, originally modeled and explained by the teachers, provided students with the structures they needed to start using their new language" can emerge, as noted by (Dorner \& Layton, 2014).

Met (2008) includes specific strategies for integrating language within the course of study, especially highlighting the importance of vocabulary development. Within this list of strategies, she includes some explicit vocabulary instruction, and also cites Krashen's (1982) concept of comprehensible input, embraced by many second language teachers as a standard for consideration. Soltero (2011), writes comprehensible input, is based on the idea that the main function of language use is meaningful communication. The importance of meaningful language use at all stages in the acquisition of second language skills has come to be recognized as a critical and 
determining factor for the successful development of a second language and the maintenance of the first language. (p. 82)

Broner and Tarone (2001) invoke the sociocultural concept of ludic play or language rehearsal to enhance language binding and acquisition. Binding is generally understood to mean connecting the concept with a lexical item in the target language, as opposed to translating the word from another language and then imagining the concept. Binding allows the learner to go directly from concept to word, rather than the roundabout (and slower) way of imagining the concept, then the word in their native language, then translating the word to the target language. Met (2008) includes the use of graphic organizers as a means of organizing language and thought to increase output. She, along with Swain and Lapkin (2013), describe the importance of highlighting student production of language (i.e. speaking and writing). This echoes the findings from teacher interviews and classroom observations featured in Bernhardt (1992) through the descriptive examples in Life in Language Immersion Classrooms, she seeks to describe the overall picture, and Hickman's chapter does make note of these overarching themes in the classroom that create,

... a picture of teachers working very hard to provide a focus on language across the curriculum and to keep children involved and interested... [yet] in spite of efforts to get children to read and speak in French, it was the teacher who actually produced most of the language, both oral and written. (p. 90) Therefore, integrating increased opportunities for students to produce language in authentic, communicative tasks should be highlighted. As Pica (2002) explains, "learners engaged in interaction with meaningful, subject-matter content must therefore be 
challenged to attend to the form in which meaning is encoded and to notice more developmentally advanced and difficult relationships of form and meaning" (p. 4). She provides examples of natural responses to breakdowns in communication, characterized as "negotiation of meaning," as a model for classroom metalinguistic consciousness. As Genesee (1987) indicated, the growth of student language, "will occur only if there are increased demands made on the learners' language system" (p. 59).

Materials for second language teachers and teachers working with English Language Learner (ELL) populations may serve to provide some specific strategies for scaffolding language use within the IL, specifically including strategies such as those proposed by Gibbons (2002). As a first step, she proposes what she describes as, "finding the language in the curriculum," (p. 122). This series of questions and prompts, originally intended for mainstream teachers teaching ELLs in the mainstream content classroom, provides a framework for considerations of where language use and understanding emerge within the content classroom. Questions such as "What specific vocabulary does the topic require students to know?" and "What spoken language demands will there be?" focus the attention upon encountering the embedded language tasks themselves. Therefore, in the initial analysis, these questions will provide a framework for approaching, grouping, and anticipating where the language supports may be found in the lesson. Methods such as Total Physical Response (TPR), a kinesthetic model, can be used to enhance concrete vocabulary understanding, recognition, and retention (Shrum \& Glisan, 2015). In the area of vocabulary, Met (2008) provides an extensive list of instructional supports including: paraphrasing, providing examples, introducing context of use, the use of synonyms, and providing alternative explanations 
as a means to accessing new vocabulary within the content areas. Met also includes more explicit language strategies that build learner understanding of connections between the L1 and the L2, such as the use of affixes (-tion in English is generally -ción in Spanish), (p. 64).

At the time of publication of Reyes and Kleyn (2010), Ofelia García complained bitterly in the introduction to the book about the lack of materials focusing specifically upon the development of skills in two languages in the bilingual classroom context. Currently, there are more texts available such as, La enseñanza de la lectura y la escritura en español y en inglés: en clases bilingües y de doble inmersión, by Freeman and Freeman (2009), that explicitly work to continue building strategies between languages. Moreover, Beeman and Urow (2013), offer a metalinguistic strategic construct labeled 'the bridge' as a means to consciously and explicitly make space for discussing and comparing the two languages of communication in the school. A limited understanding of the nature of transfer of skills between L1 and L2 may add an additional layer of complication to the work that teachers do as there have been fewer studies performed in this area.

Literacy objectives. Biliteracy is a broad goal that is a stated objective of many of these dual language programs. However, this term has been debated in a variety of ways. According to Brisk and Harrington (2007), this is a multi-faceted and multilayered issue. First, they write, "literacy has been defined in relation to context and process," skills that require development in both of the domains of primary and secondary discourses, separating the informal home domains from the more formal institutional domains. Furthermore, "Literacy is also defined as a psycholinguistic process including letter 
recognition, encoding, decoding, word recognition, sentence comprehension, and so on" (p. 2). Pérez and Torres-Guzmán (2002), in (Brisk \& Harrington, 2007), define biliteracy as "the acquisition and learning of the decoding and encoding of and around print using two linguistic and cultural systems in order to convey messages in a variety of contexts" (p.4). J. M. González (2008) explains that "there is little consensus on what it means to be literate; however, the ability to interpret or produce meaning using written text is common to most definitions" (p. 529). He cautions that this definition shifts over time based upon demands of the current cultural influences.

The development of these multi-faceted skillsets may look slightly different in their implementation depending upon the type of program, and as the reasons for supporting biliteracy differ. In most two-way immersion programs, the ultimate goal for biliteracy is a language maintenance model, which aims to preserve the home language for heritage speakers. However, teachers encounter varying levels of proficiencies and experiences related to literacy skills in the target language, so teachers in these programs must also scaffold to build literacy skills in the IL with those students as well. In addition, within the same programs, there are students who do not speak the target language in the home, who are building language and literacy skills simultaneously, and they may represent different needs.

Regarding literacy, many teachers have the same training provided by general elementary language teacher education programs that facilitate teaching literacy skills in a conventional, monolingual sense. Lessow-Hurley (2000) wrote, "Many of the strategies that teachers use to develop native literacy are useful for assisting students to develop literacy in a new language" (p. 88). She lists commonly used strategies, such as 
a "print-rich environment" structured and authentic writing tasks as examples. However, many of these teachers lack resources and education in the area of how to build literacy skills for bilingual students, and how to encourage transfer of skills between languages. The transfer of skills is an area in which there can be additional work performed. Gort (2008), provided examples of "Peer scaffolding around bilingual literacy / writing development involved collaborative support with spelling, punctuation / capitalization, the use of literary devices / stylistic writing features, and the content of students' writing across Writing Workshops, a common strategy involved including a bilingual clarification (i.e., translation) for the target word" (p. 197). The best resources for building understanding are those tailored to the two specific languages in context and comparison, rather than in the abstract. One of the primary ways to work with students effectively in the target language is to create preparatory activities, otherwise known as an anticipatory set, which can facilitate the activation of background knowledge. $\mathrm{N}$. González and Moll (2002) describe the concept of accessing students' funds of knowledge, those literacy practices first built in the home, as cruzando el puente (crossing the bridge), to validate and embrace the students' own ways with words in homage to Heath (1983). Teachers can also use these strategies to build or enhance a lesson using some of the procedures presented by Gibbons $(2002,2015)$ which include vocabulary redundancy, and scaffolding words in order for the students to attain lexical understanding of moving from a less formal register to a more formal register, and thus, to build and enhance academic literacy skills.

There are very few textbooks that actually focus on building biliteracy skills designed for teachers. This is a problem stated several times by Reyes and Kleyn (2010). 
There are some specific books on how to teach reading and writing in Spanish (language) specifically, as well as texts on building literacy skills in general. Surely as demand increases for these types of programs, the need for teachers and materials will push the market to creation of these texts. Baker (2003) believes that, "A comprehensive framework for integrating [biliteracy] ... is Hornberger's Continua of Biliteracy (see Hornberger, 2003). Using dimensions of media, context, development and content, she provides an agenda for full biliterate development and expression" (p. 104).

Teachers can also share ideas about how to find authentic materials that can assist in scaffolding naturalistic use of the target language through artifacts that were created by native speakers for native speakers. These authentic and culturally relevant texts have been found to contain greater amounts of inherent message redundancy and schemafriendly formats than those created by teachers. Technology and technological resources can be leveraged to demonstrate to the students the relevance of these skills to the global marketplace. These can also be utilized to bolster their understandings of target language-speaking cultures outside of their home communities, thus enhancing the cultural understandings objective of these programs.

Other considerations. One can note that the vast majority of dual language programs are elementary school programs. In terms of programming that may extend beyond 5-6 grade, many programs do suffer from a lack of articulation (Tedick et al., 2011b). In Finland, they do not suffer from the same lack of program articulation, primarily because the multilingual model is supported by the political environment. It is interesting to note that the students who felt most interested in the target language in those schools, were taught using an emphasis on communication and authentic materials 
(Björklund \& Mård-Miettinen, 2011). These two areas are strongly emphasized within the current second language teaching profession in the United States, as evidenced by the ACTFL Standards (https://www.actfl.org/publications/all/world-readiness-standardslearning-languages ). This is not an area that is commonly emphasized in elementary teacher education programs in the United States. So, this type of research in other countries may represent for us some opportunities for areas of dialogue about the objectives and course materials in current use within U.S. dual language programs.

Concluding remarks on dual language programs. Bringing together the scholarship housed within ESL/ ELL teaching programs, second language teaching programs, and elementary language teaching programs to create and share best practices in attaining these objectives of bilingualism, biliteracy and cultural understanding for students in the immersion programs continues to be a challenge that can be explored through future research. While the discipline acknowledges the primary goals of immersion education (Cammarata and Tedick 2012, Genesee 1987), and some of its unique features, there remains a gap in the area of scholarship, where one may seek to answer the call by Genesee who wrote over thirty years ago that, "little systematic examination of interaction patterns in immersion classes has been undertaken so that we do not know precisely how language is used by immersion teachers" (p.180). This overall sentiment has been expressed in a variety of ways by other, more recent researchers, that we do not possess the desired corpus of studies representing the lived experiences of language immersion teachers and students in the content areas (Cammarata \& Tedick 2012, Dorner \& Layton 2014, and Met 2008). 
This research project is situated at the nexus of several fields of study. The theoretical lens of sociocultural theory frames this research, as I investigate the use of teacher scaffolds within the zone of proximal development. The study itself is situated within a dual language program that identifies itself as a Spanish language immersion school. In the fields of dual language programs and second language teaching there are certain parameters under which these types of programs are generally understood to operate. Bilingualism and biliteracy are the desired results of these types of language programs, and the understanding of variables associated with these areas is essential to understanding the immersion school context. The available literature cites a lack of descriptions of the experiences of teachers and students in the immersion school context. 


\section{Chapter 3: Methodology for this Study}

\section{Rationale for the Study}

The purpose of this case study is to describe the ways that teachers help students to become more literate in two languages in the language immersion school context. Some of these ways of 'helping' include scaffolding strategies used by a fifth-grade teacher in the Spanish language immersion classroom to engage and support students as they work within the continua of biliterate development. As the development of biliteracy is one of the primary stated goals of any dual language program, it is important to investigate how this is embodied and developed over time.

According to Genesee (1987), "The most distinctive feature of immersion programs is their use of the second language to teach regular academic subjects, such as mathematics and science, in addition to language arts" (p. 16). And while the discipline acknowledges the primary goals of immersion education (Cammarata and Tedick 2012, Genesee 1987), and some of its unique features, there remains a gap in the area of scholarship, where I seek to answer the call by Genesee who wrote over thirty years ago that, "little systematic examination of interaction patterns in immersion classes has been undertaken so that we do not know precisely how language is used by immersion teachers" (p.180). This overall sentiment has been expressed in a variety of ways by other, more recent researchers, that we do not possess the desired corpus of studies representing the lived experiences of language immersion teachers and students in the content areas (Cammarata \& Tedick 2012, Dorner \& Layton 2014, and Met 2008). Therefore, this research seeks to provide a description of an immersion classroom environment and the ways that a particular teacher supports biliteracy development in 
language and content class periods. The high stakes value of literacy should compel us to investigate specifically what teachers do in the classroom to promote literacy development as it provides one of the primary, essential keys to academic success.

In response to more numerous studies in the realm of test scores related to English language and literacy outcomes from immersion programs, Cammarata and Tedick (2012) write that,

Despite the wealth of research findings on language development in immersion and other scholarship to date, our understanding about content and language integration in immersion teaching remains incomplete. Missing are descriptions of immersion teachers' actual experiences with attempting to balance content and language in their instruction. (p. 254)

This assertion by Cammarata and Tedick clearly expresses a gap in the current body of research in the area of what teachers do to balance language and content area knowledge within the dual language school environment. In addition to this, Broner and Tedick (2011), specifically call for future qualitative research projects because, "qualitative analysis allowed for a description of contexts of L1 and L2 use that are often overlooked by quantitative data analysis" (p183).

In addition to the calls for additional research made by these previously mentioned researchers in the field, I maintain an intense personal and professional interest in these contexts. As a person who was raised in the multilingual milieu of Northern California, I have personally witnessed some of the lost opportunities to develop the rich linguistic resources of students in the American school context. As a language teacher who is bilingual (in Spanish and English), I am passionate about 
discovering and describing the work of individual teachers within the context of the dual language school environment.

Therefore, in order to respond to the gaps in research described by these researchers, and my own interests and experiences, this qualitative research project will seek to specifically describe the fifth-grade teacher's interactions with students, particularly in the area of scaffolding biliteracy development.

\section{Primary Research Questions}

This study seeks to discover answers to the following central question: How does the teacher scaffold student development of biliteracy within language and content instruction in the immersion school context? Additional, supportive questions include: What scaffolds are pre-planned as part of the lessons, and what are those that emerge organically through teacher interactions with students? What differences exist in the types of scaffolds provided for content areas knowledge versus language, or their place relative to or within the continua of biliteracy? Additionally, as all of these are embedded within a particular context: What forces or tensions does the teacher face as she scaffolds for biliteracy development?

\section{Theoretical and Methodological Frames}

Instrumental case study. The case study was designed in accordance with the writings of Stake (1995) to gain deeper understanding of the specific case, and create an opportunity to describe the classroom interactions that assist students in building language and literacy skills in the dual language classroom. The bounded case in this study consists of the classroom of one fifth grade teacher in the dual language program at an urban public school district in the Midwestern United States. Stake acknowledges his 
own Sociocultural Theory orientation, therefore this framework is advantageous to the present case study design. This is an instrumental case study because its ultimate purpose is to seek deeper understanding of the interactions leading to biliteracy that can and do occur within the language immersion classroom. As Stake (1995) indicates, the underlying rationale of an instrumental case study is, "to understand something else" (p. 3). While guided by the procedures described by Stake, the research questions themselves are framed through the lens of Sociocultural Theory with a particular focus upon the notion of scaffolding within the Zone of Proximal Development (ZPD) (Vygotsky).

Sociocultural Theory. Sociocultural Theory is a uniquely supportive and complementary theoretical frame for studies in multilingual contexts. According to Zuengler and Miller (2006), “[Vygotskian] sociocultural perspectives on language and learning - view language use in real-world situations as fundamental, not ancillary, to learning" (p.37). Another affordance of the sociocultural theoretical frame is the concept of Communities of Practice as a way to examine the habits and embodiments of teacher philosophy within the classroom setting. It is this authenticity of context and nuanced social and cultural aspects that can be central to facilitating qualitative research in bilingual schools.

Lee and Smagorinsky (2000) wrote an appeal for research through the lens of sociocultural theory in order to better understand the development of language skills, knowledge, and the employment of various meditational means (tools) within their social contexts, in examining four key areas. These areas are; the nature of the relationship between spoken language and knowledge development, the use of semiotic materials, the 
co-construction of understandings within groups working on assigned tasks, and "the ways in which literate practices occur and evolve outside traditional schooling” (pp. 4-5). Embedded within this study, there will be opportunities to view a portion of what they request. This will include what the teacher does to leverage, enhance, and build upon the interaction and relationship between the student knowledge of the first language (English), and the second language (Spanish) and the meditational means employed to support the development of biliteracy. To better understand these core concepts and terms, Zuengler and Miller (2006) explain,

These means are the socioculturally meaningful artifacts and symbolic systems of a society, the most important of which is language. Of significance for SLA [second language acquisition] research is the understanding that when learners appropriate mediational means, such as language, made available as they interact in socioculturally meaningful activities, these learners gain control over their own mental activity and can begin to function independently. (p. 39)

It is this precise goal of functioning independently that is a key feature of the instructional leverage provided by scaffolding. Scaffolding by definition (as explained in the Literature Review section) initially provides "expert" support for student work and skill building, but the subsequent steps are learner appropriation with the ultimate ideal progress toward learner independence.

Clearly, based upon the nexus of these claims, within the area of language immersion education, and dual language or two-way programs in particular, there is a need for additional qualitative research that richly describes how the communities of practice function through authentic descriptions of the teachers' (and students') 
experiences within the uniquely designed sociocultural environment in which this type of language learning takes place.

Analytical methods borrowed from Grounded Theory. In this study, I borrow some analytical techniques and tools from Grounded Theory. It is Charmaz (2006) who wrote, "Grounded theory methods can complement other approaches to qualitative data analysis." She also describes the rationale and the means for doing so explaining that in her view, "grounded theory methods [are] a set of principles and practices, not...

prescriptions or packages" (p. 9). The grounded theory methods described by Charmaz were an explicit, useful, flexible, and efficient means of analyzing the data in this case. In the Analysis section, I will present the specific methods that were employed inspired by the writings of Charmaz (2006).

\section{Research Site}

An immersion school in an urban Midwestern setting in the United States provides a setting for investigating teacher scaffolding of literacy skills throughout the curriculum. For the past five years, the school has had an enrollment of approximately 350 to 400 students. Of these students, there are $65-75 \%$ with free and reduced lunches (based upon statistics provided by the State Department of Education). The racial composition of the school overall as described in the same report are: approximately $50 \%$ black, 25\% white, 15\% Hispanic, and 5\% multiracial student participants in the Spanish Language Immersion Program. There are $5-10 \%$ of the students with Individualized Education Plans depending upon the school year. The school currently offers a Title I program to the entire school population. 
The school is a charter school within a large urban public school district. Its structure is somewhat independent but relies upon supervisory demands of the sponsoring university and its own school board. It has been in existence for nearly a decade in the same location at which the observation period took place in the Fall of 2017. This school, which I refer to as SLIP (Spanish Language Immersion Program), is an early total immersion program (also called "full" or "one-way immersion") that started with Spanish language instruction exclusively in Kindergarten, and later added English language in the second grade for 50 minutes per day. The remainder of the curriculum is intended to be taught completely in Spanish. The students within this program, many of whom are children from English-speaking homes, come to this charter school to become immersed in the Spanish language throughout the school day. What this means in practical terms, is that content instruction in math, science, history, music and others are delivered through Spanish, the second language (L2) for many students. At the time of this study, the school continues to undergo changes in leadership and program format, some of which are noted in the Introduction. These concepts will also be explored further in the Findings section as they have impact upon the fifth-grade class of study.

\section{Research Participants}

The primary research participant of focus is the fifth-grade classroom teacher, Profesora Nuria (pseudonym), who enthusiastically consented to participate. The teacher participant was selected from those recruited due to the emphasis upon the learnercenteredness of her teaching philosophies. Our previous acquaintance occurred through a small graduate class project, approximately two years prior to the initiation of this research. At that time, two of the prospective teachers were interviewed to gain an 
overall understanding of the philosophies and practices of the Spanish Immersion School. Based upon the content of that interview (from 2015), I approached particular teachers to see if either would be willing to participate in this research study about scaffolding techniques in supporting biliteracy. In this research project, Profesora Nuria was interviewed at several points throughout the academic semester (Fall 2017), one initial interview, and then two semi-structured follow-up interviews. The interviews are labeled with pseudonyms to ensure minimal risk for the teacher participant.

Two school administrators participated through individual interviews as representatives of the overall school culture (community of practice) and the stated objectives of the overall academic programs. The first of these interviews was with the Enrollment Coordinator (Ana María), and the second with the only school administrator (referred to as Doctora Rodríguez) who has been present since the founding year of the school.

The student participants in the fifth-grade class were observed and recorded within the course of regular classroom activities only. The student participation in this research was subject to the confirmation of (parental) consent and student assent. There were 19 students who assented to participate in this study. Parental permissions were obtained first as required by ethical standards for working with minors. I observed only during the regular operations of the fifth-grade classroom and was not an active participant in the classroom activities as a component of this research. The role of observer in this case was most appropriate as Merriam (2009) indicates, "As an outsider an observer will notice things that have become routine to the participants themselves, things that may lead to understanding the context" (p. 119). The risks to any student 
participants in this research were limited in scope. The permissions and consent from the school director were the first steps towards application for Institutional Research Board approval for this research study and IRB approval (see Appendix A) was received during the Summer of 2017.

Student demographic data as provided by the teacher. The teacher participant, Profesora Nuria, completed a chart upon request to describe the basic demographic information of the student participants. (All student names have been substituted with their self-selected pseudonyms.) The descriptors included are those selected by the teacher herself and are un-modified.

Table 3.1 Student participant demographics

\begin{tabular}{l|l|l|l}
\hline Student name & $\begin{array}{l}\text { Race / } \\
\text { Ethnicity }\end{array}$ & $\begin{array}{l}\text { Free / } \\
\text { Reduced } \\
\text { Lunch }\end{array}$ & Home language(s) \\
\hline Ahmose & Black & No & English \\
\hline Asha & White & No & English \\
\hline Astrid & White & No & English \\
\hline Barry & Hispanic & Yes & Spanish \\
\hline Clyde & White & No & English \\
\hline Estrella & Hispanic & Yes & Spanish \\
\hline Imani & Black & No & English \\
\hline James & Black & No & English \\
\hline Jenna & Black & Yes & English \\
\hline Kishanda & Black & No & English \\
\hline
\end{tabular}




\begin{tabular}{l|l|l|l}
\hline & & & \\
\hline Laney & White & No & English \\
\hline Messi & Hispanic & Yes & Spanish \\
\hline Nikki & White & No & English \\
\hline Rianna & Black & No & English \\
\hline Santiago & Hispanic & Yes & Spanish/English \\
\hline Snowy & Black & No & English \\
\hline Stacy & Asian & No & English/Mandarin \\
\hline Terrell & Black & Yes & English \\
\hline Tessa & White & No & English \\
\hline
\end{tabular}

In surface analysis of this demographic data, there are nineteen student participants out of a class of 23 students. Of those 19 students, the teacher identifies eight as black, six as white, four as Hispanic, and one as Asian. There are six student participants who receive free and reduced lunches, often used in research as an indicator of lower socio-economic status (SES). The teacher also completed the table with the home languages of the student participants. Of nineteen student participants in this study, fourteen speak English as the only language in the home, while four speak some Spanish in the home, and one student speaks Mandarin and English. The expanded version of this table also includes the assessed reading levels of the students in both Spanish and English, and will be discussed extensively in Findings.

\section{Data Sources}

The data sources, collected over a period of ten months, consist of semi-structured teacher interviews, classroom observations, field notes, photographs of displayed 
classroom artifacts, school board documents, media reports, transcripts, and audio recordings of regular classroom interactions. I visited the fifth grade classroom to observe the class in the course of regular instruction during social studies, science, and reading language arts (in both English and Spanish) class periods during regular site visits in the Fall of 2017.

Table 3.2 Research questions and data sources

\begin{tabular}{|c|c|}
\hline Primary Research Questions & Data Sources \\
\hline $\begin{array}{l}\text { How does the teacher scaffold student } \\
\text { development of biliteracy within language } \\
\text { and content instruction in the immersion } \\
\text { school context? }\end{array}$ & $\begin{array}{l}\text { Semi-structured interviews } \\
\text { Classroom artifacts } \\
\text { Classroom observations (incl. audio } \\
\text { recordings, field notes, and transcripts) }\end{array}$ \\
\hline $\begin{array}{l}\text { What scaffolds are pre-planned as part of } \\
\text { the lessons, and what are those that emerge } \\
\text { organically through teacher interactions } \\
\text { with students? }\end{array}$ & $\begin{array}{l}\text { Semi-structured interviews } \\
\text { Classroom artifacts } \\
\text { Classroom observations (incl. audio } \\
\text { recordings, field notes, and transcripts) }\end{array}$ \\
\hline $\begin{array}{l}\text { What differences exist in the types of } \\
\text { scaffolds provided for content area } \\
\text { knowledge versus language, or their place } \\
\text { relative to or within the continua of } \\
\text { biliteracy? }\end{array}$ & $\begin{array}{l}\text { Semi-structured interviews } \\
\text { Classroom artifacts } \\
\text { Classroom observations (incl. audio } \\
\text { recordings, field notes, and transcripts) }\end{array}$ \\
\hline $\begin{array}{l}\text { What forces or tensions does the teacher } \\
\text { face as she scaffolds for biliteracy } \\
\text { development? }\end{array}$ & $\begin{array}{l}\text { Semi-structured interviews } \\
\text { Classroom artifacts } \\
\text { Classroom observations (incl. audio } \\
\text { recordings, field notes, and transcripts) }\end{array}$ \\
\hline
\end{tabular}

The analysis of data emerged through what the teacher did to support the language learners with their understanding and production of both languages, in terms of 
active scaffolding in the ZPD. The case study primarily bases its findings upon a body of extensive field observation data based upon the standards laid forth in Stake (1995). These observations, routinely accompanied by field notes, moved me "toward greater understanding of the case" (pp. 52-3). The classroom interactions and teacher interviews were documented through audio recordings. I sought the intersections of data, teaching methods, and strategies within the designated communities of practice and focus in upon the potential "actor intentionality" (p. 48) through teacher interviews about the observed classroom interactions. "Actor intentionality" in this case will refer to the teacher's intentional, conscious, and deliberate actions. This data set assisted in answering the research questions related to scaffolding and the nature of its use in the classroom within the bounds of the case. Additionally, evidence demonstrates how these scaffolds emerge within the process organically (as interactional scaffolds) or are planned in advance based upon topic or biliteracy-driven considerations. The established norms within the community of practice are also examined as they relate to the underlying design, employment, effectiveness, and appropriation of scaffolds.

\section{Data Collection \& Ongoing Analysis}

Interviews. The first component of the research process was a pre-observation interview with the teacher participant, Profesora Nuria. (The teacher consent form is available as Appendix B.) The interviews were semi-structured to allow for the organic development of sub-questions based upon the teacher responses. During the semistructured, face-to-face teacher interviews, I asked a series of questions designed to elicit teacher descriptions of course planning, lesson objectives, and more specifically how the teacher designs lessons centered around supporting student understandings of text in two 
languages (biliteracy). The rationale for the selection of a semi-structured type interview is supported by Nunan (1992), who explained, "the advantages of the semi-structured interview are, in the first instance, that it gives the interviewee a degree of power and control over the interview" (p.150). Therefore, the teacher participant was able to direct some of the flow of the conversation about teaching through the interview process. A secondary benefit to this type of interview according to Nunan (1992), is that it allows greater flexibility and responsiveness to the researcher, as it provides, "privileged access to other people's lives" (p.150). The original list of questions written for the semistructured interview are included in the Appendix C.

In addition, I reference a prior interview with the classroom teacher that was part of a graduate class project on developing interview skills in 2015. That prior interview represents historical context about the teacher's overall teaching philosophy and educational background that provide useful insights into the development of teacher practices over time.

I also conducted interviews with Dra. Martínez, a long-time school administrator, and Ana María, the school enrollment director to provide additional context and understanding of the case.

Classroom observations. The next step in the process consisted of regular classroom observations that were audio recorded for archival purposes with digital recorders to directly support and ensure the accuracy of the field notes. It should be noted that at the start of the research project I had a preference for videotaping, but the participating school administration did not allow video recording. While observing in the classroom, I took handwritten field notes using a template designed for that purpose. In 
Appendix D, one may see the template designed for field notes taken during classroom observation, closely aligned with the model provided by Merriam (2009). In addition to these recordings and the accompanying field notes, classroom artifacts such as class readings or assignments were collected for their relevance to the observed classroom activities. Following the first classroom observation, protocols were also re-evaluated to ensure their usefulness in this particular research context. Merriam advocates selfreflective research with the flexibility to make changes along the way with the goal of refining the research. For example, if I had started taking hand-written field notes, and later felt that typed notes might be more appropriate, that change could have been made readily. Or, if the format of a particular field note template was not as helpful as another format, based upon classroom teaching patterns, those alterations could be made to enhance the quality of research notes. In reality, what I ended up doing was using the field notes template as the brief summary or overview notes at the end of each observation period. It was more useful to take notes on lined notebook paper throughout the class periods, and then reflect on the workflow, sequence of lessons, and key concepts on the field notes template. If my position in the classroom was distracting for a given lesson, I moved to another location in the classroom. At times, there were several student 'guests' from other classrooms occupying the table at which I normally sat. As a consequence, upon entering the room, I selected a different location on the perimeter of the classroom. In addition to this, while students were working in groups after the first few weeks in the observation period, I began to circulate around the classroom to better observe what the students were doing. As a result of this guidance from Merriam, I was 
very conscious of my presence in the classroom and the comfort level of students and teacher, and willing to make adjustments as necessary.

During my time in the classroom, I was positioned solely an outside observer not an observer-participant. The teacher did provide me some links to lesson planning documents in Google Drive she shared with her partner teacher Profesor Roberto (also a pseudonym), but I did not participate in any way in their creation. I did not participate in classroom activities, although both the students and the teacher regularly acknowledged my presence in a variety of ways. It was my intention to witness the flow of activities and the character of the student-teacher interactions in as natural a state as possible.

The classroom observations took place during the Fall of 2017 at regular intervals. I was on the school campus generally on Thursdays and Fridays for a total of 16 observation days in September through early December. Due to shifts in scheduling, such as special guest speakers, holidays, and school-wide events, there were a few weeks that required a modified schedule. Typically, I would arrive at the school at 8:30 in the morning and leave at approximately $1 \mathrm{pm}$. This afforded opportunities to observe Profesora Nuria's Circle Time, English Language Arts, Math (excluded from this study), Lenguaje (Spanish Language Arts), and Social Studies or Science class periods. The Social Studies and Science classes ended up being a somewhat more complex scheduling issue than anticipated, as some weeks the focus was Social Studies, and other weeks it was Science. This issue will be addressed further in the Findings section. The afternoon schedules were excluded due to the fact that they varied significantly by day of the week and included several special classes such as art, PE, computers, and other electives taught by other area specialists. As this particular project was designed to focus upon 
interactions with text and Profesora Nuria's teaching, those other classes were excluded. There were two occasions on which the teacher let me know that a particular afternoon activity might be useful for this study, so I did remain at the school based upon her suggestion on those dates. Generally speaking, those were specifically tailored class sessions in which she allowed students to continue working on an in-class project, go over homework assignments, or review for an upcoming test.

The schedule provided a total of approximately 68 hours of classroom observation. However, the audio recordings generated were twice that number of hours, due to the fact that normally there were two digital recorders recording during any given class period. Typically, the teacher had one digital recorder with lapel microphone, and another digital recorder was placed on a table among the students. Through these two recording devices, I was able to ensure that no class period would be lost due to technical difficulties, and they also provided clear recordings of both the teacher perspective and some student perspectives of the class periods. This combination was useful, as many times the students in close proximity to recorder number two made comments that provided other insights and perspectives into the learning process. Additionally, when Profesora Nuria was not teaching to the entire group, her recorder picked up conversations with individual students, thus providing further documentation of her interactions that otherwise could not have been captured.

Merriam (2009) writes that, "Observers need to be open to early impressions and feelings about what is going on in a setting because it is these early impressions that help determine subsequent patterns of observation" (p. 120). To demonstrate understanding of this as a guiding principle, immediately following classroom observations, the field 
notes on occasion were supplemented with further audio recordings while in transit from the school observation to capture my immediate thoughts and reflections approximately once a week. This allowed me to build a running narrative or commentary on the day's events and ruminate upon them in a way that could be retained. These recordings were used to build memos and links between ideas and concepts. They also invited initial analysis of points of discussion during class periods, or reminders of intriguing classroom interactions requiring more intensive review. Within the sociocultural frame, classroom teaching strategies, and classroom interactions, all of the data was continuously analyzed as "a matter of giving meaning to first impressions as well as to final compilation" (Stake, 1995, p. 71). Thus, the research process was dynamic and responsive, while preserving the essential points of clarity and integrity to deepen understanding of the nature of scaffolding within the ZPD in the language immersion classroom.

Also, the transcripts of the classroom observations and interviews were transcribed from the classroom observation recordings as quickly as possible following observation sessions. Basit (2003) noted that one of the hallmarks of qualitative research is that data analysis is "an all-encompassing activity that continues throughout the life of the project" (p. 145). While it was my personal preference to type all transcripts personally, I did enlist the assistance of a professional transcription service due to time constraints.

Additional interviews with the teacher. As a follow-up step to the field notes and transcripts, there were opportunities for stimulated recall interviews. These simulated recall interviews emerged as a natural follow-up to some classroom observations, to allow a closer look at the teacher's thought processes behind those 
classroom interactions of note. I anticipated that those would occur with greater frequency in the first few weeks of observations to seek clarification. Those follow-up interviews were designed to discover "actor intentionality" and a deeper understanding of the organic process involved in teaching and interacting with students in student-centered classrooms. It was originally my thought to do those types of interviews in a more standardized and formal manner throughout the observation period. However, the participating teacher, Profesora Nuria, quickly became comfortable with my presence in the classroom and both regularly and readily provided insights into her thought processes and procedures. As a consequence of this, it was on rare occasion that I selected certain portions of the transcripts, or audio files, to set an interview time to inquire into the teacher's thoughts or comments regarding the specific lesson and / or student teacher interactions. These types of interviews as defined by Nunan (1992), are particularly useful in that they "can yield insights into processes of teaching and learning which would be difficult to obtain by other means" (p. 94). The frequency of the teacher 'asides' or comments directly to me about what she was doing, what she was thinking, and commentary about student interactions occurred with great regularity. It was the teacher's openness about her thought process that made this project richer and more compelling. This portion of the research presents a key element of triangulation of the data, as it provides specific teacher commentary about the lesson before, during, and after it takes place. It is through these comments and interviews that I uncovered further information about what aspects of teaching and scaffolding were pre-planned, and what elements of the interactions between the teacher and students were improvised based upon and tailored to student responses to the lesson. 
Artifacts, lesson plans, and handouts. There are examples of displayed classroom artifacts, lesson plans or classroom handouts to further enhance the depth of the study and provide more concrete triangulation of the observed scaffolding and its results. Within this research the classroom artifacts serve to provide additional context and information about the structure of the teacher's lessons and how they are used to provide scaffolding for the students. Some patterns of scaffolding that have been planned in advance are noted as evidenced through text documents, in the form of lesson plans or handouts, from the classroom. As Merriam (2009) wrote,

The data found in documents can be used in the same manner as data from interviews or observations. The data can furnish descriptive information, verify emerging hypotheses, advance new categories and hypotheses, offer historical understanding, track change and development, and so on. (p. 155)

Additionally, the authors describe types of available documents that can be used for this purpose, "A qualitative study of classroom instruction would lead to documents in the form of instructors' lesson plans, student assignments, objects in the classroom" (p. 150). Their inclusion in this study represents my attempt to remedy some of the concerns expressed by Merriam that "Documents or artifacts have been underused in qualitative research" (p. 153).

Initial data analysis. Data analysis began even in the early states of data collection. According to Gibbert and Ruigrok (2010), "an important strategy to ensure the construct validity for a case study is the triangulation of different sources of data, such as interview data, archival sources, and participatory or direct observation" (p. 713). Therefore, in this case study the desire to ensure rigor through validity and reliability is 
clearly featured throughout the entirety of the process. The triangulation of data in this particular study regarding scaffolding in biliterate development was fostered and documented through the combination of a variety of data sources. These data sources include: teacher interviews, lesson plans, classroom artifacts, classroom observation, field notes, and analytic memos. To accompany this broad range of research material data, member checks with the classroom teacher were utilized to ensure the validity of analysis. From the beginning, this process was centrally informed by the article by Gibbert and Ruigrok (2010) on data triangulation. Merriam's (2009) guidelines about the process of collecting qualitative data, the steps involved in planning the course of the study, and how to facilitate the analysis process throughout the research were also utilized. Techniques described by Charmaz (2006) heavily influenced the coding process. The entire design and procedures of this project and process have been heavily informed by the literature on qualitative research methodologies. As Merriam (2009) suggested, "the much preferred way to analyze data in a qualitative study is to do it simultaneously with data collection" as the results will be "more parsimonious and illuminating" (p. 171).

The first step in the process of data analysis involved open coding. I used open coding as defined by Merriam as an early step in the process, for initial labeling in paper transcripts and notes and developing additional questions to seek clarification with the teacher participant. The data, including transcripts, scanned field notes and audio files are stored and retrieved through the program Atlas.ti, designed specifically for researchers. The use of this software as a repository for data is valuable, not only as an audit trail, but also as a data management tool. Basit (2003) noted in her analysis of 
manual or electric in qualitative research that "the segmentation of field data and retrieval of marked data segments is a valuable resource in the management of qualitative data" (p. 145). Within this database, my thoughts on scaffolding were influenced by the research of Dorner and Layton (2014), Gibbons (2002, 2015), and Tharp (2014). Creswell (2002) includes information and guidelines for the reduction of categories to themes graphically (p. 238). The codes, categories, and themes were documented in the Atlas.ti program in conjunction with the transcripts and other artifacts to constitute documentation of the research process itself. During the research process, there were peer reviews conducted by my Academic Advisor, Dr. Carol Gilles, as well as other doctoral committee members to authenticate the objectivity and confirmability of the research.

Using techniques inspired by grounded theory methodologies, the transcripts of interviews and classroom activities were coded with initial codes through line-by-line coding. The use of these methods as "tools" is driven by the understandings provided by Charmaz (2006, p.10) who described these steps through a constructivist lens. While this is a case study that is not specifically a grounded theory study, Charmaz also wrote that the use of tools from grounded theory are not prescriptive "recipes" and can be used to analyze the data in a variety of qualitative research project types more clearly and efficiently. It is with this in mind, that I selected these research tools, prompted by the attractive description by Charmaz (2006), that this way of conducting research, "quickens the speed of gaining a clear focus on what is happening in your data without sacrificing the detail of enacted scenes" (p. 14). It is these enacted scenes that one might call vignettes that are of great importance to me personally as a researcher, as these represent 
the language(s) and the representations of cognition by the teacher and the student participants in the classroom. These scenes of language use in context are central to the findings and the purpose of this study, that provides clearer understanding of what is happening in a sample classroom of a language immersion school.

Coding the data - Phase I. There were 215 initial codes prompted by the content of the transcripts. The initial coding was performed with line-by-line, with each line of transcript as a unit. This was time-consuming but allowed for open coding based upon the guidance provided by Merriam (2009, p. 178) and Charmaz (2006, pp. 53-5), that included en vivo codes, those driven by the words of the participants themselves, my own understanding of the context or words as a teacher and researcher, and those codes prompted by previous research in the literature. The inclusion of descriptive codes is a variation on Charmaz (2006, p. 47), who wrote about the importance of coding by actions in the data, rather than using descriptive words and pre-existing categories. This exclusive use of action-oriented phrases did not really provide a useful fit with neither transcripts nor the research questions for this project, so that tool was not utilized as described in her text. However, I did code line-by-line based upon her description of its usefulness in drawing closer to the data with the motive of identifying "implicit concerns as well as explicit statements" (p. 50). There were 215 initial codes prompted by the content of the transcripts. There were 17 broad categories built from the original codes. All of the original codes did include some codes that possessed significant areas of overlap. For example: building connections, connecting to text, connecting to personal experiences, making connections to ideas within text, students sharing personal experiences, were collapsed into one category that I called "connections." Additionally, 
some of the en vivo codes were subsumed in that same connections category, including an excited exclamation from the teacher and students, “iuna conexión!”

Some of the other codes included were clearly inspired by the research literature including anticipated categories found within the observed dual language classroom. Gibbons (2002) provided essential principles for the development of the second language learners. These principles, who she attributes to Cummins (2000), are as follows: a focus on meaning (what many would label "comprehensible input"), focus on language (assisting students in "noticing" relevant language features), and focus on use (the output component, where students are guided through the process of production in the L2). Dorner and Layton (2014), and Gibbons (2002), suggest that some specific strategies used within these classrooms may include repetition, modeling, reframing, and recasting. In addition, I initially considered the "seven means of assisting performance and facilitating learning" in the ZPD identified and further defined by Tharp (1993) as cited by Daniels (2005) to include the following strategies; "modeling," "feedback," “contingency management," "instructing," "questioning," "cognitive structuring," and "task structuring" (pp. 13-14). All of these elements were evaluated individually and in concert with the considerations of the continua of biliteracy development, the pre-planned scaffolds versus the impromptu, and content area.

Other potential codes were identified from bodies of works outside of the discipline of language immersion studies. For example, Kucan (2007) labeled the process by which a teacher asks more than one student the same question, "collecting answers." Other codes were ones that are commonly utilized throughout research involving two languages such as "code-switch at the conjunction" or "code-switch at the 
end of a sentence" based upon the research of Zentella (1997) and others in bilingualism. The practice of switching languages within the context of a single conversation is a hallmark of conversations between bilingual individuals. In addition to this, the practice of code-switching is integral to the discussion of the relationship between Spanish and English in this classroom, and its expression in the continua of biliteracy (Hornberger, 2004). It is my opinion that these codes are relevant, not only as they demonstrate key ideas about the language use of the students and teacher, but also as they enhance clarity and understanding for the potential audience of this study.

Beyond the three original research questions, over time it was obvious that influences outside of the classroom such as: administration policies, school practices, testing, and others created tensions regarding the execution of practices related to literacy and biliteracy in the classroom. These tensions were integrated into the coding scheme immediately upon analysis of the interview transcripts. Therefore, the fourth question was added. The teacher interview transcripts lend invaluable insights into the processes and procedures of the school at large as well as the inner workings of the classroom of study. I coded several transcripts on paper first, to allow for greater creativity of thought away from the computer screen, but quickly moved to technological aids.

Data analysis - Phase II. Once the initial phase was completed, Atlas.ti, the CAQDAS (Computer Assisted Qualitative Data Analysis Software) program, was used to store the codes, and associate them with lines in transcripts and documents. Portions of text were grouped as "quotations" to highlight the context in which they were embedded. The added benefit of Atlas.ti as a software platform, was the use of its ability to visualize networks and create hyperlinks between related texts or vignettes ("quotations"). Its 
application can go far beyond the storage of data. As stated by Friese (2014), this program allows the researcher to spend more time analyzing data rather than completing manual tasks that the system can perform such as: "retrieving data based on various criteria, searching for words, integrating material in one place, attaching notes and finding them again...” (p. 1). The sheer volume of classroom transcripts, interview transcripts, field notes, memos, media articles, classroom materials, and official school documents was made far more manageable by the tools provided by the Atlas.ti program. It was used not only as a repository for information storage, but also it made the documents more accessible through search capabilities by code. Within the software, it is also possible to use the previously mentioned hyperlinks to visually sort and triangulate examples in various forms of data and find them again quickly, rather than shuffling through voluminous reams of paper documents.

Of course, the software does not conduct any analysis of data itself, but it did allow me to focus upon ideas I already captured through my analysis of the data housed therein. For example, as I was coding the transcript from the lenguaje class period on September 27, 2017, and a particular student described his feelings about reading in Spanish. I was able to create a memo noting this statement and describing my thoughts about it, and other transcript segments that seemed to support and confirm this idea. A few days after writing the memo, I returned to the transcripts, searched under the code "avoidance" and found that quotation and the others that I had remembered. The software allowed me to quickly link those codes into a network titled, "Asha avoidance." Atlas.ti enabled quick retrieval of these linked quotations during the analysis and writing phases of this project. In the analysis phase, the task of constant comparison was 
simplified through the use of this software, as the data began to guide natural comparisons of multiple sources. This technique of constant comparison, as outlined in Charmaz (2006) and described by Merriam (2009) is a method that "involves comparing one segment of data with another to determine similarities and differences" (p. 30) to facilitate the creation of categories. The software facilitated the accessibility of those sources and provided the ability to link in a visual manner the small group conversations that seemed to support the one-on-one conversations with the teacher or the teacher interview transcript with the school board report.

\section{Trustworthiness}

The data collected within this study is stored on a password-protected computer and any printed data or archives are stored within a file cabinet in a locked office. Those interview transcripts or associated work products files stored within the file cabinet are not labeled with participant names nor research site location to protect the research participants and minimize risks. I endeavored to exercise ethical behavior at all times, and obtained appropriate permissions for the research through the University of Missouri campus Institutional Research Board process and minimize risks to participants. In addition to this, significant member checks were integrated into the writing portion of the process to ensure that classroom events, student characteristics, and documents are accurately described. This was done following the practice as described by Stake (1995), to respect the "major role" that the teacher participant plays in the research (p. 115).

Each research finding was supported by triangulation of data sources: interviews with the teacher and administrators, class observation transcripts, field notes, and artifacts. These materials were catalogued extensively through a variety of protocols, 
including the use of Atlas.ti. All of these data sources were informative, and the member checks with the teacher and a long-time school partner served to affirm these findings as described herein. The use of member checks is based upon the guidance of Stake (1995), who describes this as a process when the participant is "asked to review the material for accuracy and palatability" (p. 115). The first draft of the Community of Practice section was sent to Profesora Nuria, who responded by writing, "I am very happy with how everything has turned out."

The week before school ended in Spring 2018, I also visited the fifth-grade classroom again to provide a form of participant debrief. At that point, I presented some of my research findings to the fifth-grade class to observe their reactions. I deliberately selected portions of the findings that focused in upon the community of practice for this purpose. This was an essential portion of this research process, as the student participants and teacher enthusiastically received the findings portions as I described them. Four sample transcripts were provided to the students with the accompanying translation and content analysis as displayed for the reader in this document. The teacher and students reported that these analyses helped them to see their own work in new and "deeper" ways. The teacher, when told individually of the student participant descriptors (presented in Chapter Four), including Ahmose in the role of "The Philosopher," pronounced “That's perfect!" Jenna approached and asked what I had called her. After my response, she immediately rushed over to tell Kishanda that I had called them "The Inseparable Duo" in this research project. They both smiled and exclaimed over this idea. 
It is these types of interactions that have assured me that I remained on a path true to the qualitative nature of the data and the research protocols of the case study design. This following chart (informed by categories in Gibbert and Ruigrok, 2010) serves to reflect the overall steps in the research process to demonstrate the rigor of this qualitative study.

Table 3.3 Evidence of rigor

\begin{tabular}{l|l}
\hline Credibility & Triangulation of Data \\
& Interview data \\
& Lesson plans \\
Classroom artifacts \\
& Classroom observation \\
& Field notes \\
& Analytic memos \\
& Member checks \\
& Participant debrief \\
\hline Reliability \& Dependability & Coding process influenced by \\
& Creswell, Merriman, and \\
& Charmaz \\
& Initial codes informed by the \\
& literature and line-by-line \\
& coding \\
& Audit Trail \\
& Documentation of research \\
& through Atlas-ti software \\
& program \\
& Peer reviews by Academic \\
& Advisor and Committee \\
& members \\
& Audit trail \\
& Researcher as observer \\
\hline Objectivity \& Confirmability
\end{tabular}

The data is documented, analyzed, and triangulated to create an accurate representation of the case and establish a standard of high quality academic rigor. The combination of observations, interviews, and artifacts (documents) serve to provide 
triangulation of the data. This concept is also highlighted by Merriam (2009),

"Observations are also conducted to triangulate emerging findings; that is, they are used in conjunction with interviewing and document analysis to substantiate findings" (p.

\section{Limitations}

The limitations to this research are those known to be inherent to case study in general. This case is only intended to represent the work of a particular teacher in a particular classroom setting at a particular school. This research is primarily intended to describe a particular classroom setting and the interactions therein during a particular semester. These observations can assist the education community in understanding the teaching and learning process embodied within a particular language immersion (or dual language) classroom.

Other limitations exist due to the restrictions imposed by the participating site. Video recordings of the classroom interactions would have been useful. Video can provide some supportive data about student and teacher interactions and invite forms of discourse analysis that are not possible through audio recordings. However, video recordings were explicitly prohibited by the school administration, so that was not an option in this case.

Regardless, the data sample of classroom interactions through audio files does supply a significant source of data regarding the teacher-student interactions in this fifthgrade classroom in the Spanish Language Immersion Program. This research will enhance our body of knowledge about the interactions among teachers and students around biliteracy development and how we can move the profession forward. 


\section{Concluding Remarks Regarding Methodology}

The selected primary sources of data for this case study research are based upon guidance from Stake (1995) and Merriam (2009). As such the data set includes: interviews, artifacts, classroom observations, and field notes. All of these serve to provide both triangulation and credibility for this project. The data was principally analyzed using some procedures from grounded theory as described in the writings of Charmaz (2006) and general qualitative research principles from Merriam (2009).

There were 19 student participants who are represented through demographic data provided by their fifth grade classroom teacher. The classroom observations included personal site visits and audio recordings, accompanied by extensive field notes. The data was compiled, stored, and coded utilizing the software program, Atlas.ti with guidance from Friese (2014).

As a follow-up to the data collection and analysis, member checks, participant debriefs, and peer reviews were utilized to strengthen the confirmability and credibility of the research presentation. The findings section will unpack and describe the information encountered through this process, and articulate the central messages about immersion education, scaffolding, and the sociocultural contexts housed within the case. 


\section{Chapter 4: Research Findings}

\section{Introduction to Findings}

This section explores and describes the observed community in Profesora Nuria's fifth grade classroom. The original primary research question that guided this study was: How does the teacher scaffold student development of biliteracy within language and content instruction in the immersion school context? There are several themes related to Sociocultural Theory that are useful to articulate and describe the classroom of focus in this study. These themes include: communities of practice, the zone of proximal development (ZPD), scaffolding, and the intersection of these theoretical frames with the continua of biliteracy. The findings in this study center around those sociocultural frames while taking into account the dynamics present in this community of practice, the scaffolding of literacy practices, the language ideologies of the teacher, and the relationship between Spanish and English in the classroom. Included within these findings related to scaffolding, I also present a new visual model to represent scaffolding episodes within the continua of biliteracy.

The first portion of this chapter describes in great detail the research participants as community members and participants in the fifth-grade classroom led by Profesora Nuria. This section is of great importance and relevance to the central research questions about scaffolding due to the inextricably linked nature of language, thought, and action as observed through the sociocultural lens. The central messages of the classroom routines and environment, including: organization and structure are valued, knowledge is prized, encouragement is contagious, reading is central, and language is a choice are explored as they relate directly to the interactions between teacher and students. 
The central section of this chapter reflects upon the scaffolds employed by Profesora Nuria during the English, lenguaje (Spanish Language Arts), Social Studies, and Science class periods. Throughout this exploration, a new visual model of my design, titled "Scaffolding Episodes in the Development of Biliteracy" is employed to visibly document the central task that is being assisted by the teacher or peers. "Scaffolding the continua of biliteracy" notes the role of affective needs, "struggles" and "help," and classroom atmosphere as ways to facilitate scaffolding. The intentions and means of the scaffolds presented include a focus upon examples of visual support, student requests for assistance, and connections with real-life scenarios. Included within this section are extensive examples of student and teacher interactions from the observed class period observations, as well as commentary provided by the teacher on the relationships between teaching, learning, and bilingualism. These combine to enlighten the reader about the thought process of the teacher and to highlight and honor the authentic voices of the teacher and student participants. The transcript segments throughout are presented with the language(s) of the original conversation and my translation to English as necessary. The translations are intended to capture the spirit of the message and include some reflection of the original syntax. With lengthier examples, I also include content analysis codes to guide the reader through the conversations featured within these word tables. I have deliberately departed from APA guidelines with the construction of these tables through the inclusion of vertical lines to separate columns. This election is designed to enhance the comprehensibility of the text.

The third section focuses in upon the impact of the broader community upon the language and literacy practices in this fifth-grade classroom and addresses the fourth 
question of my study. The embedded language ideologies, teaching practices, and administrative details inform the reader about the contexts that have direct consequences upon the classroom of study. The design of this chapter guides the reader through the experience of visualizing the classroom context, its participants, its activities, and then its ideological and experiential foundations.

\section{Community Members}

Teacher profile. Profesora Nuria is a dynamic, petite, young woman in her twenties. She has been teaching at this school for four years. Originally from Honduras, she has straight, glossy black hair that falls just below her shoulders and she habitually dresses in flowing blouses, slim-cut dress pants (fashionably rolled at the cuffs), and shiny, metallic-colored shoes. She greets everyone with a beaming smile and outstretched arm. When the students from lower grades come in the classroom with their clipboard checklists, they are greeted warmly, given individualized attention, and pulled to her side to look together at the information written on the behavior chart. She frequently says, “Clase, dale el bienvenido a nuestro amigo...” (Class, please welcome our friend...) Then, she will focus in on the clipboard and the individual student, quietly reading over the comments from the regular classroom teacher about attitudes and behaviors from that morning. The follow-up remarks from her usually follow one of two patterns - "Wow! I see you did really well during art class..." or, "Okay, now what can you do to change your attitude?" Typically, a student will arrive somewhat downcast but leave smiling, albeit sometimes reluctantly. Profesora Nuria has an infectious attitude of positivity mixed with high expectations. 
Appropriately, above her work table, a heart-shaped wooden plaque is visible on the wall that says, "Teaching is a work of heart." In our interactions, she focuses on the "struggles" of the students, i.e., with two languages, the curriculum, their peer relations, or their family situations. There was one day in particular that the level of her skillful direction of all events in the classroom captured my attention. On that day, there were four students "visiting" from a third grade classroom who were seated at a corner table. Their teacher had become ill suddenly, and there were no substitutes available to cover their class, so the third graders from that section had been distributed to other classrooms throughout the school. Regretfully, the students had been placed in Profesora's classroom with virtually no notice, and with no assigned work. In addition to this complication, one of the four students was reportedly labeled autistic and had some difficulty communicating her needs. Profesora took this situation in stride and photocopied work for each subject area for them to practice and regularly checked in with them while teaching the scheduled lesson for her fifth-grade class. At one point in the day, there was a 15-minute period in which I noted a great many times she was interrupted by events from inside and outside of her classroom. There were students from another class fighting in the hall, students arriving to pick up the laptop cart, questions from the third graders, the arrival of the clipboard student, and the principal checking in on the third graders. In spite of these interruptions, she did not lose focus nor become impatient while successfully completing her planned fifth-grade lesson for lenguaje. She made the visiting third graders feel so comfortable that when everyone lined up to go to lunch, I overheard one of them ask, "Profesora, when can we be your students and be in your class all of the time?" 
Additional sociocultural considerations. In order to better understand the dynamic present in this community of practice, it is also essential to understand the nature of some key participants within this community. As reflected through the Sociocultural lens, individuals are shaped by their community and sociocultural influences as they simultaneously shape and influence characteristics of that selfsame community. Another purpose for sharing this information about students of focus is is to inform the reader of some variables relevant to scaffolding and working within the Zone of Proximal Development. In order for scaffolding to be effective within the ZPD, it is incumbent upon the mentor (primarily Profesora Nuria in this case) to leverage understanding of individual student needs, recognize potential for growth, and provide appropriate assistance to accomplish the task. The word "yet" is a key term utilized by Johnston (2012) to reflect the potential that exists in our learners. It is essential that teachers maintain the outlook that detects the promise and the potential in our students for understanding, for learning and for growth. The attention to the potential level of capability with assistance is different than a deficit model. There are specific steps to the work of scaffolding within the ZPD that include leveraging knowledge and skills to accomplish a task with assistance, followed by student appropriation of skills with the final goal of learner independence. Clark and Graves (2005) described the gradual release of responsibility model by (Pearson \& Fielding, 1991) as "a related construct that is very helpful in understanding scaffolding" (p. 571). This model illustrates work over time progressing from the teacher bearing the majority of the responsibility for a reading task, and then gradually moving to the point at which the student is capable of independent responsibility for the task. Shrum and Glisan (2016) describe the overall 
process of scaffolding in the ZPD as, "what learners can do with assistance today, they will be able to do on their own tomorrow or at some future point in time" (p. 25). Indeed, the practitioner text by Burkins and Yaris (2016) intensifies the focus upon moving the student expeditiously towards independence.

Classroom interactional patterns are reliant upon willing participants. Factors related to the Willingness to Communicate (MacIntyre, Clément, Dornyei, and Noels, 1998) are also relevant to this research, as they indicate a multiplicity of elements that affect how the student works within the learning community, and guide if he or she is willing to accept the intended scaffolding and guidance within the lessons.

Student profiles. Terrell: The social leader. Terrell walks into the classroom and announces his presence in a variety of ways, not only verbally, but also with physical signals. He walks with a slight swagger, shoulders back, and chin slightly elevated. This projection of confidence does not last all day. Unfortunately, he is not a confident reader and has been recently diagnosed with Attention Deficit Hyperactivity Disorder. An athletic boy with mocha-colored complexion, his build reflects his preferred level of activity. He frequently paces around the classroom, seeking jobs and tasks that will allow him to move around to avoid sitting for extended periods of time. He tends to be social and at times is scolded for interruptions, but he is generally helpful. For example, on more than one occasion, he jumped up and retrieved stacks of dictionaries or books to pass to classmates. Unfortunately, his posture of challenge and his activity level appear to cause conflicts with other teachers in the building, most notably during lunchtime. More than once, following a negative report from another teacher, la Profesora inclined her head towards Terrell and asked me, "Do you ever feel that sometimes a person is just 
misunderstood?" In listening to recordings of small group conversations, and seeing evidence of his efforts to make academic progress, I believe this project illuminates some of the positive academic moves he makes that otherwise might have remained unnoticed.

Tessa: The business manager. Tessa is one of the top contributors to virtually all class discussions. She speaks confidently and with authority in a direct, somewhat blunt way with crisp consonants. Frequently seen with a thick copy of one of the Harry Potter novels on her desk, she projects herself as a highly motivated and involved student. One of her preferred activities is clearly reading, as evidenced by her sneaking glances at her outside reading books any chance that she can. She has long hair styled into a multitude of ultra-thin, quarter-inch braids down the middle of her back. She has bright eyes and a café au lait complexion. She smiles easily and frequently, even as she bluntly lectures others on how to proceed in a small group task. She and Nikki at times appear to work in concert to contribute to whole class discussions and move them forward.

Nikki: The gymnast. Nikki demonstrates the greatest flexibility with language, and a frequent volunteer to contribute to any conversations centered around reading. She is a petite, slim, athletic girl with delicate features, tiny freckles, and honey-colored hair. The daughter of an educator herself, she tends to be a patient, nurturing, and creative peer to those around her. When other students in her midst struggle with comprehension on something that comes easily to her, she assists readily without appearing impatient or reluctant. She presents herself as highly motivated and task-oriented student, traits which are evidenced by her way of participating in all formats, large groups, small groups, and even individually. Notably, she is the only student who takes out the leveled ENIL (Estructura para la Evaluación del nivel independiente de lectura) (Structure for the 
Evaluation of Independent Reading Level) student card and keeps it with her independent reading book, visibly checking for the objectives and words on the list.

Santiago: The bridge builder. Santiago is an athletic, heritage speaker of Spanish with curly black hair and a broad smile. At first he appears to be more easy-going than Terrell, but also shows greater intensity of focus. He tends to be quieter in classroom discussions than his peers, but he makes strong, though infrequent contributions to large class discussions during lenguaje. He appears more comfortable with small group discussions and task-oriented work time. I was quite surprised by his strong performance on the ENIL, as I had not heard him respond so overtly nor in-depth in any discussions about text in the past. In the social network of the class, he seems to "build bridges" and unite boys from different backgrounds who are interested in sports. There were several times that I witnessed him diffusing competitive tensions within the boys' peer group with a soft-spoken flash of humor and a smile.

Ahmose: The philosopher. Ahmose distinguishes himself with slowly and deliberately articulated interjections into classroom conversations of an abstract and insightful nature. He was one of the first students in the class to ask questions about this project, and he specifically asked if students could select their own pseudonyms. A small-framed boy with caramel-colored skin and somewhat delicate features, he could easily be underestimated or overlooked by teachers at first. In September, he was constantly sneezing, and his puffy eyes (almost swollen shut by allergies) challenged his engagement with the class. He is a student who regularly volunteers to participate in classroom discussions with contributions ranging from insightful inference, humorous asides, or personal connections to the story. When students had the opportunity to dress 
in costume for Halloween parties, he wore a suit and tie and went to the front of the class to write on the board. While writing he slowly and deliberately announced, "I am your substitute teacher and your surprise is... extra homework!" accompanied by a coy smile. His participation during the observation period was of particular interest for this project, not only because of his rather philosophical outlook, but, also because of his developing perspectives on language choice (Spanish vs. English) in the classroom.

Rianna: the conscience. Rianna speaks with gentle, soft tones and makes numerous contributions to discussions that center around themes related to kindness toward others, memories, and perspectives on history. She is a tall, slender girl with short braids, a cinnamon-colored complexion, and bold, metallic, turquoise-colored glasses. A member of a blended family, she frequently speaks about the importance of relationships and her travels to the American Southwest. Those travels allowed her to enthusiastically contribute to and personalize the discussions of the Puebloan peoples in the Social Studies class.

Jenna and Kishanda: the inseparable duo. Jenna is at first one of most noticeable in the classroom for her large, brightly colored, cheerleading style hair bow perched on top of her head. However, this flashy adornment does not really match her classroom persona. She rarely volunteers to participate in large class discussions in Spanish, and this could possibly be attributed to her lower assessed reading levels as compared to the most active participants. While Jenna is slightly more outspoken than Kishanda, and they are both capable of contributing to class discussions, although they tend to wait for others to go first. In addition to this characteristic, they speak to one another more than with other classmates and constantly seek opportunities to work 
collaboratively. During the silent reading periods, they sit on the floor against the wall with postures inclined towards one another in a variety of positions: back-to-back, sideto-side, and feet-to-feet. They consult each other on book choices for independent reading and at times they are admonished for their whispered conversations.

Asha: Man on a mission. Asha is similar to Tessa in that he surreptitiously attempts to read the thick, independent reading tomes on his desk. However, every action, including page turning, spoken words, and articulated thoughts are conducted with haste. It is not clear exactly why this student always appears to be in a hurry. Perhaps it is that he simply wishes to get back to that wonderful book he was reading, which he does at every opportunity, with or without "official permission." A slender boy with olive-toned skin and wavy brown hair, he wears Harry Potter styled, wire-framed glasses that echo his preference for fantasy and science fiction. Within large class discussions in lenguaje, he contributes when called upon, but does not volunteer at the level one would expect of a person who so greatly enjoys reading. In small group discussions, at times he takes charge and rushes through generating answers, whether they are correct or not, and he attempts to dispatch with the task as quickly as possible. In some small groups, he became noticeably upset and started to cry when he was unable to complete the assigned task. In other small groups, he was noticeably impatient with his peers and even overpowered their words and questions causing Ahmose to plaintively cry out in frustration, "Wait...wait... wait! What?"

\section{The Context: Environmental concerns and learning.}

Urban schools present environmental challenges that directly impact students. In this particular school context, students have been affected by high teacher turnover rates, 
local violence, and poverty. Profesora Nuria shared information with me about her first year teaching in the Spanish Language Immersion Program, and described how high teacher turnover rates affected the students and their behaviors,

Even if, I feel like now if I could change my job, I wouldn't. It's, at the end of the day, it's the kids that make the whole difference and again because of where most of these kids come from, I feel like I have made an impact on them. They've had teachers quitting on them in the past in the middle of the year. My kids last year had three different teachers. The very first week was challenging for me- they were trying to push my buttons. You know, they were trying to see how far I would let them go, and I had a girl crying to me and asking me, "Are you going to quit, are you going to quit like the other teachers? Are you going to leave us?" And I grabbed her from the shoulders I remember, and I told her "Hey, you can do whatever you want, you can stomp, you can whine, you can do whatever you want, I'm never going to quit, I'm not going to quit." And she looked at me, and she goes "Wow." And I never, like for me, it's like common sense that I'm not going to leave but I guess it's just because I know who I am. They didn't know who I was and now they know. (Interview, March, 27, 2015)

The students voiced their needs for stability, safety of routine, and caring to Profesora Nuria in this conversation. As described in the teacher profile, even students "visiting" her classroom for a day due to teacher illness recognized something special and welcoming about Nuria's classroom. It is clear from other researchers (Guin, 2004) that teacher turnover and burnout are major issues affecting urban schools. The surrounding public school district, as reported in local media disclosed a greater than $15 \%$ teacher 
vacancy rate and a 50\% five-year attrition rate for teachers overall. The teacher vacancy rate is of concern, as this means that there are substitutes working in upwards of $15 \%$ of the classrooms, rather than permanent hires. The attrition rate is also of concern, as it translates to fewer experienced teachers in the school buildings. This lack of consistency and structure is particularly detrimental to students with reported low socio-economic status based upon free and reduced lunch rates. While observing in this particular school, one of the teachers quit mid-week, the same week as the sudden illness of another teacher. In addition to this, Profesora Nuria received regular email updates that the substitute pool was critically low, so the school administration made official requests that teachers not take leave unless in cases of emergency. Two of the observed days, Profesora Nuria was visibly ill with scratchy throat, and quite congested, but she felt that she could not leave.

Another issue impacting the school is local violence. In this city, there are high homicide rates as regularly reported by local and national media. The location of the school itself is in the heart of the city, and in close proximity to the school there are several "notorious" intersections. Discussion of these issues serves to highlight the value of Profesora Nuria's teaching style and how it impacts daily classroom interactions and relates to scaffolding. What she offers to her students is a classroom that is peaceful and safe when compared to its surrounding environs. The value of a low-anxiety classroom environment is stressed by a range of researchers in urban education, reading education, and second language teaching (J.A. Baker, 1999; Garcia, 2009 Krashen, 1985; Gibbons, 2002). 


\section{Community of Practice}

Classrooms and schools can become their own communities of practice that are based upon the embodiment of the teacher's own social worlds and mediational means (Swain and Lapkin, 2013). In this particular fifth grade classroom there are established literate habitus and understandings that reflect the community of practice built by the teacher in her space within the broader school context at SLIP. As noted by ComptonLilly (2014), "People construct habitus across the life span in relation to the contexts they occupy and the relationships they form" (p. 373). It becomes clear that there are certain routines and habits that are built in this classroom that are practiced and, subsequently, adopted by students over time. In this classroom, in which I will call the students collectively as a group las estrellas de quinto grado (the stars of fifth grade), there are five basic tenants by which the classroom community operates. Briefly, these are organization, knowledge, encouragement, reading, and language choice.

Organization and structure are valued. First, Profesora Nuria values organization and structure. This tenant is embodied in a variety of ways. First, every single day, Profesora Nuria begins class with the same routine. She collects student notebooks at her desk before class begins. Then, students move away from their desks, and sit on the floor with her in a circle (oval) in the center of the classroom. This "Circle Time" is a classroom meeting to discuss the day's schedule. The class schedule for the day is also posted in a classroom pocket chart at the front of the room near the door and next to the white board. The typical schedule morning schedule looks like this: 
Table 4.1 Sample class schedule

\begin{tabular}{l|l|l}
\hline Time & Original Description & Translation to English \\
\hline $8: 00$ & hora del trabajo & work time \\
\hline $8: 30$ & reunión del plan del día & daily plan meeting \\
\hline $8: 40$ & clase de inglés & English class \\
\hline $9: 40$ & matemáticas & Math class \\
\hline $10: 40$ & lenguaje & Spanish language arts \\
\hline $11: 40$ & ciencias & Science \\
\hline
\end{tabular}

Students are also invited to share information about their week if they like. The first class of the day is English. Two days a week, that class is with another teacher in her classroom. Three days a week, they have English class with Profesora Nuria in homeroom. Then, following English is Math, then Lenguaje (Spanish Language). At each transition point, las estrellas de quinto grado know that the teacher consistently says, "Cinco, cuatro, tres, dos, uno" (Countdown 5, 4, 3, 2, 1 in Spanish) to gain their attention and begin the instructions for the next segment. In this same vein, in one particular class session she said,

Table 4.2 Transcript excerpt: Five, four, three, two, one routines

\begin{tabular}{l|l}
\hline Original Transcript & Translation to English \\
\hline $\begin{array}{l}\text { Cinco, cuatro, tres, dos, uno. Muy bien } \\
\text { hecho chicos. Cuando diga 'vamos' quiero }\end{array}$ & $\begin{array}{l}\text { Five, four, three, two, one. Well done, } \\
\text { students. When I say 'let's go,' I want you }\end{array}$ \\
\hline
\end{tabular}


que por favor guarden sus libros, si es un libro que tu estás leyendo y que es el libro que quieres seguir leyendo, guárdalo en tu caja de libros, si no guárdalo en una canasta apropiada y sacan sus cuadernos para la clase de ciencias. to put away your books. If it is a book that you are reading and you want to keep reading, put it in your book box. If not, put it in the appropriate basket and take out your notebook for science class.

This routine script became so predictable to everyone that Snowy (a student in the class on the autism spectrum) on a separate date completed her sentence in anticipation of what she would say with the same tone and pace as the teacher would have done, “...y sacan sus cuadernos para la clase de ciencias. ¡Vamos!" (....and get out your notebooks for Science. Let's go!). Everyone, teacher included, thought this was hilarious. Those types of verbal cues ensure that everyone knows what to expect.

Profesora Nuria also explicitly emphasizes the importance of organization to her students in written forms. In one of the interviews, she described a scenario in which she emphasized this point,

I feel like because of the kids that we have, it's important for me that they're organized. It's important for me that they show ... For example, Asha and Clyde have been so used to at school, since they're so smart, they read all the time, they get great scores, they're always the first ones to finish, they're so used to getting away with not having pretty handwriting. And I always tell them, "I'm not expecting a girly, girly handwriting, but you're in 5th grade, you're going to middle school, I need you to be organized." So now they'll take a longer time finishing, but for them, when I look at their notebooks, they know that I'm looking at organization and cleanliness. And they're proud of it. I actually sent a picture to 
their moms the other day and they were like, "Is this really my kid?" And I'm like, "It really is." And they even are proud. They'll tell you like, "Oh, look Profesora, this is from now. This is from the first day." They notice a difference. So for me it's just for them to be able to ... I'm really trying to have them learn how to take notes. (Interview, October, 6, 2017)

Within these quotes, one can notice that she prioritizes the importance of handwriting, organization, cleanliness (neatness), and note-taking skills in her communications with students about their written work. Similarly, with their student notebooks, the teacher repeatedly tells the students at the beginning of the class period, just before a reading in lenguaje she says, "Recuerden que deben escribir titulo y fecha..." ("Remember that you should put the title and date...”). After reading Jiménez, Smith, and Martinez-León (2003) and their research about literacy practices in Mexico, I began to wonder if the teacher's own desire for the notebooks with title and date was a sociocultural construct from her own schooling in Honduras. While Jiménez et. al. (2003) completed their work in Mexico, it was noted by the team of researchers that there was an extensive amount of time dedicated to the creation of "notebooks" as a form of "recurring literacy event" and that the "written work manifested a deeply rooted concern with the physical appearance of the document" (p. 500). This was noted as a form of literate habitus and one of the teachers specifically "reminded the students that each of their entries in their notebooks required a specific title and the date of that particular lesson" (p. 500). This seemed to be a strikingly similar practice to that of Profesora Nuria. From Profesora Nuria's perspective, organization enhances the classroom functions overall and assists students in developing what she considers to be a valuable life skill. 
Knowledge is prized. Second, las estrellas de quinto grado know that within this classroom knowledge is prized. As I will discuss further in the section on scaffolding, one of the most commonly employed strategies by this teacher is the activation of background knowledge. The students are invited to share what they think about given topics throughout various phases and stages of class discussion. For example, in a pre-reading activity, the teacher gives the students a few minutes to consider the following question,

Table 4.3 Transcript excerpt: Notebooks

\begin{tabular}{|c|c|}
\hline Original Transcript & Translation to English \\
\hline $\begin{array}{l}\text { Bien, en sus cuadernos van a escribir el } \\
\text { título de la lectura y van a contestar la } \\
\text { pregunta número uno, que dice-- Antes de } \\
\text { comenzar la lectura, quiero ver a todos } \\
\text { escribiendo el título y contestando la } \\
\text { pregunta antes de comenzar la lectura. Voy } \\
\text { a leer la pregunta en voz alta... Dice: "En } \\
\text { los concursos de cantantes en la televisión } \\
\text { vemos que durante la semana anterior a su } \\
\text { actuación le dan clases de canto. ¿Creéis } \\
\text { que esas clases son importantes?, ¿por qué } \\
\text { o por qué no?." }\end{array}$ & $\begin{array}{l}\text { Good. In your notebooks, you are going to } \\
\text { write the title of the reading and you are } \\
\text { going to answer question number one } \\
\text { which says... Before you start the reading, } \\
\text { I want to see everyone writing the title and } \\
\text { answering the question before beginning } \\
\text { the reading, I am going to read the } \\
\text { question aloud... It says, "In the singing } \\
\text { competitions on television we see the } \\
\text { previous week's singing classes that are } \\
\text { given to the participant. Do you believe } \\
\text { these classes are important? Why or why } \\
\text { not? }\end{array}$ \\
\hline
\end{tabular}

This discussion directly led to a reading about Mockingbirds in Japan that were trained to sing in specific ways. The questions posed include the starter "Do you believe?" establishing immediate precedence to the student's personal opinion based upon their experiences. In this case, the questions refer to personal familiarity with popular 
television programs featuring singing competitions. This teacher clearly prioritizes and highlights students' prior knowledge in class discussions. This is an important feature of this teacher's work with students. As Moll, Neff, and Gonzalez (1992) described, in U.S. schools there generally exists a systemic gap between home and school language and literacy practices. Minimizing this gap can occur when teachers acknowledge, value, and leverage the funds of knowledge of their students. During a follow-up interview, Profesora Nuria specifically addressed this issue,

I told [my cohort teacher] Roberto that sometimes I enjoy doing more of these kind of readings [rather] than tying in the reading centers to a social studies reading that not everyone's going to be so involved in. I feel like these kids love tying it into their lives... because even Jenna who barely ever participates... today she was on a roll with "El Error más grande" [name of a specific reading from lenguaje class, "The Greatest Mistake"]. Like, making all these connections with the things that we were reading. It was nice to see her involved. (Interview, October, 6, 2015)

Similarly, in another class discussion Rianna was able to provide "eyewitness testimony" about the Mesa Verde ancestral Pueblo people and their home constructions based upon a family trip. She had seen the ancient homes that were relevant to the social studies topic on that particular date and shared uniquely personal perspectives and impressions about their construction. These comments served to pique the interest of the other students in the class and provoke richer discussions on the topic. This is a consistent message delivered throughout all class periods. Even during a game, students are overtly told knowledge is the highest goal. During the science class period, students were preparing 
to play BINGO to review scientific terms about matter. Terrell asked, "Do we get a prize?” The teacher immediately responded, “Todo en este día es un prize. ¿Sabes lo que vas a ganar? Knowledge! Y eso nadie te lo puede quitar." ("Everything on this date is a prize. Do you know what you will win / earn? Knowledge! And no one can take that away from you.")

Encouragement is contagious. There is also a deeply interwoven message that encouragement is important in this community. This priority is embodied by Profesora Nuria. She radiates welcome and encouragement to everyone, even in the face of numerous interruptions throughout the day. At approximately 10:15a.m., in the middle of the lenguaje class period, a student with a clipboard knocks on the door. "Debe ser mi buddy (student name)." (It must be my buddy.) He is in second or third grade and comes to check in with Profesora Nuria regarding his behaviors on a daily basis. She never seems frustrated to be interrupted in the middle of the lesson (or even in the middle of a sentence). She greets him with a smile and goes over the notes from his regular classroom teacher. Frequently, the teacher jovially tells the students to greet him as soon as he arrives. The students respond as a chorus, “iHola (student name)!” At times, he is invited to join in a classroom activity with the fifth graders. On day, after participating in a "Brain Break" activity called "Enano Gigante" (Gnome Giant) this is the brief conversation that takes place,

Table 4.4 "Keep it up, little buddy!"

\begin{tabular}{|l|}
\hline Original Transcript \\
\hline Profesora: Good job, mi amor! \\
Santiago: Keep it up, little buddy! \\
Clipboard Student: I will! (leaves laughing)
\end{tabular}


As one can see from this example, by the end of the third month of school, the teacher's model has been appropriated by another student in the class. The teacher says an encouraging phrase, and another student in the fifth grade class follows it up with "Keep it up, little buddy." Notice that the teacher has consistently called the clipboard student "mi buddy" (my buddy), and Santiago imitates both her word choice and attitude of encouragement without prompting.

In another observation period, a female student from fourth grade arrived with a clipboard. She did not even want to enter the room, and another teacher knocked on the classroom door where she had been hovering to call Profesora Nuria's attention to the situation. A week or two later, the same student knocked on the door and entered readily. Following her report with the clipboard, she was invited to sit with Nikki who whispered answers in her ear, so she could actively participate in the science activity. Students do not only benefit from the encouragement of the teacher. The tone has been established, and as shown by the quote from Santiago, students often encourage one another. This behavior of mutual support was openly praised by la Profesora after math class one day, when she complimented the students on their compañerismo (comradeship or team spirit are the closest translations for this word).

Another way the teacher promotes this positive and supportive atmosphere is by highlighting the strengths and interests of individual students. Snowy (self-selected pseudonym) is a student who has been diagnosed as on the autism spectrum. He loves to look up words in the dictionary. So, when it was time to define a few words during lenguaje, Profesora Nuria asked for volunteers. Of course, due to his strong interest in dictionaries, he was one of the first to enthusiastically volunteer for the task. The entire 
class cheered while he and another classmate looked for the words. Snowy chortled with glee as he looked up words faster than James and reported back with some of the definitions.

Students also celebrate with each other. When Tessa arrived one morning, the teacher was already aware that she had her orthodontic braces removed the night before. So, upon her entrance, Profesora Nuria exclaimed, "DDanos una sonrisa de Colgate!" (Give us that Colgate smile!) during circle time, and everyone cheered and clapped for her achievement. The teacher has also given students tips on ways to support and encourage one another in small groups. On one such occasion, Asha began to cry during a small group activity. Profesora Nuria was working with another small group when a student walked over and tapped on her shoulder saying, "Profesora, Asha is crying" to alert her. The teacher gave Asha a moment to leave the room and compose himself after she checked in with him. Then she immediately went to his group members and asked them, "What happened?" After carefully listening to their responses, she said, I want you guys to be able to communicate with Asha and let him know what's going on. Maybe he feels a little bit lost and if you know that he's a little bit lost... we've all been there before where sometimes we feel lost. So it's important that we're able to communicate, okay?

The teacher acknowledges the problem, offers a solution, and attempts to build empathy with the statement, "we've all been there." The caring that the students show for one another is further on display by other occasions. On one particular date, Snowy appeared very sad in class, and even covered his head with his hoodie during independent reading time. These were atypical behaviors for him. One of the other students was so 
concerned about this, that she went over to the teacher's desk and asked her what they could do to help. The teacher told the student that she was waiting to hear back from his mother, but that it was wonderful that she had asked. There are other numerous examples of the teacher and students building one another up in a variety of ways throughout the observation period.

Reading is central. Profesora Nuria's classroom practices also send the message that reading is central to everything they do. The classroom is full of books. Along one wall, a low bookshelf displays students' individual bins with books and notebooks. The two shelves below contain bins full of English language independent reading materials organized in a variety of ways: author, title, series, and genre.

Figures 4.1 and 4.2 Classroom photographs: English reading materials and close-up
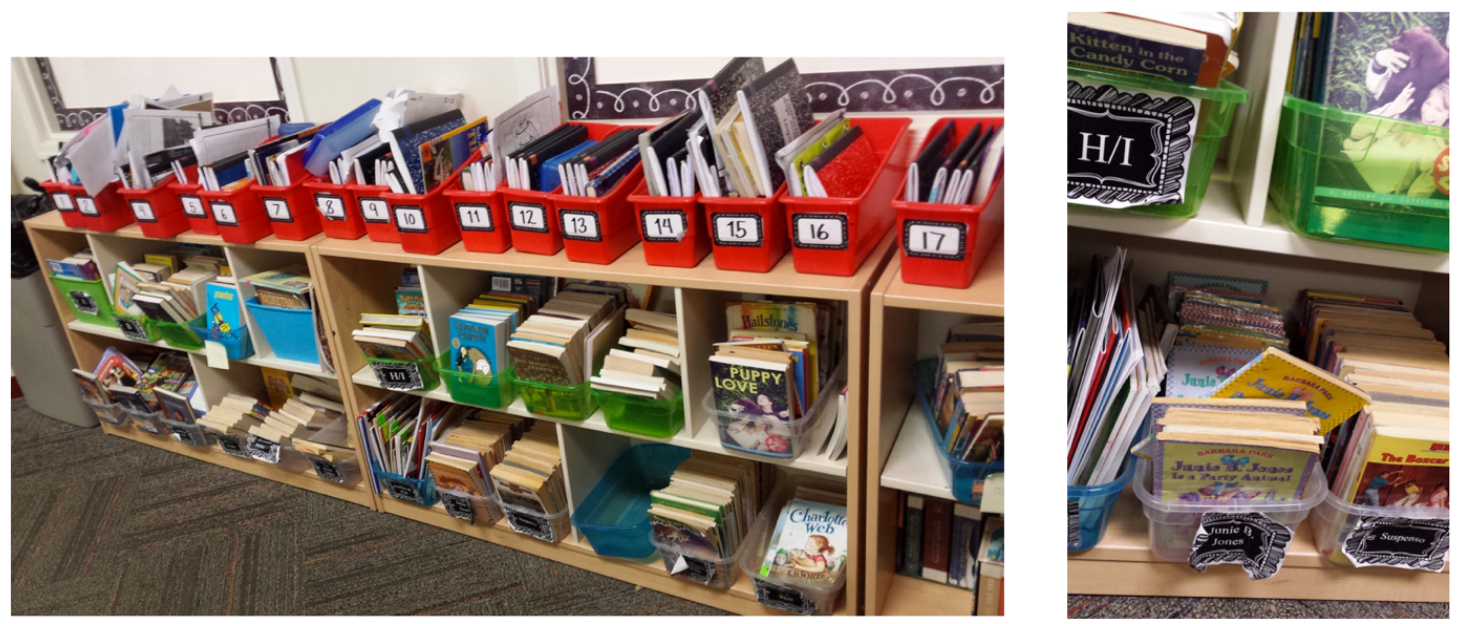

On an adjacent wall, a tall bookshelf unit contains hundreds of Spanish language independent reading books organized in bins by reading level color (associated with the ENIL, Estructura para la Evaluación del nivel independiente de lectura, by the American Reading Company, 2017). 


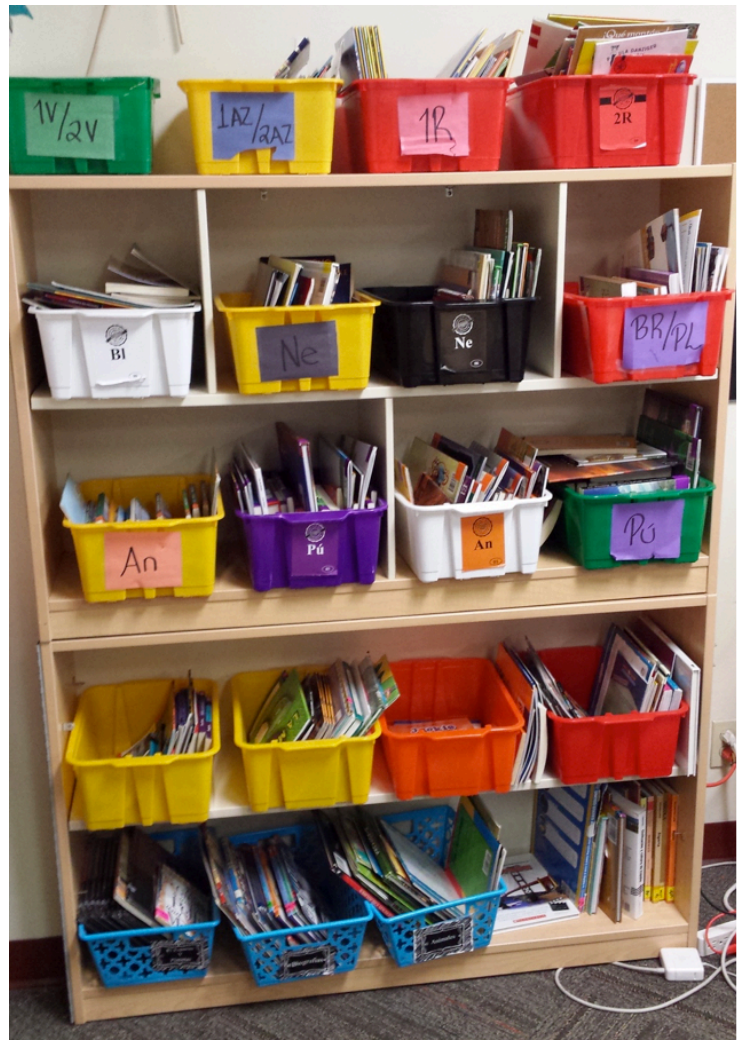

Figure 4.3 Classroom photograph: Spanish reading materials

All students have 20-25 minutes of independent reading in English three days per week, and 20-25 minutes of independent reading in Spanish five days per week. The students are also assigned the task of reading 30 minutes daily for homework. This information about quantity of time read at home is reported to the teacher when handing in homework before circle time. At the end of each week, students who complete their reading time goals receive Smarties ${ }^{\circledR}$ candy. The concept of encouraging reading volume is supported by research. Allington (2014) has found links between reading volume and reading proficiency. Another sign on the wall says "Leer es pensar" (To read is to think). In addition to the visual cues around the classroom, nearly every class period involves reading of some type. For English class with Profesora Nuria, students complete individual adaptive reading tasks using the software iReady before independent reading. In the lenguaje class period, students typically take turns reading aloud from a provided text and answer questions orally. In social studies, the same basic routine as lenguaje is often followed. In another section, I will discuss these practices further as they relate to reading instruction and teacher education. 
Language is a choice. Being bilingual means a student can choose to communicate in Spanish or English (or both). Profesora Nuria is not a teacher who is a purist about the separation of languages. She does not regularly overtly push for students to ask questions or respond orally in a particular language. With regards to written responses, she is somewhat stricter in stating clear preferences for the language of production, but students are not penalized for responding in their other language. In the Retrospective Analysis Interview in October, she explained her philosophy for providing feedback to students in this way,

Usually [I write in their notebooks], "I love how you've paid attention in class. I can tell that you were being very attentive. Thank you for using complete sentences." Or, "Thank you for ..." For me it's always like, "Thank you." Or, "I loved how you made a connection with something from your life." Little notes like that. And mostly just like, "Muy bien. Buen trabajo. Incompleto." (Very good. Good work. Incomplete.) (Interview, October, 6, 2017) When asked what happens if she cannot understand what a student has written due to breakdown of syntax or lack of response, she said, I will say Terrell sometimes just has a hard time organizing his thoughts. And sometimes he'll just write one word or two words and he believes that I'll somehow assume what the other three words are meant to be. And in that case I'll sit down with him and I'll say, "Hey, what did you try to say here?" For me, and I always tell them, for me it's more about knowing whether you know the answer to these rather than how you're doing it right now. Because I don't like punishing for 
something that they didn't know, and then so we just try to set up a goal to,

"Okay, so next time we're going to do this." (Interview, October, 6, 2017)

Through these discussions with Terrell, the encouragement to look forward to the next opportunity underscores the attitude of valuing the potential of the individual student, "next time." Simultaneously, one can observe the privileging of understanding the message, "Hey, what were you trying to say here?" indicates the drive towards valuing the ultimate goal of communication through language use. Some research about the evaluation of writing in second languages has noted that teacher's comments about content and comprehensibility (rather than grammatical features) have greater positive impact upon future student writings (Semke, 1984).

Her cohort teacher, Profesor Roberto, seems to share her sentiment about language choice, as demonstrated by his interactions with Terrell during a classroom discussion of “¿Qué alegre se pone el rio!” a famous poem by Juan Ramón Jimenez.

Table 4.5 Transcript excerpt: "I want it in English"

\begin{tabular}{l|l}
\hline Original Transcript & Translation to English \\
\hline Profesor Roberto: Yo te había preguntado, & Profesor Roberto: I just asked you. What \\
¿qué es lo que piensas? & do you think? \\
Terrell: I want it in English. & Terrell: I want it in English. \\
Profesor Roberto: Me da igual. Yo no te & Profesor Roberto: It's all the same to me. \\
estoy diciendo en español o en inglés. & I am not saying you have to speak in \\
¿Qué piensas de lo que quiere decir en el & Spanish or in English. What do you think \\
poema? & that [the author] wants to say in the poem? \\
\hline
\end{tabular}

As one can observe through this conversation, Terrell's reaction is to avoid and negate the necessity to respond in Spanish. Moreover, he is quite direct with the statement, "I 
want it in English." Profesor Roberto could have responded in a variety of ways to this statement of opposition. However, he selected to state clearly to the student that he just wants an answer to the question and that the language choice (Spanish or English) is up to the student. Notably, the teacher continues to speak to the student directly, deliberately, and continues the line of questioning in Spanish (the target language).

However, it also must be noted that oftentimes, if Profesora Nuria does request a language switch, what happens is that the student demonstrates he or she is capable of answering in either language. In this example, the teacher specifically requests a response in the other language to a question posed about the reading during lenguaje class:

Table 4.6 Transcript excerpt: Can you tell me in Spanish?

\begin{tabular}{l|l}
\hline Original Transcript & Translation to English \\
\hline Profesora Nuria: A ver, ¿aqui qué & Profesora Nuria: So, what do we think \\
pensamos? & here? \\
Clyde: I think that it's nervous to sing in & Clyde: I think that it's nervous to sing in \\
front of other birds, but it's really good at & front of other birds, but it's really good at \\
singing. & singing. \\
Profesora Nuria: ¿Y en español me lo & Profesora Nuria: And can you say it to me \\
puedes decir? & in Spanish? \\
Clyde: Pienso que es muy nervioso de & Clyde: I think that it is very nervous to \\
cantar enfrente de otros pájaros. & sing in front of other birds. \\
\hline
\end{tabular}

This message concerning the nature of bilingualism is also transmitted through her own class structures. Some researchers, most notably García (2009) consider biliteracy practices and wrote about specific class formats and language relationship types. In Social Studies class, most readings are in English, but the teacher's (verbal) questions 
regarding the text are in Spanish, and students can answer in either English or Spanish.

In our interview, I asked Profesora Nuria why this was the case, and her response includes concerns about both student motivation and comprehension.

Social studies... in fifth grade we talk a lot about the United States and the history of the United States, it is so hard to find Spanish readings that will make sense to them. And I know that when we talk about Native Americans and other topics, those are kind of topics that kids [here] usually are not even so interested in. It depends on the kid. Like Kishanda today was telling me, "Profesora, I'm having a hard time understanding all these things about Native Americans." I know that if I give something to her about Native Americans in Spanish on top of that, it's going to be double the trouble. (Interview, October 6, 2017)

Profesora Nuria explains the format for the Social Studies readings in this way, "It's mostly English, and then we try to do discussions in Spanish. But it is mostly in English." When asked if Science was the same format or not she explained the readings for Science were in Spanish. She replied, "Science is, yeah, it's way easier to do it in Spanish." However, it is compelling to note that Profesora Nuria, in the interview on March 27, 2015, expressed a slightly different idea, stating that she believed science was the most challenging for the students. Interestingly, her statement regarding the challenges of teaching science as a content area in dual language schools specifically due to register and range of vocabulary is affirmed by the research of Met (2008, p. 53).

\section{Scaffolding the Continua of Biliteracy}

Research questions. This study seeks to discover answers to the following central question: How does the teacher scaffold student development of biliteracy within 
language and content instruction in the immersion school context? Additional, supportive questions include: What scaffolds are pre-planned as part of the lessons, and what are those that emerge organically through teacher interactions with students? What differences exist in the types of scaffolds provided for content areas knowledge versus language, or their place relative to or within the continua of biliteracy? This study focuses upon scaffolding. However, the school setting requires acknowledgement of other factors that directly impact the effectiveness of the scaffolds used by the teacher. There are sociocultural considerations within the classroom community that directly attend to some of the issues prevalent in urban school settings. Therefore, the additional question was added: What forces or tensions does the teacher face as she scaffolds for biliteracy development? The teacher, Profesora Nuria, negotiates a wide variety of complications in the classroom that impact the willingness of students to accept her assistance and later appropriate these languages, skills and strategies.

"Struggles" and "help." In the interviews with Profesora Nuria, what becomes clear is that she is intensely focused upon meeting the needs of the students. However, these needs are framed as "struggles" and "challenges." When a student "struggles" she wants to find ways to make him or her more comfortable. When discussing the adoption of the iReady software program in 2017 , she said,

But I told the kids, "It's really important for you to understand that it's not I give you a computer and off you go!" It's more, "let me see what you can do by yourself and I'm going to be here to help out with what I see that you're struggling with." And so I think it's a really good program. (Interview, September 14, 2017) 
One can see above that she says the word "struggle" and it is accompanied by the word "help." This was a consistent theme in the interview from 2015, that was repeated several times within the 2017 interviews as well. The message of help or assistance in the event of "struggles" is a student-centered practice that directly leads to interactional scaffolding. Interactional scaffolds, defined as "responsive in-person support an expert reader offers to a novice" (Reynolds, 2017, p. 135). Profesora Nuria, in the role of "expert," directly focuses her attention on the struggles of individual students and seeks ways to provide assistance. In the context of this particular study, this inclination is one that makes Profesora Nuria the ideal teacher participant, as the nature of scaffolding requires that the mentor or teacher provides assistance that moves the student towards accomplishing goals that he or she could not complete independently. This message of struggles accompanied by help from a mentor is one that is also conveyed to the students through her interactions with them, as she guides them towards working with others. In this portion of the interview, she describes that students frequently are allowed to choose their own small groups, but at other times, she chooses for them. This is what she reportedly says to the students as they prepare to work with others who are not their closest friends,

"If you know that you're working on something that you're very good at and you're working with someone that you know struggles... how patient are you? How are you going to deal with this?" So when they know what I'm looking for, it's really interesting to see how the kids will be like "Good job, (student name)!" (Interview, September 14, 2017) 
From an analytical standpoint, in language research there are several points in the literature that relate to the relevance of this concept of attention to the overall classroom ambience. First, Krashen's input hypothesis discusses the role of the affective filter and how stress or anxiety can negatively impact the reception of input in the second language (1982, 1985). Also, Pérez and Huerta (2011) explore the importance of the affective support in the Model for Dynamic Biliteracy Development. Finally, MacIntyre, Clément, Dõrnyei, and Noels (1998) directly tied components of their theory about the Willingness to Communicate to the "comfort level" of the students. This "willingness" was even broken into smaller categories, describing confidence and motivations affecting the participation levels within whole class activities versus small group activities. Profesora Nuria in her own words, at times relates this tension between "struggles" and feeling "comfortable" to her own understandings of the relationship between L1 and L2. These understandings are clearly based upon personal experiences related to her own willingness to communicate within the bilingual school of her childhood in Honduras. This theme will be explored and discussed further in the section on language ideologies and language practices.

Attending to affective needs. Another way that Profesora Nuria provided scaffolding is to attend to the affective needs of the students so that they feel empowered to get the most out of the lesson and to participate. This is reflected broadly by her attention to routine encouragement and welcome as previously discussed in the Communities of Practice section. Additionally, this is a point that theoretically provides scaffolds for students in their biliterate development as it enhances their receptive skills (reading and listening) in Spanish through decreases in stress. As stated previously, this 
may be even more worthwhile, relevant, and appropriate in urban school contexts where a greater number of stressors exist in the students' lives. In this example, Profesora Nuria is preparing the students by providing reassurance prior to combining with Profesor Roberto’s class for lenguaje (Spanish language).

Table 4.7 Thank you to everyone who is ready

\begin{tabular}{|c|c|c|}
\hline Original transcript & Translation to English & codes / notes \\
\hline $\begin{array}{l}\text { Gracias a todos que ya están } \\
\text { listos con su cuaderno y lápiz en } \\
\text { sus mesas. Chicos, recuerden } \\
\text { que yo quiero que Uds. absorben } \\
\text { esas oportunidades con Profesor } \\
\text { Roberto. Para participar okay, } \\
\text { recuerden que somos muy } \\
\text { diferentes. Las experiencias que } \\
\text { pueden tener con él son muy } \\
\text { diferentes de las que pueden } \\
\text { tener aquí conmigo. Así sácale } \\
\text { provecho Take advantage of this } \\
\text { experience, y yo sé que algunos } \\
\text {... porque hay tantas personas, } \\
\text { tantos chicos maybe you feel a } \\
\text { little bit embarrassed de } \\
\text { participar... pero no te sientas } \\
\text { así. Estamos todos aquí para } \\
\text { aprender (siéntate bien, Terrell, } \\
\text { gracias) estamos todos aquí para } \\
\text { ser estudiantes, disfrutar y tú } \\
\text { sabes que ni Profesor Roberto ni } \\
\text { yo vamos a permitir que te }\end{array}$ & $\begin{array}{l}\text { Thank you to everyone who is } \\
\text { ready with your notebook and } \\
\text { pencil on your desks. Students, } \\
\text { remember that I want you to } \\
\text { absorb these opportunities with } \\
\text { Profesor Roberto. In order to } \\
\text { participate, okay, remember that } \\
\text { we are very different. The } \\
\text { experiences that you can have } \\
\text { with him are very different than } \\
\text { those that you can have with me } \\
\text { here. So, take advantage, take } \\
\text { advantage of this experience,... } \\
\text { and I know that some, because } \\
\text { there are so many people, so } \\
\text { many students that maybe you } \\
\text { feel a little bit embarrassed to } \\
\text { participate. However, don't feel } \\
\text { that way. We are all here to } \\
\text { learn. (Sit down, Terrell, thank } \\
\text { you.) we are all here to enjoy } \\
\text { and be students, and you know } \\
\text { that neither Profesor Roberto nor }\end{array}$ & encouragement \\
\hline
\end{tabular}




\begin{tabular}{l|l|l}
\hline juzguen. Asi que di lo que & I will allow anyone to judge you. & support \\
sientas, di lo que piensas, ¿okay? & $\begin{array}{l}\text { Say what you feel, say what you } \\
\text { think, okay? }\end{array}$ & \\
\hline
\end{tabular}

As you can see in the above passage, Profesora Nuria reassures the students that they should participate in Profesor Roberto's classroom. She prepares the students to enter Profesor Robert's classroom from a practical stance, praising those ready with "notebook and pencil," and then moves to the affective considerations. She acknowledges and embraces the difference in teaching style of her cohort teacher and encourages the students to try to overcome their hesitation to participate in front of their peers from the other fifth grade class. She acknowledges that they may "feel a bit embarrassed" and encourages them by stating the teachers will not "allow anyone to judge" their participation. All of these points are accompanied by the central message that "We are all here to learn," underscoring the previously noted elevation of knowledge as "the prize."

High-challenge, low-anxiety. Other aspects of this affective component of scaffolding, as described by Gibbons (2015) include providing a high-challenge, lowanxiety classroom with levels of support commensurate with the task. This overall concept is echoed by Profesora Nuria in the 2015 interview when she explains,

At this age, they already get the gist of how real Spanish is... and if I feel like they really don't understand, then it's a red flag, letting me know, that okay, this is just a little bit too challenging for them. So, I look for something, same topic, same subject, but a little bit easier, so we can get you know, into that rigor. Because, you know, because I do believe in challenging them, because the more you are 
challenging them, I feel like the more on task they are. I have a very wellbehaved classroom, you know, and you can just see the difference when you're really not giving them the challenging stuff, they just get bored, and they start wandering off. (Interview, March, 27, 2015)

This quote directly acknowledges that she is sensitive to when the students don't understand, and how she negotiates the difficulty by selecting additional texts to assist in their understanding. Indeed, it is a delicate balance for teachers to provide enough challenge to avoid boredom and distraction, while simultaneously providing enough challenge and support to intrigue and develop new or enhanced skills. Clark and Graves (2005) explain that scaffolding "should provide enough support that students succeed but not so much support that they do not put in the cognitive effort it takes to learn and grow as readers" (p. 575). Daniel, Martin-Beltrán, Peercy and Silverman (2016), "advocate for responsive, contingent scaffolding to keep learners productively engaged” (p. 393).

These are important points, as the reported data below from the classroom indicates the variety in reading levels in both languages among the student participants in this classroom.

Table 4.8 Student participant reading levels information

\begin{tabular}{l|l|l|l|l}
\hline $\begin{array}{l}\text { Student } \\
\text { name }\end{array}$ & $\begin{array}{l}\text { Home } \\
\text { language(s) }\end{array}$ & $\begin{array}{l}\text { Reading level } \\
\text { English (Based } \\
\text { on NWEA) }\end{array}$ & $\begin{array}{l}\text { Reading level } \\
\text { Spanish (Based } \\
\text { on American } \\
\text { Reading System } \\
\text { in Spanish, } \\
\text { ENIL) }\end{array}$ & $\begin{array}{l}\text { Additional comments / } \\
\text { information about } \\
\text { reading practices or } \\
\text { levels, as reported by } \\
\text { Profesora Nuria }\end{array}$ \\
\hline Ahmose & English & 8 th & An $\left(5^{\text {th }}\right)$ & $\begin{array}{l}\text { Only reads when } \\
\text { interested in a certain } \\
\text { topic }\end{array}$ \\
\hline Asha & English & Above 12 th & An $\left(5^{\text {th }}\right)$ & $\begin{array}{l}\text { Loves to read in English } \\
\text { during free time }\end{array}$ \\
\hline Astrid & English & 5 th & Ne $\left(4^{\text {th }}\right)$ & $\begin{array}{l}\text { (Researcher note: } \\
\text { Moved away during }\end{array}$ \\
\hline
\end{tabular}




\begin{tabular}{|c|c|c|c|c|}
\hline & & & & $\begin{array}{l}\text { observation period. } \\
\text { Information limited.) }\end{array}$ \\
\hline Barry & Spanish & 2 nd & $\mathrm{Bl}\left(3^{\mathrm{rd}}\right)$ & $\begin{array}{l}\text { Has a hard time reading } \\
\text { in either language, no } \\
\text { interest }\end{array}$ \\
\hline Clyde & English & 8 th & $\operatorname{An}\left(5^{\text {th }}\right)$ & $\begin{array}{l}\text { Not too much into } \\
\text { reading but definitely } \\
\text { making an effort }\end{array}$ \\
\hline Estrella & Spanish & $3 \mathrm{rd}$ & $\mathrm{Bl}\left(3^{\mathrm{rd}}\right)$ & $\begin{array}{l}\text { Feels more comfortable } \\
\text { reading in Spanish than } \\
\text { English }\end{array}$ \\
\hline Imani & English & 6 th & $\mathrm{Bl}\left(3^{\mathrm{rd}}\right)$ & $\begin{array}{l}\text { Mom has been trying to } \\
\text { get her reading books in } \\
\text { Spanish to get her } \\
\text { interested }\end{array}$ \\
\hline James & English & 6th & $\mathrm{Bl}\left(3^{\text {rd }}\right)$ & $\begin{array}{l}\text { Enjoys reading in } \\
\text { English more than } \\
\text { Spanish }\end{array}$ \\
\hline Jenna & English & 4th & $1 \mathrm{R}\left(2^{\text {nd }}\right)$ & $\begin{array}{l}\text { Is starting to take } \\
\text { interest in the Diary } \\
\text { books }\end{array}$ \\
\hline Kishanda & English & 4th & $\mathrm{Bl}\left(3^{\mathrm{rd}}\right)$ & $\begin{array}{l}\text { When she finds a good } \\
\text { book she is interested in } \\
\text { she will definitely take } \\
\text { her time to read. }\end{array}$ \\
\hline Laney & English & 6 th & $\mathrm{B} 1\left(3^{\mathrm{rd}}\right)$ & $\begin{array}{l}\text { Is starting to take } \\
\text { interest in reading books } \\
\text { in English } \\
\text { independently }\end{array}$ \\
\hline Messi & Spanish & $3 \mathrm{rd}$ & $\mathrm{Bl}\left(3^{\mathrm{rd}}\right)$ & $\begin{array}{l}\text { Has a hard time reading } \\
\text { in either language, no } \\
\text { interest }\end{array}$ \\
\hline Nikki & English & 9th & $\operatorname{An}\left(5^{\text {th }}\right)$ & $\begin{array}{l}\text { Likes to read and does } \\
\text { her } 30 \text { mins of reading } \\
\text { at home }\end{array}$ \\
\hline Rianna & English & 5 th & $2 \mathrm{Az}\left(1^{\mathrm{st}}\right)$ & $\begin{array}{l}\text { Parents try to get her to } \\
\text { read to them every day } \\
\text { at home }\end{array}$ \\
\hline Santiago & $\begin{array}{l}\text { Spanish } \\
\text { English }\end{array}$ & 4th & $\operatorname{Ne}\left(4^{\text {th }}\right)$ & $\begin{array}{l}\text { Does not like reading, } \\
\text { easily distracted }\end{array}$ \\
\hline Snowy & English & 2 nd & $2 \mathrm{~A}\left(1^{\mathrm{st}}\right)$ & $\begin{array}{l}\text { Can be fluent when } \\
\text { reading in Spanish and } \\
\text { English but lacks } \\
\text { comprehension }\end{array}$ \\
\hline Stacy & $\begin{array}{l}\text { English } \\
\text { Mandarin }\end{array}$ & 9th & $\operatorname{An}\left(5^{\text {th }}\right)$ & $\begin{array}{l}\text { She enjoys reading in } \\
\text { English and Spanish }\end{array}$ \\
\hline Terrell & English & $3 \mathrm{rd}$ & $1 \mathrm{R}\left(2^{\text {nd }}\right)$ & $\begin{array}{l}\text { Is improving more on } \\
\text { his interest in reading in } \\
\text { English }\end{array}$ \\
\hline Tessa & English & 8th & $\operatorname{An}\left(5^{\text {th }}\right)$ & $\begin{array}{l}\text { Bookworm. Always is } \\
\text { reading in English }\end{array}$ \\
\hline
\end{tabular}


In this chart, one can note the home languages of the 19 classroom participants. Additionally, the reading levels in English (as measured by the NWEA assessment www.nwea.org) indicate grade levels ranging from second grade through above twelfth grade. The reading levels in Spanish (as measured using the ENIL system www.americanreading.com) range from Dos Azul (2 Blue), or first grade, through Anaranjado (Orange), or fifth grade.

The teacher comments regarding reading habits include a range of statements, generally focused upon "interest." For example, in the chart above, Santiago's reading habits or interests are described in this way, "Does not like reading, easily distracted." The teacher further articulates her views on student "interest" in reading during one of the retrospective analysis interviews on October 6, 2017,

It helps knowing [information] also when I ... [am] conferring [individually] with them. Santiago, for example, is one kid that it's easy to get to know because he always wants to share his stories. So I know he loves cars, I know he loves sharks, because even when he's reading by himself he's like, "Profesora, look. Look at this shark." So I know that if we're doing a reading involving sharks, it's something that will get him into it.

These statements indicate that the teacher believes that her role as teacher includes seeking opportunities and texts that will "interest" the students in order to motivate them to read more.

While these affective components emerged as a theme of Profesora Nuria's work with the students, the variety of scaffolds that were the primary focus of the research 
question were closely aligned to the individual development of biliteracy. As Van de Pol, Volman, and Beishuizen (2010) noted,

Because scaffolding is such a dynamic intervention finely tuned to the learner's ongoing progress, the support given by the teacher during scaffolding strongly depends upon the characteristics of the situation like the type of task... and the responses of the student. Therefore, scaffolding does never look the same in different situations and it is not a technique that can be applied in every situation the same way. (p. 272)

It is important to note that the focus upon the individual task, the individual student, and his or her ongoing progress are key elements identified by these researchers.

The data presented in the table can also be sorted to include socio-economic data as represented through free and reduced lunch. If one separates out the students who are on free and reduced lunch, this appears to correlate to the majority of students who have below grade level assessed reading scores in English.

Table 4.9 Student participant reading levels with free and reduced lunches

\begin{tabular}{l|l|l|l|l|l}
\hline Name & $\begin{array}{l}\text { Race } / \\
\text { Ethnicity }\end{array}$ & $\begin{array}{l}\text { Free } / \\
\text { Reduced } \\
\text { lunch }\end{array}$ & $\begin{array}{l}\text { Home } \\
\text { language(s) }\end{array}$ & $\begin{array}{l}\text { Reading } \\
\text { level } \\
\text { English } \\
\text { (Based on } \\
\text { NWEA) }\end{array}$ & $\begin{array}{l}\text { Reading level } \\
\text { Spanish } \\
\text { (Based on } \\
\text { American } \\
\text { Reading } \\
\text { System in } \\
\text { Spanish, } \\
\text { ENIL) }\end{array}$ \\
\hline Barry & Hispanic & Yes & Spanish & 2 nd & $\mathrm{Bl}\left(3^{\text {rd }}\right)$ \\
\hline Estrella & Hispanic & Yes & Spanish & 3 rd & $\mathrm{Bl}\left(3^{\text {rd }}\right)$ \\
\hline Jenna & Black & Yes & English & 4 th & $1 \mathrm{R}\left(2^{\text {nd }}\right)$ \\
\hline Messi & Hispanic & Yes & Spanish & 3 rd & $\mathrm{Bl}\left(3^{\text {rd }}\right)$ \\
\hline
\end{tabular}




\begin{tabular}{l|l|l|l|l|l}
\hline Santiago & Hispanic & Yes & Spanish/English & 4 th & $\mathrm{Ne}\left(4^{\text {th }}\right)$ \\
\hline Terrell & Black & Yes & English & 3 rd & $1 \mathrm{R}\left(2^{\text {nd }}\right)$ \\
\hline
\end{tabular}

Six out of the eight students who score below grade level in English reading have free and reduced lunches. It is also notable that all four of the students (out of 19 participants total) who speak Spanish as a home language are also represented on this list. There are eight students total who score below grade level in the NWEA assessments for English reading level. The primary outlier to this observation about the potential correlation between SES and reading scores is represented by Snowy, who has been diagnosed as autistic. The other outlier is Kishanda, who scores in the $4^{\text {th }}$ grade level according to the NWEA assessment in English.

In this classroom, with such a represented range of student reading levels, it is important to discover what the teacher does to work with individual students and meet them where they are, valuing their current skills. Graves and Graves (2003) wrote that additional benefits to scaffolding are that it

helps children complete tasks they could not otherwise complete, scaffolding can aid students by helping them to better complete a task, to complete a task with less stress or in less time, or to learn more fully than they would have otherwise (p. 30).

The environment created by this community of practice is what can also support and facilitate the student growth, skill-building, and willingness to communicate. It is this concept of willingness to communicate that may serve to provide a window of opportunity to not only assist the student in the task, but to provide the willingness on the 
part of the student necessary to allow the next steps in the process; appropriation and independence.

\section{Graphic representations of scaffolding in the continua of biliteracy.}

Hornberger's model. A portion of Hornerberger's model called the Continua of Biliteracy was integrated into the primary research questions for this project. There are multiple intersecting lines that she used to visually express her model. I selected one specific grouping of her "nested" boxes. In some writings this portion is referred to as "the continua of biliterate development of the individual." However, as must be noted, Hornberger's (2004) position is that while a researcher can point out a specific incident, or point within all of the nested continua, “... any single point is inevitably and inextricably related to all other points; and all the points have more in common than otherwise with each other" (p. 156). I do not deny in any way the relevance or intertwined nature of the other characteristics within the nested continua that she describes in her model.

For the purposes of this project, I deliberately selected the portion that I felt was most relevant to describe the classroom interactions in the bounded case of Profesora's Nuria's classroom, and more specifically to analyze when these scaffolds occur. Additionally, as previously explained in the literature review, the ZPD (Zone of Proximal Development) narrows in upon what the individual can and cannot perform alone. Therefore, the "continua of biliterate development of the individual" and scaffolding as two theoretical frames seemed to fit together neatly for this project. 
Complications arise. However, once I had observed numerous fifth-grade class discussions at SLIP led by Profesora Nuria, I came to understand that it would be challenging to visually represent the intersection of so many factors using Hornberger's (2004, p.15) concept alone as re-illustrated in Figure 4.4.

Figure 4.4 Re-illustration of Hornberger's (2004) The continua of biliterate development in the individual

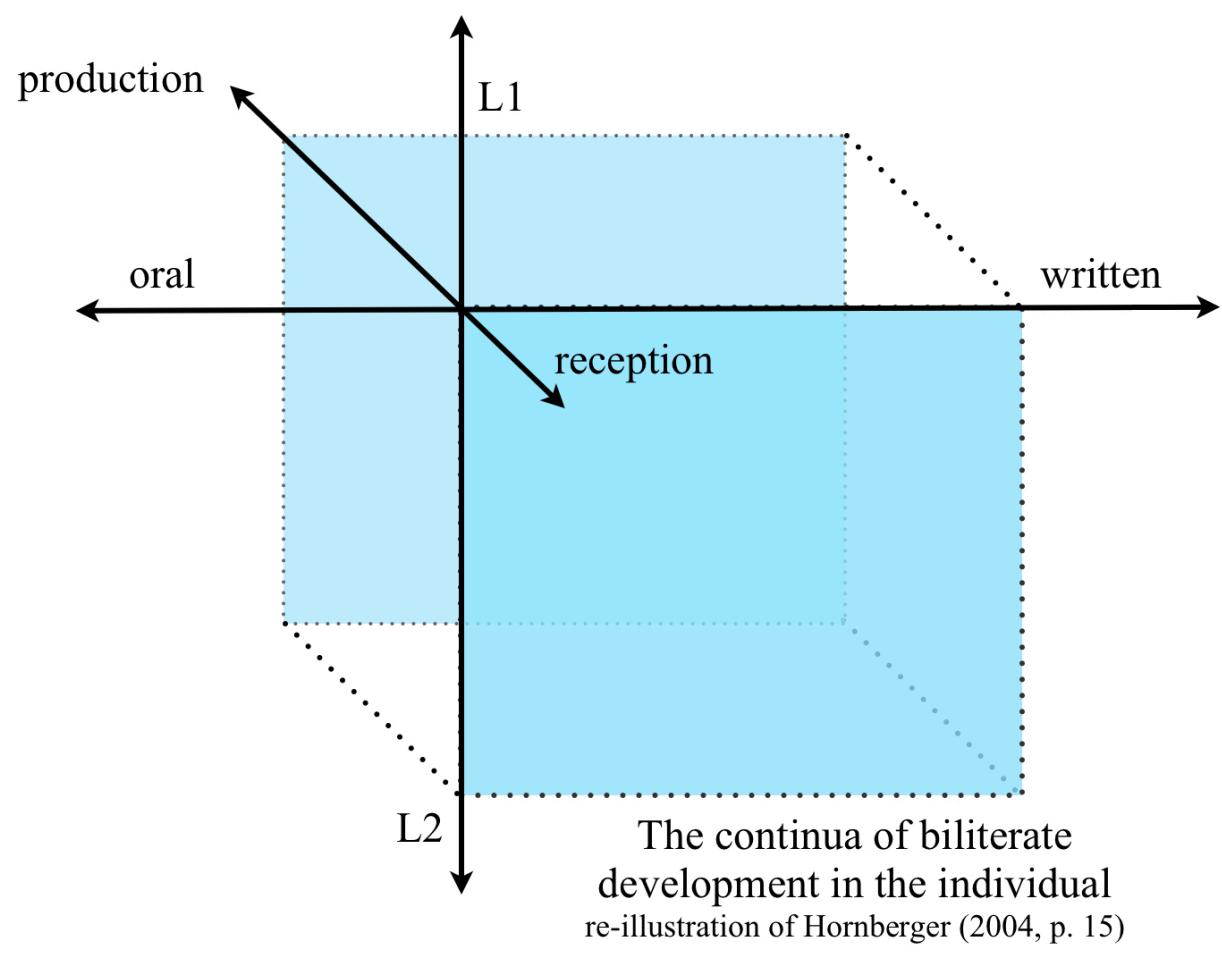

One of the primary complications to this issue was the flexibility with which the students and teacher moved from English to Spanish and vice versa. Hornberger's model allows for movement along a bidirectional line from L1 to L2. Her rational for this is that she does not intend for the intersections of her lines to create an issue with the binary, as she specifically writes that her model design intends to, "break down the binary oppositions so characteristic of the fields of bilingualism and literacy and instead draw attention to 
the continuity" (Hornberger, 2004, p. 156) of a variety of skills and contexts. There is a continuity and interrelationship between both languages spoken by an individual. However, it would be difficult to illustrate at what point the teacher's scaffold is useful and relevant when operating in two languages. Additionally, when a scaffold takes place, the primary idea behind it is to assist the student in accomplishing a task that he or she cannot perform alone. The previous model is inadequate to reflect the purposes of this particular study and report its findings. Therefore, I sought to create a model that could visually show what language and biliteracy skill (or task) was being addressed within a particular episode. Therefore, I decided to split apart the two languages (Spanish and English) by placing each one on a separate line (Figure 4.5) based upon the concept that scaffolding is task-oriented.

Figure 4.5 Model illustration

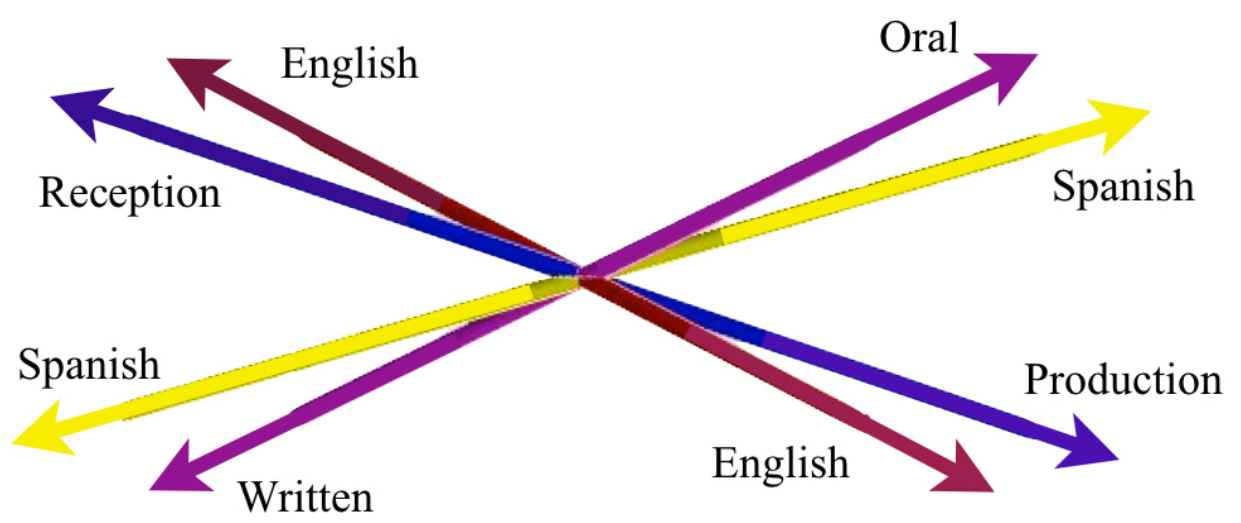

Adding a Line: Split English and Spanish 
Then, I went another step further and separated the lines for oral and written tasks and created zones for production and reception divided where the intersecting lines meet in the middle (Figure 4.6).

Figure 4.6 Model illustration

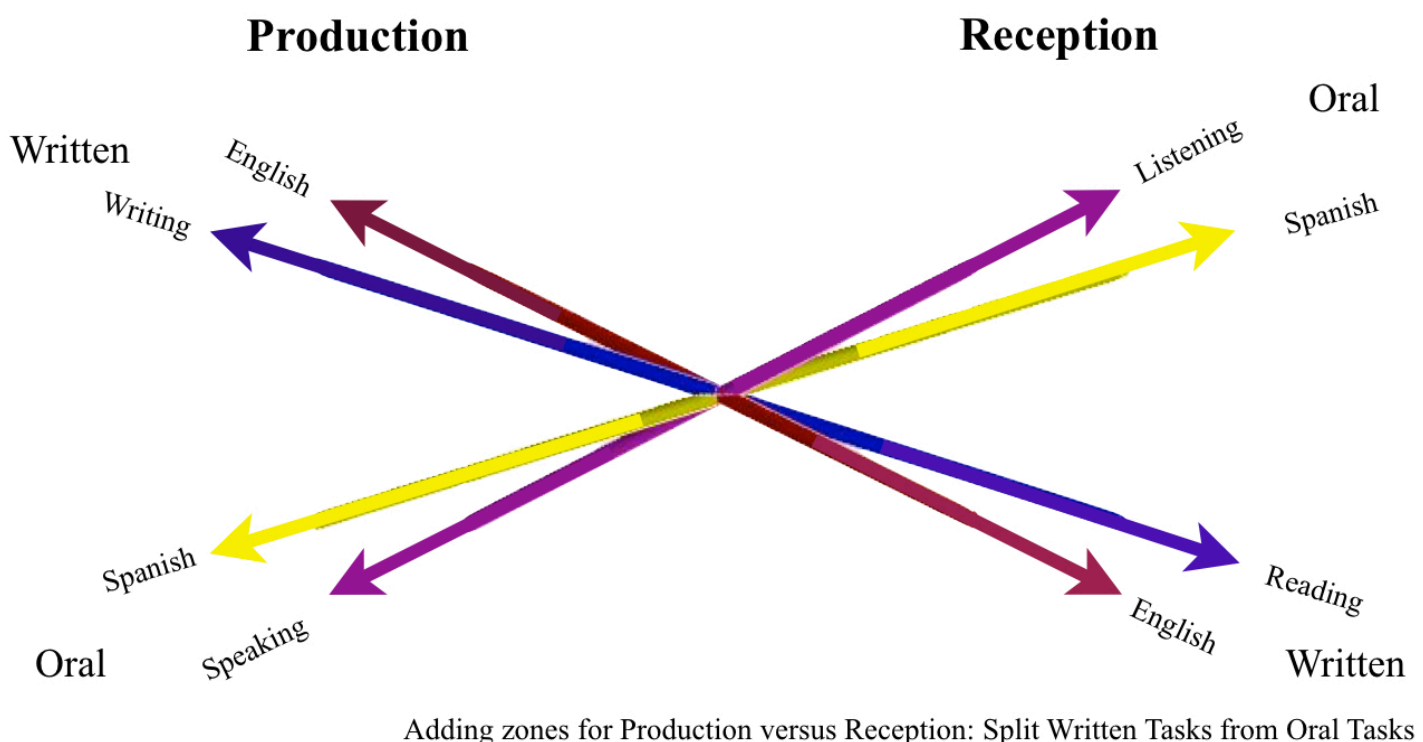

The rationale for this is to move the discussion of what the student is able to accomplish with assistance to more concrete terms. Is the student trying to say something in Spanish to express an idea? Is the student trying to read a text and understand? Is the student trying to write and express themselves in English? What if the student simultaneously is listening to the teacher question in Spanish and using that information to interpret text in English based upon what she says?

\section{New visual model emerges: Scaffolding Episodes in the Development of}

Biliteracy. Therefore, I made the decision inspired by that portion of Hornberger's model to enhance and expand elements of that visual for the purposes of this specific project. This new visual model is particularly helpful for building understandings of where / when 
the teacher scaffolds for the student to accomplish a specific task. I do agree with Hornberger and other researchers who write that these skills, oral and written, receptive and productive are deeply interwoven characteristics of language and cognition in the student's individual biliteracy practices. However, this new graphic, that I call Scaffolding Episodes in the Development of Biliteracy (Figure 4.7), is motivated by the necessity to describe the application of the scaffold in the ZPD.

Figure 4.7 Model illustration

\section{Production}

Reception

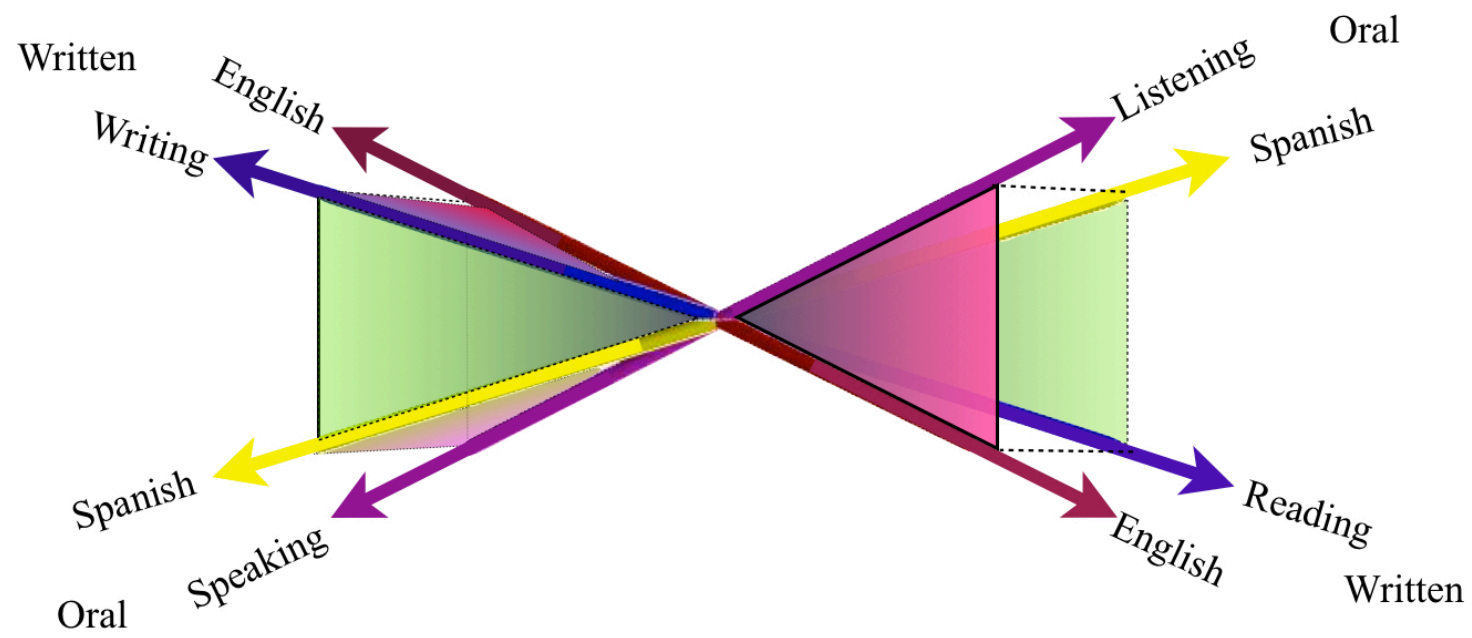

Scaffolding Episodes in the Development of Biliteracy

Through its use I seek to allow visual representations of where the assistance is situated relative to the student's work in that moment. This visual does not negate in any way the deeply intertwined nature of a whole host of variables. Therefore, this model maintains the interconnected nature of intersecting lines that create a third dimension.

In order to address the issue of this intertwined nature of language, you can see in this illustration that the planes on each face reflect a specific skill, for example, reading in 
Spanish or listening in English. However, in this model there is a three dimensional space that exists between these planes within the pyramid that represents the processing that occurs and moves freely between these two languages. Additionally, it mimics Hornberger's continua of Oral and Written language and Receptive and Productive skills, though in this model they are separated for a specific purpose into a more binary, but interconnected format, for a specific, task-oriented purpose.

If the teacher were to intervene to assist the student, or to scaffold information about the reading, using Hornberger's illustration it would be difficult to visually reflect when and where this scaffold occurs. Through this new model, "Scaffolding Episodes in the Development of Biliteracy," the intersecting planes can be marked to represent when the teacher intercedes or assists student work with a scaffold. Regardless of whether the student reads, writes, speaks or listens with assistance and in what language can be reflected by visual cues in this model. Within the third dimension of each pyramid created by the intersecting planes, (also demonstrating the interconnectedness between communicative modes) processing and knowledge moves fluidly from one language to the other within the episode. For example, if the teacher or peer scaffold assists the student with a reading task in Spanish, it could be indicated in this way and marked with a puzzle piece as in Figure 4.8. 
Figure 4.8 Model illustration

Production

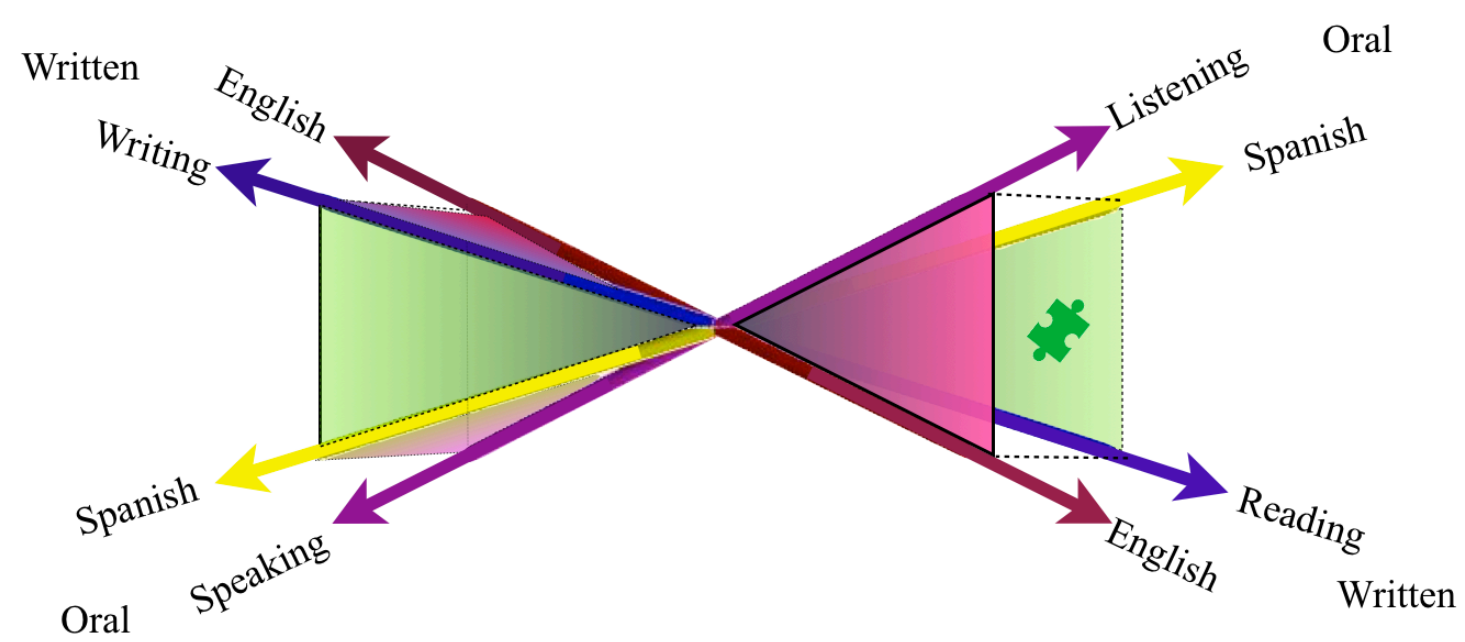

Scaffolding Episodes in the Development of Biliteracy Task: Spanish Reading

Shrum and Glisan (2016, p. 25) attribute the puzzle as metaphor for the zone of proximal development to a presentation by Adair-Hauck in 1995. The puzzle analogy is an effective one as both the student and the mentor provide essential components to the accomplishment of the task.

What is helpful about this model of my design, is that if the teacher scaffolds understanding of text in Spanish and English, it can also be reflected on separate planes (Reading in Spanish, Reading in English, Listening in Spanish or Listening in English), while maintaining this sense of interconnectedness of these facets of language in use. This graphic was designed to also mimic understanding in the second language field of both the interconnectedness and the distinct differences between reception and production. Krashen's (1982) original research called the "Input Hypothesis" was criticized for its limited focus upon input processing, while Swain's research (1985) 
continued to expand understanding of output (production) in the L2. For the purposes of this study, it is helpful to separate the two for the sake of simplicity in showing where the teacher's scaffold seeks to intercede. Does the teacher wish to assist the student in his or her understanding of text (receptive skill)? Or, does the teacher wish to assist the student with his or her ability to describe what he or she wants to write or say (productive skill)? The rationale behind this separation in the new model is in response to the writings of Broner and Tedick (2011), who expressed concerns about studies that demonstrate lower proficiency rates in the productive skill versus the receptive skill outcomes for students in one-way immersion programs (p. 166). While their mixed-method case study investigated the student language choice in classroom interactions, my study investigates the role of the teacher in providing support in these two phases in the form of scaffolding.

This visual representation can also be useful for educators in the classroom. It can assist teachers in self-reflection about pre-planned scaffolds and where one's own teaching strategies could be enhanced to better serve the objectives of the literacy activity and the students. It is my hope that teachers will use this model to consider the ways they assist students in the reception phase versus the production phase. As the research indicates, it is possible that within language immersion schools in particular, the students production of language requires further attention (Bernhardt, 1992). Additionally, the biliteracy label is motivated by the definition of this term in (Hornberger 2004) as I strive through this model to create visual representations of the development of the individual in biliteracy that can be utilized to relate to more than one text type, genre, topic, subject, and language with a focus upon the task that the student is accomplishing with assistance. 
Scaffolding with intentions and means. Tharp and Gallimore (1988) separate the intentions (the why's) of scaffolding versus the means (methods of delivery) of scaffolds. In describing the scaffolding episodes in the classroom of study, I include notations about why and how the scaffolds occurred. However, I am not bound exclusively by the terminologies used by any one particular researcher. As explained the methodologies section, this project generated 215 unique codes that have been broken down into themes. These themes may include terms known throughout the literature for clarity's sake, but there are others that were generated purely by the interactions within the bounded case.

Visual support in the production phase. Throughout the course of weeks of observation, it was clear that Profesora Nuria employed several visually-oriented techniques to scaffold student literacy skill development. Some of these pre-planned scaffolds served to support student production of language. Some of the intentions of these scaffolds were explicitly available through written objectives on the board. A routine part of Profesora Nuria's procedure every day at the beginning of each class, was to note on the board a lesson objective. These objectives were usually based upon the Common Core statements. In this section I will seek to offer a variety of examples that show not only the integration and use of these pre-planned visual scaffolds for production, but the techniques the teacher used to move the students toward appropriation and independence in literacy-oriented tasks.

While participating in the study, Profesora Nuria provided initial explicit instructions to students concerning the following objective in Spanish: students will be able to summarize a short story. Profesora Nuria has also described how she initiated the 
lesson about creating a story summary framed through a relatable real-life scenario and graphic organizers. She described the process in our pre-observation interview in this way,

Even before I teach we'll do some anchor charts and kind of talk give them an introduction about how to do some sort of things for example, summary we talked about how to give a how many of you have a hard time summarizing without giving all of the details of the story? Then they all raise their hand and I raise my hand too. And I tell them, "Don't ever ask me to tell you what a movie is about... because I'll tell you all about everything from the beginning to the middle to the end." And so, we did like a little anchor chart. Okay. I think I have to remember the character and then, finally and so those are like the five things I want to see when they are summarizing their books, for example. (Interview, September, 14, 2017)

Through this description, one can understand that the teacher has built the lesson around an explicit objective, but with real-life examples (describing a movie) and building a "chart" together. As the teacher and students discussed the summary process, they created a wall poster with guiding questions. This wall poster contained the following

Figure 4.9 Classroom photograph: Wall poster, Resumir (Summarize) information and guiding questions:

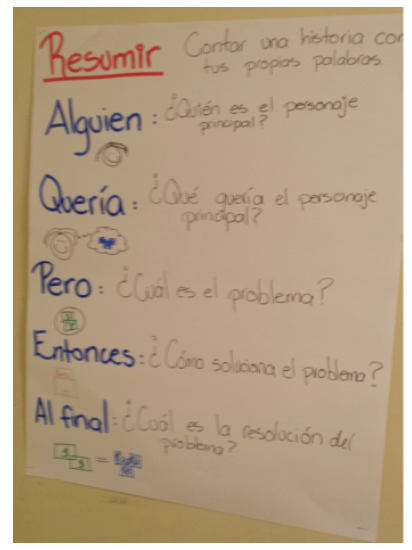




\begin{tabular}{l|l}
\hline Original Text & Translation to English \\
\hline Resumir Contar una historia & Summarize Tell a story in \\
con tus propias palabras & your own words \\
Alguien: ¿Quién es el & Someone: Who is the main \\
personaje principal? & character? \\
Quería: ¿Qué quería el & Wanted: What did the main \\
personaje principal? & character want? \\
Pero: ¿Cuál es el problema? & But: What is the problem? \\
Entonces: ¿Cómo soluciona el & Then: How is the problem \\
problema? & resolved? \\
Al final: ¿Cuál es la & At the end: What is the \\
resolución del problema? & ultimate resolution to the \\
& problem? \\
\hline
\end{tabular}

On subsequent days, she employed a variety of strategies to move the students towards independence. One should keep in mind that writing a summary of a story requires the interaction of at least two operations in our visual model - reading in Spanish, and writing in Spanish (Figure 4.10).

Figure 4.10 Model illustration

Production

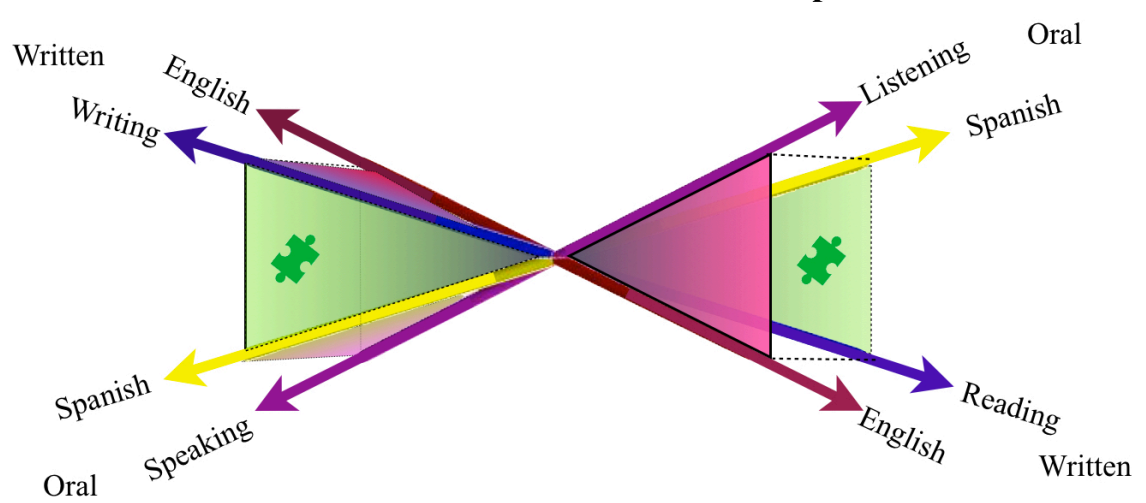

Scaffolding Episodes in the Development of Biliteracy

Task: Spanish Reading and Spanish Writing 
As indicated on the model, Scaffolding Episodes in the Continua of Biliteracy, the task of summarizing requires interpretation of text (in this case, Spanish reading), and production of text (in this case, writing in Spanish). These two areas of scaffold are both indicated by puzzle pieces on the graphic. Beeman and Urow (2013) in their practitioner text emphasize that once a literacy skill such as this, summarizing, is taught in one language (Spanish), it should transfer to the other language (English). One of the observed continuing scaffolds employed by Profesora Nuria included a combination of kinesthetic and word cues to remember the steps to write the summary. She gestured (as if counting) and used her five fingers while repeating each word indicated in blue on the poster, "Alguien, Quería, Pero, Entonces, Al final" (Someone, Wanted, But, Then, In the end). She asked the students to do this with her.

Table 4.10 Transcript excerpt: Use your five fingers

\begin{tabular}{l|l}
\hline Original Transcript & Translation to English \\
\hline Profesora Nuria: Recuerden que & Profesora Nuria: Remember that you \\
pueden usar sus cinco dedos-- & can use your five fingers. \\
Terrell: What are those? & Terrell: What are those? \\
Prof A: Alguien, quería, pero, & Prof: Someone, wanted, but, then, in \\
entonces, al final. & the end. Various students: Someone, \\
Varios: Alguien quería pero entonces & wanted, but, then, in the end. \\
$\begin{array}{l}\text { al final. } \\
\text { Terrell: Oh yeah, I remember that. }\end{array}$ & Terrell: Oh yeah, I remember that. \\
\hline
\end{tabular}


She used these statements, "pueden usar sus cinco dedos" (you can use your five fingers) to assist students in remembering the steps to writing a summary based upon their mutually constructed document. In this conversation excerpt, one can see that Terrell engages with the teacher's instructions, asking for clarification, "What are those?" The teacher clarifies the steps in Spanish for Terrell. Although his next response continues to be in English, he acknowledges understanding of the teacher's instructions by saying, "Oh, yeah, I remember that." On other days, she would occasionally gesture towards the poster when individual students needed a reminder of the steps in the process. She asked students to write a story summary within small groups and she walked around the room to check on their progress. Also, as a formative assessment, she asked students to individually re-read a story they had read a few weeks prior and write a summary about "Las ranitas en la nata" ("The frogs in the cream").

Other confirming data also included an audio recording of small group discussion that demonstrated that while some individual students had already appropriated the ability to summarize a story independently, while others were not yet capable of doing so. The conversation took place within a small group that was asked to collaboratively create a summary about "El nacimento de las tortugas" (The birth of the turtles). This was a short story about a girl who went with her family to observe sea turtles hatching on a beach. In this segment, I focus in upon the participation patterns of Ahmose in the small group. 
Table 4.11 Transcript excerpt: You are going to write a summary together

\begin{tabular}{|c|c|c|}
\hline Original Transcript & Translation to English & codes / notes \\
\hline $\begin{array}{l}\text { Profesora Nuria: Juntos van a } \\
\text { escribir un resumen. } \\
\text { (Another student asks about the } \\
\text { main idea.) }\end{array}$ & $\begin{array}{l}\text { Profesora Nuria: You are } \\
\text { going to write a summary } \\
\text { together. }\end{array}$ & instructions \\
\hline $\begin{array}{l}\text { Ahmose: Here is the punch line. } \\
\text { Hey. (Begins talking about Harry } \\
\text { Potter.) }\end{array}$ & & off-task \\
\hline Ahmose: Mini story. I don't have & & self-talk \\
\hline $\begin{array}{l}\text { five. Whenever I do this, I crack } \\
\text { my neck. }\end{array}$ & & off task \\
\hline $\begin{array}{l}\text { Astrid: Okay. Amanda wanted to } \\
\text { see the turtles. }\end{array}$ & & peer scaffold \\
\hline $\begin{array}{l}\text { Ahmose: Can you write this in } \\
\text { Spanish or in English? }\end{array}$ & & Q: clarification \\
\hline $\begin{array}{l}\text { Profesora: En español. } \\
\text { Ahmose: Truth or dare? I dare you } \\
\text { to memorize the dictionary. }\end{array}$ & Profesora: In Spanish. & $\begin{array}{l}\text { A: clarification } \\
\text { off task }\end{array}$ \\
\hline $\begin{array}{l}\text { Astrid: Oh, there's a poem about } \\
\text { that. }\end{array}$ & & off task \\
\hline (Another student who sounds & & Q: task- \\
\hline $\begin{array}{l}\text { panicked asks Ahmose if he is } \\
\text { ready to read a summary. Ahmose } \\
\text { does not respond directly to this }\end{array}$ & & oriented \\
\hline question, and begins talking about & & off task \\
\hline burping. The other student tries & & Q: task- \\
\hline $\begin{array}{l}\text { again and asks Ahmose what he has } \\
\text { written down so far.) }\end{array}$ & & oriented \\
\hline
\end{tabular}




\begin{tabular}{l|l|l}
\hline $\begin{array}{l}\text { Ahmose: Tortugas. } \\
\text { (Another student is heard asking } \\
\text { faintly in the background what else } \\
\text { they should write just as the teacher } \\
\text { announces it is time to share what } \\
\text { they have written.) }\end{array}$ & & $\begin{array}{l}\text { A: one word } \\
\text { Q: task- } \\
\text { oriented }\end{array}$ \\
\end{tabular}

Based upon this conversation, I noted that Ahmose was primarily off-task. He talked about burping, Harry Potter, the dictionary, and his neck, and did not address the questions of his classmates in the small group. However, at one point he does say the phrases, "Mini story. I don't have five." It is not entirely clear on the audio recording if he is talking to a classmate or himself. (This is where a video recording might have provided greater range of information.) It does seem that he is talking to himself at this point, as he is whispering. Interestingly, Vygotsky himself (1978) wrote about the importance of self talk in the development of language skills, describing this as a phase that demonstrates when individuals process information.

Later, I listened with surprise to the audio recording of what happened when the teacher asked the students to report back to the class what they had written. Ahmose was one of the first students to volunteer to share his summary. The words below are his exact words (including syntactical errors) transcribed from the recording.

Table 4.12 Transcript excerpt: Ahmose provides a summary

\begin{tabular}{l|l|l}
\hline Original transcript & Translation to English & codes / notes \\
\hline Ahmose: Amanda se estaba & Ahmose: Amanda was waiting & Someone \\
esperando para los nacimientos de & herself for the births of the turtles. & \\
las tortugas. Su hermano era dicho & Her brother was said that the & Wanted \\
que las tortugas nacían cerca del & turtles were born near the ocean. & \\
océano. Cuando los tortuguitas & When the turtles were born they & \\
\hline
\end{tabular}


nacian se marchan hasta la océano.

Los pájaros se atacan las

tortuguitas. Muchos murió, pero

otros sobrevivian. Esto hace a

Amanda muy triste. Cuando

Amanda se fui a su casa y su papá

se explica que esa era su vida.

\begin{tabular}{l|l}
$\begin{array}{l}\text { walked toward the ocean. The } \\
\text { birds attack the little turtles. Many } \\
\text { died but others were surviving. }\end{array}$ & But \\
That makes Amanda very sad. \\
$\begin{array}{l}\text { When Amanda I left for her house } \\
\text { and her father explained that this } \\
\text { was life. }\end{array}$ & At the end \\
\hline
\end{tabular}

While there are errors of syntax that can be noted, particularly in the area of verb tense and agreement, this summary demonstrates that Ahmose is clearly capable of communicating the points described in the poster. He focuses upon who the main character is, what problems emerge, and how those problems are resolved within the story. This recording was of particular interest, as Ahmose did not use the scaffold of collaborative peer work provided by the teacher, and yet successfully completed the task. One can note that he did not integrate Astrid's starter sentence, "Amanda wanted to see the turtles." Ahmose's answer was an oral response, apparently not written down (at least not in its entirety) based upon the queries from his classmates who were sitting next to him. The other students in the small group were left distracted as evidenced by Astrid's uptake of his conversational thread about dictionary memorization.

Additionally, other group members did not receive any assistance from him as he crafted his own response, and were heard asking what to do, receiving only jokes and one-word answers. His classmates did not benefit from his knowledge or skills, nor did they work collaboratively on this task without his participation. These examples are interesting, as they illustrate that opportunities for peer scaffolds and exploratory talk (Barnes, 1992, p.6) do not always work as intended by the teacher. Additionally, they demonstrate that the knowledge and proficiency of students are not always visible through collaboration. 
With regards to the writing of summaries, Profesora Nuria also provided some individualized visual scaffolds as a means of differentiated instruction to assist Snowy. Snowy is a student who is on the autism spectrum. He is occasionally pulled out of Profesora Nuria's class for specialized instruction. However, he is generally in the fifth grade classroom and is involved in all other activities. At times he struggled with comprehension of text. When he returned to the classroom, Profesora Nuria selected other students to provide peer scaffolds to re-integrate him into the current class activity. He was gone while the class read, "El Nacimiento de las tortugas" (The birth of the turtles) story, and arrived at the point at which everyone else was already in small groups to write the summary. Profesora Nuria asked him to sit with Tessa for this activity and these were her instructions:

Table 4.13 Transcript excerpt: Snowy, since you were not here

\begin{tabular}{l|l}
\hline Original transcript & Translation to English \\
\hline $\begin{array}{l}\text { Profesora Nuria: Snowy, tú como no } \\
\text { estabas aquí con nosotros, mi amor, no }\end{array}$ & Profesora Nuria: Snowy, since you were \\
pudiste leer la lectura. Tal vez Tessa, si & not read the text. So, Tessa, if you want, \\
quieres, contarle a él sobre la historia. Y & tell him about the story. And you \\
tú le puedes ayudar a ella con ideas sobre & (Snowy) can help her with ideas regarding \\
lo que tú piensas que puede ser la idea & what you think could be the main idea and \\
principal, o como tú te sientes sobre la & how you feel about the story. Okay? \\
historia, ¿okay? &
\end{tabular}

As one can see from the above transcript example, the teacher welcomes the student back, acknowledges the potential problem, and offers directions for the participation of 
Tessa as mentor and Snowy as active participant. This use of peer scaffolding allowed the teacher to continue to circulate around the classroom to assist others, while providing Tessa an opportunity to act as mentor. The last portion of this particular exchange that we hear from the teacher's lapel microphone is Tessa immediately addressing Snowy, saying "So do you want to look in the story to see--?" As mentioned previously, the supportive nature of this community of practice is a continuous thread demonstrated by numerous examples. In this situation, the peer scaffolds have the potential to emerge in a variety of areas. Unfortunately, I do not have a recording of the interactions between Snowy and Tessa in this conversation. However, there are potential interactions that could be described through the visual model in Figure 4.11.

For example, if Tessa began to describe information from the text, showing Snowy features on the page, her work could present scaffolds in the area of Spanish reading. His listening to her description could be supported by scaffolding if he asked her to repeat or clarify an idea. If he gave Tessa descriptions of his feelings about the text in Spanish, as requested by the teacher, Tessa's writing process and inquiries for clarification of his viewpoint could constitute oral Spanish scaffolds.

Figure 4.11 Model illustration

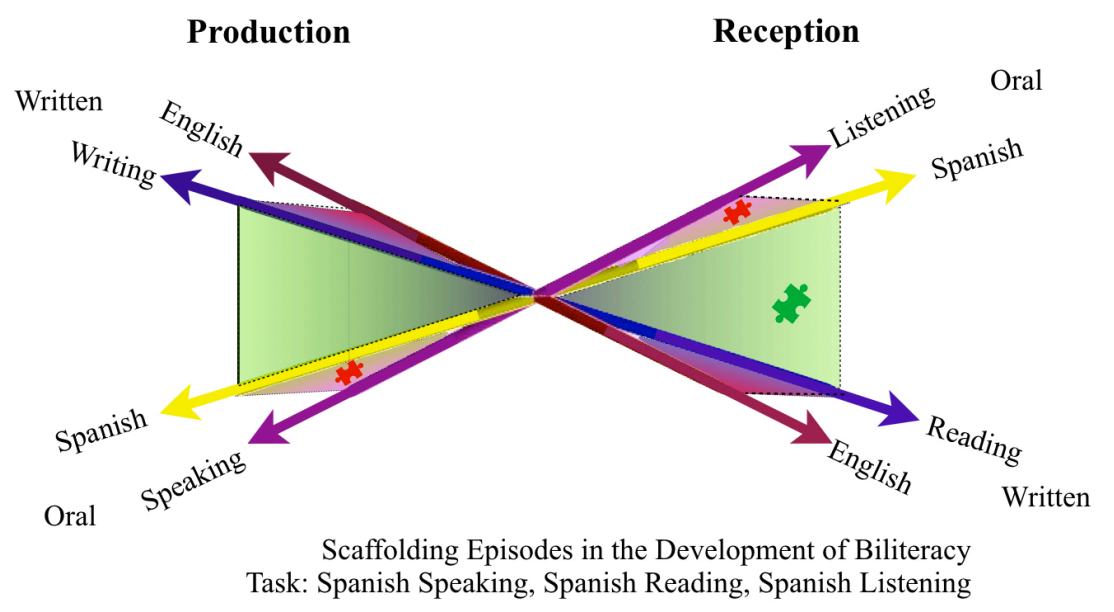


On a different date, when it was time to write for the formative assessment, Profesora Nuria approached Snowy to guide him through the exam format personally page by page, while pointing to key elements in the instructions. This pointing assisted Snowy with focusing on key elements of the assigned text. (While doing so, she also made a general announcement loudly to the rest of the class based upon the collective need for clarification.) This is the conversation that took place:

Table 4.14 Snowy, you will answer this

\begin{tabular}{|c|c|}
\hline Original transcript & Translation to English \\
\hline $\begin{array}{l}\text { Profesora N: (En voz baja.) You'll } \\
\text { answer this. Snowy, ¿te acuerdas? Lee } \\
\text { esto y ponme las respuestas aquí. } \\
\text { (En voz alta al resto de la clase.) Tercera } \\
\text { y última vez, ya leímos “Las ranitas de } \\
\text { nata”' juntos en la clase. No es necesario } \\
\text { que volvimos a decir. } \\
\text { (En voz baja a Snowy.) Okay. Tienes que } \\
\text { leer esa lectura, y contestar estas } \\
\text { preguntas. Okay? (Snowy indica si.) Y } \\
\text { después, pasando a leer esta y haciendo } \\
\text { un resumen. }\end{array}$ & $\begin{array}{l}\text { Profesora N: (Whispering.) You'll answer } \\
\text { this. Snowy, do you remember? Read this } \\
\text { and put the answers here. } \\
\text { (Loudly and to the rest of the class.) Third } \\
\text { and last time, yes, we already read "The } \\
\text { frogs in the cream" together in class. It is } \\
\text { not necessary to keep repeating this. } \\
\text { (Whispering again to Snowy.) Okay. You } \\
\text { have to read this text and answer these } \\
\text { questions. Okay? (Student nods.) And } \\
\text { afterwards, go on to read this and write a } \\
\text { summary. }\end{array}$ \\
\hline
\end{tabular}

In this example, she provides the necessary individual scaffolding for Snowy to focus in upon each portion of the assigned task. As Snowy is a student with autism, this is an important step to assist in his successful completion of the assignment. The announcement to the class demonstrates the teacher's acknowledgement of student conversations and repeated requests for clarification about the instructions on the assessment that included reading a story that they had read a few weeks previous. 
Profesora Nuria acknowledged in one of her aside comments that the assessment design of including at least one portion from a previous reading was a decision made in consultation with Profesor Roberto. This design was to promote feelings of confidence upon the part of the students, and to provide oral scaffolds through class discussions for these written assessments. The poster with guiding steps for crafting a summary was still visible on the wall as the students took the assessment, although the teacher did not mention it to them at the time. After students turned in their formative assessments, I asked her what she would do next to provide feedback to students and later, more specifically, how the assignment would be graded.

Table 4.15 Transcript excerpt: I love it when you use the five (steps)

\begin{tabular}{|c|c|}
\hline Original transcript & Translation to English \\
\hline $\begin{array}{l}\text { Me encanta cuando utilicen los cinco... } \\
\text { así lo aprendimos ... de cómo que me } \\
\text { pongan detalles, esto lo que quiero. } \\
\text { Siempre pongo "Me encanta como } \\
\text { utilizaste los cinco pasos de resumir que } \\
\text { utilizamos en clase. Me encantan los } \\
\text { detalles específicos que ...” o } \\
\text { especialmente cuando usen evidencia del } \\
\text { texto para defender su resumen'. Si me } \\
\text { escriben tal vez ... un resumen muy vago } \\
\text { - digo debería usar un poco más de } \\
\text { detalles un poco más... } \\
\text { Y la calificación para resumen es de } \\
\text { cinco puntos... lo que mencionan de quién } \\
\text { hablan, de qué quieren, cómo resolverlo, }\end{array}$ & $\begin{array}{l}\text { I love when they use the five... as we } \\
\text { learned it... and how they include details, } \\
\text { this is what I want. I always put "I love } \\
\text { how you used the five steps to summarize } \\
\text { that we use in class. I love these specific } \\
\text { details that..." or especially when they } \\
\text { use evidence from the text to defend their } \\
\text { summary. If they write for me, for } \\
\text { example, a summary that's very vague, I } \\
\text { say he or she should use a few more } \\
\text { details more often. } \\
\text { And the grading for the summary is out } \\
\text { of five points. Those that mention who it } \\
\text { is about, what they want, how to resolve it } \\
\text { and what happens at the end (gestures to }\end{array}$ \\
\hline
\end{tabular}




\begin{tabular}{l|l}
\hline $\begin{array}{l}\text { lo que pasó al final (gestures towards the } \\
\text { Wall poster). Si no me mencionan las }\end{array}$ & $\begin{array}{l}\text { the wall poster). If they don't mention the } \\
\text { characters to me, I take away a point. } \\
\text { personajes, quito un punto. Cosas así. }\end{array}$ \\
\hline
\end{tabular}

Based upon these comments, it is clear that Profesora Nuria selects positive and encouraging terms in her feedback as well, as evidenced by the phrasing "Me encanta como..." (I love how you...), to praise the student adoption of the summary steps they had practiced in class. She reinforces the use of reading strategies (Mokhtari and Reichard, 2002, p. 259), including the use of evidence from the text. She directly addresses the content of the student writings, rather than the grammatical features. Semke (1984) wrote about the importance of teacher feedback in the form of encouragement and commentary on content in L2 writings. Semke's study in particular noted the effectiveness of these two strategies in improving future writing achievement and student attitudes toward writing (p. 201). In all of the above examples in this section, Profesora Nuria's desires for explicit instructions, clarity, and organization are expressed through the use of visual support in student writing and subsequent feedback loops.

Visual support in the reception phase. As previously stated, Profesora Nuria employed the strategy of writing the lesson objective on the board on a regular basis. Throughout the observed classes, vocabulary emerged as one of the primary challenges for the students. This was noted by Profesora Nuria herself who said in an interview on October 6, 2017 that "vocabulary" was the greatest challenge. One way that she tried to bridge the vocabulary gap was through the use of pre-planned visual support. This form of support was employed within both the content area (science) and the lenguaje (Spanish language arts) class to support the domain of animal vocabulary. 
In the content area. For example, the students were provided with an assignment to illustrate and create their own food webs in pairs for two different ecosystems. The instructions for this assignment were in Spanish and included a list of animal and plant names that could be integrated into these food webs. The animal and plant relationships reflected within the sentences are in a random order. This is a portion of the assignment page text:

Table 4.16 Assignment description: Create a food web for the tropical rainforest

\begin{tabular}{|c|c|}
\hline Original Text & Translation to English \\
\hline Bosque Lluvioso & Rain Forest \\
\hline Red Alimentaria & Food Web \\
\hline $\begin{array}{c}\text { Instrucciones: Haga una red alimentaria } \\
\text { utilizando las siguientes afirmaciones. }\end{array}$ & $\begin{array}{l}\text { Instructions: Make a food web using the } \\
\text { following statements. }\end{array}$ \\
\hline $\begin{array}{l}\text { - Plátanos (árbol de musa acuminate) son } \\
\text { comidos por tapires, guacamayo, monos } \\
\text { araña y hojas-Katydids }\end{array}$ & $\begin{array}{l}\text { - Bananas (tree) are eaten by tapirs, parrots, } \\
\text { spider monkeys and Katydids. }\end{array}$ \\
\hline $\begin{array}{l}\text { - Los guacamayos son comidos por águilas de } \\
\text { alcón }\end{array}$ & - The parrots are eaten by eagles and falcons. \\
\hline $\begin{array}{l}\text { - Cocos (árbol de los cocos nucifera) son } \\
\text { comidos por los monos araña }\end{array}$ & - Coconuts are eaten by spider monkeys. \\
\hline - Monos araña son comidos por los jaguars & - Spider monkeys are eaten by jaguars. \\
\hline $\begin{array}{l}\text { - Los granos de cacao (planta de teobroma } \\
\text { cacao) son comidos por monos araña y } \\
\text { planeador de azúcar }\end{array}$ & $\begin{array}{l}\text { - Cacao seeds are eaten by spider monkeys } \\
\text { and sugar gliders. }\end{array}$ \\
\hline - Las orquideas son comidas por las & - The orchids feed the butterflies and the \\
\hline $\begin{array}{l}\text { mariposas azules y negras y las hojas- } \\
\text { Katydids }\end{array}$ & Katydids. \\
\hline $\begin{array}{l}\text { - Las piñas (árbol de bromeliaceae) son } \\
\text { consumidas por tapires, tucanes y Mariposas } \\
\text { azules y negras }\end{array}$ & $\begin{array}{l}\text { - The pineapple plants supply food to tapirs, } \\
\text { toucans and butterflies. }\end{array}$ \\
\hline - Hoja-Katydids son comidos por Boa & - Katydids are eaten by boa constrictors and \\
\hline
\end{tabular}


Constrictors y ranas venenosas del dardo

- Los tapires son comidos por jaguars, Pumas

y Boa Constrictores

- Los tucanes son comidos por los jaguares poison tree frogs.

- The tapirs are eaten by jaguars, pumas and boa constrictors.

- The toucans are eaten by the jaguars.

Prior to starting student work upon the assignment, the teacher reminded students about the visual elements of a red alimentaria (food web) by projecting an image of an example with different animals on the interactive whiteboard. The students had previously viewed these types of food webs within the ecosystems unit, and this reminder served as a model to students who had not yet created one of their own.

Figure 4.12 Classroom photograph: Food web visual on the interactive whiteboard

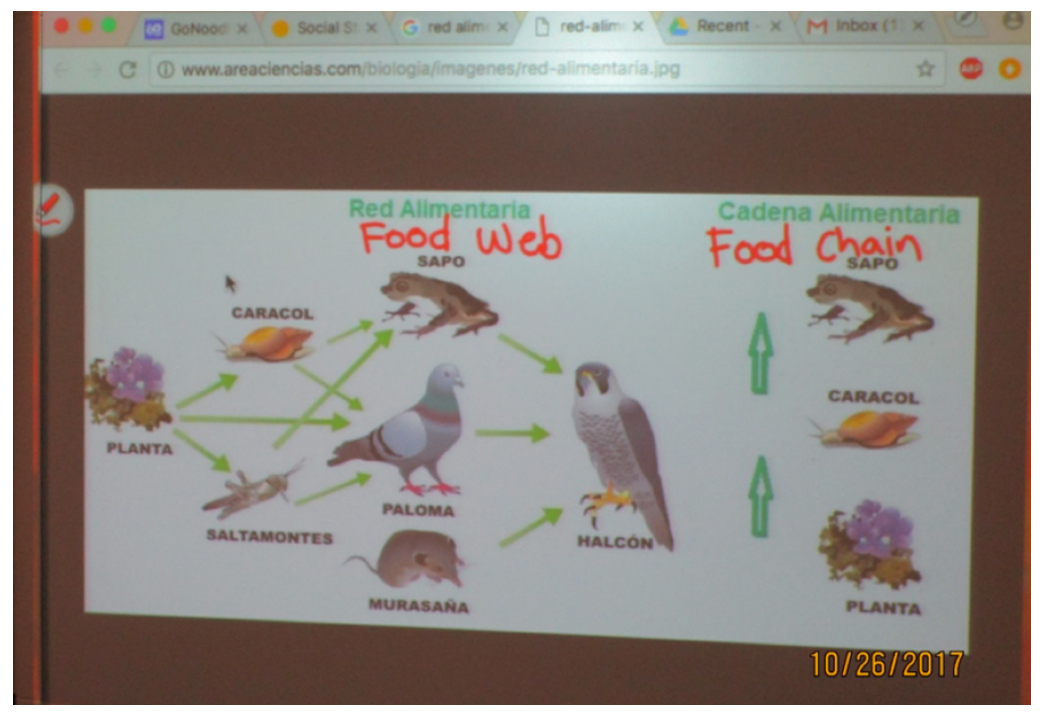

Then, she read portions of the assignment description aloud to the students. The reading aloud of phrases from the assignment description served as a multi-modal scaffold for comprehension, as the students could listen and read along with their own papers.

Spanish has a highly transparent orthography, and listening to the words can assist with understanding meaning. This creation of the Redes alimentarias (food webs) was primarily a reading comprehension task, aimed at creating visual representations of the 
interactions of plants and animals within a specific ecosystem based upon comprehension of the sentences on the handout.

Figure 4.13 Model illustration

\section{Production}

\section{Reception}

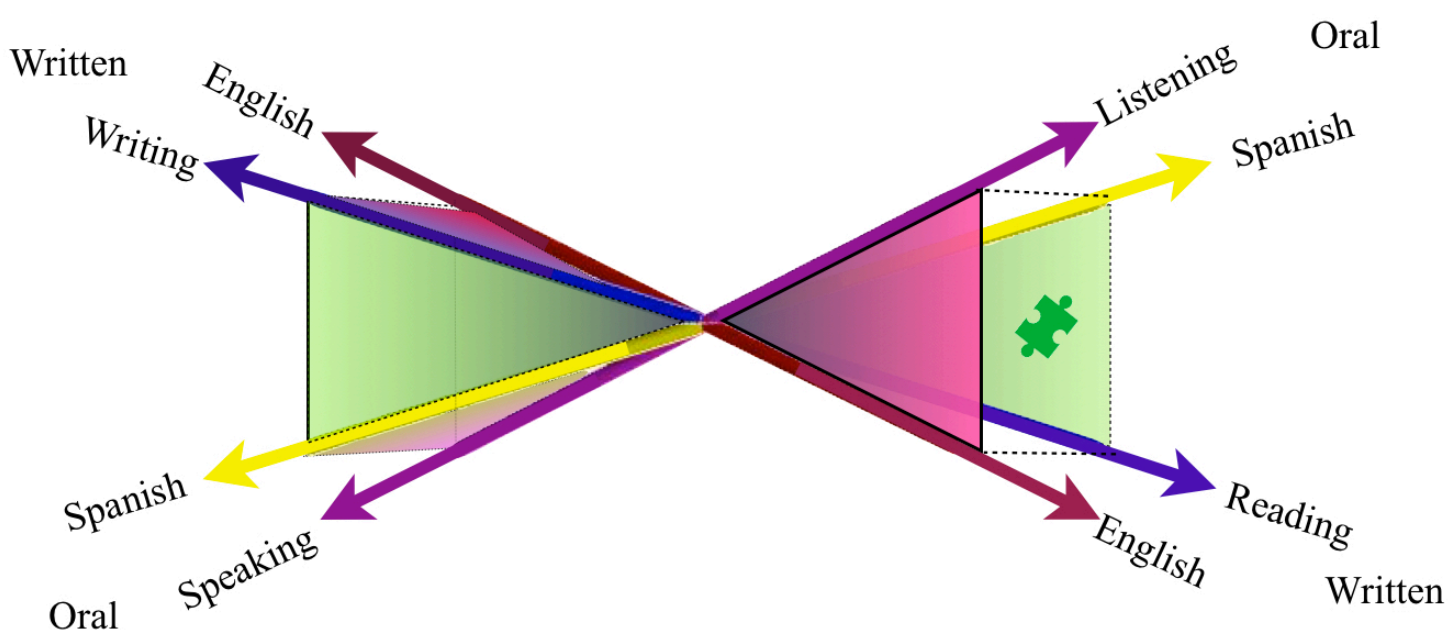

Scaffolding Episodes in the Development of Biliteracy

Task: Spanish Reading

As reflected by the model (Figure 4.13), in this activity the teacher is specifically scaffolding the reading of Spanish through the use of visuals to reinforce their responses to text. Additionally, she suggested individualized scaffolds related to previously unknown animal vocabulary. Profesora Nuria recommended that students employ $21^{\text {st }}$ Century literacy skills to assist them in reading and understanding the sentences within the assignment description. The weekly student workers passed out laptops to each pair of students working together. The teacher advised students to use Google Images to assist themselves if there were any unknown or unfamiliar animal names on the assignment description. This use of Google Images could be considered scaffolding of 
strategic competence in Spanish reading. Strategic competence is a valuable tool for learners, as it empowers them to conquer linguistic obstacles through a variety of methods. In this case, the question could be posed: what mediational means (tools) can one use to find information about animal vocabulary? Additionally, the task of using images, rather than dictionaries with text, has the potential to enhance binding (Terrell, 1986). Binding allows the language learner to directly link concept to L2 word, rather than concept to L1 to L2. The task was primarily a receptive and interpretive content area task, as the students were to read the sequence of sentences in Spanish about different components of the ecosystem and then illustrate the connections between the animals and plants and label them. This use of Google Images served as a scaffold to bridge vocabulary gaps in the domain of plants and animals. Some students chose to work individually, with each person illustrating one of the ecosystems alone (tropical rain forest vs ocean). One such group consisted of Stacy and Estrella who very quietly drew separate webs while sitting next to each other. Other pairs worked collaboratively. I noted that there was only one group, in which Nikki was a participant, that took the time to create a "rough draft" on lined paper prior to illustrating the food web on the $11 \times 17$ " white papers provided by the teacher.

Unfortunately, some of the resulting visual scaffolds provided by Google Images were a bit distracting. Snowy laughed out loud when he typed in the search bar "coco" (coconut) and one of the first images to appear was a clip art image of a coconut wearing sunglasses. It should also be noted that Snowy is one of the most highly skilled artists in the class, so this activity provided him a chance to shine. Clyde and Asha searched for "jaguares" (jaguars) and exclaimed with surprise when the search resulted in a variety of 
car images mixed in with the animals. In the end, it was a successful activity and an authentic assessment of the unit of ecosystems study.

In the language class. As previously stated, the domain of animal vocabulary was also scaffolded through visual support in the lenguaje (Spanish language arts) class. The day after the Red alimenticia activity was introduced, the class reading for lenguaje was called "El Puercoespín y el invierno" (The porcupine and the winter). Even the name of this reading presents a bit of a conundrum if a non-native Spanish speaker tries to use reading strategies including root words to break down an unfamiliar word combination. Puerco usually means pork or pig, depending upon the context, and espín sounds closer to spin, although a person might be able to come up with spine. So, in the interim, a non-native Spanish speaker unfamiliar with this animal name might say to oneself, "pig...spin... spine? What's that?" The handout containing the short story did not offer any visual support in the form of pictures, so the visuals provided by the teacher created a scaffold for the Spanish reading, as indicated by the model below (Figure 4.14).

Figure 4.14 Model illustration

Production Reception

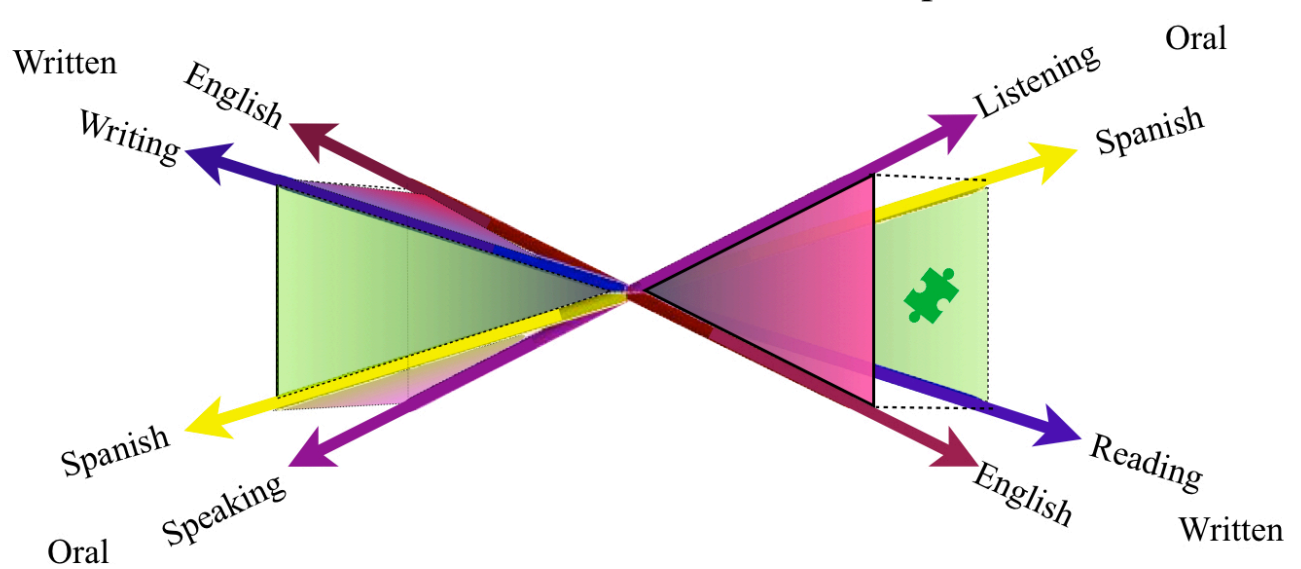

Scaffolding Episodes in the Development of Biliteracy

Task: Spanish Reading 
In anticipation of vocabulary-related questions, Profesora Nuria displayed a collage of images on the interactive whiteboard; a porcupine and a variety of winter scenes as part of a pre-reading activity. Here are portions of the discussion that unfolded:

Table 4.17 Transcript excerpt: El puercoespin (The Porcupine)

\begin{tabular}{|c|c|c|}
\hline Original transcript & translation to English & codes / notes \\
\hline Profesora Nuria: El día de hoy & Profesora Nuria: Today for & explicit \\
\hline para lenguaje vamos a leer una & Spanish language arts we are going & preparation \\
\hline lectura sobre el puercoespín en el & to read a text about the porcupine & \\
\hline invierno. & in the winter. & \\
\hline (Varios estudiantes intentan & (Various students try out the & \\
\hline pronunciar las dos palabras en & pronunciation of words in Spanish & \\
\hline español e inglés con varias formas & and English with different syllabic & \\
\hline de estrés silábico): puercoespín & stress): puercoespín porcupine & bilingual \\
\hline porcupine porcUpine PORCupine & porcUpine PORCupine & word play \\
\hline puerCOespin puercoespÍN & puerCOespin puercoespÍN & \\
\hline Tessa: I don't know my animals in & Tessa: I don't know my animals in & lexical gap \\
\hline Spanish. & Spanish. & described \\
\hline Stacy: Too hard to learn. & Stacy: Too hard to learn. & \\
\hline Prof: En la pizarra estamos viendo & Prof: On the board, we can see a & visual \\
\hline un puercoespín. & porcupine. & support \\
\hline $\begin{array}{l}\text { Tessa: Awwww. That's a } \\
\text { porcupine. }\end{array}$ & $\begin{array}{l}\text { Tessa: Awwww. That's a } \\
\text { porcupine. }\end{array}$ & pictures \\
\hline Snowy: Dang! It's that spikey! & Snowy: Dang! It's that spikey! & \\
\hline $\begin{array}{l}\text { Prof: Okay. ¿Qué significa el } \\
\text { invierno? }\end{array}$ & $\begin{array}{l}\text { Prof: Okay. What does winter } \\
\text { mean? }\end{array}$ & Q: define \\
\hline Ahmose: Um. Winter. & Ahmose: Um. Winter. & \\
\hline $\begin{array}{l}\text { Prof: Winter. Muy bien. Tengo } \\
\text { aquí algunas imágenes... ¿Qué }\end{array}$ & $\begin{array}{l}\text { Prof: Winter. Very good. I have } \\
\text { here some images. What do we }\end{array}$ & Q: describe \\
\hline
\end{tabular}


vemos?

Estrella: nieve

Nikki: hielo

Prof: Hielo, nieve, muy bien.

Estos árboles, ¿cómo se ven? No

son tan coloridos como en el

otoño.

Kishanda: secos.

Prof: Claro. No salen hojas como

en el otoño. ¿Y qué más vemos?

Jenna: It looks like it's white.

Prof: Todo está blanco. Muy bien.

Ahora que Uds. han visto estas

imágenes, ¿por qué creen que el

titulo es el puercoespin y el

invierno? ¿Qué relación hay entre

estos?

Nikki: Oooooo.

Prof: ¿Nikki?

Nikki: En algunos de los spines, los spines del puercoespín miran como los árboles.

Prof: Oooo. ¡Muy buena conexión! No había pensado en esto, de verdad. Bueno, ahora vamos a leer la lectura. see?

Estrella: snow

Nikki: ice

Prof: Ice, snow, very good. These trees, what do they look like? They

Q: describe comparison are not as colorful as in the autumn.

Kishanda: dry

Duo

Prof: Of course. The leaves do not come out like they do in the autumn. What else do we see?

Jenna: It looks like it's white.

Prof: Everything is white. Good.

Now that you all have seen these images, why do you believe that the title is the porcupine and the winter? What relationship is there between those?

Nikki: oooo

Prof: Nikki?

Nikki: In some of the spines, the spines of the porcupine look like the trees.

Prof: Oooo. Very good connection! Truly, I hadn't thought of that before. Good. Now praise we are going to read the story.

The students themselves acknowledge that animal vocabulary is a domain of challenge.

This is first noted by Tessa, the business manager, who says bluntly, "I don't know my animals in Spanish." Stacy follows this comment with, "Too hard to learn." I will note 
that while some animal names are similar to English (jaguar, león, etc.), there are many others that are difficult to decode and / or recall for their lack of similarity to English. Studies have shown regardless that even if words are cognates, students may not be able to detect and recognize them as cognates on their own (Echeverría, 2017). If we consider this question of vocabulary gap, it can be explained by some of the differences between home and school discourses. Or, as Gee (2012) describes them, primary and secondary discourses. In school, students may discuss a few animals within the range of academic discussions of ecosystems, but most animal terms are learned through the home (primary) discourses. This source of lexical information is primarily gained through readings, through activities such as going to the local zoo, or through the habitat in which they reside. The animal (a porcupine) as the subject of this lesson, is not found in the habitat of this large city. It could be seen at a local zoo. However, if the majority of these students went to the zoo with their families, all of the conversations about the animals would be in English. As noted in the student participant chart, Spanish is the home language for only four out of nineteen student participants in this study.

In this conversation, one can also understand how the teacher prepares the students for the reading, not only through support of discrete vocabulary items, but also for the setting of the story. As she discusses the setting of wintertime with the students, most answers are one word answers. Jenna and Kishanda, ever the "Inseparable Duo," take turns responding one after the other with "secos" (dry) and "it looks white." Then, Nikki, the gymnast, leaps beyond the anticipated answers to the teacher's question, making a comparison between the long spikes of the porcupine with the naked branches of trees in winter. This leaves the teacher saying, “Oooo. ¡Muy buena conexión! No 
habia pensado en esto, de verdad." (Oooo. Very good connection. Truly, I hadn’t even thought of that.)

This pre-reading activity of looking at pictures of wintertime and the porcupine provided an anticipatory set for the setting of the story. The teacher provided additional pictures of animals as they read of the castor (beaver) and the cuervo (raven) that were other characters in the story. The story itself was somewhat abstract in nature, as it was based upon a Native American myth regarding the origins of the number of months in the wintertime. The scaffold of the setting allowed students to envision the setting and to anticipate the content of the text that also contained the words, "El invierno es la estación más hermosa" ("The winter is the most beautiful season"). As the students reached this point in the text, the teacher asked them to describe their preferences about each of the seasons. As they had already discussed the winter scene, they were more prepared for this portion of the discussion.

Student requests for assistance. In virtually every observed class period, students explicitly requested assistance from the teacher. Student questions prompted the use of interactional scaffolds, those scaffolds that arise in the moment, based upon student need. Profesora Nuria acknowledged that for the most part, student comprehension of Spanish is very high, saying in 2015, "They understand [Spanish] completely. It really amazes me, because sometimes I forget that their first language is English. You know, yeah, they understand... and when they don't understand, they'll ask, 'Wait, what does that word mean?"' Patterns quickly emerged that indicated two primary sources of student questions: vocabulary and clarification of instructions. In this section, I will address the student requests for assistance with vocabulary in the reception 
and production phases. The questions seeking clarification of instructions also evoke ties back to the discussion of language ideologies as they are closely related in this case.

Vocabulary and clarification questions in production. As noted previously, only four of the nineteen student participants speak Spanish in the home. This impacts the students in a variety of ways related to language exposure. Baker (2011) wrote about the variety of considerations of language context, domain, and register and their relationships to language and literacies. In this example, Profesora Nuria begins by reminding the students prior to a writing task to write the title and date in their notebooks, and asks them to write answers for the first question set on the handout. She reads the pre-reading question set aloud, "Dice: "En los concursos de cantantes en la televisión vemos que durante la semana anterior a su actuación le dan clases de canto. ¿Creéis que esas clases son importantes?, ¿por qué o por qué no?" (It says, "In the singing competitions on television, we can see that during the week before the performance, they give them singing lessons. Do you believe these classes are important? Why or why not?) She then proceeds to scaffold instructions for Snowy individually and responds to the questions of others.

Table 4.18 Transcript excerpt: “¿Cómo se dice 'to warm up’?”

\begin{tabular}{l|l|l}
\hline Original Transcript & Translation to English & codes / notes \\
\hline Profesora Nuria: (En voz baja para & Profesora Nuria: (In a soft voice & individual \\
hablar con un estudiante & speaking to a student individually) & scaffold \\
individualmente) Okay. En tu & Okay. In your notebook you will & \\
cuaderno me escribes por qué. & write why. Okay, and here you & \\
Okay, aquí me vas a escribir "El & are going to write "The Little & \\
pequeño ruiseñor." (A todos) Y no & Mockingbird." (Speaking to & \\
se les olvide esa fecha, chicos. Eso & everyone) And don't forget the & literate \\
\hline
\end{tabular}




\begin{tabular}{|c|c|c|}
\hline tiene que ser automático. ¿Nikki? & $\begin{array}{l}\text { date, students. This needs to be } \\
\text { automatic. Nikki? }\end{array}$ & habitus \\
\hline $\begin{array}{l}\text { Nikki: ¿Necesitamos escribir la } \\
\text { pregunta? }\end{array}$ & $\begin{array}{l}\text { Nikki: Do we need to write the } \\
\text { question? }\end{array}$ & $\begin{array}{l}\text { Q: } \\
\text { clarification }\end{array}$ \\
\hline $\begin{array}{l}\text { Prof: No, no, no, la pregunta no, } \\
\text { solo la respuesta a la primera } \\
\text { pregunta. }\end{array}$ & $\begin{array}{l}\text { Prof: No, no, no, not the question, } \\
\text { just the answer to the first } \\
\text { question. }\end{array}$ & \\
\hline $\begin{array}{l}\text { Nikki: ¿Cómo se dice "to warm } \\
\text { up?" }\end{array}$ & $\begin{array}{l}\text { Nikki: How do you say "to warm } \\
\text { up?" }\end{array}$ & $\begin{array}{l}\text { Q: lexical } \\
\text { item }\end{array}$ \\
\hline Prof: Calentar. & Prof: Calentar. & A: word \\
\hline Nikki: ¿Cómo? & Nikki: What? & Q: \\
\hline Prof: Calentar. Sí, cuando jugaba & Prof: Calentar. Yes, when I used & clarification \\
\hline a fútbol yo, decíamos: "Vamos a & to play soccer, we would say, "We & A: word + \\
\hline calentar antes de jugar fútbol". & $\begin{array}{l}\text { are going to warm up before we } \\
\text { play soccer." }\end{array}$ & example \\
\hline
\end{tabular}

When asked, the teacher answers Nikki's question about what to write in the notebook. “Necesitamos escribir la pregunta?” (Do we need to write the question?) This was a lesson that took place in September, so this question both acknowledges the importance that Profesora Nuria places on the notebook as an archive of work, and seeks further information about what else she requires. Nikki then requests the Spanish expression for "to warm up." The need for this word may be related to the fact that students may not discuss the techniques of singing often in academic domains, and they have not yet read the text. The teacher provides the lexical item requested by the student in Spanish and then provides an example of its use in context. Other students asked for expressions in Spanish for these words also: "to mess up" and "rehearsal." Both of these interactional scaffolds based upon student requests for information, served to assist the students with completion of a written response to the prompt in Spanish (Figure 4.15). 
Figure 4.15 Model illustration

\section{Production}

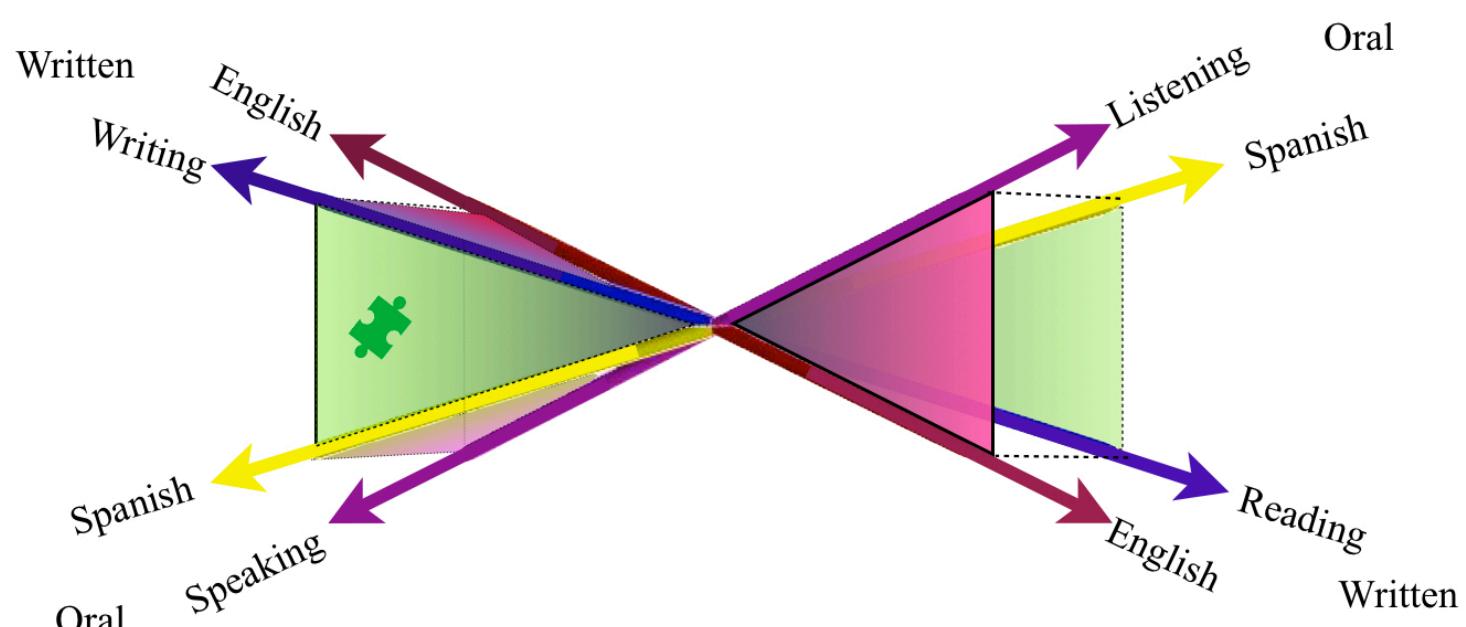

Scaffolding Episodes in the Development of Biliteracy

Task: Spanish Writing

Following the few minutes of written response time, the word calentar (to warm up) has been appropriated by several students, and used in more than one way. The Profesora Nuria noted that several students had finished writing, so she began to "collect answers" aloud from the students.

Table 4.19 Transcript excerpt: It is like a warm up

\begin{tabular}{l|l|l}
\hline Original transcript & Translation to English & codes / notes \\
\hline Profesora Nuria: Okay, veo que & Profesora Nuria: Okay. I see & Collecting \\
algunos ya hemos terminado de & that some have already finished & answers \\
contestar la pregunta. ¿Quién me & answering the question. Who & Q: opinion \\
comparte su respuesta sobre si es & will share with me their answer & connection to \\
importante o no tener esas clases & if it is important or not to have & real life \\
de canto antes de la actuación? & singing lessons before a & \\
¿Barry? & performance. Barry? & \\
Barry: Es bueno porque es como & Barry: It is good because it is a & use of \\
un calentamiento. & warm up. & different form \\
\hline
\end{tabular}


Prof: Muy bien, es bueno porque es como un calentamiento. ¿Nikki?

Nikki: Las clases sí son importantes porque ayudan a calentar su voz, y para que las personas puedan saber cómo usarla.

Prof: Muy bien. Me encanta tu respuesta, Nikki... ¿Tessa?

Tessa: Sí es importante porque tienes que calentar tu voz, y necesitas bien saber cómo usar tus voces y tienes que aprender las notas.

Prof: Me encanta, me encanta que hayas escrito todo eso en tu cuaderno y que hayas utilizado el español de esa manera.

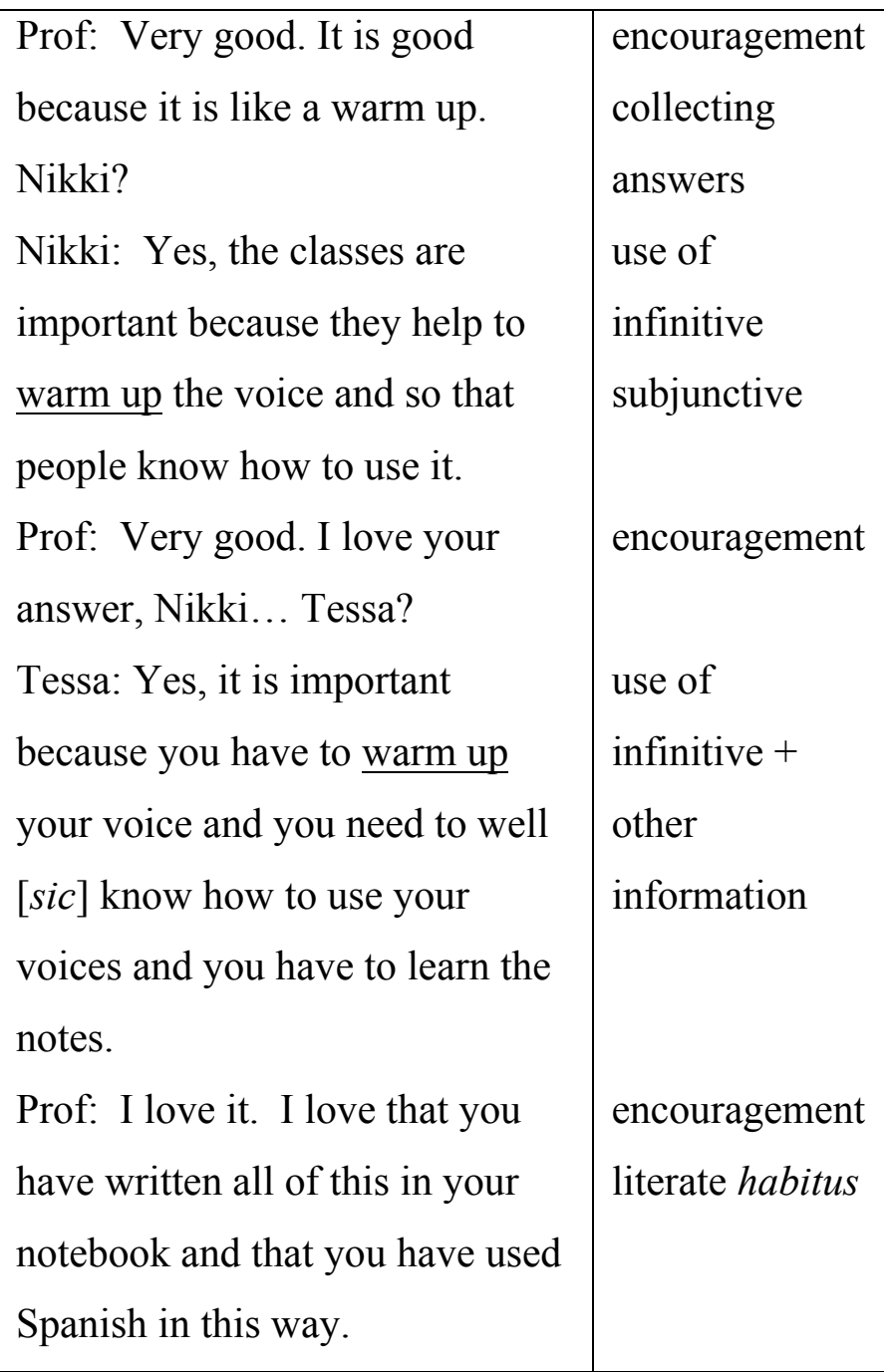

In this segment, the teacher can be seen "collecting student answers" to the original question posed in the pre-reading activity, as well as praising and encouraging the students. She praises them for not only answering the question, but also the completion of a written task in the notebooks that serve as the previously mentioned literacy archive. The interaction patterns within this classroom do generally follow the teacher's lead, as Profesora Nuria initiates the conversation, students respond, and then the teacher "evaluates" the answer with either "muy bien" (very good) or a recast. Cazden (2001) noted that most classroom interactions between teachers and students still follow these traditional IRE patterns. This is also the case in Profesora Nuria's classroom, as seen 
through this example. Regardless of interaction patterns, in this segment one of the most notable features is the way that three students have used and integrated the root word 'calentar' (to warm up) into their answers. Barry, who does speak Spanish at home, uses the noun form 'calentamiento' (a warmup), which the teacher did not say. While not the focus of this study, he may possess greater linguistic flexibility in the area of morphemes as a result of his home language use. However, Nikki and Tessa use the verb in its infinitive form, which was the one provided by the teacher. Their sentences were complex though, which indicates a high level of syntactical control. Nikki's sentence also integrates the correct use of the subjunctive, which represents one of the most challenging forms in Spanish syntax for non-native Spanish speakers (Collentine, 2010). If we compare their assessed reading levels (below), as reported by Profesora Nuria, one can observe that Nikki and Tessa receive higher scores on reading assessments than Barry. It is also notable that the teacher did not highlight nor explore the different forms of the word that she provided earlier. This is consistent with the other findings in this study. The teacher did not appear to differentiate between scaffolds (nor encouragement) provided to heritage Spanish speakers versus students from monolingual English homes. The teacher's notations about how much each student enjoys or does not enjoy reading are also of note, as Nikki and Tess display their literate habitus of 30 minutes or more per day. Researchers including Allington (2014) have made connections between quantity of reading time and assessed reading level. 
Table 4.20 Comparing student reading levels: Barry, Nikki, and Tessa

\begin{tabular}{l|l|l|l|l}
\hline $\begin{array}{l}\text { Student } \\
\text { name }\end{array}$ & $\begin{array}{l}\text { Home } \\
\text { language(s) }\end{array}$ & $\begin{array}{l}\text { Reading level } \\
\text { English (Based } \\
\text { on NWEA) }\end{array}$ & $\begin{array}{l}\text { Reading level } \\
\text { Spanish (Based } \\
\text { on American } \\
\text { Reading System } \\
\text { in Spanish, ENIL) }\end{array}$ & $\begin{array}{l}\text { Additional comments / } \\
\text { information about } \\
\text { reading practices or } \\
\text { levels, as provided by } \\
\text { Profesora Nuria }\end{array}$ \\
\hline Barry & Spanish & 2nd & Bl $\left(3^{\text {rd }}\right)$ & $\begin{array}{l}\text { Has a hard time reading } \\
\text { in either language, no } \\
\text { interest. }\end{array}$ \\
\hline Nikki & English & 9 th & An $\left(5^{\text {th }}\right)$ & $\begin{array}{l}\text { Likes to read and does } \\
\text { her 30 mins of reading at } \\
\text { home }\end{array}$ \\
\hline Tessa & English & 8 th & An $\left(5^{\text {th }}\right)$ & $\begin{array}{l}\text { Bookworm. Always is } \\
\text { reading in English }\end{array}$ \\
\hline
\end{tabular}

Vocabulary and clarification questions in reception. At times, students asked

the teacher to clarify words in the readings or questions that they did not understand.

One of the primary resources of texts for fifth grade lenguaje was Mis Lecturas de $5^{\circ}$ y $6^{o}$ (My readings for fifth and sixth), collected by Inspectores de Educación del Servicio de Sevilla (Directors of Education in Sevilla, Spain) and available online at:

http://www.ceiploreto.es/sugerencias/Comprension lectora/mis lecturas ciclo3.pdf.

However, many of the questions posed on these handouts used the vosotros (informal second person plural) form that is only used in Spain. Since Profesora Nuria is from Honduras, she does not use this form in her own patterns of language production, and many of the other teachers in the building (from various Latin American countries) do not use it either. Therefore, some of the student questions were regarding what the question says. When those questions emerged, Profesora Nuria simply repeated the question in the tú form (second person singular), and the students were usually able to interpret it and respond immediately. 
Figure 4.16 Model illustration

Production

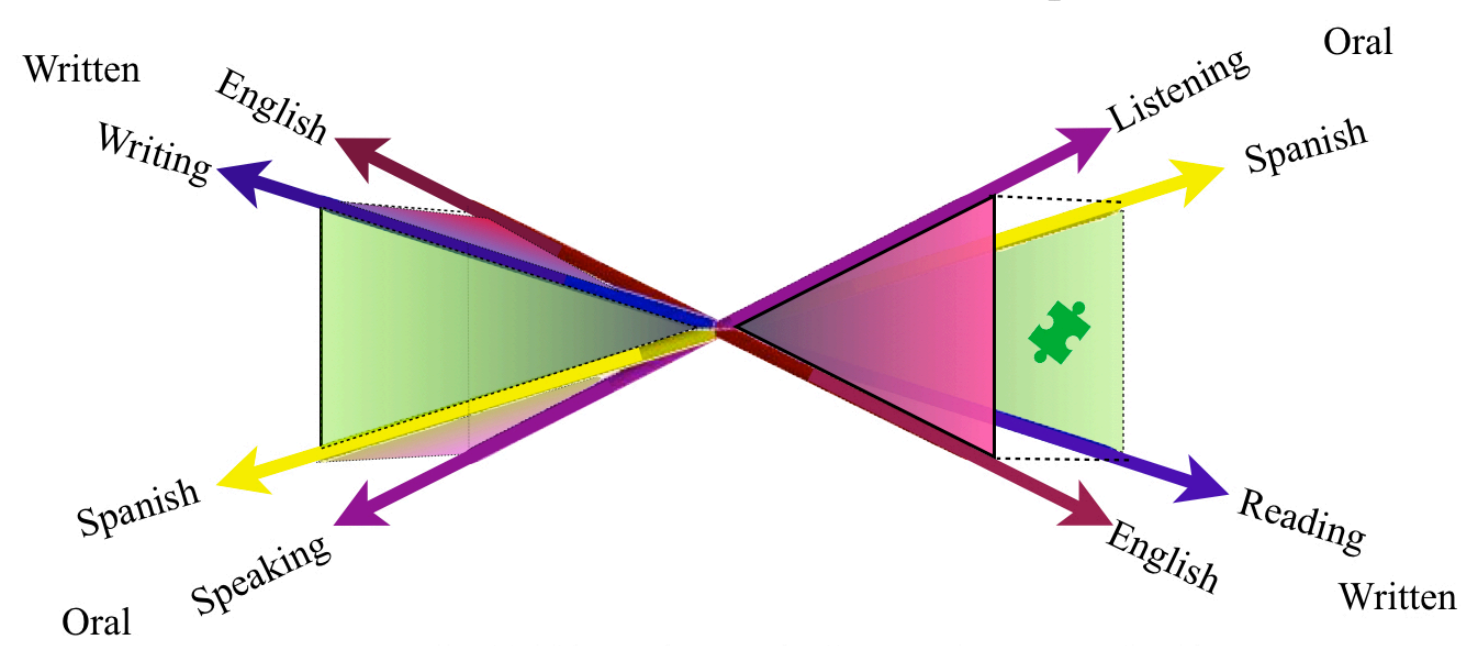

Scaffolding Episodes in the Development of Biliteracy Task: Spanish Reading

These scaffolds enabled the students to complete the task of reading in Spanish, as indicated by the model (Figure 4.16). Other student questions emerged regarding vocabulary. For example, James read the sentence, “Tenemos más compromisos y menos tiempo.” Then, he asked the teacher, “Qué significa compromisos?” (What does "compromisos" mean?) The reasoning behind this question is excellent. The word "compromisos" looks like the word "compromises" in English. This is a false cognate. It does not mean "compromises" it means "promises" or "responsibilities." If a student whose native language is English tries to interpret the sentence, the person might come up with "We have more compromises and less time." This does not really make sense. Therefore, James' question demonstrates that he clearly understands the rest of the sentence, and recognizes where the problem may lie, and is seeking clarification of this 
particular lexical item. In this case, the teacher responds and simply tells him the English translation "responsibilities."

At some points, individual students appeared to struggle with words that had already been discussed in the context of the lesson. In this particular conversation, the students were assigned with the task of responding to comprehension questions about a short story "El Pequeño ruiseñor" (The Little Mockingbird). The students in this small group of three (Asha, Ahmose, and Clyde) scaffold one another's understanding and interpretation of one of the assigned reading comprehension questions, and were able to successfully complete the writing assignment upon adopting Profesora Nuria's interactional scaffold based upon observed student difficulties (Figure 4.17).

Figure 4.17 Model illustration

\section{Production}

\section{Reception}

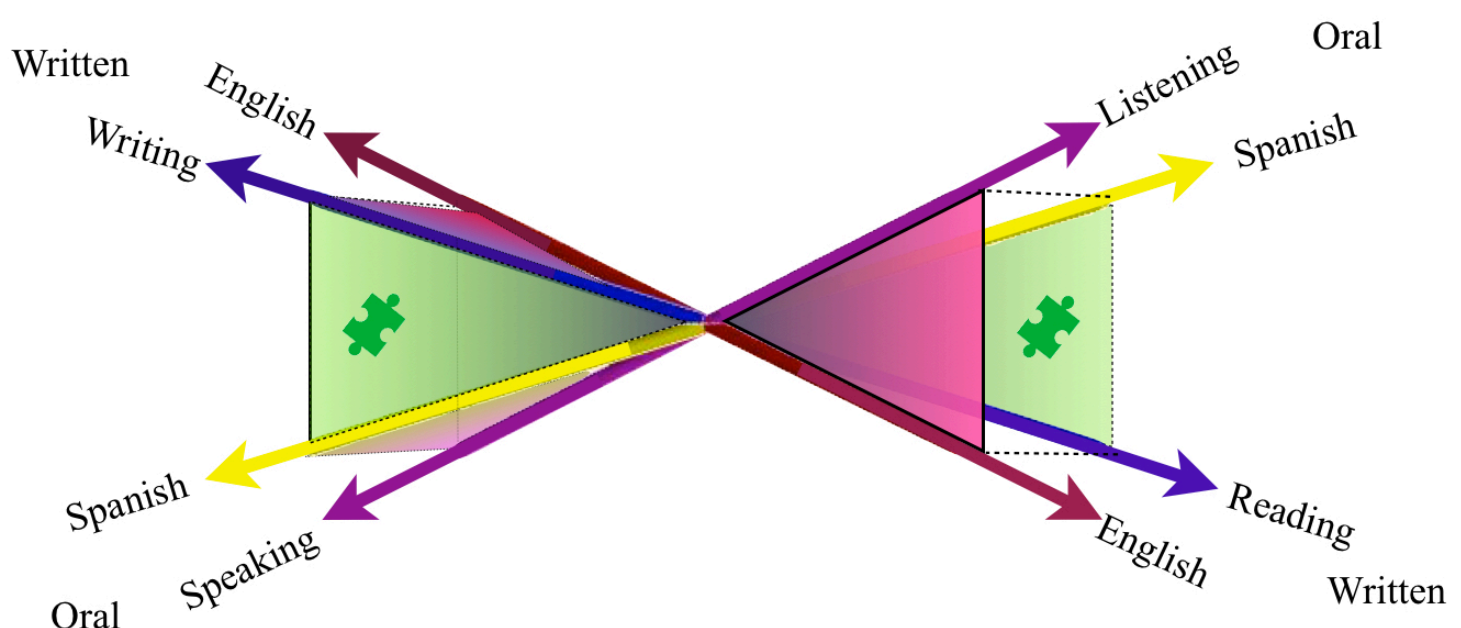

Scaffolding Episodes in the Development of Biliteracy

Task: Spanish Reading and Spanish Writing

On this particular date, the students in the group spoke over one another and it was difficult to identify who was speaking during two periods of "exploratory talk" (Barnes, 1992). Therefore, I have indicated those phrases in bold font, as the students talked over 
one another, spoke in one word intervals, and interjected to create new knowledge in the form of exploratory talk. In this example, student names are indicated when it was clear who was speaking at the time.

Table 4.21 Transcript excerpt: Un pájaro. Mocking.

\begin{tabular}{|c|c|c|}
\hline Original Transcript & Translation to English & codes / notes \\
\hline $\begin{array}{l}\text { Asha: Un pájaro. Mocking... } \\
\text { How do you say mocking in } \\
\text { Spanish? }\end{array}$ & A bird. & Q: lexical item \\
\hline $\begin{array}{l}\text { Profesora Nuria: Un ruiseñor. } \\
\text { Asha: What? }\end{array}$ & A mockingbird & $\begin{array}{l}\text { A: lexical item } \\
\text { Q: clarification }\end{array}$ \\
\hline Profesora Nuria: Un ruiseñor. & A mockingbird & A: repeated \\
\hline $\begin{array}{l}\text { Clyde: Un pájaro, que canta. } \\
\text { Canta. }\end{array}$ & A bird. That sings. Sings. & description \\
\hline $\begin{array}{l}\text { Asha: Pájaro, Mockingbird. } \\
\text { Pájaro que canta. }\end{array}$ & $\begin{array}{l}\text { Bird. } \\
\text { Bird that sings }\end{array}$ & description \\
\hline Ahmose: Number two, ¿Cuándo & When do they take the & reading Q \\
\hline se cogen los ruiseñores & mockingbirds that are destined to & aloud \\
\hline $\begin{array}{l}\text { destinados a vivir con los } \\
\text { hombres? }\end{array}$ & live with human beings? & \\
\hline Asha: What? & & Q: clarification \\
\hline Clyde: What? & & Q: clarification \\
\hline When--? & & collaborative \\
\hline When do the--? Is it [caught & & attempts to \\
\hline on?] take? & & translate \\
\hline So when-- & & question word \\
\hline I think so. & & by word \\
\hline Asha: --does it take the & & (bottom-up \\
\hline mockingbird's destiny to live & & \\
\hline with humans? & & \\
\hline Clyde: No, they're destined to & & negation \\
\hline
\end{tabular}




\begin{tabular}{|c|c|c|}
\hline live with humans-- & & translation \\
\hline Asha: Oh. & & \\
\hline Clyde: --or something like that. & & additional \\
\hline Asha: When does it take--? & & attempts \\
\hline Clyde: What? & & Q: clarification \\
\hline What does that say? & & \\
\hline ¿Cuándo se cogen los ruiseñores & When do they take the & repetition in L2 \\
\hline destinados a--? & mockingbirds destined...? & \\
\hline Asha: Okay, wait. Wait. & & Pause \\
\hline When do they take-- & & collaborative \\
\hline Yeah. & & attempts to \\
\hline --the mockingbirds-- & & translate \\
\hline Mockingbirds-- & & continue \\
\hline --that are destined-- & & exploratory talk \\
\hline --to live with-- & & \\
\hline Humans. & & \\
\hline --humans, yes. & & \\
\hline Profesora Nuria: Cinco, cuatro, & Prof: Five, four, three, two, one. & Clarification of \\
\hline tres, dos, uno. Recuerden que & Remember that we have been & instructions \\
\hline hemos estado aprendiendo a & learning how to go back to the & scaffold of \\
\hline cómo regresar al texto y apoyar & text and support our answers & reading \\
\hline nuestra respuesta buscando & looking for examples or details & strategies \\
\hline ejemplos o detalles del texto. Así & from the text. So, I want to see & \\
\hline que quiero ver que ustedes & that you are all returning to the & \\
\hline regresen al texto y traten de & text and trying to find these & \\
\hline encontrar estas respuestas, con & answers with details and & \\
\hline detalles y ejemplos. & examples. & \\
\hline Clyde: Well, let's do it. & & Affirmation \\
\hline Ahmose: This might take a while & & \\
\hline [crosstalk]. & & \\
\hline Clyde: El primer mes de vida del & In the first month of live the & appropriation \\
\hline
\end{tabular}


ruiseñor es el que... Oh, it's el primer mes.

Asha: What?

Clyde: El primer mes.

Asha: Oh. I kind of looked back

on the thing as like... when do

we take the mockingbirds

destined to live with humans?

Clyde: When do we take the

mockingbirds destined to live

with humans?

Ahmose: En el primer mes.

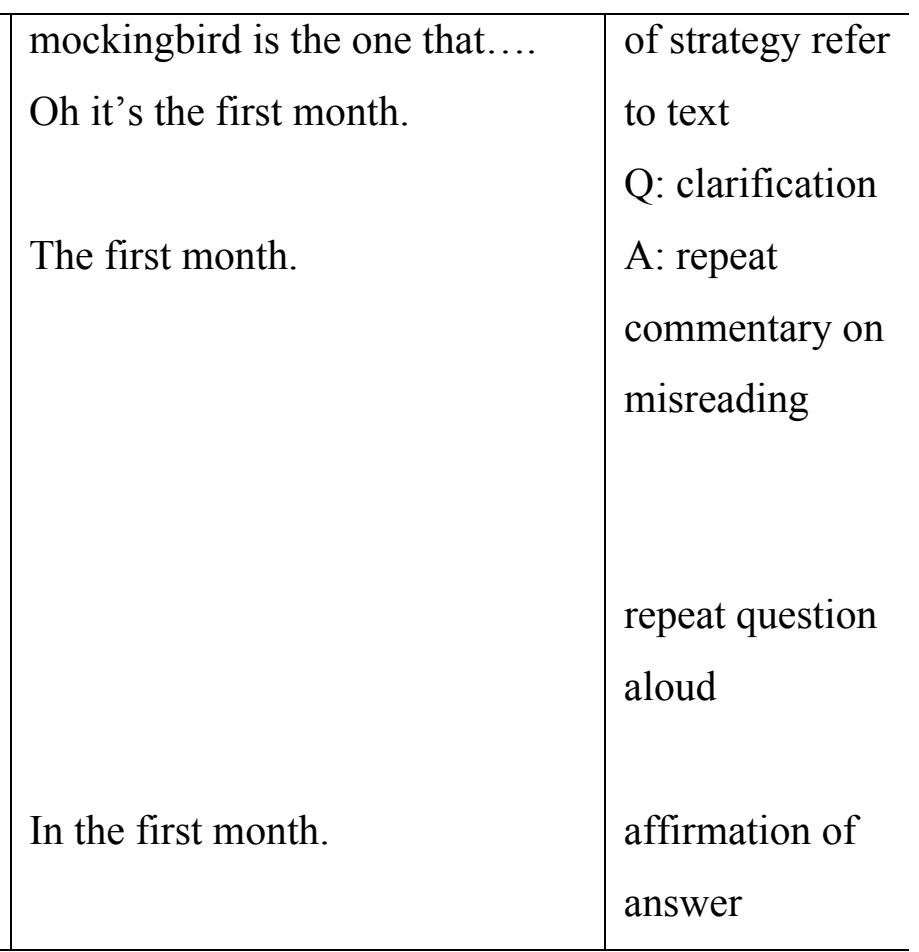

In this transcript, one can note that Asha directly asks the teacher for the lexical item he as they first started reading. However, either Asha was not paying attention, or he failed to note this word, as it does not on its surface appear to have anything to do with birds.

This is why Asha phrases his question in this way, starting off with the part that he believes he knows, “Un pájaro. Mocking... How do you say mocking in Spanish?” The common and most general words for birds in Spanish are pájaro and ave, neither of which are included in the Spanish word for mockingbird, which is ruiseñor. Moreover, the word señor (the last morpheme in this new vocabulary word) means "sir," which adds to the confusion. This explains why Clyde and Asha, who are good friends, keep repeating the word pájaro in more than one way in an attempt to resolve this cognitive dissonance between the formation of the compound word in English mocking + bird, versus ruiseñor, which does not resemble any anticipated word by word translation. The second part of this conversation of note is the way that the students resolve among 
themselves the meaning of the question posed on the worksheet. Looking at the words in bold, each student contributes one or two words that are put together collaboratively in translation to build their understanding of the question. This is a form of exploratory talk, as described by Barnes (1992), its value lies in the "students working in small groups to make connections, re-arrange, reconceptualise, and internalize the new experiences, ideas, and ways of knowing offered in the curriculum" (p. 6). The building of new understandings of the question posed in Spanish through their collaborative work is an example of peer scaffolding through exploratory talk. Profesora Nuria explained in her 2015 interview that she placed students in groups on occasion because, "a veces entienden mejor a un compañero que a mi'" (sometimes they understand a classmate better than they understand me).

Just as the students in this group finish their bottom-up strategy of translating the question word-by-word, the teacher interjects into the work time with additional reminders and instructions. Delivered through this interjection, the teacher scaffolds the student collaborative work with a reminder to use the reading strategy of re-reading to find supportive details and examples within the text. This strategy is immediately adopted by this group, as Clyde indicates by his statement, "Well, let's do it," followed by reading aloud from the text. The group members agree upon the answer and Asha states that he "kind of looked back" to the text. Ahmose concludes this is the correct answer, re-reading it as he writes down the phrase, "En el primer mes" (In the first month) in his notebook.

Scaffolding through building connections. In the observed and recorded class activities, one of the primary ways that Profesora Nuria scaffolds for students in the 
continua of biliterate development is through building connections with real life experiences (outside of school). As previously noted in this findings section, one area of deficit acknowledged by Heath (1983), Moll, Neff, and Gonzalez (1992), Compton-Lilly (2014), and others is the lack of connection between home and school literacies. By building connections with real life experiences, Profesora Nuria constructs access to funds of knowledge that the students possess outside of the academic literacy context. In the realm of second language teaching, researchers including Nassaji (2007) can refer to schema theory, as a means of leveraging students' experiences outside of the school context. This theory advances the idea that people possess "scripts" of how situations may unfold based upon a given context. However, Nassaji (2007) cautions that while our understanding of the impact of schemata and background knowledge "lead to useful insights by bringing our attention to the role of this knowledge" in reading comprehension, the mental processing required for reading in two languages is so complex that their role cannot yet be completely understood (p. 101). However, both of these concepts, funds of knowledge and schema theory, point to the broader idea that call teachers to meet students where they are. Also, as stated previously, the entire concept of scaffolding within the ZPD is to meet students where they are and use what they know, in conjunction with the knowledge and skills of the mentor, to accomplish a task. The combination of these theories together present a symbiotic relationship when considered in this classroom context. It is ironic, however, that while Profesora Nuria sees this practice as a tool for engaging students, she had this to say about it during our preobservation interview, 
See, I always struggled, it [lenguaje] always takes more than 20 minutes. They would like talk to each other. And if the passage was about respect and honesty, I wouldn't just focus on the main idea and the key details. I would like talk with them about what examples of respect are and examples of honesty and just getting them into the passage. So, that's one of my weaknesses, my being able to get sidetracked.

While she seems to see this as being "sidetracked," this practice of real-life applicability and relevance was leveraged in a variety of ways to engage students with the texts in class throughout the observation period.

Connecting real-life scenarios to reading objectives. One of the other ways that Profesora Nuria scaffolds for students is by calling their attention to language and literacy objectives. Gibbons (2002) calls this "noticing” as a means of scaffolding. Through direct talk about global reading strategies, problem-solving strategies, and support reading strategies including predicting, and using textual features to enhance reading comprehension, the teacher builds metacognitive awareness of these reading strategies (Mokhtari and Reichard, 2002, p. 259). Metacognitive awareness allows students to think about their own thinking and ways of understanding and approaching texts. Profesora Nuria regularly posted the lesson objective at the beginning of each class segment. On many occasions she tied the idea of "noticing" the objective to an easily relatable real-life scenario. Through these methods, she is actually scaffolding reading in both English and Spanish through metacognitive understandings of the reading process and reading strategies, as indicated on the model (Figure 4.18). 
Figure 4.18 Model illustration

Production

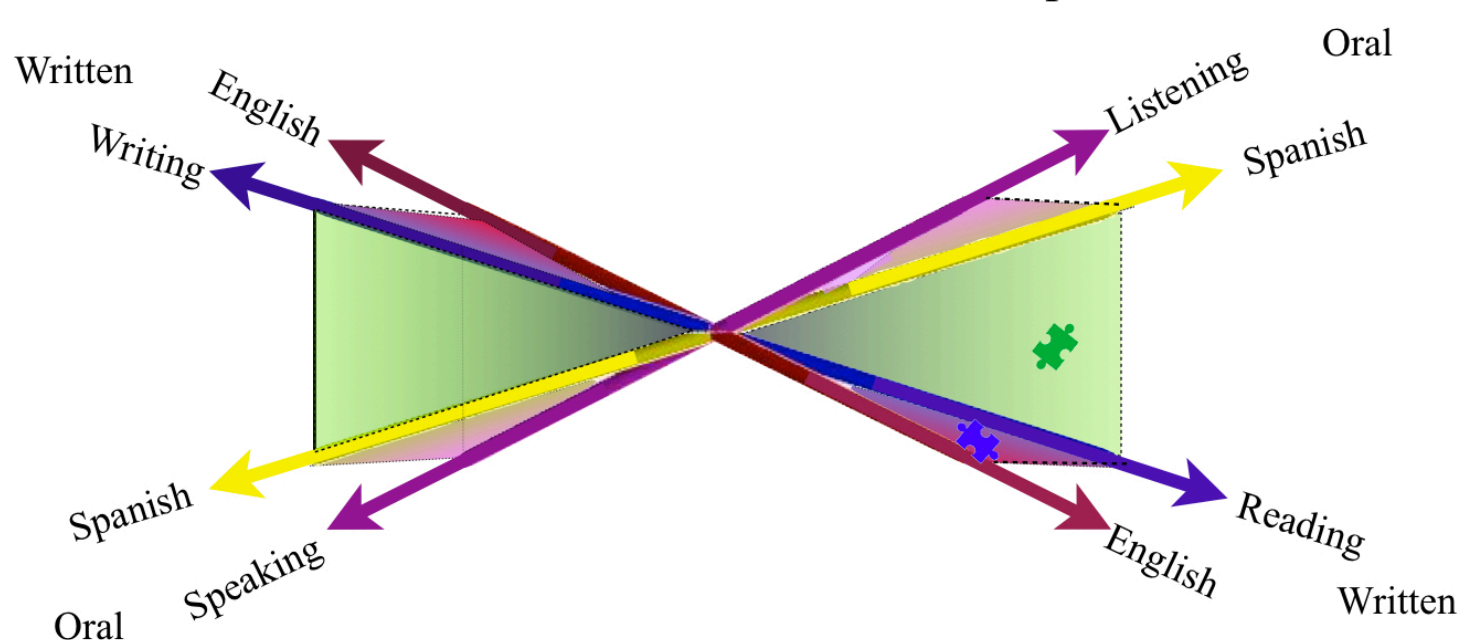

Scaffolding Episodes in the Development of Biliteracy

Task: English Reading and Spanish Reading

In this conversation, she refers to the iReady program, which is a software license purchased by the school this school year to serve as differentiated instruction of English reading skills. She asks the students for their feedback and opinions about the program first. The students respond with a list of generally favorable feedback in both languages, including “iMe encanta!” (I love it!), "It's just like Dreamworks,” (as an affirmation of the colorful animations). After the opportunity to provide their positive and negative comments, Profesora Nuria addresses the students directly:

Table 4.22 Transcript excerpt: Connecting with iReady objectives

\begin{tabular}{l|l|l}
\hline Original transcript & Translation to English & codes / notes \\
\hline Profesora Nuria: Okay. Um... & Profesora Nuria: Okay. Um... no & \\
nadie me ha mencionado algo que & one has mentioned something that I & \\
esperé haber escuchado.... Antes & was hoping to hear. Before & \\
de comenzar una lesson... antes de & starting a lesson, before you start a & guiding \\
\hline
\end{tabular}


que comiencen Uds. con el juego... o lo que sea... ¿Qué es lo que les dan? A ver, ¿Rianna?

Rianna: El objetivo.

Prof: Muy bien. El objetivo. Y quien me dice o quien me explica para que te ponen ese slide no tienes que hacer nada ... ¿Para que es este slide con el objective? Dice objective. A ver, ¿cuántos de Uds actually read that objective? Me da un poquito de... un poquito de heart attack.

Tessa: I don't know what you are talking about.

Nikki: you know that thing where you like press it, so you can go on...

Rianna: Oh oh! I don't read it sometimes.

Prof: Mira. Me encanta tu honestidad. Pero, ¿para qué sirve? It sure is not fun, yo lo entiendo, no es tan divertido como un juego, pero, ¿Para que está ese slide, Clyde?

Clyde: Para que sabes que tienes que aprender durante la lesson. Prof: Muy bien. ¿Laney? game or whatever... What is it that they give you? Let's see... Rianna?

Rianna: The objective.

Prof: Good. The objective. And who can tell me or who can explain to me for what (purpose) do they put this slide where you don't really have to do anything? What purpose does this slide with the objective serve? It says objective. Let's see... How many of you actually read that objective? This gives me a little bit of a heart attack.

Tessa: I don't know what you are talking about.

Nikki: you know that thing where you like press it, so you can go on...

Rianna: Oh oh! I don't read it sometimes.

Prof: Look. I love your honesty. However, what purpose does it serve? It sure is not fun, I understand, it is not as fun as a game. What purpose does this slide serve? Clyde?

Clyde: So that you know what you have to learn during the lesson.

Prof: Good. Laney? question

response

praise

Q: explain

Q: describe

Q: seeking affirmation

A: negation

A: peer scaffold

A: negation

praise

Q: analyze empathy Q: analyze

A: analysis collecting 
Laney: Para que tienes una idea de que es tu rol para...

Prof: Muy bien. Eso te permite a ti saber que es lo que tu vas a aprender o para que ... por ejemplo, ¿cuántos de Uds. les gusta subirse al carro o el autobús con su familia y lo primero que hacen es, “¿Adónde vamos? ¿Adónde vamos?"

Varios: Oh yes. I do that.

Prof: A ver. A todos nos gusta saber adonde vamos, ¿no? Es lo mismo con esto es como ¿Qué voy a aprender? ¿De qué me va a enseñar iReady hoy? Te dan ese slide ese objective y chicos... ¿de qué estamos hablando? No es un párrafo. Les da una oración o dos...
Laney: So that you have an idea of your role for...

Prof: Good. This permits you to know what you are going to learn about... or for example, How many of you have gotten into the car or the bus with your family and the first thing you do is ask, "Where are we going? Where are we going?"

Various students: Oh yes. I do that.

Prof: So. All of us like to know where we are going. Right? It is the same with this, it's like... What am I going to learn? What is iReady going to teach me about today? They give you this slide.. this objective and students, what are we talking about? It's not a paragraph. They give you a sentence or two...
A: analysis

praise explanation real-life example Q: seeking affirmation

A: yes real-life example comparison encouragement

As one can see through this classroom conversation, the teacher first asks guiding questions to find out if students have noticed the objectives posted on the first slide of each lesson in the iReady system. She addresses the students in Spanish during this English class period, but interweaves the words, "lesson," "objective," and "slide" in English, as though she is speaking of brand names, which are not normally translated. She collects answers as the students assist each other in understanding where the objectives are found and what they look like. The students are honest in expressing the 
thought that they just "click" past the lesson objective. The teacher praises their honesty, and expresses empathy for their point of view that it may not be as fun as the "game" type activities that they praised in the previous part of this conversation. Then she asks them to consider the importance of actually reading the objectives by relating it to the real life scenario of asking their parents "Where are we going?" In addition to this, she relates it to everyone's experiences by including travel by car or bus as natural options in this urban environment. The students clearly respond in the affirmative to their ability to relate to the situation she poses. She then invites them to make the comparison between asking the destination to the objectives statement as a guide to their destination within the iReady system. She finishes this with encouragement to read the lesson objective, as it is not very lengthy (and she has already explained its importance).

On another occasion, Snowy and James looked up the terms relevante (relevant) and irrelevante (irrelevant) in the dictionary. The lesson objective for lenguaje on this day was: distinguir entre detalles relevantes e irrelevantes. (Distinguish between relevant and irrelevant details.)

Table 4.23 Transcript excerpt: ¿Relevante o irrelevante? Part 1

\begin{tabular}{l|l|l}
\hline Original transcript & Translation to English & codes / notes \\
\hline $\begin{array}{l}\text { Profesora Nuria: Gracias Snowy, } \\
\text { gracias James. Siempre }\end{array}$ & $\begin{array}{l}\text { Profesora Nuria: Thank you, } \\
\text { Snowy. Thank you, James. }\end{array}$ & praise \\
superincreible tenerlas en mi clase & Always super-incredible to have & encouragement \\
con su diccionario. Esas son las & you in my class with your & \\
definiciones que pretty much ayer & dictionary. These are the & connection \\
nosotros hablamos ¿no? Relevante & definitions that we pretty much & with previous \\
que es lo que tiene importancia, lo & talked about yesterday, right? & lesson \\
que es importante, lo que tiene & Relevant is that which has & \\
\hline
\end{tabular}


significado ¿okay?

Stu: Que es excelente.

Prof: Lo que es excelente, exacto. Irrelevante es a lo que se aplica a lo que no tiene importancia ¿okay? Por ejemplo, y otra vez, eso es solo un ejemplo. Si yo le hubiera dado a Snowy un diccionario y a James un Flip-OMatic Spanish Verb Flashcards $a$ James (al mismo momento le da el libro a él) y le digo "James encuéntrame la definición de relevante. Go!"

[risas]

Prof: ¿Por qué te ríes?

[risas]

A ver. ¿Por qué se ríe James?

Stu: Es..

Varios: No es relevante, es irrelevante.

Prof: Perfecto. Es irrelevante que yo le de un-- irrelevant, que yo le de esto (les muestra el libro Flipo-Matic a todos) y le pida que de una palabra ¿okay? No tiene importancia. Esto ahorita no tiene importancia. O como que yo te estoy hablando de relevante e importance, that which is important, that which has significance. Okay?

Student: That is excellent.

Prof: That which is excellent, exactly. Irrelevant is that which does not apply or that does not have importance. Okay? For example, and again, this is just an example. If I had given a dictionary to Snowy and a FlipO-Matic Spanish Verb

Flashcards book to James (at this time, hands the book to him) and I say "James, find me the definition of relevant. Go!" [laughter]

Prof: Why are you laughing? [laugher]

So. Why is James laughing? Student: It's...

Various students: It's not relevant. It's irrelevant.

Prof: Perfect. It is irrelevant that I give a ...irrelevant that I give him this (holds up the FlipO-Matic book) and ask him to look up a word. Okay? It has no importance. This right now is not important. Or when I am talking about relevant or definition

definition

recast

real-life

example

humorous

reference to

mediational

means

Q: explain

A: explanation

A: praise

rephrase

explanation 
irrelevante. Estoy tratando de dar mi clase y alguien levante la mano y me diga. "Is it time to go to lunch yet?" No tiene relevancia.

\begin{tabular}{l|l} 
irrelevant, and I'm trying to & second \\
teach my class and someone & example \\
asks, "Is it time to go to lunch & \\
yet?" It has no relevance. &
\end{tabular}

In this vignette, one may observe again the highlighting of the participation of Snowy as a valued member of the classroom community, and the lavish praise and encouragement provided by the teacher to each student individually. The teacher provides two concrete examples of the application of relevant versus irrelevant. In the first example, the teacher provides the student with the incorrect resource to find an answer to a question. This created a memorable experience with the reading objective. Students were laughing, and they were enjoying the lesson objective and understanding how it was applicable to a real life academic scenario. The teacher used the dictionary and the Flip-O-Matic Verb Flashcards book to demonstrate when these recognized mediational means are relevant and when they are irrelevant. The selection of the Flip-O-Matic Verb Flashcards book is deliberate, it has a funny and unusual name, and emphasizes her sense of humor and engagement with the students. The students, including James, immediately recognized that one cannot look up the meaning of a word in this book, and that it is not useful in that particular situation. The students could not have recognized the irrelevance / irrational nature of this request without their own understanding of the "proper" use of these tools (mediational means). Then, the teacher provided a second authentic example, using student questions about lunch during class time as "irrelevant" and not pertinent to the lesson.

Another scaffold that the teacher uses is subtle in the above conversation. Recasts are generally considered oral scaffolds. A recast occurs when the teacher restructures all 
or part of what the student says and omits the error without explicitly drawing student attention to the issue.

Figure 4.19 Model illustration

\section{Production}

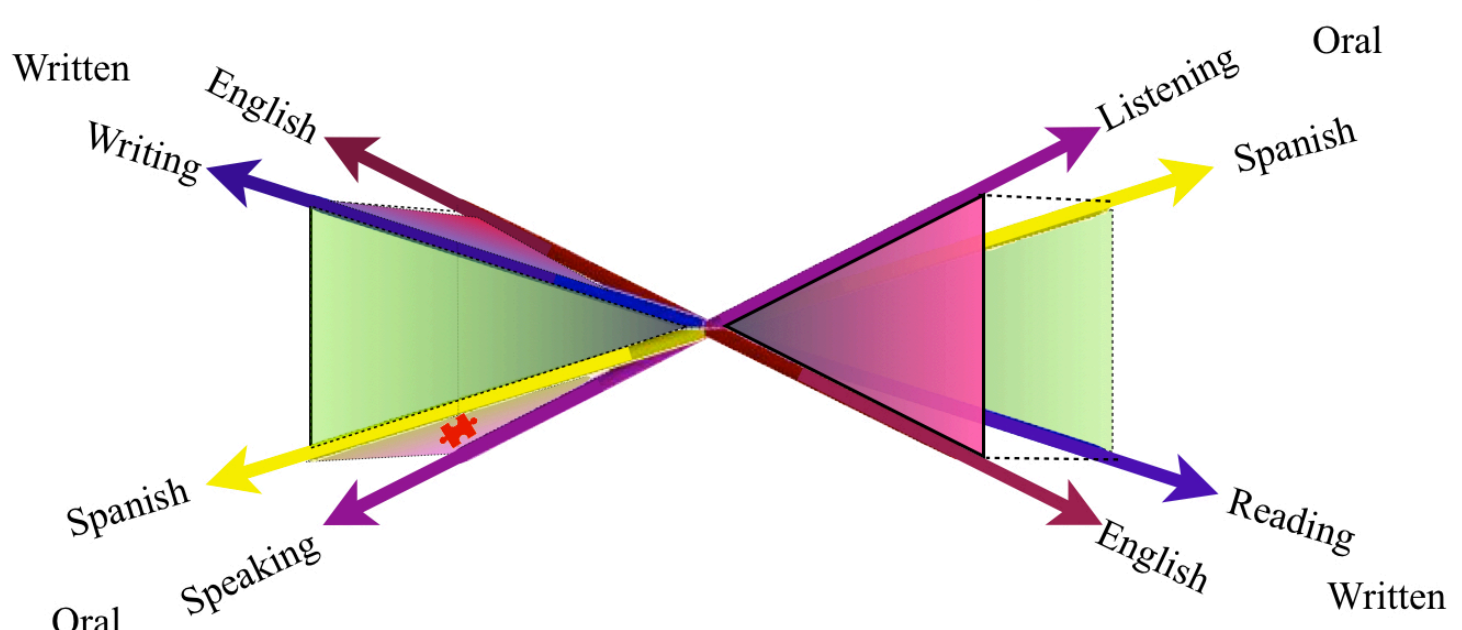

Scaffolding Episodes in the Development of Biliteracy Task: Spanish Speaking

As indicated in the model (Figure 4.19), the teacher provides the scaffold of the student speaking Spanish. A student says that one definition of relevant is, "Que es excelente," (That is excellent), and the teacher responds, "Lo que es excelente, exacto" (That which is excellent, exactly). Recast is considered a scaffold technique in frequent use in classrooms. Indeed, in the classroom of study it occurred in virtually every lesson. However, I have deliberately decided not to highlight the numerous examples of these types of scaffolds in this study. In Lyster and Ranta's (1997) well-received research, their "findings indicate an overwhelming tendency for teachers to use recasts in spite of the latter's ineffectiveness at eliciting student-generated repair" (p. 37). Recasts have been criticized for being such subtle and implicit means of error correction, that it is difficult to encounter evidence of student uptake or adoption of the scaffold. As my 
study specifically intends to feature moves towards independence, the use of recasts is not as compelling as some of the other scaffolds employed by Profesora Nuria.

Following the previous conversation, the teacher then went immediately to the reading saying, "Vamos a hacer una lectura y ustedes me van a ayudar a escribir detalles relevantes y detalles irrelevantes sobre la historia." (We are going to read this text and you all are going to help me to write relevant and irrelevant details about the story.) Later on this same day, while reading the story, a clipboard student from third grade knocked on the door to report his progress. Profesora Nuria talked to him and drew a smiley face on his chart to show that she was happy that he was doing well in class. As he leaves, this is the conversation that follows:

Table 4.24 Transcript excerpt: ¿Relevante o irrelevante? Part 2

\begin{tabular}{|c|c|c|}
\hline Original Transcript & Translation to English & codes / notes \\
\hline $\begin{array}{l}\text { Jenna: Es irrelevante. } \\
\text { Prof: ¿Irrelevante? [risas] De la } \\
\text { clase sí, pero mira que tiene } \\
\text { mucha relevancia para que él } \\
\text { pueda tener un superdía. Pero me } \\
\text { encanta la conexión que hiciste } \\
\text { Jenna. }\end{array}$ & $\begin{array}{l}\text { Profesora Nuria: (to the third } \\
\text { grade student) Good. Keep that } \\
\text { up, sweetie. Good job. Okay, } \\
\text { thank you. Say "goodbye" to } \\
\text { everyone. } \\
\text { Jenna: It is irrelevant. } \\
\text { Prof: Irrelevant? [laughing] } \\
\text { For this class yes, but look at } \\
\text { how much relevance it has for } \\
\text { him so that he can have a super } \\
\text { day. But I love the connection } \\
\text { that you made, Jenna. }\end{array}$ & $\begin{array}{l}\text { praise } \\
\text { encouragement }\end{array}$ \\
\hline
\end{tabular}

As one can see from this conversation, Jenna (one of the Inseparable Duo) has already appropriated and independently used the new term without prompting. This occurred as she recognized the fact that the interruption by the clipboard student was not relevant nor 
applicable to the classroom reading activity. Additionally, through this brief

conversation, we also see again another example of the repeated theme of Profesora Nuria's attention to the affective needs of students, even from other classes. This is demonstrated through her comment explaining that while the interruption was not relevant to the fifth grade lesson, to the clipboard student, it was important (and relevant). Then, she praises her own student, Jenna, for making the connection.

Connecting real-life scenarios to abstract readings. The prompt was written on the board, "Para pensar: Tomo por garantizado..." (Think about it: I take for granted...). Students were asked to think about this sentence starter for a moment and then report to the whole group discussion. In my field notes from that date I wrote, "I wish I could take a photo of so many students raising hands. They really want to share thoughts on this topic!" Some of the ideas shared were,

Table 4.25 Transcript excerpt: I take for granted

\begin{tabular}{l|l}
\hline Original Transcript & Translation to English \\
\hline Nikki: tecnología & Nikki: technology \\
Ahmose: respiración & Ahmose: respiration (breathing) \\
Astrid: mi vida & Astrid: my life \\
Asha: mi familia & Asha: my family \\
Terrell: la escuela & Terrell: the school \\
\hline
\end{tabular}

Then, Tessa asked if she could share her entire list, and read several items. As we can see from this list, the range of topics provided by students included both concrete and abstract concepts. This discussion directly prepared the students for a philosophical reading titled "Para pensarlo" (Think about it) that appears to be a criticism of modern society. Here is a small portion of the text: 
Table 4.26 Classroom reading: Gastamos más pero disfrutamos menos

\begin{tabular}{|c|c|}
\hline Original Text & Translation to English \\
\hline Gastamos más, pero disfrutamos menos. & We spend more, but enjoy less. \\
\hline Tenemos casas más grandes, pero & We have larger houses, but smaller \\
\hline familias más chicas. & families. \\
\hline Tenemos más compromisos, pero menos & We have more responsibilities, but less \\
\hline tiempo. & time. \\
\hline Tenemos más conocimientos, pero menos & We have more knowledge, but less \\
\hline criterio. & judgment. \\
\hline $\begin{array}{l}\text { Tenemos más medicinas, pero menos } \\
\text { salud. }\end{array}$ & We have more medicines, but less health. \\
\hline Hemos multiplicado nuestras posesiones, & We have multiplied our possessions, but \\
\hline pero hemos reducido nuestros valores. & we have reduced our values. \\
\hline Hablamos mucho, amamos poco y & We talk a lot, love little, and hate too \\
\hline odiamos demasiado. & much. \\
\hline Hemos llegado a la Luna y regresamos, & We have landed on the moon and \\
\hline pero tenemos problemas para cruzar la & returned, but we have problems crossing \\
\hline calle y conocer a nuestro vecino. & the street to meet our neighbor. \\
\hline
\end{tabular}

The more abstract texts are even more challenging to read in a second language. The teacher's pre-reading activity building connections to their own values, allowed the students to access and consider their own philosophical ideas to orient them towards the topic of the reading. While reading the passages "round robin" style, the teacher stops them and asks them to write in their notebooks their responses to the question, 
Table 4.27 Transcript excerpt: What do you think?

\begin{tabular}{l|l}
\hline Original Transcript & Translation to English \\
\hline Profesora Nuria: ¿Qué piensan cuando & Profesora Nuria: What do you think when \\
leen la frase "Hablamos mucho, amamos & you read the sentence, "We talk a lot, love \\
poco, y odiamos demasiado?" & little, and hate too much?" \\
(después de un minuto o dos, algunos & (after a minute or two, some share their \\
comparten sus respuestas) & answers) \\
James: Hablamos mucho y no & James: We talk a lot and do not listen \\
escuchamos mucho. & very much. \\
\hline
\end{tabular}

Some other students struggled with the task, and said things that were difficult to understand. Ahmose, for example, said, "No le gustas muchas cosas." (He you do not like many things.) Even without the breakdown in syntax, it is unclear as to what he refers. Who is the subject of the sentence? Is he trying to say: We do not like very many people? That people do not like each other enough?

There were numerous lessons in which the teacher worked to draw students closer to the lesson objectives through building connections. In this chart are some brief representative examples of topics covered in lenguaje, social studies, and science in sequential order.

Table 4.28 Building connections: Sequential scaffolding examples

\begin{tabular}{l|l}
\hline Reading title / topic & $\begin{array}{l}\text { Connecting to real-life experiences } \\
\text { (my translation / brief explanation) }\end{array}$ \\
\hline $\begin{array}{l}\text { "El rey y la semilla" (The King and the } \\
\text { seed) }\end{array}$ & $\begin{array}{l}\text { What are the characteristics of the ideal } \\
\text { teacher? Follow up question: What are } \\
\text { the characteristics of the ideal king? }\end{array}$ \\
\hline Science: forms of matter & $\begin{array}{l}\text { Discussion of the phases / forms of a } \\
\text { candle (solid vs. liquid), rust on the bridge }\end{array}$ \\
\hline "El Plato de madera" (The wooden plate) & $\begin{array}{l}\text { Guiding objectives: When I read I think } \\
\text { about what the author wants to teach me, } \\
\text { and why I think that. Students made their }\end{array}$ \\
\hline
\end{tabular}




\begin{tabular}{l|l}
\hline & $\begin{array}{l}\text { own connections with the interactions } \\
\text { between multiple generations in the story. }\end{array}$ \\
\hline $\begin{array}{l}\text { "El Error más grande" (The greatest } \\
\text { error) }\end{array}$ & $\begin{array}{l}\text { Students connected this philosophically to } \\
\text { past readings (including "Morir } \\
\text { lentamente" Dying slowy) on their own. }\end{array}$ \\
\hline $\begin{array}{l}\text { Social studies: Discussion of kachina } \\
\text { dolls and respect for elders as values in } \\
\text { the American Southwestern tribes }\end{array}$ & $\begin{array}{l}\text { Teacher tied this to discussion of values or } \\
\text { information transmitted to students by } \\
\text { older family members. }\end{array}$ \\
\hline
\end{tabular}

As one can observe from these examples, Profesora Nuria worked to leverage student

experiences to orient them towards the core objectives of the lesson, at times to encounter deeper understanding of the philosophical messages of text. There is also evidence that students have appropriated this strategy for their own use as evidenced by the class discussions regarding "El Error más grande" (The greatest error). Additionally, the teacher uses this to engage interest and practical applications of knowledge of scientific principles and recognition of cultural values.

Connecting real-life scenarios to student behavioral struggles. Profesora Nuria also connected real-life scenarios to student behaviors. In this vignette, she is approached by a female clipboard student from the fourth grade class who has come reluctantly to the door. Another teacher tells the student to go on in the door and that Profesora Nuria has her own class (implying that the student should hurry up). Profesora Nuria responds in this way,

Hey, come here sweetie. Hola. ¿Cómo estás? (Hello. How are you?) What's going on? (The female clipboard student wants to draw in another class, but her teacher told her not to.) Is it time to draw now? That's the thing, sweetie, there's always a time and a place for everything. How about you finish everything that you have to do and then you can ask her again if you can draw? When you've shown her that you can, yes, follow instructions. Do you know what I'm saying? 
You can't always get what you want when you want it. If it were up to me? Do you know where I would be right now? (Makes snoring noises.) But I can't, okay? So, we all have a job, and your job right now is to be a student and go there and learn. Okay? Hey, you're gonna have a great day. But it depends on who? You make your own choices. Give me a hug, and I'm going to tell your teacher that if you're done with everything you're going to ask her if you can draw. Okay? Thanks for checking in.

In this conversation with the student, one can observe again the warm greeting and welcome that the student receives from Profesora Nuria. In addition to this, the teacher directly addresses the heart of the issue in a non-confrontational, empathetic way. Nuria expresses that she understands the student's desire to draw instead of working through her humorous, real-life example that she would rather be sleeping right now (snoring noises accompanied by hands next to her tilted head as though asleep). However, as Profesora Nuria explains, "We all have a job" to do now. She encourages the student to complete her classwork and then ask again for an opportunity to draw. In this way, she explicitly scaffolds the student behavior for successful negotiation of the expectations in the classroom environment. She also provides a means that may allow the student to draw as she wishes, albeit later. This is further reinforced with the handwritten note from Profesora Nuria that prepares the other teacher for the successful appropriation of these behaviors by the student.

Profesora Nuria also scaffolded student behaviors through text selection. Throughout the observation period, the readings in the lenguaje class period focused in upon a variety of messages and morals relating to personal choices and behaviors. In the 
2015 interview, Profesora Nuria explained her feelings about her role as the teacher in shaping student behaviors this way,

Table 4.29 Interview excerpt: "Para mí, ser profesora significa...”

\begin{tabular}{l|l}
\hline Original transcript & Translation to English \\
\hline $\begin{array}{l}\text { Para mí, ser profesora significa mucho } \\
\text { más que lo académico. Con mis niños, } \\
\text { este grupo de niños, es que a veces }\end{array}$ & $\begin{array}{l}\text { For me, being a teacher means much more } \\
\text { than the academic. With my kids, this } \\
\text { group of kids, at times I feel that during the } \\
\text { siento yo que durante un día soy más } \\
\text { day I am more like a mother than a teacher, } \\
\text { habilidades de la vida... como manejarse } \\
\text { teaching them life skills... how to manage } \\
\text { for themselves situations... that they can } \\
\text { casas, con sus amigos, con sus padres. } \\
\begin{array}{l}\text { La conexión que tengo con ellos es tan } \\
\text { increíble que yo puedo estar riéndome }\end{array} \\
\text { con ellos o en cinco segundos si hagan homes, with their friends, with } \\
\text { the the connection that I have } \\
\text { algo malo, puedo ser súper fuerte con } \\
\text { ellos, ser estricta... y lo respetan. }\end{array}$ \\
\hline
\end{tabular}

As articulated above, Profesora Nuria believes that part of her role as teacher is to guide students in ways for managing situations for themselves and building live skills. She also specifically mentions her role of laughing along with them, but also being strict about their behaviors the classroom. This sentiment is also reflected through the thematic readings selected with Profesor Roberto. Central messages embedded within the readings included the value of mentors (El pequeño ruiseñor), perseverance in the face of obstacles (Las ranitas en la nata, El niño y la luz, ;Qué alegre se pone el río!), honesty (El rey y la semilla), and treating others as you would like to be treated (El plato de madera), among others. These discussions were usually rich and tied directly to student experiences through Profesora Nuria's guidance. She also asked students questions based 
upon her knowledge of their family structures. While discussing El nacimiento de las tortugas (The Birth of the turtles), she asked one student who had a younger sister if he ever did anything that he knew she would enjoy, even if he was not that interested in the activity.

She often posed questions asking students to place themselves in the story, for example asking, “¿Puedes hacer lo que hizo Kang? ¿Por qué?” (Can you do what Kang did? Why?) during the large group reading of El niño y la luz (The Boy and the light). The reading (in Spanish) focused upon a young boy in China who wanted to study after school but did not have electricity in his home. The character, Kang, searched for seasonal solutions to the problem, at one point using fireflies to illuminate his homework. The question posed by the teacher prompted one of the students to ask a specific question about the text in response. Santiago asked, "Was it like a metaphor that he could not turn a page, or is it literal?" This question demonstrated deeper analysis of the meaning of the text in his attempt to engage with the information in a personal way. Generally, students responded to these types of questions posed by the teacher employing higher-order thinking skills including evaluation, analysis, and comparison.

\section{Language Choice, Language Production, and Interpersonal Dynamics.}

As described in the communities of practice section, Profesora Nuria is a teacher who displays extraordinary sensitivity to social dynamics and interpersonal relationships. As a study oriented toward sociocultural theory as a theoretical frame, these social dynamics cannot be ignored as they form an integral part of the bilingual inner-workings of this classroom context. Researchers MacIntyre, Clément, Dornyei, and Noels (1998) explored the following related questions, 
"Why do some students seek, while others avoid, second language (L2)

communication? Many language teachers have encountered students high in linguistic competence who are unwilling to use their L2 for communication whereas other students, with only minimal linguistic knowledge, seem to communicate in the L2 whenever possible. Despite excellent communicative competence, spontaneous and sustained use of the L2 is not ensured. A colleague, who teaches a L2 and whose L2 competence is excellent, is well known to avoid "like the plague" L2 communication in social settings. A related observation is that many learners have noticed that their willingness to communicate (WTC) varies considerably over time and across situations". (p. 545)

Their theories about the willingness to communicate (WTC) explore some of the social dynamics that may affect the WTC of individual students, some of them driven by individual characteristics, and others shaped by the surrounding contexts. As such, the following sections explore some of the ways that Profesora Nuria shapes the students' bilingual interactions in the large group (whole class) setting, the impromptu bilingual language practices of students, and how Profesora Nuria works to influence the (WTC) with two individual students of note.

In whole class activities. As teachers work in the classroom, they transmit their own language ideologies to the students in a variety of ways, some explicit and others implicit. Profesora Nuria refers to "Spanglish" several times in the interview when referring to her language practices in her work with students. When asked about this term, her answer neatly ties together her personal bilingual contexts with her work with students, and what she says to them about her language ideologies and practices. This 
question was relevant as in some contexts, the word "Spanglish" is used as a pejorative, and in others, people use it as a means of recognizing movement from Spanish to English back and forth, and for others it means invented words (oftentimes mutually agreed upon in the community) that are a combination of Spanish and English vernacular. I asked, “So, when you say 'Spanglish', does that mean you're switching in the middle of a sentence? Or does that mean you're translating or...?" Profesora Nuria responded by saying,

A little bit of both. I'll say something in Spanish and then I'll say it in English. Or, I'll be saying something in English and then switch to Spanish and right back to English. Um, but for me, it's ... it's just something that I do even on a personal basis. I do it with my brother, I do it with my sister. With... I always tell my kids, because if I know that you know both languages, I can easily go back and forth. If I know that you only speak Spanish, it'll never occur to me to say something in English. If you only speak English, it'll never occur to me to say something in Spanish. And so, I love it because my kids they go, "it's crazy Profesora how I can understand everything that you're saying... like how can you go back and forth?" I tell then it's kind of like the brain, you know you train your brain to not even think about it anymore. I personally, do not feel like it's a bad thing to be able to go back and forth in a language. Because I even believe that you do it when you feel comfortable. (Interview, September, 14, 2017)

Through this explanation, one can identify key words that indicate the deeply personal philosophical and experiential underpinnings for her language practices in the classroom. Profesora Nuria notes that she views switching between two languages within a 
conversation as natural phenomena or languages in use by bilinguals. She includes her language choices in the broader community as an example, explaining to her students that she would not switch languages with people who are monolingual. However, she also includes her family as an illustration of naturalistic bilingual language practices and habits. It is also interesting that she includes the students' reflections of how they think it is "crazy" that they are able to understand "everything" she is saying when she switches between Spanish and English. Her response to their queries is notable in that she articulates the point of view that you "train your brain" to switch languages easily in conversation when you "feel comfortable."

As articulated earlier in the communities of practice section, Profesora Nuria allows students to choose the language of participation (particularly in their oral responses to questions). In the 2015 interview, she provides insights into her thoughts behind these practices saying,

Those are too cool for school [at this age]. I know that they can. I know that they, if their life depended on it, they can [speak Spanish]. You know and that's what matters to me. Y a veces, es mucho ... pero están alli escuchando a mí..(And at times, it is a lot... but they are there listening to me.) And with this group age like, they're just sometimes... it's tough. And sometimes you just have to, you really have to kind of pick your battle, you know. Does it matter to me the most that he's learning math or that he's speaking the language? Even though I know he knows the language. You know, it's kind of matters for me for him to learn that. (Interview, March, 27, 2015) 
In this description, she explains her beliefs that partially due to the age group, she needs to make some accommodations for the students' own language choices, and "pick your battle." She believes that students already "know the language," and are right there "escuchando" (listening), even though they may not be "speaking" in Spanish. Although not stated here, one can easily recall the numerous times that she has expressed the desire to make the student "feel comfortable," so this is also tied to these student language choices in classroom interactions.

That being said, Profesora Nuria made some explicit efforts to motivate the students to participate in some activities in Spanish. For example, in December the teacher introduced the students to an end of unit project (summative assessment) for science class. The handout with instructions was written in English, and Profesora Nuria started describing the requirements aloud in Spanish, including the statement "Quiero darles la opción de hacerlo en inglés o en español" (I want to give you the option to do this in either English or in Spanish). Ahmose waited a few minutes and then asked, "Do you get extra credit for doing it in Spanish?" The teacher answered in the affirmative, and later explained to me in an aside comment, "I have found that it is more motivating to them if I tell them there is extra credit to do it in Spanish." This impression was confirmed by the conversation between Ahmose, James, and Messi as they started their project:

Table 4.30 Transcript excerpt: Talking about extra credit

\begin{tabular}{l|l}
\hline Original Transcript & codes / notes \\
\hline James: First we've gotta do the research. & on-task \\
Messi: Are we doing it in Spanish or English? & Q: clarification \\
Ahmose: We're doing it in Spanish for the extra credit. & A: lang choice \\
\hline
\end{tabular}


Messi: But why?! (puts hand on forehead)

Ahmose: We'll have better grades... we'll have a better life... and more Playstation time.
Q: reluctance

A: analysis of potential

consequences

This group begins to focus upon the task at hand immediately, as evidenced by

James' statement orienting them towards the first step. Messi (self-selected pseudonym

in honor of the famous soccer player) then asks for clarification of language choice.

Messi speaks Spanish in the home while Ahmose does not. The fact that he is even more reluctant than Ahmose to complete a project in Spanish is notable. This corroborates what Nuria stated in the pre-observation interview, saying that the students who speak Spanish in the home are reluctant to speak Spanish at school. She observed that as a consistent pattern each year she has taught at SLIP. Ahmose has clearly determined his own rationale for language choice in this case, describing a series of three potential positive consequences of choosing Spanish over English. First, oriented towards school consequences "better grades," followed by broader consequences outside of school, though it is unclear if he means "a better life" in a global sense, or if it is directly related to the "more Playstation time." This line of thought clearly underscores Profesora Nuria's understanding of student motivations toward language choice in this case.

Student language choice in word play. Regardless of the various theoretical arguments for the separation of languages or the constant co-existence of the two languages, it is important to note that evidence suggests that members of this particular community of practice demonstrate complex, flexible, and complementary linguistic capabilities. Broner and Tarone (2001) examined the concept of language fun (as distinguished from rehearsal and ludic play) in this way: "Language play as fun is typically marked by laughter, whereas rehearsal is less likely to be accompanied by 
smiles and laughter" (p. 364). Their study of fifth grade immersion students focused in upon the fun and language play within the classroom, and noted a that task and with whom the students were speaking had significant impact upon whether the students used Spanish or English as the mode of communication. In this class, there were several episodes in which humorous comments were made in Spanish in response to the teacher's speech. Estrella, who is a heritage speaker of Spanish, is quite shy and does not speak aloud in front of the entire class very often. However, one day, following a discussion of the reading "El Puercoespin en el invierno" (The Porcupine in winter) in lenguaje, Terrell exclaimed, “This is not real! It's like Groundhog Day. A groundhog cannot decide" (referring to the porcupine deciding the number of months in wintertime in the myth). This statement prompts students to begin sharing riddles and examples of symbolic language. Estrella was the first to volunteer amidst the commotion with a riddle for the whole class, "Blanco por dentro, verde por fuera si no te lo sabes, solo espera." (White on the inside, green on the outside if you do not what know it just wait.) Unfortunately, this word play does not translate well, as "espera" means "wait" and "es pera" means "it is a pear," with a rhyming element between fuera and espera. Several students laughed aloud then shouted out the response, “iuna pera!” (a pear!). The teacher took advantage of their enthusiasm in a direct way, and sought additional volunteers for this impromptu activity.

On another observation date, I noted that Laney asked the teacher how to say the word "sponge." Profesora Nuria replied briefly with "esponja," and then moved on to help another student across the room with their small group work (Figure 4.20). 
Figure 4.20 Model illustration

\section{Production}

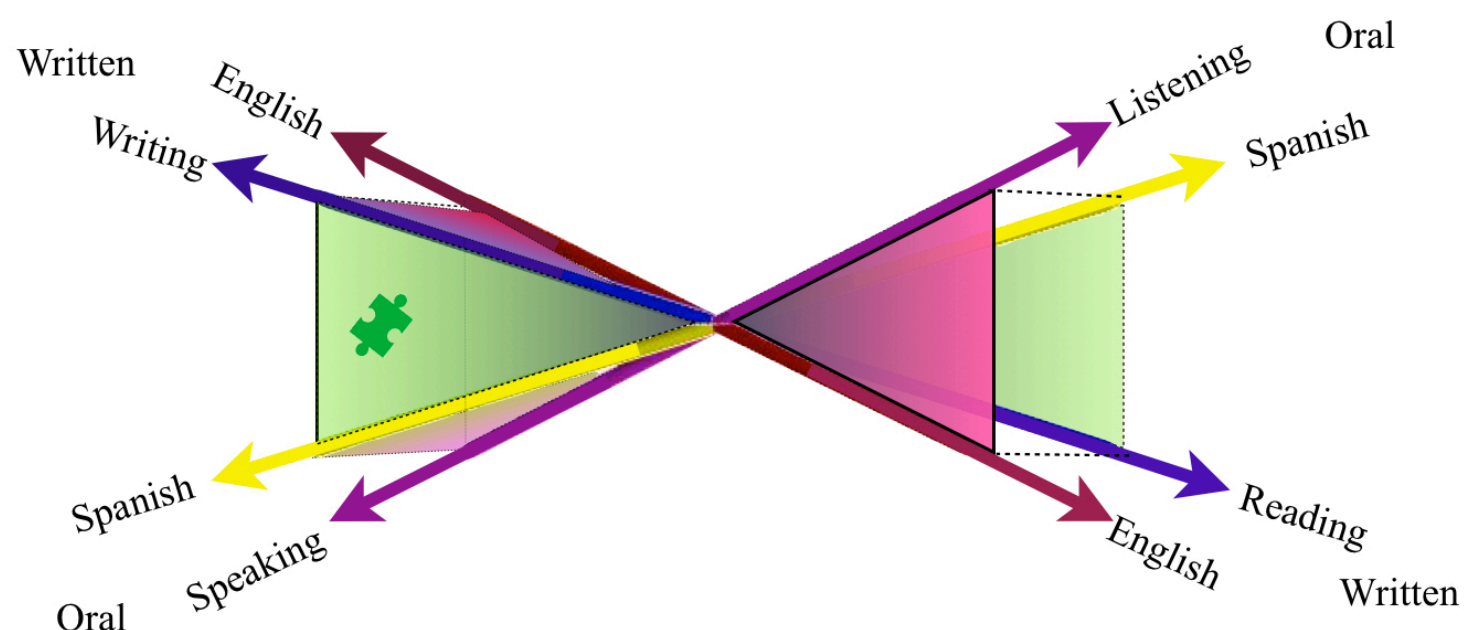

Scaffolding Episodes in the Development of Biliteracy

Task: Spanish Writing

Laney, who was working with Stacy to answer comprehension questions about the central message of the short story El plato de madera (The wooden plate), took her work very seriously. Stacy initiated the sentence and said, "El autor quiere enseñar..." Laney picked up this sentence starter and continued it saying, "van a copiar y saber lo que estás haciendo... los niños absorben como una esponja" (they are going to copy and know all that you are doing... children absorb like a sponge), producing a clear and sophisticated explanation of the central theme of the story.

Although Snowy was not directly involved in this conversation, he clearly began to make connections and play creatively with the language in response to the word cue esponja. First, he said, "Esponja Bob" (Sponge Bob), including the Spanish sounding pronunciation of the name Bob softly under his breath. Then, he laughed, and switched the word order, saying "Bob el Esponja" (Bob the Sponge), and repeated this phrase 
several times. This example is interesting, because it shows attention to syntactical features of Spanish over English. In Spanish, a person would not say Sponge Bob in the same order as English, because descriptive information is normally placed after the name, whereas in English, it is placed before the name. Snowy connects the word sponge (outside of the task-oriented context of what Laney and Stacy are doing) to his personal understanding of sponges, as they relate to the cartoon character Sponge Bob. This was clearly not the topic of the day's lesson. He then plays with the word order and constructs Bob the Sponge, "Bob el Esponja" with a more authentic Spanish word order and also selects the masculine pronoun, because Bob is a male character over the pronoun that would be feminine, as in la esponja (because the word ends with -a). This illustrates, irrespective of Snowy's autism diagnosis, a sophisticated understanding of the syntax of the Spanish language in impromptu language production. He speaks only English in the home, so his understandings of Spanish syntax and structure come entirely from this immersion school environment. There are few existing studies about children in immersion schools with diagnosed learning disabilities, and this type of language play demonstrates the need for further study in this area.

On other occasions, there were word plays that took place in English as teasing. This also echoed the findings of Broner and Tarone (2001), whose own study found that when students were off-task and surrounded by close friends, they had a tendency to use their first language (L1) for "pre-adolescent social communication" in the form of teasing or even singing (p. 368). At this point, the students were supposed to be doing collaborative group work during the lenguaje class period to answer comprehension questions. 
Table 4.31 Transcript excerpt: "I am faster than Rolando."

\begin{tabular}{l|l}
\hline Original transcript & codes / notes \\
\hline Ahmose: But I am faster than Rolando. Ain't I faster than & challenge \\
Rolando? & correction of syntax \\
Asha: Aren't I faster than Rolando? Not ain't I faster than & repeated challenge / \\
Rolando. & teasing \\
Ahmose: But I am faster than Rolando. Terrell, aren't I faster \\
than Rolando? James. James. Everyone knows that I am \\
faster than Rolando. Rolando is just afraid to admit it. It takes & response \\
a big man to admit that he is wrong. & \\
(A student from another table group makes a comment about & jokes referring to his \\
big men versus little men.) & own small stature \\
Ahmose: Thank you, because I am a little man. & \\
\hline
\end{tabular}

In this conversation, one can perceive that Ahmose is teasing other students about their running speed. Asha's only (humorless) response to the conversation is to correct Ahmose's English syntax. However, Ahmose refuses to engage with Asha, alters his syntax, and continues to make jokes, trying to recruit other friends by name into the conversation (Terrell and James). When they fail to engage with him, he jokes in a selfdeprecating way about his own small stature saying "Thank you, because I am a little man" in response to the student at another table.

Two days later, Ahmose worked collaboratively with Asha, Clyde, and Terrell. At this point in the conversation, Terrell has just returned to the table after passing out dictionaries and tries to ask for clarification from his peers. Although Terrell generally does not answer the teacher's questions in Spanish, he attempts to engage his peers in Spanish and is interrupted. 
Table 4.32 "Alright. What do you do...?"

\begin{tabular}{l|l}
\hline Original transcript & codes / notes \\
\hline Terrell: Alright. What do you do for \#3? ¿Qué & Q: clarification, switches \\
haces...? (What do you do...?) & $\begin{array}{l}\text { languages and is cut off by other } \\
\text { student } \\
\text { gives instructions } \\
\text { notebook. Like it says. }\end{array}$ \\
Clyde: From the dictionary. & $\begin{array}{l}\text { instructions } \\
\text { Q: clarification }\end{array}$ \\
Terrell: Which words..? & instructions \\
Asha: Yeah, from the dictionary. & Q: clarification \\
Terrell: What? Each of these words? 1,2,3,4,5? & affirmative \\
Asha: Yup. & negative reaction \\
Terrell: I don't like this. & Q: explain \\
Ahmose: Why don't you like this? & explains briefly \\
Terrell: all about (motions towards dictionary) & begins to sing the alphabet song \\
Ahmose: abcdefghijklmnop & returns to good humor \\
Terrell: (Laughing) You are crazy.
\end{tabular}

As one can recognize, Asha and Clyde are busily working and respond to Terrell with short instructions when asked for clarification regarding question number three on a printed handout (Figure 4.21). 
Figure 4.21 Model illustration

Production

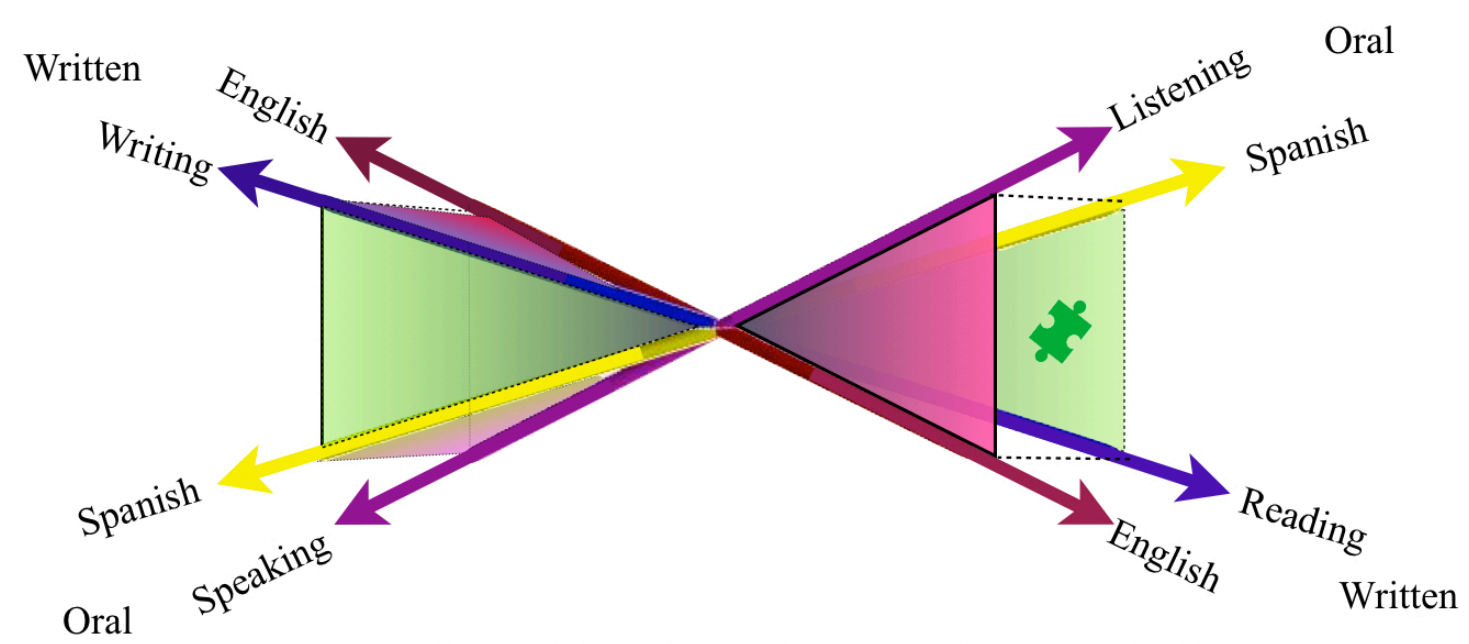

Scaffolding Episodes in the Development of Biliteracy Task: Spanish Reading

Terrell and Ahmose are good friends, but Ahmose does not get involved in the conversation at all at the four-person table until Terrell states he does not like the assignment. Ahmose then interjects and asks for an explanation saying "Why don't you like this?" Terrell then begins to explain briefly motioning towards the dictionary. In response, Ahmose begins to sing the alphabet song, which instantly cheers Terrell up. $\mathrm{He}$ begins to laugh and says to his friend "You are crazy" before commencing his work.

Language choice one-on-one. Profesora Nuria also worked with individual students in attempts to shape their attitudes toward language choice. She regularly worked with students one-on-one during the ENIL evaluations in particular. There were two students, Asha and Terrell, who both expressed reluctance to speak and read in Spanish to the teacher and to their classmates. Due to the frequency of their selfreflective comments and her responses, these interactions represent illuminating 
examples of how teachers may impact language ideologies and practices of individual students.

Asha and avoidance. While conducting the ENIL assessment of reading levels in Spanish, Profesora Nuria took the opportunity to speak directly with Asha about his reading habits. She has specifically noticed that he avoids reading in Spanish whenever possible. In the first part of the ENIL assessment, Asha defines some words on a list and then chooses one of two short story options to read aloud. He reads aloud fluidly with emotional flourishes and emphasis of key words. The teacher then stops him, putting aside the guide book and asks him directly, “Por qué no te gusta leer en español?” (Why do you not like to read in Spanish?) He explained that sometimes he does not understand what is happening in the story. The teacher then asks him a series of questions about the story he just read about a panda. She praises him for his description of the characters and main idea of the story, and concludes that he is now placed in nivel negro "a really good level. That's fourth grade." Asha seems disappointed by this news, as he places at above twelfth grade in English (according to the NWEA assessment).

Profesora Nuria encourages him to look forward toward the next step,

Table 4.33 Transcript excerpt: "Casi no leas en español"

\begin{tabular}{|c|c|c|}
\hline Original transcript & Translation to English & codes / notes \\
\hline $\begin{array}{l}\text { Prof: Pero, considera lo siguiente. } \\
\text { Casi no leas en español. Antes yo } \\
\text { pensaba que estuvieras en un nivel } \\
\text { mas bajo porque no leyeras en } \\
\text { español. Why have you gotten so } \\
\text { good at English? }\end{array}$ & $\begin{array}{l}\text { Prof: But, consider the } \\
\text { following. You almost don't } \\
\text { read in Spanish. Before I was } \\
\text { thinking that you would be in a } \\
\text { lower level because you were } \\
\text { not reading in Spanish. } \\
\text { Why have you gotten so good at }\end{array}$ & $\begin{array}{l}\text { compares } \\
\text { reading time } \\
\text { original } \\
\text { thoughts }\end{array}$ \\
\hline
\end{tabular}




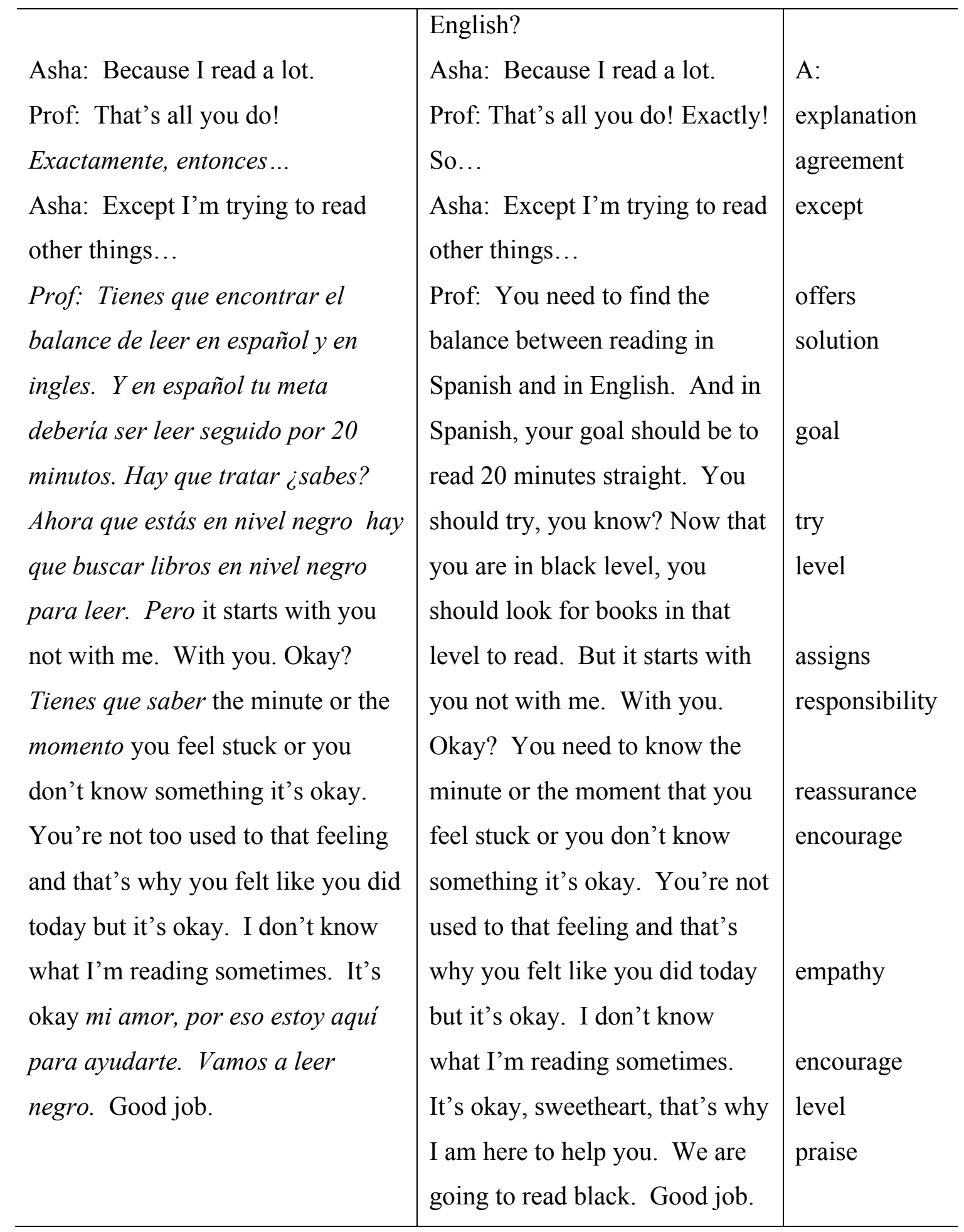

In this conversation, Profesora Nuria is focused upon assigning a level based upon the ENIL assessment adopted by the school. While working with the Asha she takes the opportunity to address his general reluctance to read in Spanish in a variety of ways. She 
asks for explanations, provides goals, reassurance, encouragement, and empathy for the situation in which he does not feel confident when he reads in Spanish. As MacIntyre, Clément, Dornyei, and Noels (1998) noted, "we see the desire to interact with a specific person and state self-confidence as the most immediate determinants of WTC" (p. 549). She explained her interactions with him during the ENIL in this way in an aside conversation,

Evalué a David que lee en inglés like no one's business, creo que lee high school level, $y$ estaba leyendo en [nivel] negro, que es cuarto grado, y... lo leyó muy bien... pero yo sé que he struggles $\mathrm{w} /$ the comprehension. Entonces nuestra meta con él es intentar de balancear la cantidad de la lectura que hacemos en los dos idiomas. (I evaluated David who reads in English like no one's business, I believe he reads high school level, and he is reading in black [level], which is fourth grade [in Spanish]. He read it very well, but I know that he struggles with the comprehension. So, our goal with him is to try to balance the amount of reading that we do in the two languages.)

What she left out of this brief narrative description of their interactions was the level of support and encouragement that she tried to provide to reassure him that she was there to assist.

In early October, I asked for her perspectives on the ENIL program and her "agreement" with the "levels" assigned by the assessment. She used Asha as an example, [He is a] kid who loves to read. He challenges himself, he came up as to read in a fourth grade level in the ENIL. But he said, "Profesora you know what, I grabbed this book that is two grade levels above where I should be and I'm 
understanding very well." So I said "okay, how about you go ahead read that, and next time when I confer with you, we'll see how your comprehension is doing." I also do understand though, the ENIL, and I explain to my kids, it comes to a point where after a certain color level, it's no longer just about fluency and comprehension. It's about different genres, having the ability of keeping up with different genres, then having the ability of keeping up with different stuff. So with this kid, I totally believe that he understands.

As Nuria explains, she recognizes some of the limitations of the evaluative levels of the ENIL program, in that some of the levels have more to do with genre-driven considerations among others. She acknowledges Asha's ability to read texts that are not "leveled" in black, and offers to meet with him "confer" to ensure his "comprehension." We may also see here some evidence of appropriation of her suggestions to encourage him, as she recognizes his efforts to challenge himself.

However, even after Profesora Nuria's work with Asha during the ENIL to encourage his reading in Spanish, this is the conversation recorded during a class transition time,

Table 4.34 Transcript excerpt: "I hate reading in Spanish."

\begin{tabular}{l|l|l}
\hline Original transcript & Translation to English & codes / notes \\
\hline $\begin{array}{l}\text { Terrell: We read...(cambio de idioma) } \\
\text { Profesora, ¿leer en español o en }\end{array}$ & $\begin{array}{l}\text { Terrell: We read... (language } \\
\text { switch) Teacher, read in } \\
\text { inglés? }\end{array}$ & Qpanish or in English? \\
$\begin{array}{l}\text { Profesora Nuria: En español } \\
\text { Terrell: uhhhh (sonidos negativos) }\end{array}$ & $\begin{array}{l}\text { Prof: In Spanish. } \\
\text { Terrell: uhhhh (groaning }\end{array}$ & A: language \\
Asha: (voz baja) She just said we & Asha: (whispering) She just & \\
\hline
\end{tabular}


have to read in Spanish.

I hate reading in Spanish. said we have to read in Spanish. I hate reading in Spanish. response

negation

As one can interpret from this conversation, both Terrell and Asha respond negatively to the instructions by Profesora Nuria to read in Spanish for this classroom activity. Terrell makes an effort to pose the question in Spanish, as he stops himself mid-sentence and switches languages to seek clarification. While Terrell's negative response is confined to groaning noises, Asha explicitly describes his feelings, saying, "I hate reading in Spanish.”

Terrell and control. In her work with Terrell, the social leader, Profesora Nuria focuses in upon understanding his need to control his interactions with others. A new student enrolled in the class in November, and Profesora Nuria immediately noted a shift in behaviors by Terrell. She found that he was noticeably more verbally assertive, bordering on combative with the new student. She questioned him about his behaviors asking what was happening to cause this change. In her comments to me, as an aside, she was surprised at his self-reflective and candid response that he needed to "show the new student" his "role" in the class. This need for "control" in the classroom is also addressed by MacIntyre, Clément, Dornyei, and Noels (1998), who described this is as a component of the social dynamics in the classroom, writing that "in the case of intergroup relations, motivation to control" can affect bilingual communication patterns "as a means of maintaining and reinforcing social positions" (p. 551).

Profesora Nuria reflected upon her own decision-making about Terrell's patterns of class participation in the October retrospective interview, saying, 
And then but yeah I also realize that when it's just Spanish, some of my kids that usually will participate if it's English, they will never participate in Spanish. You know, and that's why that's always my constant struggle. Terrell loves to participate, I've noticed. But I've also noticed that the times that he does it in Spanish are minimum to none. But I encourage him to keep participating and being on task because I don't want him to feel like, "Uh, I'm not going to say anything because she's not going to let me if it's not in Spanish." (Interview, October, 6, 2017)

Through this description of her thought processes, Profesora Nuria provides insights into her "constant struggle" to work with language choice in the participation patterns of her students overall. She then mentions Terrell as a person who enjoys participating in class discussions, though only participates in English. It is important to keep in mind that while Profesora Nuria accepts the student's participation in English, her primary language of communication with the students is Spanish. So, what she means here, is that she continues to pose the questions in Spanish while allowing the students the latitude of self-selecting the language of response. Terrell demonstrated in many ways throughout the observation period that he was indeed "on task" and "participating" with an understanding of the questions and discussions that were taking place around him in Spanish. She also underscores the importance of "encouraging" him through this decision on her part, as she does not want him to cease to participate "not say anything." In reflecting upon my original question about language choice in the same interview, she recounted a particular incident from that day that shows her thoughts about 
his need for "control" within the social dynamics as she describes her attempt to induce him to use Spanish during recess.

Table 4.35 Transcript excerpt: "Profesora, can you please go get the ball?"

\begin{tabular}{|c|c|}
\hline Original transcript & codes / notes \\
\hline Today at recess the ball went over the fence and Terrell & \\
\hline came over and said, "Profesora, can you please go get the & polite request \\
\hline ball?" And then he goes, "Can you please go get la pelota." & language switch \\
\hline And I said, "If you say it all in Spanish I will." He got & request for $\mathrm{L} 2$ \\
\hline frustrated with me, and I'm like, "Well I'm not moving." I & negation \\
\hline knew that I was walking towards the outside, but he didn't & reaction \\
\hline realize it. And he was like, "Profesora, come on, can't you & persuasion \\
\hline just go get the ball." "Not until you say it in Spanish." And & negation \\
\hline he never did. And he had friends saying, "Terrell, puedes por & inaccurate peer scaffold \\
\hline favor por la pelota." But he was so frustrated that he was & \\
\hline like, "No." And so later on today I want to sit down with him & negation \\
\hline and say like, "I hope you know that it wasn't just to like tease & sensitivity to student \\
\hline you or something. I want you to keep practicing." You know, & reactions and feelings \\
\hline and little things like that. So again, in class I'm not going to & encouragement \\
\hline do that to him because I don't want him to get discouraged. & \\
\hline But in that social aspect of life, I do want him to. Plus he & acknowledgement of \\
\hline knows, he was just frustrated because he was losing. & social dynamics \\
\hline
\end{tabular}

During recess, Terrell was playing ball with friends when the ball went over the fence.

Students are not allowed to exit the school grounds beyond the fence to get anything for safety reasons. Terrell switches languages on his own with his second request providing the code-switch at la pelota (the ball). This inspires Profesora Nuria to tell him to ask the entire question in Spanish in exchange for her retrieval of the ball. Unbeknownst to him, she was planning to get it regardless, but reports that he became frustrated, and turned to 
trying to persuade her to go ahead and get it. Some of his friends attempted to provide somewhat in accurate peer scaffolds, saying "puedes por favor por la pelota" (can you please for the ball) (Figure 4.22).

Figure 4.22 Model illustration

Production

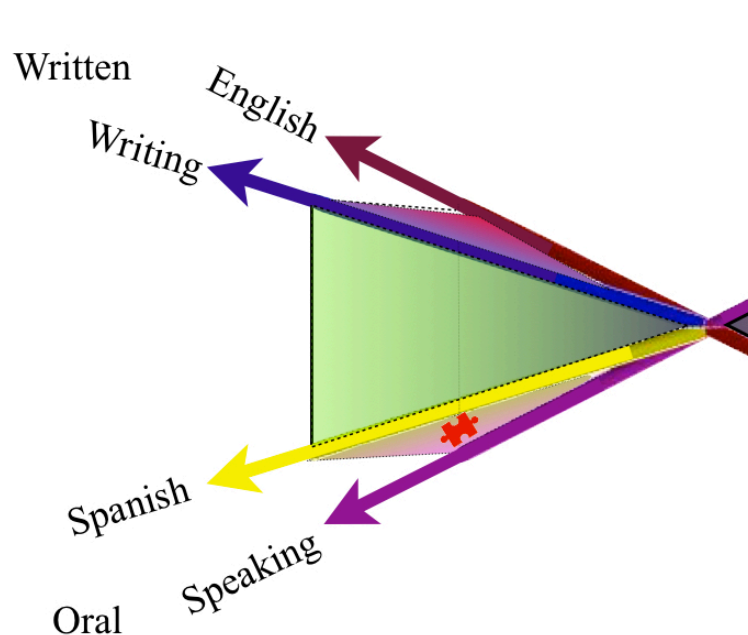

\section{Reception}

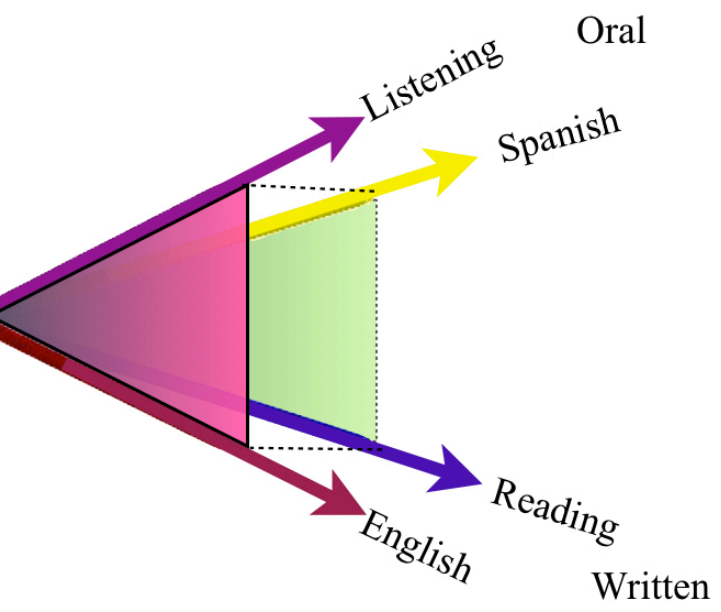

Scaffolding Episodes in the Development of Biliteracy

Task: Spanish Speaking

The scenario is interesting from a linguistic standpoint as the research shows (Potowski, 2004) that in immersion schools such as this one, where the community's minority language is the target language, students overwhelmingly use the majority community language (English) in social communications, such as during recess and lunchtime. Additionally, making polite requests and their formulations may never have been covered within the curriculum. He never responded in Spanish, even with the assistance of friends bluntly responding "no" to their urging. As articulated from Profesora Nuria's perspective, she believes that Terrell himself recognizes that he was simply trying to exert control in front of his peers in this situation. However, she does describe her own 
sensitivity to the scenario, explaining her plans to acknowledge and apologize to him because "because I don't want him to get discouraged."

There were other times that Terrell showed his desire to respond in English in somewhat challenging terms in directing his own ways of participating in the class discussions. This point is further illustrated in the discussion about the poem iQué alegre se pone el río! in Profesor Roberto's classroom,

Table 4.36 Transcript excerpt: ¿Qué piensas del poema?

\begin{tabular}{|c|c|c|}
\hline Original transcript & $\begin{array}{l}\text { Translation to English } \\
\text { underlined text originally in } \\
\text { English }\end{array}$ & codes / notes \\
\hline Terrell: Why you cryin'? & Terrell: Why you cryin'? & off-task \\
\hline Profesor Roberto: Terrell, ¿me & Prof R: Terrell, can you tell me & Q: opinion \\
\hline puedes decir lo que piensas del & what you think of the poem? & rephrase \\
\hline poema? Dime lo que piensas tú. & Tell me what you think. & question \\
\hline $\begin{array}{l}\text { Terrell: I axed him why he was } \\
\text { cryin'. }\end{array}$ & $\begin{array}{l}\text { Terrell: I axed him why he was } \\
\text { cryin'. }\end{array}$ & A: negation \\
\hline Prof R: Bueno. ¿Por qué? & Prof R: Okay. Why? Never & Q: explanation \\
\hline Anda, pues vale. Yo te había & $\underline{\text { mind. I have asked you, what is }}$ & repeat question \\
\hline $\begin{array}{l}\text { preguntado, ¿qué es lo que } \\
\text { piensas? }\end{array}$ & it you think? & \\
\hline Terrell: I want it in English. & Terrell: I want it in English. & A: negation \\
\hline Prof R: Me da igual. Yo no te & Prof R: It's the same to me. I & affirmative \\
\hline estoy diciendo en español o en & am not telling you in Spanish or & language choice \\
\hline inglés. ¿Qué piensas de lo que & in English. What is it that you & repeat question \\
\hline quiere decir en el poema? & think the poem wants to say? & \\
\hline Terrell: Well, I didn't finish it. & Terrell: Well, I didn't finish it. & A: opinion \\
\hline But I think this poem is good & But I think this poem is good & meaningful \\
\hline because it's telling you not to be & because it's telling you not to be & message \\
\hline
\end{tabular}




\begin{tabular}{|c|c|c|}
\hline $\begin{array}{l}\text { sad and like to live life to the } \\
\text { fullest. }\end{array}$ & $\begin{array}{l}\text { sad and like to live life to the } \\
\text { fullest. }\end{array}$ & \\
\hline $\begin{array}{l}\text { Prof R: And, why do you think } \\
\text { that? ¿Por qué piensas eso? }\end{array}$ & $\begin{array}{l}\text { Prof R: And, why do you think } \\
\text { that? Why do you think that? }\end{array}$ & $\begin{array}{l}\text { Q: why } \\
\text { translation }\end{array}$ \\
\hline $\begin{array}{l}\text { Terrell: Because you've only } \\
\text { got one life? }\end{array}$ & $\begin{array}{l}\text { Terrell: Because you've only } \\
\text { got one life? }\end{array}$ & A: explanation \\
\hline Prof R: Vale. Porque tienes & Prof R: Fine. Because you only & affirmation \\
\hline $\begin{array}{l}\text { solo una vida. ¿En dónde ves } \\
\text { eso? }\end{array}$ & $\begin{array}{l}\text { have one life. Where do you see } \\
\text { that? }\end{array}$ & Q: evidence \\
\hline Terrell: Nowhere. & Terrell: Nowhere. & A: negation \\
\hline Prof R: Nowhere? (risas) & Prof R: Nowhere? (laughing) & laughter \\
\hline Dame una evidencia. & Give me evidence. & Q: evidence \\
\hline Profesora Nuria: Is there & Profesora Nuria: Is there & intervention / \\
\hline $\begin{array}{l}\text { something from the poem you } \\
\text { saw? }\end{array}$ & $\begin{array}{l}\text { something from the poem you } \\
\text { saw? }\end{array}$ & support Prof N. \\
\hline $\begin{array}{l}\text { Terrell: I just thought about it } \\
\text { because... it's like that's }\end{array}$ & $\begin{array}{l}\text { Terrell: I just thought about it } \\
\text { because... it's like that's }\end{array}$ & $\begin{array}{l}\text { A: vague } \\
\text { explanation }\end{array}$ \\
\hline basically what the poem is & basically what the poem is & \\
\hline telling you to be happy and live & telling you to be happy and live & \\
\hline life. & life. & \\
\hline $\begin{array}{l}\text { Prof R: Bueno. Me gusta. Me } \\
\text { gusta que me digas lo que } \\
\text { piensas. }\end{array}$ & $\begin{array}{l}\text { Prof R: Okay. I like it. I like it } \\
\text { that you tell me what you think. }\end{array}$ & $\begin{array}{l}\text { affirmation } \\
\text { praise }\end{array}$ \\
\hline
\end{tabular}

In this conversation, Terrell is focused upon another student and off-task. From the audio file, it is not clear what is happening with his classmate. Profesor Roberto pursues a line of open-ended questions about the poem. However, Terrell first refuses to answer stating that he wants "it in English." He clearly understands the questions being posed, and has been following along with the reading and discussion, as his comments are accurate about the theme of the poem. He responds appropriately at a steady pace in English to Profesor 
Roberto's prompts, who continues to address him in Spanish. (From a linguistic standpoint, this interaction is also interesting, as he spends little time with Profesor Roberto. Profesor Roberto is from Spain, and his Spanish-speaking accent is completely different from Profesora Nuria's Honduran accent. As an English-speaking person, one might compare this difference to British English versus American English.) However, as the lesson objective was to look for evidence in the text, Profesor Roberto continues to try to find out what evidence Terrell has for his reasonable claim. Terrell seems unable to come up with answer about where he saw this in the text, saying "Nowhere" which prompts laughter from Profesor Roberto, who seems uncertain by his intonation if Terrell is simply declining to respond, or if he genuinely does not know. Profesor Roberto tries to ask for evidence again. With Profesor Roberto's second attempt, Profesora Nuria intervenes in English in a soft tone, asking him "Is there something in the poem that you saw?" Terrell responds with a generic statement, starting off by saying, "I just thought about it..." perhaps indicating he does not know where to find evidence in the text. Profesor Roberto ends the conversation with a positive statement regarding Terrell's participation.

Profesora Nuria explains her work with Terrell during the October interview, explaining that her interactions with him are times when you pick and choose your battles. I know Terrell has struggled with school so much, and just the fact that sometimes, even though he's not necessarily following the reading, even though he's not necessarily doing exactly things how I want him to do it, I see the winnings. He is trying to follow along with what's going on... He is part of my class. And I think it's a lot of expectations kind of thing. If I 
know that you can give me this, I expect nothing less. (Interview, October, 6, 2017)

It was clear towards the end of the observation period, that her work to encourage Terrell was effective. On one particular date, he brought the entire laptop with the iReady program over to her desk to show her that he was practicing and improving his "scores in vocabulary" and that he had completed his work for English class. That represented a great change from the conversation earlier in the year, in which he refused to do a particular math assignment saying, "Profesora, I don't want to do this. I'm too lazy and I'm just not going to do it." Throughout her interactions with the students, Profesora Nuria was focused upon language choice and the encouragement to look towards the future.

\section{Language Ideologies, Language Practices, and Circles of Influence.}

Although the original focus of this study was to discover and describe the scaffolds of biliterate development, questions emerged almost immediately regarding curricular program design and its effects upon scaffolding. This directly relates to the fourth research question: What forces or tensions does the teacher face as she scaffolds for biliteracy development? As I observed the (Estudios sociales) Social Studies class period, I began to wonder: Why is the reading in English? Why is the teacher asking questions in Spanish aloud as the students read in English? Why are the comprehension questions posed in English in the text, but the classroom discussions about the questions led in Spanish by Profesora Nuria, while the students respond in the language of their choice (Spanish or English)? There was a perpetual underlying message that emerged 
throughout the observation period in Fall 2017 that the teacher and students in this classroom move with great linguistic flexibility from English to Spanish, and back again.

These multi-layered language choices were unexpected, as this observed model does not mimic the target language use anticipated within a "full immersion" or "early total immersion" program. As described by Shrum and Glisan (2016), "in typical early total immersion, for the first two or three years beginning in kindergarten or first grade, all instruction is conducted in the foreign language" (p. 113). As I recall, the structure described in the above definition was echoed by the school principal when I visited the school for the first time in 2013. Doctora Martínez met with me, gave me my first tour of the school, and emphasized in our informal conversations that she showed videos to the parents of incoming kindergarteners to explain the process of arriving the first day of school and hearing an unfamiliar language from the teachers. At that time, she described the model of the school as $100 \%$ immersion until the second half of second grade, when one English class in a separate classroom with a designated "English teacher" one period per day was introduced after that. Throughout the grades, all assigned homework was in English to facilitate parental assistance and understanding of the work conducted during the day, and to reinforce the content area knowledge.

Garcia's (2009) article describes models of language and biliteracy in four different ways; the closest to what is currently occurring in the observed fifth-grade classroom at SLIP seems to be a "flexible multiple model," in which the teacher alternates between integrating and separating languages (p. 342). This model is one in which the teacher and students move flexibly between two languages, and the languages of the text, and the questions and responses are not necessarily in the same language at 
any given moment. Garcia further refines this point, explaining that within this model there is some attempt to privilege Spanish over English during certain class periods, and English over Spanish in others. However, I do not believe that the purposes behind the language switches in this case necessarily mimic those described in Garcia's model. As described through this research project, there are other forces and tensions that influenced language choice on the part of the teacher that do not seem to be aligned with translanguaging pedagogies.

The emergent line of questioning regarding this observe "flexible multiple model" that frames the language practices in this classroom in my research, led to some unanticipated findings about the circles of influence and sociocultural contexts relevant to this case. As Stake (1995) writes, the qualitative researcher in sociocultural qualitative case study needs to be responsive to the constraints and possibilities that directly affect the case. In response to this, I felt that it was essential to illuminate the tensions, constraints, and influences as they affected change and shaped curricular decisionmaking in this classroom in the Spanish Language Immersion Program (SLIP) over time. This led directly to the creation of the fourth research question following the first few classroom observations.

Therefore, in this section, I first present the teacher statements about her own language ideologies and how they were shaped by her childhood educational experiences. Then, I explore the comments that she makes about how these impacted her perspectives on teaching in the immersion school as she began her work at SLIP as a new teacher. These descriptions are followed by discussions of emerging institutional tensions within the implementation of full immersion. Then, I feature how the prior school 
administration proposed to support teacher's work in biliteracy through material selection and its influences upon current practices. Finally, I chronicle some broader communitydriven objectives, including the role of assessment, that continue to cause systemic changes that compel shifts in language choice at the curricular level.

\section{Developing language ideologies based upon personal experiences.}

Sociocultural Theory explains in a variety of ways how personal experiences can build one's own understandings and beliefs about language use. As Razfar and Rumenapp (2014) write,

Our ideas about the nature, function, and purpose of language impact our uses of language not only in the classroom but society at large. We collectively refer to these explicit and implicit ideas about language, whether in-school or in society, as language ideologies (p. 68).

Teachers' language ideologies are reflected through their own classroom practices and interactions. I observed Profesora Nuria's interactions with her students as the embodiment of practices based upon beliefs and her own ways of knowing and reflecting upon operating in two languages as mediational means.

During the pre-observation interview in September 2017, I asked Profesora Nuria about her own educational background. As she described her own schooling, she highlighted some of the ways that her childhood and adolescent experiences had shaped her perspectives on language use and bilingualism.

Table 4.37 Transcript excerpt: A private school in Honduras

\begin{tabular}{l|l}
\hline Original Transcript & Translation to English \\
\hline $\begin{array}{l}\text { It was a private school in Honduras. I went } \\
\text { there from kindergarten all the way through }\end{array}$ & \\
\hline
\end{tabular}


twelfth grade. And, my main classes like Math, Science, Social Studies, English, they were all in English. And, I had PE in Spanish. Obviously, we had the Spanish class, we had different classes in Spanish. Our teachers, some were American, but they knew both languages. So, they would do their teaching in English, but then maybe... they'd be sitting down and "Ana, ¿hiciste la tarea de ayer?” y tal... La conversación sería en español, pero the instructional era en inglés. Entonces, siempre...muy rodeados del inglés y español. $Y$ toda la escuela siempre me acuerdo que era en inglés y por las puertas "Welcome to Second Grade" and the bulletin boards "this is how third grade reads." Entonces, siempre estábamos expuestos a los dos idiomas. But here, you know, this is just a personal belief, but the fact that we knew that we were able to speak both languages without being like frowned upon, gave people more freedom to do so.

Based upon this portion of the interview, one can understand that Profesora Nuria was educated in a school that focused in upon teaching in English to Spanish-speaking children in Honduras. This school bilingual environment represents the entirety of her K12 education, and being schooled in that way, has led her to draw some conclusions about languages and learning based upon her own personal experiences. She notes that she and her classmates "siempre estábamos expuestos a los dos idiomas" (we were always exposed to both languages), and that they were "rodeados del inglés y español" (surrounded by English and Spanish). In the end of this segment she concludes by stating 
explicitly that her personal belief that the school's manner of either allowing or sanctioning the use of both languages provided students with more "freedom to do so." Also, as one can see from the previous example, in our interviews she also had a tendency to move fluidly from Spanish to English and back again.

In the same interview, she explains how the role of the interpersonal connection that an individual student has with a teacher may influence their language choices.

Table 4.38 Transcript excerpt: "Yo tenía una maestra de Aruba"

\begin{tabular}{|c|c|}
\hline Original transcript & Translation to English \\
\hline Yo tenía una maestra de Aruba, que & I had a teacher who was from Aruba, that \\
\hline hablaba súper bien el español y súper & spoke Spanish and English super well, but \\
\hline bien el inglés pero siempre me gustaba & I always liked to speak with her in \\
\hline hablar con ella en inglés... pero con otro & English... but with another teacher I felt \\
\hline maestro yo me sentía más cómodo & more comfortable speaking in Spanish. I \\
\hline hablando en español. Y creo que tiene & believe it has a lot to do with the \\
\hline que ver mucho con la conexión con el & connection with the teacher. There are \\
\hline maestro. There are some kids que me & some kids that speak with me in Spanish \\
\hline hablan en español súper bien, y no pasa & super well, and it's not a problem, but at \\
\hline nada pero a veces que se sientan más & times they feel more comfortable speaking \\
\hline cómodo conmigo hablándome en inglés - & with me in English - it's also good b/c \\
\hline it's also good b/c some kids prefer to not & some kids prefer to not even say anything \\
\hline even say anything because they're afraid & because they're afraid or embarrassed that \\
\hline or embarrassed that it will come out & it will come out wrong. And that is \\
\hline wrong. Y eso es algo que no quiero tener & something that I do not want to have in \\
\hline en mi clase, Al punto de, "I'd rather not & my class. That point of, "I'd rather not \\
\hline say it because I don't know how to say it & say it because I don't know how to say it \\
\hline in Spanish." Hay veces que se levantan la & in Spanish." There are times that they \\
\hline mano y empiezan a hablar en español y & raise their hand and begin to speak in \\
\hline dicen, "Can I just say it in English?" & Spanish and say, "Can I just say it in \\
\hline
\end{tabular}




\begin{tabular}{l|l}
\hline "Yeah, totally it's fine." Y lo dicen and & $\begin{array}{l}\text { English?" "Yeah, totally it's fine." And } \\
\text { they say it and then I'll say it so they }\end{array}$ \\
$\begin{array}{l}\text { then I'll say it so they know how to say it } \\
\text { next time, you know. So it was a little bit } \\
\text { of both in my school. }\end{array}$ & $\begin{array}{l}\text { know how to say it next time, you know. } \\
\text { So it was a little bit of both in my school. }\end{array}$ \\
\hline
\end{tabular}

She praises the speaking abilities of her teachers in both languages, including a particular teacher from Aruba. Then, she explains that with particular teachers she felt more comfortable speaking in one language over the other. She directly articulates the belief that "tiene que ver mucho con la conexión con el maestro" (it has a lot to do with the connection with the teacher) that the student possesses, which language they will choose. Profesora Nuria also compares this to the situations in the classes that she teaches now, where she does not want the student to feel "afraid or embarrassed that it will come out wrong." This attention to student feelings coincides with her overall focus upon the affective components of her work with the students, and her attention to interpersonal dynamics. Following these comments, she compares her teaching at SLIP and how she helps the students to "know" what to say the "next time" with "my school," referring back to the school of her childhood,

\section{Language Ideologies and Emerging Institutional Tensions in Full Immersion.}

As she describes her own educational background and how it relates to her work teaching in this school, she was able to articulate further details how her personal experiences shaped her work as a beginning teacher.

I grew up going to a bilingual school. So, I was always half and half. Until when I came to the Spanish school back then, four years ago. Teaching only in Spanish was a little bit hard for me because I could tell that some of my kids were not as comfortable. And, I actually started and I remember thinking "I'm going to get 
fired for this. But I'm advocating for my kids." I would be teaching math for example, and we were learning about the distributive property, associative property, and all of those in Spanish are very similar. But then when we got to the identity property...even myself, since I learned that in English all of my life, hearing that in Spanish for the first time, I'm like, “There's no way my kids are going to get this. You know? That's when it hit me. Let me go do both, as I speak, I'll sometimes write in English and sometimes write in Spanish.” My kids have already gotten used to it. I'll write el titulo, multiplicar números con multidígitos. Empiezo escribir algo en español, luego pongo algunas cosas en inglés. (I'll write the title, multiply multiple digit numbers. I'll start to write something in Spanish, and then put some things in English.) And I go back and forth. And sometimes I'm teaching in Spanish and then when I say it in English, I can see some of my kids going "Ah." So, little experiences like that have made me understand that it's kind of like differentiating, not every kid will learn at the same speed, at the same rate... maybe they won't understand it in one language, but they understand it better in the other. I do have some kids that if I taught everything in Spanish all day, they'd be fine. But I do have a lot of kids that also need that English. Kind of like reassurance kind of thing. So, I do a lot of Spanglish in my class. Sometimes I repeat myself, I'll say it in Spanish and then I'll say it in English. Um, but I think it's helped a lot. (Interview, September, 14, 2017)

This statement that "teaching only in Spanish was a little bit hard for me" referring back to her first year of teaching. She also describes her thought process as a reaction to her 
feeling that the students were "not as comfortable." As a deliberate strategy in response to the thought "they're never going to get this," she increased the amount of English translation and "Spanglish" as her language practices in class. This was viewed as a way of teaching practices that were "kind of like differentiating." Profesora Nuria explains her ideological viewpoint with her stated desire to use English as a means of "differentiation" and based upon student "need" and as a way to "advocate" for her students to make them more "comfortable." She also concludes this segment with her statement that she believes it has "helped a lot."

However, this ideologically driven decision-making is tempered by her concerns that she was going to be "fired" for this practice of switching between two languages in her first year of teaching. During her first few years of teaching, the school had a full immersion focus and a school founder (Madame Boudreaux) and principal (Doctora Martínez) with similar viewpoints framed as "la misión y la visión" (mission and vision) of language immersion by Doctora Martínez.

In Spring 2018, I met with Dra. Martínez, with the goal of understanding the broader school context and its circles of influence. She was the school principal from the opening of the school before moving into higher administration in the central office. She was one the only administrators who had remained through the entire existence of the school including the present school year. She explained that when she was the school principal (during Profesora Nuria's first years of teaching), that she maintained firm adherence to the mission of the school under the leadership of Madame Boudreaux. The school goals of full immersion were described through various communiques from Madame Boudreaux entitled, "non-negotiables" that included requiring all classroom 
posters in the target language, and all classroom discussions $100 \%$ target language on the part of the classroom teachers. There were also incentive programs in the form of "monedas" (coins) for students who spoke the target language during recess and lunch periods that could be collected in each classroom for a reward. This "full immersion" model also fits with her prior informal descriptions to me during my initial school tour in 2013.

The only question regarding Profesora Nuria that I asked of Doctora Martínez was an extremely open-ended one by design. "What was your impression of Profesora Nuria as a teacher in the school?" Her opinions corroborated the statements by Profesora Nuria's impressions of the situation. Dra. Martínez recalled that Profesora Nuria started her teaching her career at SLIP immediately following college graduation. She also mentioned that had Nuria attended an English school in Honduras, and that it was her impression that Profesora Nuria did not seem to completely embrace the overall school "vision" of full language immersion in Spanish based upon her own personal experiences. Doctora Martínez characterized this as an "obstáculo" (obstacle) she shared with a few other teachers, saying Profesora Nuria and others continued to use "un poquito más de inglés" (a little bit too much English). She believed that in her role as principal, it was necessary to work to "convencerles" (convince them) about the value of the full immersion model.

Effecting change through materials selection. Doctora Martínez worked to mediate some of the emerging institutional tensions regarding full immersion and its implementation through materials selection. This presented a real challenge, as the original design of the school, five years prior was following an International 
Baccalaureate Primary Years Programme (PYP) that openly discouraged the use of any textbooks. Therefore, the original rather organic design of the school, to have teachers design and select both the curriculum and materials (mostly online readings from a variety of Spanish-speaking countries or documents they translated to Spanish themselves), created an "overwhelming" situation for many teachers. This thought was echoed by Profesora Nuria in our pre-observation interview who explained, the PYP "is very broad. I know that's why a lot of teachers sometimes kind of struggle."

Dra. Martínez says that she felt that there were some flaws to the student outcomes based upon the extremely open-ended guidance regarding curriculum. She characterized these outcomes as "español muy básico," (very basic Spanish) "superfluo," (unnecessary or superfluous) with "una falta de vocabulario académico," (a lack of academic vocabulary) and "no era muy estricto" (it was not very strict). She described her own efforts to standardize and improve instruction through the introduction of the ENIL program to ensure greater standardization through the empowerment of teachers in Spanish literacy instruction. She enthusiastically reported that grant funding had enabled the purchase of these materials for every teacher. This purchase included teacher education workshops and publisher support for program implementation. The ENIL adoption included a reading levels assessment package as well as entire reading book sets with multiple genres available at each level for each classroom. The bins in the classroom bookshelves that indicate colored levels in Spanish are all from this American Reading Company program.

Profesora Nuria remarked upon the influence of the teacher education workshops provided by the publisher in the retrospective interview in October as she described her 
teaching during the lenguaje class period. She described the primary student "struggle" with reading is,

always vocabulary and obviously doing the ENIL, the level that they were reading at, I can tell that most of my kids are not at a fifth grade level. And you can tell when they're reading. But when we have the ENIL trainings they would tell us, you do a fifth grade or close to fifth grade reading as a whole class even if you have kids reading in a first grade level. Because you're modeling it to them, you're discussing it together. You're doing it all together and not necessarily letting them read it on their own. (Interview, October, 6, 2017)

As she describes the teacher workshops and follow-up visits, there are some emerging patterns of guidance that have prompted some changes to the way Profesora Nuria and Profesor Roberto plan their teaching of reading. She describes her struggle with reconciling the variety of student reading levels with the directive to use one on grade level reading with all students and reading as the large group which apparently constitute the beginnings of her "round robin" reading practices. She notes some times that she and her cohort teacher, Profesor Roberto were doing something different, I remember there was one time that Roberto and I were starting to have different passages for our different kids. Like oh these kids are reading in this color, these kids are reading in this color. We're going to give them readings according to their level, but we were highly encouraged not to. We actually got discouraged to do that. It didn't make sense to us because I remember last year, I even had a kid who did not read in a first grade level in Spanish and clearly there was no engagement because the reading was not there. And that's why we encourage them to read in 
their level trying to follow the objective of the class. And so that's why, oh I wonder this, oh I wonder that. I'm thinking this. So they know how I want them to think as they read in their own level. (Interview, October, 6, 2017)

When I asked her who is the "they" who encouraged them not to use leveled readings, and to read as the large group her responses were clear about the influence and guidance provided by the textbook company representatives from her point of view,

They said, "Okay, well whenever you're reading in Spanish ..." Whenever we're doing our guided reading, or we're focusing on that ENIL part of the day, no pencils, no ... They encouraged us to give them stickers, and for example if we're talking about the main idea, I would have the kids put a sticker over where they think the main idea was. But once again, we told our principal last year, it's giving them an additional manipulative for them to get distracted with. And not necessarily use it for what they have to. So for Raul and I, it was better if we just had them underline on the paper, underline the main idea. And teach them how to write notes on the sides of the paper or write their stuff on the notebook. And it also gave us a way to ... Okay, if at the end of the day I can go over their notebooks and see what they've done. But they told us no. That it takes their attention away from reading, when they're so concentrated on writing. But Raul and I still have our thoughts about that. They came back, and I actually someone asked again, you know, "We want to see our kids writing." We truly feel that we don't do much writing, that we ... Again, maybe this is our fault that it just seems like again, last year, the ENIL was so embedded in us as you do your reading with the whole class and after this, you need to dedicate 30 minutes ... They would tell 
us 30 minutes of independent reading. Sometimes I don't even get to do that because there's just so much discussion and whatnot. It feels like we have to do that every day to build a consistency with the kids. They even discouraged us to ... You know how in social studies, we'll do some reading? They'll answer the question in their notebook. They would even discourage that. They said, "For the kid has to be reading, it's reading time." For example, today I ... In my own personal mind, I would say, "Please write in your notebooks what you believe is el error más grande (the greatest mistake)." So they can all write something. And then I would ask someone to share. And when we did that last year, the person who was observing us for the ENIL would say, "No, no writing, no notebook. It's just reading." So that's when Roberto and I complained about that, and we were trying to say, "Okay, but this is our way to know who really is with us, who is following the instructions, who understands what we're doing." (Interview, October, 6, 2017)

In this long narrative, Profesora Nuria provides the information that both she and Profesor Roberto disagreed with some of the components of what the publisher representatives were encouraging them to do. She also describes ways that they tried to resist these techniques by "complaining" to the administration. Additionally, she describes some of the practices that she would prefer to be doing if not for this guidance imposed and overtly supported by the administration to build greater standardization of teaching practices regarding reading in the building.

Profesora Nuria also complains that she and Roberto believe that some commercial interests at the heart of this implementation pattern enforced by the 
representatives. The complete separation of reading and writing does not make real sense from a pedagogical standpoint as the research (Hornberger, 2004) clearly describes the intertwined nature of these skills. Profesora Nuria expressed their suspicions this way, And apparently this ENIL thing is just for reading. But there's a whole different program for writing. That we never purchased, or even got into to. Because we still wanted just everyone to get used to this. And so sometimes Roberto and I even wonder, "I wonder if they're just saying that so we can go ahead and purchase their writing." And we don't know, but it just seems like there should be a whole period aside for writing. (Interview, October, 6, 2017)

As noted by Dra. Martínez, the school constantly suffered financial constraints, and the reading materials were purchased with grant money. Therefore, it is entirely possible that the writing programs were not purchased for financial reasons. However, Dra. Martínez reported that she felt the adoption of the ENIL program as a means of program standardization and support was a great success. She stated that after the first year of implementation of this program that the state test scores improved notably.

Current language practices and seeking la "balanza." I also asked Profesora Nuria about her personal language practices of switching between English and Spanish during the observed class periods were conscious or subconscious, or whether they were based upon the interactions with students. She responded,

Sometimes I do switch without even thinking about it. But, I know that especially in math, I am very aware when I am switching to English. Like I'll say it in Spanish. I'll still see these confused faces, and I'll say the same thing back in English. Then, I'll see those 'lightbulbs' going on like, “Oh, okay” Let's move 
on. So, I think it's a little bit of both. I'm very aware most of the time, sometimes I'm not, like when I'm very comfortable going on and on about a topic. It helps for me knowing that these kids are very comfortable with the language, with Spanish. I used to switch way more last year and the year before that because they were not comfortable with the language. It's like in fifth grade, they need to have their academics down to a $\mathrm{T}$, not just focusing on the language. I will say that that has been a struggle personally. Because I know that it's and immersion school and parents want to have their kids there because they're learning the language, but also I always think, but would it be for parents if the kid is proficient in Spanish but then when the scores come in, the kid is not doing so well. So, it's always like that balanza (balance, as if weighed on scales)... you know. (Interview, September, 14, 2017)

There are several notable elements that lead one directly into her statements on these topics in 2017. The first of these, is that she is consciously aware of most switches, based upon "worry" that they won't know the terms in English, and as a reaction to "confused" looks from the students. Additionally, Profesora Nuria makes available her inner thoughts processing her concerns for the students through her statement, "So when in my head I was like am I hurting them more by speaking in Spanish and not meeting their needs in their academics or am I meeting their academics and being language not as important?" She also describes these dilemmas as a personal "struggle" to find a balance between "language" and "academics."

In 2015, she echoed similar points about concerns about academic biliteracy and understanding specific terms in both languages. I asked, "so... during the day, what 
subject would be the one that, that seems to be the hardest for them to understand the readings?" She immediately responded, "Science," and then elaborated with the following explanation,

I feel like it's science. Or, it really just depends on the topic, I mean, it depends on their interest. You know, because for Social Studies, Social Studies, can be challenging as well. Especially because... and I know that this is where my challenge comes, because like for example, their [state standardized] test is in English... So, I always try to do a lot of Spanish, and then we try to translate it into English. Make sure that they know, that ángulo obtuso, that that is an obtuse angle. (Interview, March, 27, 2015)

The most salient to the current trends within this school environment relates to her point in this portion of the 2015 interview, in which she refers to the standardized testing "scores." She describes this in 2017 as part of her own personal "struggle" to find a balance between the mission of language immersion and the importance of standardized test scores. Indeed, in all of our interviews, this is also a repeated theme, that has intensified over the intervening year and a half.

This idea of moving fluidly from one language to another based upon student or topic-based needs, is articulated clearly by Profesora Nuria in her interviews. I will explain the phenomena further with comparative examples from classroom observations and interviews. One such example can be found in a social studies class period at SLIP. In this brief vignette, the reader can note that the text read by the students, and by the textbook publisher audio files is in English, but the discussion facilitated by teacher questions and student responses is flexible and bilingual. 
Table 4.39 Transcript excerpt: Talking about pueblos and Mesa Verde

\begin{tabular}{|c|c|}
\hline Original transcript & Translation to English \\
\hline $\begin{array}{l}\text { Narrador (del libro de texto, clip auditivo } \\
\text { en inglés): Fast fact. Ladders were used } \\
\text { to enter pueblos. In the event of an attack, } \\
\text { the villagers pulled up the ladders. }\end{array}$ & $\begin{array}{l}\text { Narrator from the audio clip of the } \\
\text { textbook (in English): Fast fact. Ladders } \\
\text { were used to enter pueblos. In the event } \\
\text { of an attack, the villagers pulled up the } \\
\text { ladders. }\end{array}$ \\
\hline $\begin{array}{l}\text { Profesora Nuria: Entonces, chicos. Esto } \\
\text { también, nos hace pensar...que cuando las } \\
\text { escaleras estaban allí, estaba todo bien. } \\
\text { ¿En qué momento es que las escaleras las } \\
\text { escondían o las levantaban? ¿Stacy? }\end{array}$ & $\begin{array}{l}\text { Teacher Nuria (in Spanish): So, students. } \\
\text { This too, makes us think... when the } \\
\text { ladders were there, everything was fine. } \\
\text { At what point in time is it that the ladders } \\
\text { were hidden or pulled up? Stacy? }\end{array}$ \\
\hline $\begin{array}{l}\text { Stacy: Cuando una persona viene a atacar } \\
\text { a su pueblo. }\end{array}$ & $\begin{array}{l}\text { Stacy (in Spanish): When a person came } \\
\text { to attack their village. }\end{array}$ \\
\hline Profesora Nuria: Muy bien. ¿Rianna? & $\begin{array}{l}\text { Teacher Nuria (in Spanish): Good. } \\
\text { Rianna? }\end{array}$ \\
\hline $\begin{array}{l}\text { Rianna: ¿Ves esta madera que está } \\
\text { sticking up de la um... de las casas? }\end{array}$ & $\begin{array}{l}\text { Rianna (in Spanish except where } \\
\text { underlined): Do you see that wood that is } \\
\text { sticking up from the houses? }\end{array}$ \\
\hline $\begin{array}{l}\text { Prof: Sí. } \\
\text { Rianna: Estos allí... cuando fuimos a } \\
\text { Mesa Verde, esa parte allí fue de los } \\
\text { Balcony Houses... }\end{array}$ & $\begin{array}{l}\text { Teacher Nuria (in Spanish): Yes. } \\
\text { Rianna (in Spanish except where } \\
\text { underlined): Those there, when we went } \\
\text { to Mesa Verde, that part there was from } \\
\text { the Balcony Houses... }\end{array}$ \\
\hline
\end{tabular}

As in the previous example, during Social Studies, the students are reading a text in

English, and responding in Spanish. Profesora Nuria explains a scenario from Science class that demonstrates moving from Spanish to English and back to Spanish in a variety 
of ways. It is also interesting to note the rationale that she includes for these shifts in language. She began with the following statement, "Yesterday, or I think a week ago we did a Bill Nye video and they had a worksheet." My question was, "So, Bill Nye videos are in English. So, did you watch it in English?” This question was intent upon understanding the relationship between the two languages in the classroom. Profesora Nuria described the interaction between the languages in this Science example, Yeah, we watch the videos in English and then at the end when we have any kind of discussion, we do it in Spanish. And it's also something that I started, I realized my first year. And again, kids are very different every single year. These kids are way more into Spanish than any of my other three years. But I remember my first, second, and even third year when I would play something in Spanish, the attention span was slim to none. (Interview, September, 14, 2017)

Through these statements, Profesora Nuria reflects a difference that she has noted between year that she has been teaching and that this year, in particular, the students are more receptive to using the Spanish language. I responded by asking, "Really?" which prompted Profesora Nuria to continue,

Yeah. It was just like the mentality of, "Awwwww, it's in Spanish". And I know that for some kids it's not that they don't want it. Sometimes they just don't understand fully what they're looking at or maybe the person who is doing the videos speaks too fast, speaks too slow or the accent... So sometimes I like for them to hear it in English so they get the information and then discussion in Spanish. Because I've also realized that kids get used to your accent. Because I feel like I talk very normal to my fifth graders, then I'm talking to a third grader 
and they look at me (wide-eyed expression) but they can understand that Puerto Rican [referring to another teacher] that speaks like ten times faster, you know. So, it's kind of like a comfort zone type of thing. (Interview, September, 14, 2017)

As indicated by the findings of Profesora Nuria's attention to the affective components of teaching and learning, she is very sensitive to the desires of the students. In this case, she explains that she seeks to find the students' "comfort zone" with the language practices in the classroom.

\section{Language Ideologies, Systemic Constraints and Influences}

Between the Spring 2015 and Fall 2017 interviews, the school changed its leadership team. As noted in the school context information, the original founder of the immersion school, Madame Boudreaux, was removed in a controversial decision by the school board. Following the removal of Madame Boudreux, Doctora Martínez saw that the ideal of full immersion was being removed in favor of more and more English in the classroom with the explicitly stated motive of increasing standardized test scores.

The removal of Madame Boudreaux was controversial for more than one reason. As reported in the local media the question was posed in school board meetings by parents who wanted to know where to find the visionaries who embrace the concept of "immersion" with the comment that this "vision" seemed to be absent in the new administration. The article reported that the new administration was seeking to integrate more English into the curriculum as a response to low test scores on standardized tests. As a charter school within a public-school district, the school is ostensibly expected to meet or exceed average scores in the state, or at least in the local district. Indeed, in my 
conversation with Dra. Martínez, she lamented the changes to the program, saying that she felt very strongly that the full immersion model would still be in place if not for concerns over test scores. In the year of this research observation period, the school had adopted a number of measures aimed directly at increasing test scores. A contract with NWEA, a private company aimed at standardized score alignment and improvement for a variety of state tests, was adopted as a means of tracking student scores, objectives, and improvements throughout the academic year. What this meant in the aggregate was that students would be tested in the subject areas three times per year for the NWEA and once more for the "official" state exams.

I asked Profesora Nuria further questions about her language ideologies and practices in the classroom without mentioning testing in the form of the question. However, many of her responses eventually circled back to concerns about standardized test preparation and scores repeatedly. In this transcript segment, I ask about the changes to the schedule. In 2015 , the teachers were strictly separated, the regular classroom teacher was instructed to teach exclusively in the target language (Spanish), and the students would physically leave the home classroom and go to another teacher for English class. However, one of the first changes that I noticed about the schedule for 2017-2018, was English three days per week with the primary classroom teacher (in this case, Profesora Nuria). Therefore, I asked, her about how this has impacted what she is doing in the classroom. Profesora Nuria responded, Now it's [English in my classroom] three days a week. I personally love it. I get to teach my English comfortably in English, them knowing that it's English. Me knowing that it's okay for me to be teaching in English. We do have this new 
program called iReady - and we are using that for English and Math. But, for English it's just covering reading, so it's pretty much this program where they take a test called a diagnostic and that will place them in their right level. In their, level that they should be in. And so they have different lessons, so they'll be using the computers and get these lessons taught to them but I can look online and see, "Okay, this person has been doing this lesson two or three times already and is not moving on..." Then, that makes me realize "Okay, I'm going to do small groups with these kids that are not moving on from lesson number two." And the rest of the kids at the computer keep benefiting from the lessons that keep moving on. Um, so so far, I'm really excited about it. I guess it's just a personal thing. Because before I taught at [this school], I thought I was going to teach in an all English speaking school. So, I feel comfortable and I like it. I think, I think it's good. It's just a matter of having good communication with the English teacher as well. So we know what we're doing - and so the students don't feel like it's one class with her and a different class with me. Um, I think it's good. It helps the kids also get encouraged to do more reading in English. Which I believe, it's a huge thing for when they test. (Interview, September, 14, 2017)

This description indicates that Profesora Nuria feels more comfortable teaching in English, knowing that she has the administration's support for doing so and that it is now "okay." She describes the expectations that after graduating from college, that she would be teaching in an English-speaking school. Also, she indicates positive feelings about the software program that was adopted by the school to inform teachers with "diagnostic" information about individual students. She does also indicate preferences for meeting 
with small groups of students and individuals to assist them while other students work. In the end of this response she indicates that she believes these new practices will have a positive impact upon testing.

During one of my last observation periods in the fall, Profesora Nuria informed me that more changes were on the way. The schedule was going to be shifted again as they were increasing the amount of English instruction in all grade levels. It was startling to me that they were making scheduling programming changes mid-year. However, Profesora Nuria stated that some of the lower grade teachers were pressing for more dedicated teaching time in English. Again, the rationale was tied to test scores. What is regretful is that it appears from both Profesora Nuria's and Dra. Martínez's statements that the standardized testing is guiding and directing not only academic practices, but also language choice in this school context.

During the 2017-2018 school year, the students are assessed in a variety of ways that are not directly driven by classwork. The number of assessments has increased each year as described through this incremental drive for change as described by both Dra. Martínez and Profesora Nuria. Moreover, the extreme number of "standardized" assessments is as follows: NWEA assessments occur three times per year, iReady has an initial diagnostic test followed by adaptive activities that score students perpetually, the ENIL is a one-on-one in person assessment of reading level in Spanish generally occurring twice per year, and the state standardized testing takes a full week in the Spring. Obviously, in addition to those more "standardized" assessments, there are unit or chapter tests that the students take within their own classes as formative assessments. 
With all of the testing, students are clearly impacted. Profesora Nuria attempts to disrupt the implicit message delivered by repeated testing and scores, saying during Science class in October that your "grades do not determine who you are," and throughout the school year explicitly and implicitly valuing "knowledge as the prize." However, as with most people, actions speak louder than words. Students who are not close friends, who are from disparate "assessment levels," demonstrate clear recognition of this point in the following conversation:

Table 4.40 Transcript excerpt: "I'm tired of tests!" Original Transcript Terrell: I'm tired! I'm tired of tests.

Tessa: Then that must mean you're tired of school because school is pretty much about tests.

In this conversation, Terrell expresses his frustration "I'm tired! I'm tired of tests." It is relevant that Terrell could be considered an at-risk student based upon his diagnosis of ADHD, lower socio-economic status, and lower "assessed" reading levels. It would not be unusual for a student who is not generally "successful" on these assessments to express frustration. Unfortunately, as observed through Tessa's blunt response, “Then that must mean you're tired of school because school is pretty much about tests," the broader message that school is about "tests" has also been received loud and clear by one of the top academic performers in the class.

\section{Conclusion to findings}

In this chapter, the findings uncover clearly articulated ties between sociocultural contexts and classroom conversations through the investigation of scaffolding in the zone 
of proximal development. Among the findings, Profesora Nuria has established a classroom community bound by certain ethos including: organization and structure are valued, knowledge is prized, encouragement is contagious, reading is central, and language is a choice. All of these principles are evidenced through the student and teacher interactions, teacher interviews, classroom artifacts, and visual images. The attention to affect is also well-documented as the teacher provides a learning environment that demonstrates her attention to the affective components of teaching in this urban environment. The scaffolds provided by the teacher also serve to reinforce the central messages of the community for her responsiveness to student questions and the connections that enhance relevance of the readings to the students' lives. These findings also align with some of the research by Many (2002), who found teachers "connecting [readings] to personal experiences" (p. 383) in her study as well.

The task-oriented scaffolds employed by the teacher are accentuated by the presence of my new visual model "Scaffolding Episodes in the Development of Biliteracy." This model enhances the focus upon the teacher's assistance in the reception phase versus the production phase to directly address concerns about the difference in proficiency levels (in reception versus production) by students educated in one-way immersion programs in particular (Broner and Tedick, 2014; Genesee, 1987). Additionally, the scaffolds indicate responsiveness to in the moment student questions, issues of relevance of texts, and the use of visual support to enhance student work with literacy skills. The voice of Profesora Nuria explaining the thoughts behind her lesson designs (seeking "la balanza"), her work with individual students, and her interactions with administrative changes presents essential components to this project. 
Through her scaffolds, the findings indicate that visual support in the production phase, such as the anchor chart for summarizing a story, can scaffold development of literacy skills in both languages. Other scaffolds, including the use of visual support for the development of vocabulary resources in the second language, can assist with reading comprehension in the content areas. This can be especially helpful with specialized, concrete vocabulary that may be found in science or in social studies. The student requests for assistance indicate points at which students acknowledge their own need for assistance. One of the most important findings regarding the issue of vocabulary and classroom interactions lies with the relationship that Profesora Nuria was able to build with her students. The approachable and positive nature of her interactions with the students encouraged them to ask questions as needed. Even students deemed problematic or difficult by other teachers, such as Terrell, were drawn to her authentically positive, patient, and encouraging personality. As a direct result of her sensitivity to student interests and motivations, Profesora Nuria worked extensively and deliberately to build connections to students' funds of knowledge. Moreover, this privileging of student knowledge base served to scaffold content, language, and behavioral objectives.

The circles of influence, including Profesora Nuria's language ideologies demonstrate the inextricable links between language, thought, and action. Her use of Spanish and English in the classroom are the embodiment of her beliefs and experiences. Therefore, all of her beliefs and experiences influence her ways of interacting with students and scaffolding their work in biliteracy development. In turn, the students' language choices and ways of communicating are deeply influenced by the practices of 
the teacher. The broader school environment, including the "mission" and "vision" of the school are explored for their relevance and influence upon the classroom as well. The impact of administrative directives upon the case are analyzed in greater detail in Chapter Five as they have direct influence upon Profesora Nuria's work with her students in the classroom. 


\section{Chapter 5: Concluding Remarks and Discussion of Future Research}

In this research project, "Scaffolding the Continua of Biliterate Development in the Spanish Immersion Classroom," I sought to explore the ways that a particular teacher assists students in their development of biliteracy skills through pre-planned and interactional scaffolds. This particular research project serves to draw attention to a variety of considerations germane to the language immersion classroom. First and foremost, the primary focus is to engender deeper understanding of the role of the teacher in supporting the biliterate development of students and building classroom community. There are other insights into the work of students with texts in two languages, and the questions that emerge through those interactions. Broadly, underlying themes about language ideologies and language practices were also considered.

Selecting an individual teacher working with a particular class in the form of a case study was based upon the call by Met (2008) and Genesee (1987) to conduct more research to understand what teachers are actually doing in these dual language classrooms. Additionally, Cammarata and Tedick (2012), conducted research into teachers' attitudes and experiences shaping content versus language teaching in the dual language programs. Their research perspectives clearly had an influence upon the lines of questions I asked within the interview phase as I sought to make more transparent the thought processes of the teacher in building lessons with attention to content and language objectives. This was informative in discerning what scaffolds were preplanned. The work of Gibbons (2015) in her practitioner text, was particularly inspirational to me for its focus upon the potential for the development of student skills 
through teacher support. This was effectively paired with the text by Burkins and Yaris (2016), who asked the essential question, "Who is doing the work?" That text inspired the focus on the final step of the scaffold, evidence of when students were able to complete tasks on their own that had previously required teacher support.

\section{Discussion of Findings}

\section{Profesora Nuria Created a Community of Practice to Facilitate Learning.}

Having met Profesora Nuria over a year prior to the start of this project, I anticipated that conducting research in her classroom on scaffolding would be entirely appropriate, and I hoped that she would be willing to participate. The rationale for this decision was based almost entirely upon her persona as a teacher who deeply values the potential of the individual student and her vision for achievement and academic progress. Her infectious attitude of welcome and encouragement engaged a variety of student personalities and academic interests. This reminded me of a statement by Orellana (2016), who wrote, "love can serve as a driving force to connect people with each other across all kinds of borders, and to motivate children to engage powerfully with learning and life" (preface).

The Community of Practice established by Profesora Nuria is a key component of this project, as it leads to deeper understandings of the inner-workings of the case. Her consistent kindness and patience coalesce to build a positive atmosphere for learning. Additionally, Profesora Nuria's value of organization and structure, knowledge, reading, encouragement, and choice of language serve to advance the work of the teacher and the student participants. All of these points within the Community of Practice Section underscore for teachers and researchers the importance of context as seen through the 
sociocultural lens. The precepts of SCT enumerated in Chapter Two, including the social components of the context as well as mediational means (tools) are emphasized through Profesora Nuria's work with her students.

Throughout this research, I was humbled to see the teacher's strength and persistence in the face of great challenges. These challenges, as I enumerated some of them in the findings, were related to the nature of today's urban school environments and charter schools in general. The reader may recall my descriptions of a particular day, when there were four third-graders "visiting" Profesora Nuria's classroom who had been brought in without notice and without assigned work, and the variety of interruptions that occurred during just that 25 minutes of lenguaje. Today's teachers require models for the way that these interactions can take place. There are practices that can preserve the integrity of the lesson in the midst of systemic challenges while continuing to treat the students with kindness and patience.

The findings of this study highlight the leveraging of the interpersonal and sociocultural aspects of teaching as scaffolds in a variety of ways. This included the teacher's relationships with her students and her understanding of their needs for assistance, both those anticipated broadly (pre-planned scaffolds) and those created in the moment (interactional scaffolds). These concepts were well-represented, including in her interviews in which she discusses both "struggles" and "help." In this vein, the findings also explore the concept of the high-challenge, low-anxiety classroom (similar to the high-challenge, high-support classroom described by Gibbons, 2015 and Walqui 2006) and the work of the teacher to strike a balance in which the students are engaged with 
text, but not anxious. It is at that point, that I explained the new model that emerged through this project, "Scaffolding Episodes in the Development of Biliteracy" as a way to visually depict the focus of the task when the teacher intercedes to assist the student.

Scaffolding is not chewing up the fruit. In our understanding of scaffolding and its purposes, we circle back to the metaphor provided by the reading, "El Maestro Sufi'" first introduced in Chapter One. Maestro Sufí invites the student to eat a peach with him as a way to show his goodwill and ostensibly apologize for his "failure" to fully explain his parables to his students. However, he continues to graciously offer to peel the peach, asking the student if that would be acceptable. He then offers to cut up the peach into sections for the student. Finally, the teacher says, "Permiteme que te lo mastique antes de dártelo." (Permit me to chew it up for you before I give it to you.) To which the student replies in surprise that he would not like that at all. Profesora Nuria's students instantly reacted with disgust at this point in the story and shouted "Ewwww!" Then, they listened intently as Maestro Sufí said that if he explained every story to his students it would be as if he gave his student the chewed up fruit. This story was read in September during class. However, in my field notes I recorded more than once during the observation periods students would admonish one another, "Do you want her [the teacher] to chew the fruit for you?" Profesora Nuria found this hilarious, and asked me directly in October if I recalled the story "El Maestro Sufi" and if I had noticed that the students kept referring back to its central message. What is ironic, is that this is the central message of scaffolding. Teachers should provide scaffolds to assist students when they are unable to accomplish tasks on their own in a form of support, but not to the 
point where it is like "chewing up the fruit" for them when they are fully capable of "chewing" on their own.

Pre-planned Scaffolding with Visual Support. Specific to pre-planned scaffolding, Profesora Nuria's work with her students shows ways to utilize visual support in the production and reception phases to assist students in the content area and in the language class. She also leveraged the background knowledge of students to increase the relevancy of texts by relating key themes and concepts to their real-life experiences. Interactional scaffolds were created in the moment to student requests for assistance, primarily through vocabulary and clarification questions. Additionally, all scaffolds were explored in light of their guidance toward student appropriation and then independent completion of biliteracy-related tasks.

Pre-planned Scaffolding Leveraging Background Knowledge. Several preplanned scaffolds anticipated the text through the leveraging of student background knowledge and building personal connections to text. These scaffolds served as a "hook" to draw the students into the reading, increased attention to relevance of their own lives and allowed quicker access to vocabulary sets through frames of reference. All of these avenues were beneficial, and were noted by the teacher to strengthen the student participation in class discussions, including those students who "rarely" participated.

Scaffolds as Vocabulary Support in Reception and Production. Other means of integrated, pre-planned scaffolds included the use of visual support to assist with the writing process (production phase), while others assisted in understanding the readings (reception phase) particularly in the area of vocabulary development. As reflected 
through the "Scaffolding Episodes in the Development of Biliteracy" visual model

(Figure 5.1), the assistance provided by the teacher was task-oriented and specific to their interactions in the moment as represented by an "episode."

Figure 5.1 Model illustration

Production

\section{Reception}

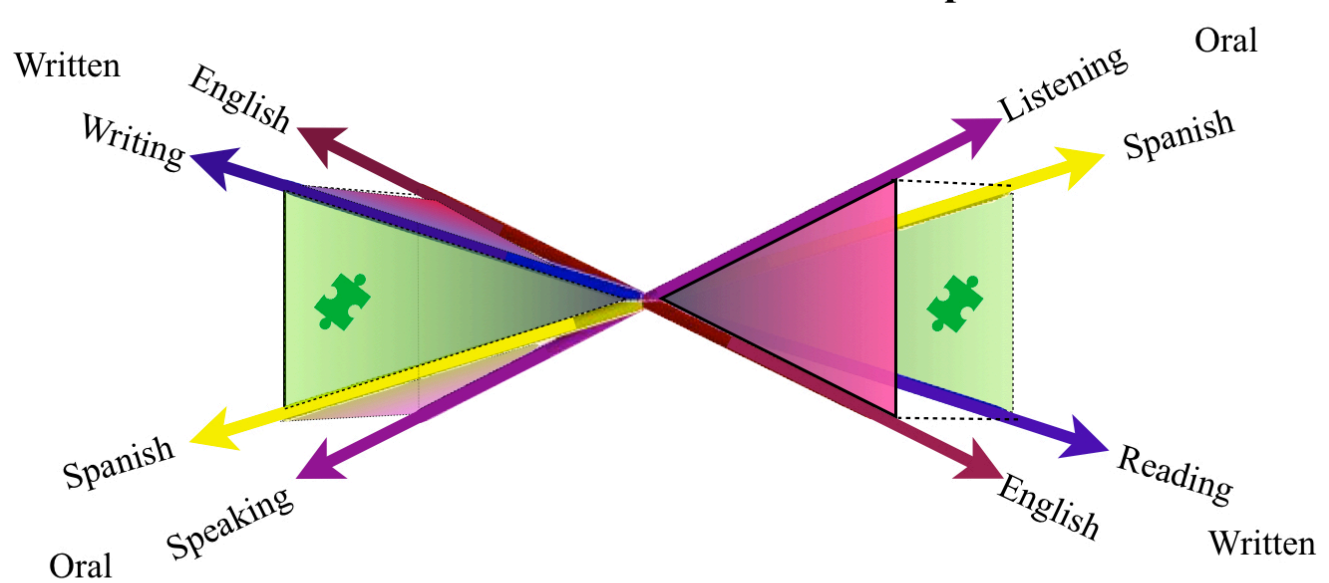

Scaffolding Episodes in the Development of Biliteracy Task: Spanish Reading and Spanish Writing

Nuria indicated in her interviews that vocabulary was a primary factor of difficulty for students. As such, she employed a variety of scaffold types that were pre-planned to support its development. Students tended to ask more questions in the production phase than in the reception phase, and they frequently centered around vocabulary-related queries, requiring interactional (in the moment) scaffolds. Met (2008) affirms the importance of vocabulary, explaining "Vocabulary is a critical element in language and literacy" (p. 54) that goes beyond knowing the meaning of an individual word, but also includes deeper levels of knowledge including how it is used in relation to other words. Moreover, she indicates that the "critical" role of vocabulary in student development within language immersion programs (such as the one at SLIP) is particularly heightened 
due to the fact that, "immersion students in one-way programs enter the program with close to zero knowledge of the new language" (p. 55).

\section{Using the Sociocultural Lens to Unpack Elements of the School}

Environment. As described in the findings section, the sociocultural lens provided insights into the social aspects of the classroom context, as well as the mediational means in practice within the ZPD. As described in the literature reviews, the ultimate tool (or mediational means) is language. However, mediational means can also include books, texts, and other materials used as tools.

At the beginning of this research project I began with a primary research question about scaffolding with two sub questions. However, after the pre-observation interview, and subsequent interactions, additional questions emerged about the school and community contexts and their influences upon the work of the teacher in the classroom. Following Stake's (1995) guidelines, I was sensitive to these effects upon the case, and as emic issues (p. 20) evolved from the interviews and classroom observations, new questions about the context emerged. Additionally, I felt that the understandings of these emergent issues were so deeply intertwined with the particular case that they embodied Stake's (1995) description of using qualitative research to promote "understanding the complex interrelationships" (p. 37). Through these interviews and classroom observations, the fourth research question emerged: What forces or tensions does the teacher face as she scaffolds for biliteracy development? It is my hope that one will be able to gain further understanding of these complexities through my descriptions of this particular fifth-grade class at SLIP under Profesora Nuria's guidance. The 
comprehension of Profesora Nuria's interactions with her students is inexorably tied to their own individuality, while simultaneously under the influence of broader contexts: her own experiences and language ideologies, school policies, school-sponsored materials, school histories, and community interests. All of these in combination serve to create a fuller picture of the sociocultural contexts relevant to this case. Yet, in describing this case it is my intention to bring the reader as close as possible to the inclass interactions as representations in time of these student participants and their teacher who kindly allowed me to visit and observe at SLIP.

Centripetal and centrifugal forces. The most unanticipated findings of this study are housed within the sociocultural theoretical lens and expressed through the relationships between the Spanish and English languages in the classroom and the policies and language ideologies that shape them. Founded as a full language immersion program, the bilingual interactions in this classroom do not align with the expected model as described in the literature. Based upon the local media reports, teacher interviews, student conversations, and administrative interviews, the role of languages in this context are moving towards valuing English over Spanish, although it is already the dominant language outside of the classroom. This can best be described using the words of Bakhtin (1981) as "centrifugal versus centripetal forces" (p. 272). As represented through my illustration (Figure 5.2), there are forces pressing inexorably inward towards "standardization" versus those privileging innovation and bilingualism that act in opposition to those forces. 
Figure 5.2 Model illustration: Centripetal versus centrifugal forces, Innovation versus standardization

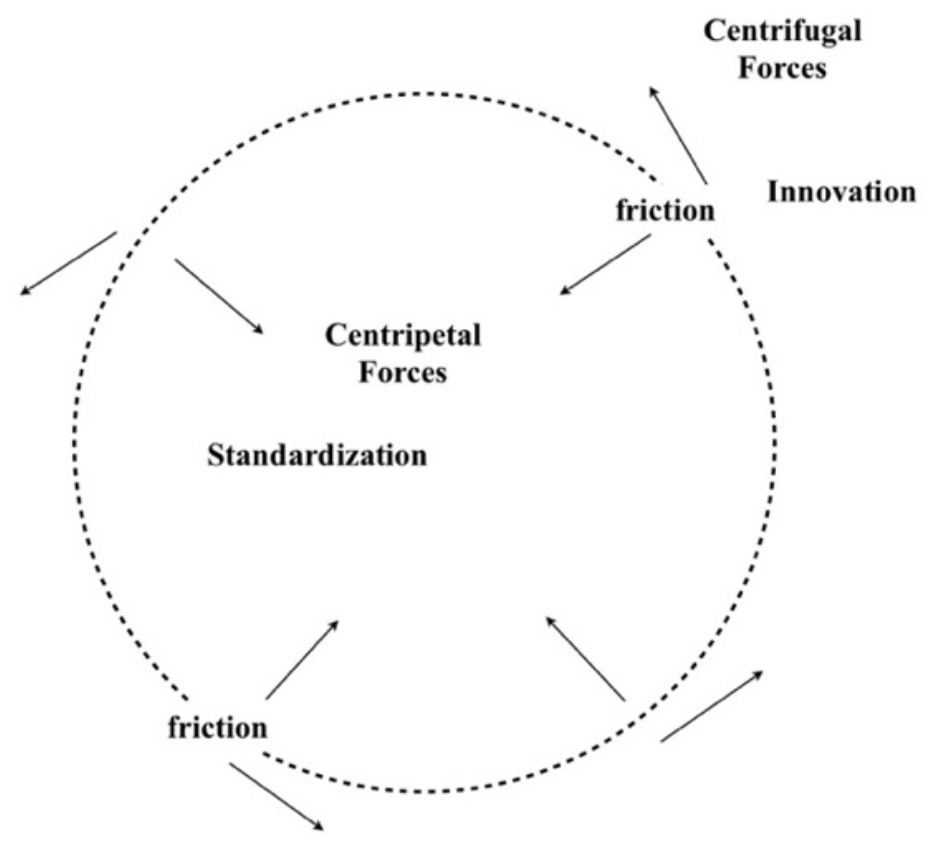

The centripetal forces are further described by Bakhtin (1981) as "centralizing... forces in any language or culture" that acts as "a homogenizing and hierarchicizing influence" (p. 425). As noted by Orellana (2016), "Currently, strong forces are at work to homogenize learning in school: to define what children should know and be able to do at the end of each grade, in each subject area, and in sub-divisions of those disciplines" ( $p$. xii). Whereas, the centrifugal forces are those influences that are "decentering forces" (p. 425) that move away from standardization and towards decentralization or innovation. It is important to note that from a physics standpoint, what one might call points of "tension" are points of friction. These terms are intended to reflect those moments at which the forces are in opposition to one another. Crowley (1989) explained that a "crucial point" of Bakhtin's model is that the "forms and effects of such forces" will vary 
according to "historical periods" (p. 73). This is also the case within the history of schooling in the United States overall and this school in particular.

As described throughout the findings section in Chapter Four, there arose numerous points of tension that affected how Profesora Nuria taught her students. At first, I believed some of the findings were "inconsistencies" or "anomalies." However, upon closer review of the classroom transcripts, teacher interviews, and artifacts from the school website and local media, a broader picture began to emerge that accounted for these at times, disparate teaching practices. As such, I will present these teaching practices employed by Profesora Nuria and how they related to the broader school and historical context.

The Research site section in Chapter One, explained that the initial school design promoted full language immersion. This is considered an innovative program, as it is different than most U.S. public school program designs. Within that structure, the administration, as represented by Madame Boudreaux and Dra. Martínez, communicated "non-negotiables" for 100\% Spanish language use in all regular classrooms (except for those designated English language teachers). However, Profesora Nuria was conflicted about using Spanish $100 \%$ of the time for two primary school-related reasons: a) concern about student lack of comprehension and b) recognition that statewide school testing programs were in English. Additionally, her personal language ideologies and practices tended towards a more bilingual model that could be labelled "translanguaging" by researchers. "Translanguaging" is a term used by numerous contemporary researchers (Gort, 2015; Hornberger \& Link, 2012; Martínez, Hikida \& Duran, 2015; Zapata \& 
Laman, 2016) and others to describe in the moment switches between languages in oral and written form. Martínez, Hikida \& Duran (2015) explain the concept in this way,

Scholars who have begun to use the term translanguaging do not argue that it is a new form of bilingualism, or that it ought to be used in place of the term bilingualism but rather that it is a way of highlighting the dynamic and flexible ways in which bilinguals actually practice bilingualism (p. 27).

At this point, Profesora Nuria's personal language ideologies tend to lean towards "translanguaging" when described as a naturalistic practice of language switches by bilinguals. However, due to the research findings, I find it problematic to describe Profesora Nuria's in-class language practices as "translanguaging." There were numerous occasions when she described her classroom language switches as due to: time constraints, concerns about standardized testing, and material selection by the school (available textbooks in one language or the other). Issues of expediency and standardized testing as the types of rationale for language choices fall outside of the more naturalistic and holistic language practices described by translanguaging pedagogies. Regardless, they represent the authentic reasons described by the teacher participant for bilingual language switches in this immersion school context, and directly reflect some of the "forces or tensions" that the teacher faced while scaffolding student work at the research site. 
Figure 5.3 Model illustration: Centripetal versus centrifugal forces, Phase 1

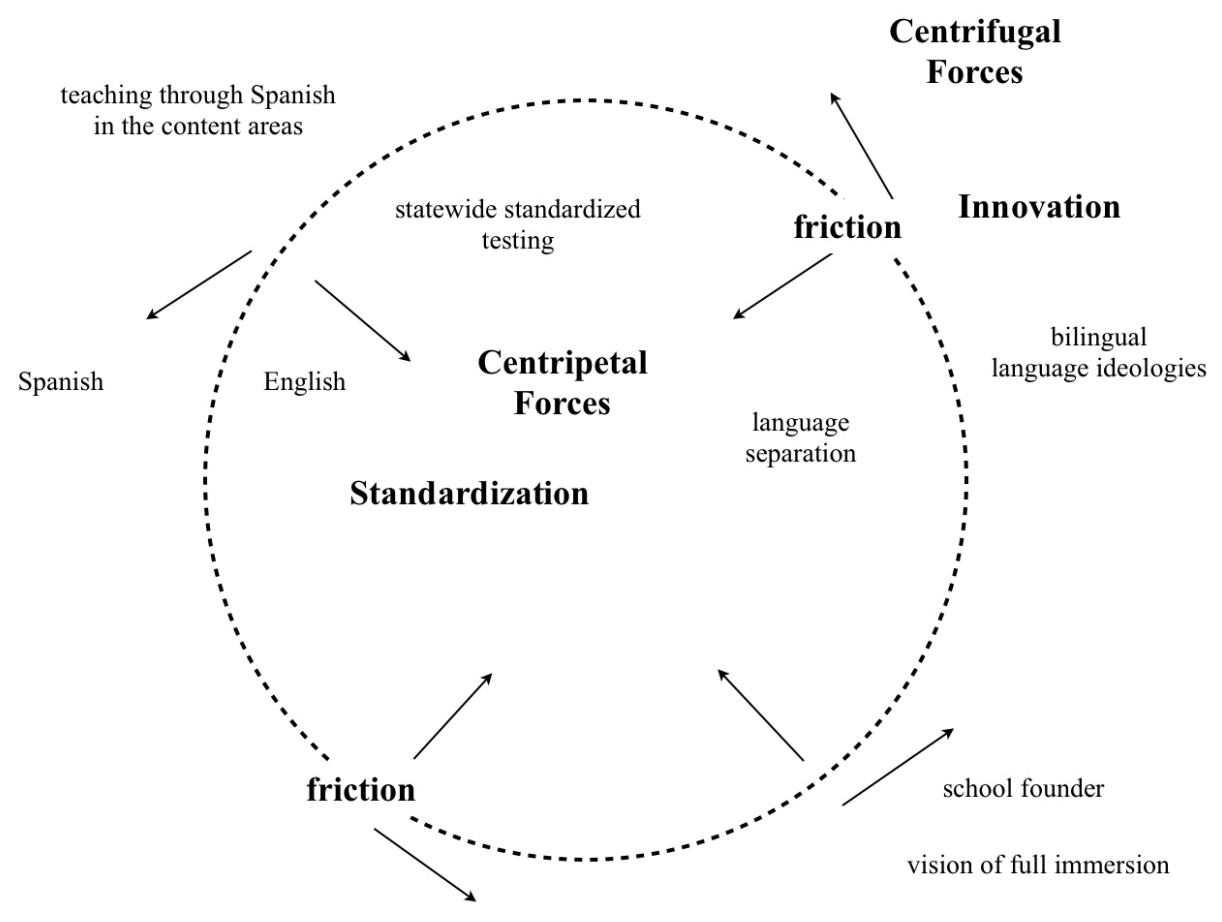

Figure 5.3 is an illustration of the accumulation of the centripetal versus centrifugal forces noted in this phase of the school history based upon the research findings. Through this research project, I have demonstrated that the teacher and the students in this classroom use both languages in flexible ways. This is evidenced by the interactions in every class period in which the reading could be in Spanish or English, and the teacher-led conversations were in Spanish, while students could choose to respond in English or Spanish. The students demonstrated that they understood the oral questions by the teacher, and many of the points in the reading through their answers in either 
language. The Spanish language used by the top students in the class rivaled that of my undergraduate Spanish minors with greater exhibited depth and range of vocabulary specific to the content areas (science, social studies, and math).

Other points of tension or friction emerged in the building as the original administrators attempted to "convencerles" (convince) the teachers of the effectiveness of the mission the full language immersion model. At the same time, the administration began to recognize that teachers were simply "overwhelmed" by the amount of work that it took to assemble, create, and design their unique curricula based upon a combination of the PYP themes and the Common Core Standards. My understanding of these issues introduced additional components to the centrifugal versus centripetal forces model as shown in Figure 5.4.

Figure 5.4 Model illustration: Centripetal versus centrifugal forces, Phase 2

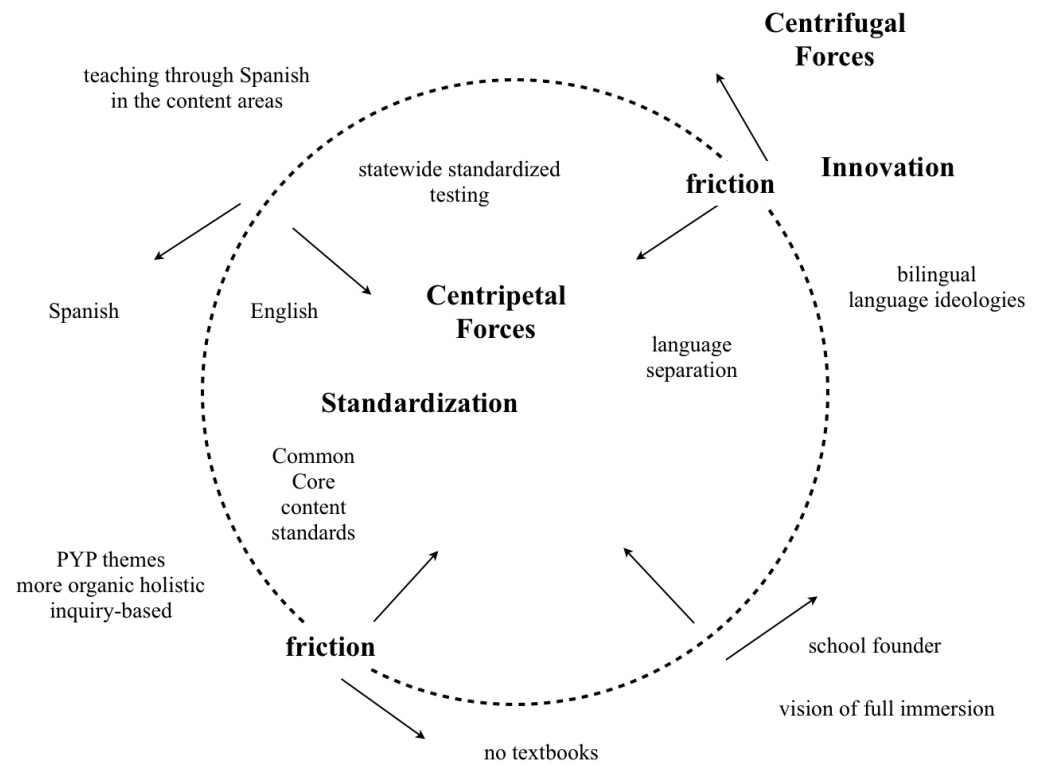


The administration and the teachers were also cognizant of the local media reports, school board meetings, regarding comparatively low standardized test scores. Although some of the scores were higher than neighboring schools, there remained a disparity between targeted levels and actual scores. Profesora Nuria explained that the test scores were "always in the back of her mind." These issues in combination spurred a drive toward other forms of standardization, such as: increased contact hours for designated English instruction, and the adoption of textbook materials in the content areas and the Spanish language program (the ENIL). The adoption of the ENIL is among the most noteworthy, as its adoption and subsequent implementation training sessions directly impacted the reading habits within virtually every class period.

In 2015, Profesora Nuria and her then cohort teacher were using reading logs for independent reading, small groups with leveled readings, and teacher read-alouds of novels. All of those practices changed with the adoption of the ENIL program. As noted through interviews presented in Chapter Four, the teacher professional development provided by the publishing company promoted round-robin reading of short stories on grade level, stickers (no pencils) for all grade levels, and strict separating of writing from "reading time." Profesora Nuria explained that she discussed these practices with her cohort teacher Profesor Roberto, and that they then went to the administration with "concerns" that resulted in the following modifications to the proposed strategies: use pencils to underline key points in the text and create occasional written responses in the form of a few sentences here and there. 
In speaking with Dra. Martínez and Profesora Nuria, it was clear that all of these areas of tension affected the inner-workings of the classroom and created a strong pushpull atmosphere between monolingual language ideologies versus bilingual language ideologies, standardized testing in English versus teaching the content areas in Spanish, textbooks versus no textbooks, and the new administration versus the previous administration, among others. These are all reflected within this illustration (Figure 5.5) as a visual representation of the systemic centripetal forces toward standardization or homogenization versus the centrifugal forces toward innovation and difference.

Figure 5.5 Model illustration: Centripetal versus centrifugal forces, Phase 3

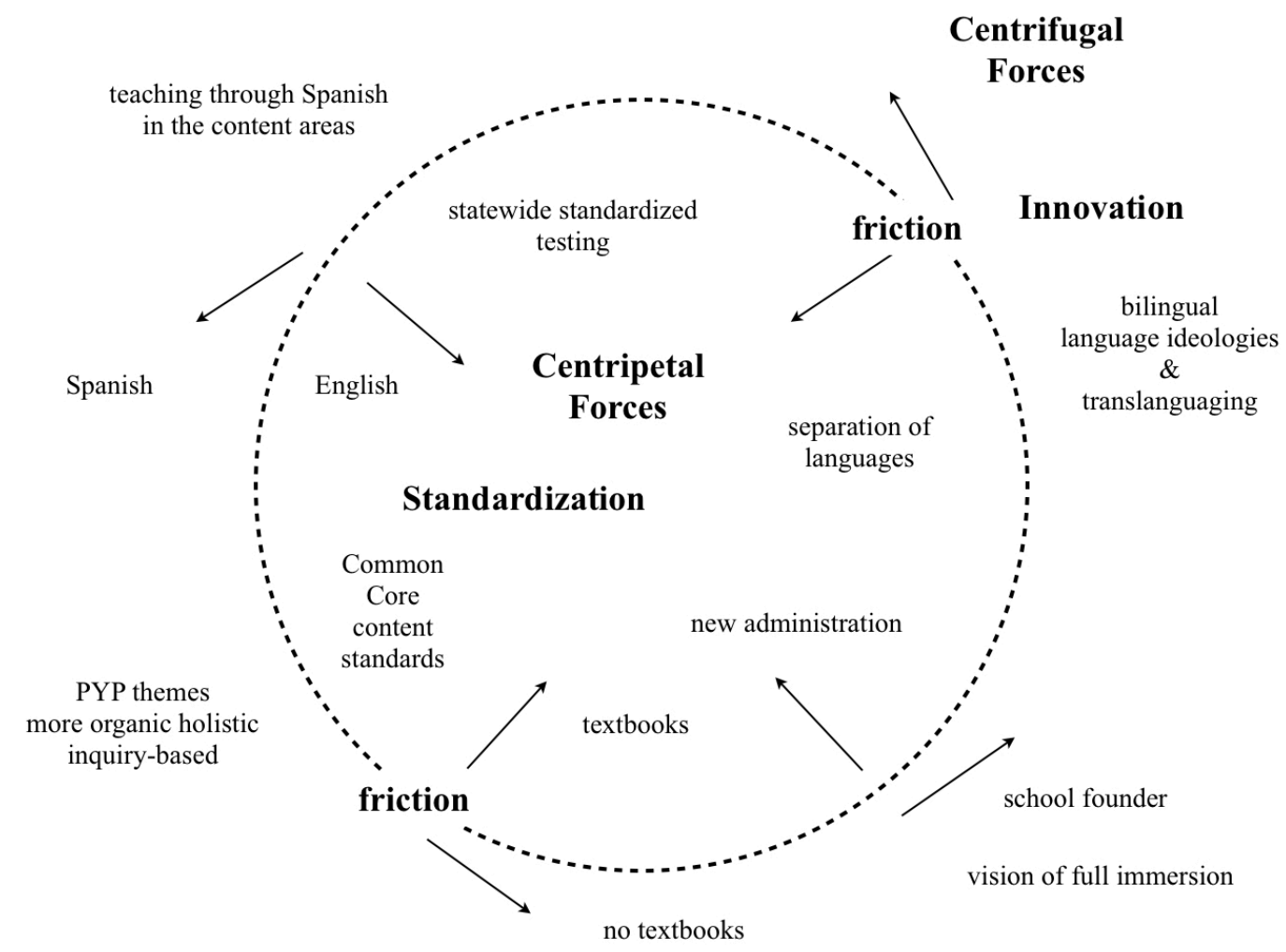


The "non-negotiables" communicated by the original administration and the focus on inquiry-based IB frameworks were no longer present. Indeed, the Staff Handbook reads like any other Human Resources manual for a public school district, and there is no mention of language policies. Profesora Nuria said that this academic year (2017-2018) she had received no communications from the administration about language policy guidelines, other than changes to the schedule to include more English contact hours. Toward the end of the observation period, as previously noted in Chapter Four, more changes are slated to occur as a result of these tensions, including a move to a $50 \%$ Spanish / 50\% English model in academic year 2018-2019.

\section{Exploring Consequences of Friction as a Lack of Harmonic Balance}

Following this journey, there are many remaining questions, and some of those relate to those elements that were clear examples of results of the points of friction identified in the section on Centripetal versus Centrifugal Forces. In my research memos, there were some concepts that were originally labelled "inconsistencies" or "anomalies." However, under further examination, what I discovered was that these practices demonstrate that the classroom teacher's ideological positionality in contrast to a variety of sociocultural pressures (as embodied by the school administration and broader community) provoke and demand discordant oscillation between disparate theories, methods, and procedures. This educational environment is experiencing extreme amounts of friction and pressures relating to language ideologies, teaching practices, educational goals, and visions of successful outcomes. In the aggregate this means that the work in the classroom is out of harmonic balance. Evidence of this lies within the 
oscillation between separation and combination of languages, emphasis on the goal of knowledge versus test scores, traditional versus inquiry-based literacy practices, and divergent presentation of choices in reading materials.

Separation or combination of languages. In one of our interviews, Profesora Nuria referred to her work with students in English as a "bridging kind of thing." Dra. Martínez indicated in our interview that at one point during her duration as principal, there was a teacher professional development session with Teaching for Biliteracy, in which the concept of "bridging" as defined by Beeman and Urow (2013) was explained. However, no explicit language strategies aligned with their model were observed during this period. I did not see any work with word families, nor contrastive analysis, nor end of the unit work in the second language to "bridge." Indeed, as described in the Findings section, Profesora Nuria's work was consistently bilingual, constantly moving from one language to the other with the students, which does not fit with Beeman and Urow's model of deliberate and timed language "separation" and "bridging" periods that allow for metalinguistic discussions of language similarities and differences.

Emphasis on the goal of knowledge versus test scores. As noted in the Language Ideologies, Systemic Constraints and Influences section of Chapter Four, there are extreme pressures to improve test scores. These pressures have resulted in an overwhelming amount of time spent assessing and evaluating the students in a variety of ways. As illuminated through the brief conversation between Tesssa and Terrell, the students have received this message that testing is of such importance that it has become the central message of schooling. As described by Tessa, “...that must mean you're 
tired of school because school is pretty much about tests." This is truly regretful in light of all of the work that Profesora Nuria has done to emphasize the idea that "Knowledge is the prize," as described in the Community of Practice section.

Segregation of writing from other literacy practices. Students were seldom provided with opportunities to respond to questions in the form of extended writing other than summaries. When students did have the opportunity to write answers to individual questions in their notebooks, and then report back to the large group in the form of an oral comprehension check, example answers were not written on the board as a matter of practice. During the interview, Profesora Nuria had discussed this lack of writing instruction as an area that needed strengthening. She articulated two primary reasons for this lack: its position counter to the school-sanctioned teacher education parameters and time. The purchase of the ENIL led to professional development sessions in which reportedly teachers were told to separate writing instruction (and even the general task of written responses) entirely from "reading periods." The deep connections between all modes of communication, reading, writing, speaking, and listening are well-recognized (Genesee, 1987; Gibbons, 2015; Hornberger, 2004). ACTFL (The American Council on the Teaching of Foreign Languages) describes the "interwoven" nature of different modes of communication (Shrum \& Glisan 2015), and NCTE (the National Council for the Teachers of English) (2005) responds with a call for multi-modal literacies. Perez and Huerta (2011) specifically promote their model as it incorporates, "balanced literacy practices" that include reading and writing together with problem solving (p. 120). As I was not present for these teacher work sessions, I rely upon the interpretations of Profesora Nuria and her reported discussions with Profesor Roberto about the instructions 
to entirely separate reading from writing received during those presentations.

Additionally, the segregation of literacy practices takes more time, as you have to then find a "designated" time for writing, as opposed to interweaving it into other "readingoriented" activities.

As to the lack of time, there were several other areas of scheduling that were modified weekly (most notably science and social studies), due to a "lack of time" or being "behind schedule." Additionally, the practice of "round-robin reading" does take more time, and the practice of independent reading in Spanish and English on a daily basis accounted for at least one hour per day. As a consequence, the sample lesson plans provided by Profesora Nuria with stated objectives were often out of synch with the actual classroom activities.

Regretfully, Profesora Nuria said multiple times that she felt that the students did not have enough writing practice during these in-class activities, nor was there a designated time slot assigned for a focus upon writing. Met (2008) wrote that in these immersion settings that many activities are "time-intensive," and that "when time for teaching literacy in two languages (not just one) is added to the mix, it can be challenging to find the time required for engaging students in extended language output" (pp. 65-6). This aligns closely to the research findings of this project, as the students spent proportionally more time reading than writing by far. Most responses to text were represented through whole-class (oral) discussions of readings, rather than written responses. I also wondered if student questions in the reception phase were suppressed by the ubiquitous IRE and round robin reading practices. As those are both teacher- 
initiated patterns of communication within an established rhythm of turn-taking, they do not on their surface encourage inquiry.

Reading practices and encouragement (or not). One of the methods used in Profesora Nuria and Profesor Roberto's classrooms was "round robin reading" (reading aloud by taking turns as an entire class). When I visited SLIP in 2015, Profesora Nuria had a different cohort teacher and various reading formats including: read-alouds by the teacher from Spanish novels, reading logs, and writing sessions during science class as well as free-writing. All of these items were absent during this observation period in 2017. This change, as described by Profesora Nuria seems to have occurred directly following the adoption of the ENIL program. The currently used "round-robin" readings as a practice are problematic for two primary reasons. It takes a great deal of time, more time than required to read a text silently, and lastly, it emphasizes reading as a performance in which some students are not successful. This is why the repeated use of this practice seemed inconsistent with Profesora Nuria's Community of Practice where students were constantly encouraged. The traditional practice of round-robin reading is one that is generally rejected by contemporary reading researchers. Rasinski and Hoffman (2003) noted its historical roots but explained that it is a practice that can prove to be "frustrating" and that some students may find this "public display of their lack of competence in reading an ongoing source of embarrassment” (p. 512). Beeman and Yaris in their practitioner text bluntly exhort, "Please don't torture your students with round-robin reading" (p. 66) and recommend other formats such as: "teacher read-aloud, shared reading, and guided reading practices" (p. 139) instead to promote growth for all students. The recommended practices generally avoid whole class on-the-spot reading 
"performances" (Hammond \& Nessel, 2011) that can create negative long-term "lasting memories" of reading failures for some students (Rasinski \& Hoffman, 2003, p. 512). It should be noted that reading researchers have made recommendations more closely aligned to what Profesora Nuria used to do in her classroom.

All of this on a deeper level, has implications for school administrators broadly. Administrators must be cautious when adopting materials and make sure they align with research-based current practices. Teachers do feel the tensions of working in contrary to their own instincts, but they also feel a sense of obligation to follow instructions that are sanctioned by the school leadership.

Divergent presentation of independent reading materials. Another impact of the book program adoption is visible in the way that independent reading books are displayed in the classroom. There are some very valuable materials in the book sets that were purchased with the ENIL program. However, there is a notable difference in the way that books are stored in the classroom in the English language collections versus the Spanish language collections. The English language collections are categorized alphabetically by author, by genre, and by series names. In contrast, the Spanish language collections are categorized by color-coded reading levels exclusively, as they arrived purchased from the publisher in bins color-coded to match levels in the ENIL evaluation. The implicit message with this organization is that books for independent reading in Spanish must be selected primarily by level, and that student interest is secondary. As described by Glasswell and Ford (2010), with constant concerns about "leveling" of texts, teachers "can lose sight of what matters in reader-text interactions" 
(p. 57). This focus on the primacy of "levels" is contrary to the underlying philosophy that student interest in independent reading builds growth of literacy skills and doesn't seem to match Profesora Nuria's philosophy regarding ways to engage reluctant readers.

These consequences of tensions prompt additional questions about reading, writing and the practice of teaching as situated within an immersion school. The influences of textbook companies are undeniable as they work in these contexts, sanctioned by schools. I continue to question what the impact of these variables may be upon the students and the teachers. I also wonder what implicit messages are delivered to students through the different treatments of aspects of biliteracy in the classroom. Certainly, those questions did not fall within the scope of this particular study on scaffolding, but they could prompt additional studies in the future, as we acknowledge these variables upon the learning and teaching contexts.

\section{Practical and Theoretical Implications}

Within this study, the findings highlight the leveraging of the interpersonal aspects of teaching as scaffolds for facilitating less stressful accomplishment of tasks. The understanding of relevance of texts by relating key themes, ideas and concepts to students' experiences and interests are important elements of teaching. Other aspects of teacher scaffolds in this case allow one to see the steps toward internalization and independence on the part of the students. This is of key importance, as the entire purpose of teacher scaffolds, is to assist students with tasks they cannot complete on their own at the time. The examples presented through this study may push teachers to consider ways of moving students towards the independent completion of tasks in the future. More 
questions remain, however, in the level of awareness or consciousness students have regarding these scaffolds and steps that teachers make to assist them. It is also unknown and challenging to quantify the impact of Profesora Nuria's encouraging environment. How can we as teacher educators work with pre-service teachers to highlight the advantages of forward-thinking regarding the potential of the students?

Through this exploration of themes and findings, a number of issues provoke and prompt further lines of questioning to guide future studies in the disciplines of Sociocultural Theory, Biliteracy, and Dual Language School environments. In this section, I explore what implications these findings may have upon teachers, teacher educators, schools, and researchers in those three areas.

Implications for teachers. This research presents some implications for teachers in a variety of areas including: scaffolding, interaction patterns, urban schools, reading programs, and language production. Scaffolding, as described in the research is not simply help, it is assistance specific to the completion of a task that the student cannot complete independently. This case study prompts teachers to consider the various ways that teachers can scaffold for students and at what point in the lesson to scaffold. The model, "Scaffolding Episodes in the Development of Biliteracy," can provide teachers with a tool for consideration about when to intercede and assist with pre-planned scaffolds. For example, this allows the teachers to consider where they are investing their time in the classroom to encourage deliberately planned student language production opportunities with teacher support. This model could also be utilized for self-reflection following teaching. Using the model as a visual tool, teachers can consider their support 
for student work in both the reception and production phases and the interactions between the two. Specifically, teachers should consider ways to further scaffold writing. As Wells (2000) indicates, "the oral mode has one serious disadvantage as a medium for knowledge building: it leaves no record of what has been jointly constructed" (p.77). The findings in this study, including how the teacher utilized an anchor chart in a variety of ways to scaffold student writing of summaries can be further extrapolated and employed in a variety of ways in the classroom.

This study also provides context for consideration of classroom interaction patterns and their impact on individual students. As a researcher, I accentuated the student discussions in small groups as a way to indicate that we do not always know what students are thinking about while working (or while off-task). Teachers can envision ways to keep students on-task in groups and provide structured ways of peer scaffolding through practitioner texts such as those by Barnes (1992) and Mercer and Hodgkinson (2008) that focus on classroom and exploratory talk.

With regards to the urban school setting, this research is deeply rooted in sociocultural contexts and presents Profesora Nuria's interactions with her students as a model for the way to treat students with consistent patience, kindness, and encouragement. The section of analysis on language ideologies invites self-reflection on the part of teachers in these language immersion schools. When a teacher enters this school environment, what shapes his or her teaching philosophies? How does the interaction between languages work? What is the school's official position on language use? What reading materials are adopted and why? Are reading materials treated 
differently in one language than another? Are there tensions between what the teacher wishes to do and what the school desires? How can those tensions be resolved?

Implications for teacher educators. The growth of these dual language and language immersion programs require that teacher education programs at the university level respond with programs designed to empower teachers with strategies specific to these multilingual environments. The first step to this is the inclusion of multilingual teaching strategies for "regular" classroom teachers. There are specific understandings of bilingualism and biliteracy that can assist teachers in working with bilingual students and building their skills. Specific to teachers preparing to teach in dual language or immersion schools, there is a need for teacher education programs that invest in a fusion of second language acquisition, biliteracy, and content instruction in two languages.

While attending the La Cosecha Dual Language Conference, the presentations on the differences between literacy instruction in Spanish versus English were instructive. I observed most attendees of the specific session "So what is so different about developing literacy in Spanish anyway?” (Weaver and Márquez, 2017) fervently taking notes. At the close of the session, several people groaned and blurted out, "When will your presentation be posted to the conference website?" Other teachers and administrators remained afterwards to talk to the presenters to ask further questions and praise them for their work in drawing attention to this area of study. This demonstrated that educators in these contexts are hungry for the knowledge to more effectively and efficiently work with students in two languages (and particularly in Spanish). Developing new horizons within teacher education programs can assist pre-service teachers prepare for their teaching 
contexts and work with bilingual student populations throughout the United States. As noted by a variety of researchers (Cammarata and Tedick, 2012; Pérez and Huerta, 2011), the teachers in these immersion and dual language schools rarely receive an education in a university program tailored to the unique contexts in which they will be teaching.

Implications for schools. For school leadership, this project illustrates some of the ways that school adoptions of materials may impact teachers in their work in the classrooms. More specifically, the drive to ensure success on "standardized" testing is becoming an overwhelming force that is exerting untold influence upon the work in each classroom. This particular context highlights contrasting or competing goals through its uniqueness as a Spanish language immersion program. These findings echo the question by Baker and Lewis (2015), "what tests or other sources of evidence are used to determine whether a form of bilingual education is successful or not?" (p. 121). As more schools work towards innovation, it is essential for school leadership to define goals and "measures of success," and provide ways for teachers to work towards those goals and measures. It is also important to recognize the role that the language ideologies of individual teachers may influence their adoption (or not) of administrative goals. Lyster and Tedick (2014) write that "when it comes to classroom practice, teachers are the ultimate decision makers; everything they do is filtered through their prior experiences and knowledge in addition to their beliefs, attitudes, and perceptions" (p. 218). Additionally, Ek, Machado-Casas, Sánchez, and Smith (2011) found a range of attitudes about the importance of Spanish in society and in schooling within the community and among their teacher candidates, explaining, "Just as Latino/a communities are not homogeneous in history, culture, or political orientation, neither are their language 
ideologies" (p. 32). It is important to note the reluctance of heritage Spanish-speaking students to embrace Spanish as a means of communication in this immersion school. They have their own language ideologies, both influenced by their families and the community outside of the school walls. Further recognition of the range of represented ideologies and experiences within the teaching staff and the student populations should be leveraged to enhance the educational mission. Recognition of and planning for all of these components are necessary to promote the harmonic balance of theory and practice.

One of the complaints by researchers (Fortune, Tedick, and Walker, 2008) is that while immersion and dual language teachers say they are constantly teaching language, the content instruction seems to take "center stage" (p. 80), even in the area of vocabulary development. Kong (2009), while conducting research within Chinese language contexts, found that pairing content-trained teachers with language-trained teachers in cohort groups was an effective model to introduce greater language and literacy focused objectives on a regular basis into the curriculum. Administrative selection of cohort groups based upon teacher education deserves some consideration in light of the importance of a strong literacy foundation in both languages as a desirable outcome.

In the work towards the primary aims of the school, it is noteworthy that at times, when schools adopt materials there are unintended or unanticipated consequences to the adoption. This is where communication with the teachers, parents, and students may assist leadership in understanding how these adoptions impact the students. It is a deliberate feature of this project that I have emphasized the voices of the students in this school, as they are the real reasons for our work as educators. It is my hope that 
revealing these perspectives, school leadership teams may weigh goals, strategies, and measures of success in partnership with students, teachers, and families to craft cohesive programs that do not emphasize testing to the detriment of other educational goals.

Implications for future research. In future research, it is my personal goal to continue into the next phase of this project. One option would be to build a collective case study project to compare commonalities and differences between language immersion classrooms. Alternatively, I could pursue work with individual student participants from this study to deepen understandings of student perspectives on the work in Profesora Nuria's classroom specifically, and the Spanish immersion experience more broadly. It would also be interesting to conduct research in a two-way immersion program with a larger Spanish-heritage speaking population to compare teacher scaffolds that assist heritage speakers versus non-native speakers of Spanish.

To clarify, I believe this research illuminates some deep questions that we have about the nature of language immersion programs. What are the primary goals in reality? Are the teachers in these schools able to enact these goals? What materials and tools can aid or support teachers in their work in the dual language or immersion classroom? What is the impact of teacher encouragement upon student engagement and the development of skills? Is translanguaging a practice that is helpful in contexts in which the vast majority of students do not possess a cultural connection to the target language? Or, is it better to have strategic separation of languages? How can we possibly assess these languages in a way that takes into account the extreme number of variables related to versions of Spanish in use in the United States? 


\section{Concluding Remarks}

This project was initiated to provide a better understanding of scaffolding student development of biliteracy in the Spanish immersion school. This was a goal that through the lens of sociocultural contexts rapidly expanded to school and community considerations and their impact upon the learning environment. Through Profesora Nuria's work with las estrellas del quinto grado, we can see the possibilities of what can be, and how encouragement can move students towards progress in understanding texts in two languages. Unfortunately, as with many studies, this research project does not stand alone in that it prompts more questions than it answers. However, through this project, the case study does highlights the voice of a teacher in Profesora Nuria who works faithfully everyday with her students to build a community of practice that is encouraging, values knowledge and promotes reading, and allows students choices in language practices. In closing, Profesora Nuria's words embody the work of the teacher and what this type of project means. At the end of her first interview, she said she was glad to participate and responded to my thanks with the following statement: "I mean I feel that as a teacher, there's nothing you can hide. You have to be who you are. I really love it. I can't picture myself doing anything else." 


\section{Appendix A}

June 01, 2018

Principal Investigator: Dawn M Heston

Department: Romance Languages \& Literature

Your Annual Exempt Form to project entitled Scaffolding the Continua of Biliterate Development in the Spanish Language Immersion Classroom was reviewed and approved by the MU

Institutional Review Board according to the terms and conditions described below:

IRB Project Number
IRB Review Number
Initial Application Approval
Date
Approval Date of this Review
IRB Expiration Date
Project Status
Risk Level
HIPAA Category

2008052

238126

July 24, 2017

May 25, 2018

July 24, 2019

Active - Exempt

Minimal Risk

No HIPAA

The principal investigator (PI) is responsible for all aspects and conduct of this study. The PI must comply with the following conditions of the approval:

1. No subjects may be involved in any study procedure prior to the IRB approval date or after the expiration date.

2. All changes must be IRB approved prior to implementation utilizing the Exempt Amendment Form.

3. The Annual Exempt Form must be submitted to the IRB for review and approval at least 30 days prior to the project expiration date to keep the study active or to close it.

4. Maintain all research records for a period of seven years from the project completion date.

If you are offering subject payments and would like more information about research participant payments, please click here to view the MU Business Policy and Procedure:

http://bppm.missouri.edu/chapter2/2 250.html

If you have any questions, please contact the IRB at 573-882-3181 or irb@missouri.edu.

Thank you,

MU Institutional Review Board 
Appendix B

\title{
Teacher Consent Form to Participate in a Research Study
}

\author{
InVESTIGATOR's NAMe: DAWN Heston \\ ProJeCT \# 2008052
}

\section{STUdy Title: SCAFFOLDING THE CONTINUA OF BILITERATE DEVELOPMENT IN THE SPANISH LANGUAGE IMMERSION CLASSROOM}

\section{INTRODUCTION}

Today I ask for your permission to participate in a research study. This research is being conducted to learn about the ways that the teacher in the Spanish Immersion classroom helps students understand what they read and listen to in class. You have the right to be informed about the study procedures so that you can decide whether you want to consent to participate in this research study.

Your participation is voluntary.

\section{DESCRIPTION OF THE RESEARCH}

Your school is especially interesting to me as a researcher because most of the learning takes place in Spanish and I am a Spanish teacher. You have been invited to be in this study because students are learning about many different topics in your classes, all while discussions take place mostly in Spanish. I hope to see what you do to help students learn and understand the materials and topics within the classroom.

\section{PROCEDURES OF THE STUDY}

If you agree to be a part of the study, you will be asked to continue doing your regular classroom activities. Before I come to observe in the classroom, I would like to interview you to discuss how you plan for your classes and how you work with your students. Then, it is my plan to come into the classroom and watch the students work with you and the other students in class. I may use a small audio recorder to allow me to play back some of the conversations that happened during class. This way, it will help me to remember what I heard in the classroom. In my written reports, I might include something you said to a specific child in the classroom or the entire group during a class discussion. However, if I include that conversation in a report, it will not include you or the child's name or any identifying information. It is not my intention to interrupt or change what is happening in the classroom. I will not ask students to do anything differently than what they are already doing at school. It is my hope to visit the classroom 2-3 days per week. After some of the observations, I would also like to discuss some of the specific classroom activities with you. Of course, the interviews and observations will take place at your convenience and at agreed upon times.

\section{HOW LONG THE STUDY TAKE PLACE?}

This study will take approximately one year to complete. You can stop participating at any time without penalty.

HOW MANY PEOPLE WILL BE IN THIS STUDY?

It is my plan to observe and listen in one classroom at (your school) during this school year. 


\section{WHAT ARE THE BENEFITS OF THE RESEARCH?}

With my project, I hope to learn more about how teachers work with their students in a Spanish immersion classroom. It is intended to help people understand language education better.

\section{WHAT ARE THE RISKS OF THE RESEARCH?}

The risks of this research are minimal. This project will allow me to visit the classroom during regular lessons and tape record. I am not planning to interrupt the class, but you and the students will be aware that I am there watching what the class is doing. All of my observations are intended to be during class times only and this project should not have any negative effects upon the students. All interviews will be at the time and location of your choosing.

\section{PARTICIPATION IS VOLUNTARY}

Participation in this research study is voluntary. You may refuse to participate or withdraw from the study at any time.

\section{WHAT ABOUT CONFIDENTIALITY?}

We will do our best to make sure that your words during class and recordings are kept private. You will be audio recorded during this study during regular classroom activities as well as during the interviews. Information produced by this study will be stored in the investigator's file and identified by a code number only. The code key connecting your name to specific information about you will be kept in a separate, secure location. Information may not be given to anyone unaffiliated with the study in a form that could identify you without your written consent, except as required by law.

\section{WHO CAN I TALK TO ABOUT THE STUDY?}

If you have any questions about the study or if you would like additional information, please call Dawn Heston at (573) 882-4874 or email at hestondm@missouri.edu . The faculty advisor for this project is Carol Gilles, and she may be contacted at (573) 882-8498 or gillesc@missouri.edu.

You may contact the University of Missouri Institutional Review Board (which is a group of people who review the research studies to protect participants' rights) if you have questions regarding your participation and/or concerns about the study, or if you feel under any pressure to participate or to continue to participate in this study. The IRB can be reached directly by telephone at (573)882-9585 or e-mail umcresearchcirb@missouri.edu .

\section{CONSENT}

I have read this consent form and have been given the opportunity to ask questions. I am willing to participate in this study. I understand that participation is voluntary and I can withdraw my consent at any time without penalty or loss of benefits.

Teacher signature Date: 


\section{Appendix C}

\section{SEMI-STRUCTURED INTERVIEWS OF CLASSROOM TEACHER}

\section{INVESTIGATOR'S NAME: DAWN HESTON}

PROJECT \# 2008052

\section{STUDY TITLE: SCAFFOLDING THE CONTINUA OF BILITERATE DEVELOPMENT IN THE SPANISH LANGUAGE IMMERSION CLASSROOM}

\section{Proposed list of questions for the semi-structured pre-observation interview}

What considerations do you have in mind first when you prepare or plan lessons in general?

How do you support students as they work with texts in general? (Interviewer will also clarify

the meaning of text in line with the NLS, if necessary.) How do you decide what strategy to use?

What does that look like? Can you tell me more about that? What types of texts do you use during the day? What are the relationships between reading, writing, speaking, and listening in your classroom? How do you support student understanding of texts? How do you use support student responses (oral or written) to texts / classroom materials? When you think of the term "scaffolding" what comes to mind? Do you use peer to peer scaffolding? How does that work? When do you use that strategy? Do you model language or text interactions for your students? How? What is the role of English in supporting the students' understanding of text in your classroom? What is the role of background knowledge of your students' in the classroom? Is it more based upon topic or the language? How? Can you give me an example? 


\section{Appendix D}

\section{Spanish Immersion Program Field Notes}

\section{Researcher: Dawn Heston}

Place: Spanish Immersion Program

Purpose: How does the teacher scaffold student development of biliteracy within language and content instruction in the immersion school context?

Date / Time:

Classroom setup:

Chronological notes of classroom interactions:

Observer comments: 


\section{References}

Allington, R. L. (2014). How Reading Volume Affects Both Reading Fluency and Reading Achievement. International Electronic Journal of Elementary Education, $7(1), 13-26$.

Baker, C. (2003). 6. Education as a site of language contact. Annual review of applied linguistics, 23, 95-112. doi:10.1017/S0267190503000217

Baker, C. (2011). Foundations of bilingual education and bilingualism (Vol. 79): Bristol, U.K.: Multilingual Matters.

Baker, C., \& Lewis, G. (2015). A synthesis of research on Bilingual and Multilingual Education. In W.E. Wright, S. Boun, \& O. García (Eds.) The handbook of bilingual and multilingual education (109-126). Malden, MA: John Wiley and Sons, Inc.

Baker, J. A. (1999). Teacher-student interaction in urban at-risk classrooms: Differential behavior, relationship quality, and student satisfaction with school. The elementary school journal, 100(1), 57-70.

Bakhtin, M. M., Holquist, M., \& Emerson, C. (1981). The dialogic imagination: four essays. Austin, TX: University of Texas Press.

Barnes, D.R. (1992). From communication to curriculum. Portsmouth, NH: Boynton/Cook.

Basit, T. (2003). Manual or electronic? The role of coding in qualitative data analysis. Educational research, 45(2), 143-154.

Beeman, K., \& Urow, C. (2013). Teaching for biliteracy : strengthening bridges between languages. Philadelphia: Caslon Publishing. 
Bernhardt, E. B. (1992). Life in language immersion classrooms (Vol. 86) Bristol, UK: Multilingual Matters.

Björklund, S., \& Mård-Miettinen, K. (2011). Integrating multiple languages in immersion: Swedish immersion in Finland. Immersion education: Practices, policies, possibilities, 13-35. Buffalo, NY: Multilingual Matters.

Brisk, M. E., \& Harrington, M. M. (2007). Literacy and bilingualism: a handbook for all teachers: Mahwah, N.J.: L. Erlbaum Associates, 2007. 2nd ed.

Broner, M. A., \& Tarone, E. E. (2001). Is it fun? Language play in a fifth-grade Spanish immersion classroom. The Modern Language Journal, 85(3), 363-379.

Broner, M., \& Tedick, D. (2011). Talking in the fifth-grade classroom: Language use in an early, total Spanish immersion program. Immersion education: Practices, policies, possibilities, 166-186. Buffalo, NY: Multilingual Matters.

Burkins, J. M., \& Yaris, K. (2016). Who's Doing the Work?: How to Say Less So Readers Can Do More. Portsmouth, NH: Stenhouse Publishers.

Cammarata, L., \& Tedick, D. J. (2012). Balancing content and language in instruction: The experience of immersion teachers. Modern Language Journal, 96(2), 251269. doi:10.1111/j.1540-4781.2012.01330.x

Cazden, C. B. (2001). The language of teaching and learning. The language of teaching and learning, 348-369.

Charmaz, K. (2006). Constructing grounded theory: A practical guide through qualitative analysis. Washington, DC: Sage.

Clark, K. F., \& Graves, M. F. (2005). Scaffolding students' comprehension of text. The Reading Teacher, 58(6), 570-580. 
Cole, M. (1985). The zone of proximal development-where culture and cognition create each other. In J.V. Wertsch (Ed.). Culture, Communication and Cognition: Vygotskian Perspectives. Cambridge, UK: Cambridge University Press.

College Board. (2013). AP Spanish Language and Culture: Course and Exam Description [Data file]. Retrieved from https://apcentral.collegeboard.org/pdf/apspanish-language-and-culture-course-and-exam-description.pdf?course=apspanish-language-and-culture

Collentine, J. (2010). The acquisition and teaching of the Spanish subjunctive: An update on current findings. Hispania, 39-51.

Compton-Lilly, C. (2014). The development of writing habitus: A ten-year case study of a young writer. Written Communication, 31(4), 371-403.

Creese, A., \& Blackledge, A. (2010). Translanguaging in the bilingual classroom: A pedagogy for learning and teaching?. The modern language journal, 94(1), 103115.

Creswell, J. W. (2002). Educational research: Planning, conducting, and evaluating quantitative and qualitative research. Upper Saddle River, NJ: Prentice Hall.

Crowley, T. (1989). Bakhtin and the history of the language. Bakhtin and cultural theory, 2. Manchester, UK: Manchester University Press.

Cuddapah, J. L., \& Clayton, C. D. (2011). Using Wenger's communities of practice to explore a new teacher cohort. Journal of Teacher Education, 62(1), 62-75.

Cummins, J. (1993). Empowerment through biliteracy. The power of two languages: Literacy and biliteracy for Spanish speaking students, 9-25. 
Cummins, J., Baker, C., \& Hornberger, N. H. (2001). An introductory reader to the writings of Jim Cummins (Vol. 29). Buffalo, NY: Multilingual Matters.

Daniel, S. M., Martin-Beltrán, M., Peercy, M. M., \& Silverman, R. (2016). Moving beyond yes or no: Shifting from over-scaffolding to contingent scaffolding in literacy instruction with emergent bilingual students. TESOL Journal, 7(2), 393420.

Daniels, H. (2005). An introduction to Vygotsky: London ; New York : Routledge, 2005. 2nd ed.

Dorner, L. M., \& Layton, A. (2014). “¿ Cómo se dice?” Children's multilingual discourses (or interacting, representing, and being) in a first-grade Spanish immersion classroom. Linguistics and Education, 25, 24-39.

Dorner, L. M., Orellana, M. F., \& Li-Grining, C. P. (2007). "I helped my mom,” and it helped me: Translating the skills of language brokers into improved standardized test scores. American Journal of Education, 113(3), 451-478.

Echeverría, S. A. (2017). All Cognates are not Created Equal: Variation in Cognate Recognition and Applications for Second Language Acquisition. RaeL: Revista Electronica de Linguistica Aplicada, (16).

Ek, L. D., Machado-Casas, M., Sánchez, P., \& Smith, H. L. (2011). Aprendiendo de sus comunidades/Learning from their communities: Bilingual teachers researching urban Latino neighborhoods. Urban literacies: Critical perspectives on language, learning, and community, 15-37. New York, NY: Teachers College Press.

Fortune, T., Tedick, D. J., \& Walker, C. L. (2008). Integrated language and content teaching: Insights from the immersion classroom. In T.W. Fortune \& D.J. Tedick 
(Eds). Pathways to Multilingualism: Eveolving Perspectives on Immersion Education, 71-96. Buffalo, NY: Multilingual Matters.

Freeman, Y. S., \& Freeman, D. E. (2009). La enseñanza de la lectura y la escritura en español y en inglés en clases bilingües y de doble inmersión: Portsmouth, $\mathrm{NH}$ : Heinemann.

Friese, S. (2014). Qualitative data analysis with ATLAS. ti. Washington, DC: Sage.

García, O. (2009). Bilingual education in the 21st century: A global perspective. Malden, MA: John Wiley \& Sons.

Garcia, O., Bartlett, L., \& Kleifgen, J. From biliteracy to pluriliteracies. Handbook of multilingualism and multilingual communication, 5, 207. Germany: Walter de Gruyter GmbH \& Co. KG.

Gee, J. P. (2012). Social linguistics and literacies: Ideology in discourses. Routledge.

Genesee, F. (1987). Learning through two languages : studies of immersion and bilingual education: Cambridge, MA: Newbury House Publishers.

Genesee, F. (2008). Dual language in the global village. In T.W. Fortune \& D.J. Tedick (Eds.). Pathways to multilingualism: Evolving perspectives on immersion education, 22-45. Buffalo, NY: Multilingual Matters.

Gibbert, M., \& Ruigrok, W. (2010). The “what”'and “how”'of case study rigor: Three strategies based on published work. Organizational research methods, 13(4), 710737.

Gibbons, P. (2002). Scaffolding language, scaffolding learning: Teaching second language learners in the mainstream classroom. Portsmouth, NH: Heinemann. 
Gibbons, P. (2015). Scaffolding language, scaffolding learning: Teaching second language learners in the mainstream classroom ( $2^{\text {nd }}$ ed.). Portsmouth, NH: Heinemann.

Glasswell, K., \& Ford, M. P. (2010). Teaching flexibly with leveled texts: More power for your reading block. The Reading Teacher, 64(1), 57-60.

González, J. M. (2008). Encyclopedia of bilingual education / Josué M. González, editor: Los Angeles, CA: Sage.

González, N., \& Moll, L. C. (2002). Cruzando el puente: Building bridges to funds of knowledge. Educational Policy, 16(4), 623-641.

Gort, M. (2008). “You Give Me Idea!”: Collaborative Strides Toward Bilingualism, Biliteracy, and Cross-Cultural Understanding in a Two-Way Partial Immersion Program. Multicultural Perspectives, 10(4), 192-200.

doi:10.1080/15210960802526086

Gort, M. (2015). Transforming literacy learning and teaching through translanguaging and other typical practices associated with "doing being bilingual”. International Multilingual Research Journal, 9: 1-6.

Graves, M., \& Graves, B. (2003). Scaffolding reading experiences: Designs for student success. Norwood, MA: Christopher-Gordon Publishers, Inc.

Guin, K. (2004). Chronic teacher turnover in urban elementary schools. Education policy analysis archives, 12, 42.

Hammond, W. D., \& Nessel, D. D. (2011). The comprehension experience: Engaging readers through effective inquiry and discussion. Portsmouth, NH: Heinemann. 
Heath, S. B. (1983). Ways with words: Language, life and work in communities and classrooms. Cambridge, UK: Cambridge University Press.

Hedegaard, M. (2005). The zone of proximal development as basis for instruction. In H. Daniels \& H. Daniels (Eds.), An introduction to Vygotsky, 2nd ed. (pp. 227-251). New York, NY: Routledge.

Hopewell, S., \& Escamilla, K. (2014). Biliteracy development in immersion contexts. Journal of Immersion and Content-Based Language Education, 2(2), 181-195.

Hornberger, N. H. (2004). The continua of biliteracy and the bilingual educator: Educational linguistics in practice. International Journal of Bilingual Education and Bilingualism, 7(2-3), 155-171. Buffalo, NY: Multilingual Matters.

Hornberger, N. H., \& Link, H. (2012). Translanguaging in today's classrooms: A biliteracy lens. Theory into practice, 51(4), 239-247.

Jiménez, R. T., Smith, P. H., \& Martínez-León, N. (2003). Freedom and form: The language and literacy practices of two Mexican schools. Reading Research Quarterly, 38(4), 488-508.

Johnston, P. H. (2012). Opening minds: Using language to change lives. Portsmouth, NH: Stenhouse Publishers.

Kong, S. (2009). Content-based instruction: What can we learn from content-trained teachers' and language-trained teachers' pedagogies?. Canadian Modern Language Review, 66(2), 233-267.

Krashen, S. D. (1982). Principles and practice in second language acquisition. Oxford, UK: Pergamon Press. 
Krashen, S. D. (1985). The input hypothesis: Issues and implications. New York, NY: Addison-Wesley Longman Ltd.

Kucan, L. (2007). Insights from teachers who analyzed transcripts of their own classroom discussions. The Reading Teacher, 61(3), 228-236.

Lantolf, J. P., \& Beckett, T. G. (2009). Sociocultural theory and second language acquisition. Language teaching, 42(4), 459-475.

LeBlanc, R. J. (2012). Words at work and play: Three decades in family and community life. Canadian Journal of Education/Revue canadienne de l'éducation, 35(2), 428431.

Lee, C. D., \& Smagorinsky, P. (2000). Vygotskian perspectives on literacy research: Constructing meaning through collaborative inquiry. Cambridge, UK: Cambridge University Press.

Lessow-Hurley, J. (2000). The foundations of dual language instruction: White Plains, N.Y. : Longman Publishers. 3rd ed.

Lindholm-Leary, K. (2012). Success and challenges in dual language education. Theory into practice, 51(4), 256-262. doi:10.1080/00405841.2012.726053

Lyster, R., \& Ballinger, S. (2011). Content-based language teaching: Convergent concerns across divergent contexts. Language Teaching Research, 15(3), 279288.

Many, J. E. (2002). An exhibition and analysis of verbal tapestries: Understanding how scaffolding is woven into the fabric of instructional conversations. Reading Research Quarterly, 37(4), 376-407. 
Martínez, R. A., Hikida, M., \& Durán, L. (2015). Unpacking ideologies of linguistic purism: How dual language teachers make sense of everyday translanguaging. International Multilingual Research Journal, 9(1), 26-42.

Mercer, N., \& Dawes, L. (2008). The value of exploratory talk. In N. Mercer \& S. Hodgkinson (Eds.). Exploring Talk in School: Inspired by the Work of Douglas Barnes, (55-71). Thousand Oaks, CA: Sage.

Mertzman, T. (2008). Individualising scaffolding: teachers' literacy interruptions of ethnic minority students and students from low socioeconomic backgrounds. Journal of Research in Reading, 31(2), 183-202.

Merriam, S. B. (2009). Qualitative research : a guide to design and implementation: San Francisco, CA: Jossey-Bass.

Met, M. (2008). Paying attention to language: Literacy, language and academic achievement. In T.W. Fortune \& D.J. Tedick (Eds). Pathways to Multilingualism: Evolving Perspectives on Immersion Education, (49-70). Buffalo, NY: Multilingual Matters.

Mills, K. A. (2010). Shrek meets Vygotsky: Rethinking adolescents' multimodal literacy practices in schools. Journal of Adolescent \& Adult Literacy, 54(1), 35-45.

Mokhtari, K., \& Reichard, C. A. (2002). Assessing students' metacognitive awareness of reading strategies. Journal of educational psychology, 94(2), 249.

Moll, L. C., Amanti, C., Neff, D., \& Gonzalez, N. (1992). Funds of knowledge for teaching: Using a qualitative approach to connect homes and classrooms. Theory into practice, 31(2), 132-141. 
Nassaji, H. (2007). Schema theory and knowledge-based processes in second language reading comprehension: A need for alternative perspectives. Language Learning, $57,79-113$.

National Council of Teachers of English. (2010). Principles for learning: A foundation for transforming K-12 education [data file]. Retrieved from http://www.ncte.org/library/NCTEFiles/Involved/Action/AdvocacyDay/Principles _for_Learning.pdf

Nunan, D. (1992). Research methods in language learning. Cambridge, UK: Cambridge University Press.

Orellana, M. F. (2015). Immigrant children in transcultural spaces: Language, learning, and love. New York, NY: Routledge.

Palmer, D. K., \& Martínez, R. A. (2016). Developing Biliteracy: What Do Teachers Really Need to Know about Language? Language Arts, 93(5), 379.

Pérez, B., \& Huerta, M. E. (2011). Dynamic biliteracy: Teacher knowledge and practice. In B. Bustos Flores, R. Hernández Sheets, \& E. Riojas Clark (Eds.). Teacher preparation for bilingual student populations: Educar para transformar, 115130. New York, NY: Routledge.

Pica, T. (2002). Subject - matter content: How does it assist the interactional and linguistic needs of classroom language learners? The Modern Language Journal, $86(1), 1-19$.

Potowski, K. (2004). Student Spanish Use and Investment in a Dual Immersion Classroom: Implications for Second Language Acquisition and Heritage Language Maintenance. Modern Language Journal, 88(1), 75-101. 
Purcell-Gates, V., Melzi, G., Najafi, B., \& Orellana, M. F. (2011). Building Literacy Instruction From Children's Sociocultural Worlds. Child Development Perspectives, 5(1), 22.

Rasinski, T. V., \& Hoffman, J. V. (2003). Oral reading in the school literacy curriculum. Reading Research Quarterly, 38(4), 510-522.

Razfar, A., \& Rumenapp, J. C. (2013). Applying linguistics in the classroom: A sociocultural approach. New York, NY: Routledge.

Reading, S. (2008). Differential Effects of French and Spanish Immersion Education on English Literacy Skills. Bilingual Research Journal, 31(1-2), 115-145.

Reyes, I. (2006). Exploring connections between emergent biliteracy and bilingualism. Journal of early childhood literacy, 6(3), 267-292.

Reyes, S. A., \& Kleyn, T. (2010). Teaching in two languages: A guide for K-12 bilingual educators. Thousand Oaks, CA: Corwin Press.

Reynolds, D. (2017). Interactional scaffolding for reading comprehension: A systematic review. Literacy Research: Theory, Method, and Practice, 66(1), 135-156.

Rodriguez, D., Carrasquillo, A., \& Lee, K. S. (2014). The bilingual advantage : promoting academic development, biliteracy, and native language in the classroom. New York: Teachers College Press, Columbia University.

Semke, H. D. (1984). Effects of the red pen. Foreign language annals, 17(3), 195-202. Servicio de Inspección Sevilla. (2011). Mis Lecturas de 5o y 6o [Data file]. Retrieved from http://www.ceiploreto.es/sugerencias/Comprension_lectora/mis_lecturas_ ciclo3.pdf 
Shrum, J. L., \& Glisan, E. W. (2015). Teacher's handbook, contextualized language instruction. Boston, MA: Cengage Learning.

Smagorinsky, P. (2011). Vygotsky and literacy research : a methodological framework: Boston, MA: Sense.

Smagorinsky, P. (2013). What does Vygotsky provide for the 21 st-century language arts teacher?. Language Arts, 90(3), 192-204.

Soltero, S. W. (2011). Bilateracy: the connection between language, culture and literacy. Revista Educación y Ciencia (ISSN 2448-525X), 1(16).

Stake, R. E. (1995). The art of case study research. Thousand Oaks, CA: Sage.

Stoller, F. L. (2002). Content-based instruction: A shell for language teaching or a framework for strategic language and content learning. Paper presented at the Keynote presented at the annual meeting of Teachers of English to Speakers of Other Languages, Salt Lake City.(online at CoBaLTT website ).

Stoller, F. L. (2004). 12. Content-Based instruction: perspectives on curriculum planning. Annual review of applied linguistics, 24, 261-283.

Swain, M. (1985). Communicative competence: Some roles of comprehensible input and comprehensible output in its development. Input in second language acquisition, $15,165-179$.

Swain, M., \& Lapkin, S. (2013). A Vygotskian sociocultural perspective on immersion education: The L1/L2 debate. Journal of immersion and content-based language education, 1(1), 101-129. 
Swain, M., Steinman, L., \& Kinnear, P. (2011). Sociocultural Theory in Second Language Education : An Introduction Through Narratives. Bristol, UK: Multilingual Matters.

Tedick, D. J., Christian, D., \& Fortune, T. W. (2011a). The future of immersion education: An invitation to 'dwell in possibility'. Immersion education: Practices, policies, possibilities, 1-10.

Tedick, D. J., Christian, D., \& Fortune, T. W. (2011b). Immersion education: Practices, policies, possibilities (Vol. 83) Buffalo, NY: Multilingual Matters.

Tharp, R. G., \& Gallimore, R. (1988). Rousing minds to life: Teaching, learning, and schooling in social context. Cambridge, UK: Cambridge University Press.

Thomas, W. P., \& Collier, V. P. (2002). A national study of school effectiveness for language minority students' long-term academic achievement. https://files.eric.ed.gov/fulltext/ED475048.pdf

VanPatten, B., \& Williams, J. (2014). Theories in second language acquisition: An introduction. New York, NY: Routledge.

Vygotsky, L. S. (1978). Mind in society: The development of higher psychological processes. In M. Cole, V. John-Steiner, S. Scribner, \& E. Souberman (Eds.). Cambridge, MA: Harvard University Press.

Vygotsky, L.S. (1986). Thought and Language. Cambridge, MA: MIT Press.

Walqui, A. (2006). Scaffolding instruction for English language learners: A conceptual framework. International Journal of Bilingual Education and Bilingualism, 9(2), 159-180.

Weaver, L., \& Márquez, J. (2017). So what is so different about developing literacy in 
Spanish anyway? Presentation at the La Cosecha Dual Language Conference, Albuquerque, NM.

Wells, G. (2000). Dialogic inquiry in education. Vygotskian perspectives on literacy research, 51-85.

Zapata, A., \& Laman, T. T. (2016). " I write to show how beautiful my languages are": Translingual Writing Instruction in English-Dominant Classrooms. Language Arts, 93(5), 366.

Zehrbach, G. (2011). Two-way immersion charter schools: An analysis of program characteristics and student body compositions. In D.J. Tedick, D. Christian, \& T.W. Fortune (Eds.). Immersion education: Practices, policies, possibilities. Buffalo, NY: Multilingual Matters.

Zuengler, J., \& Miller, E. R. (2006). Cognitive and sociocultural perspectives: Two parallel SLA worlds?. Tesol Quarterly, 40(1), 35-58. 
Dawn Heston grew up near San José, California and moved to Missouri to study Vocal Music Education with Dr. Wendy Sims. She received her B.S.Ed in Vocal Music in 1995, and simultaneously received K-12 teacher certification in Vocal Music and Spanish Language. After graduation, she taught high school Spanish in rural Callaway County for five years. During that period, she received the New Teacher Award and doubled the enrollment in Spanish language studies at the school. She returned to the University of Missouri to study for the M.A. in Language Teaching with an Emphasis in Spanish under the esteemed auspices of Dr. Flore Zéphir. As a Graduate Instructor, she taught Elementary Spanish language, and continued teaching in a local middle and high school Spanish program part-time. In 2004, she was selected to coordinate sections of the Elementary Spanish Language Program in the Department of Romance Languages, where she continues in her faculty position. She has remained a member of the Teaching Faculty since 2004 and has mentored numerous graduate instructors while teaching Spanish Language and Teacher Education courses. In 2013, she enrolled in the doctoral program in Learning, Teaching, and Curriculum in the College of Education to further her studies in literacy development with Dr. Carol Gilles. Dawn has presented at local and national conferences on a broad range of topics including: teaching with technology, developing biliteracy skills through multi-modal projects, finding authentic materials, and preparing high school students for university language studies. 